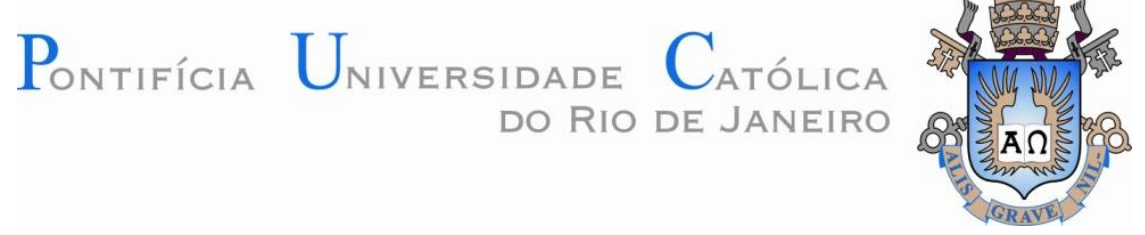

Silvia Regina dos Santos Gonçalves

Metodologia para mensuração do impacto do potencial de geração fotovoltaica no planejamento da operação energética de médio prazo

Dissertação de Mestrado

Dissertação apresentada como requisito parcial para obtenção do grau de Mestre pelo Programa de PósGraduação em Metrologia (Área de concentração: Metrologia para Qualidade e Inovação) da PUC-Rio.

Orientador: Prof. Rodrigo Flora Calili

Rio de Janeiro

Abril de 2017 


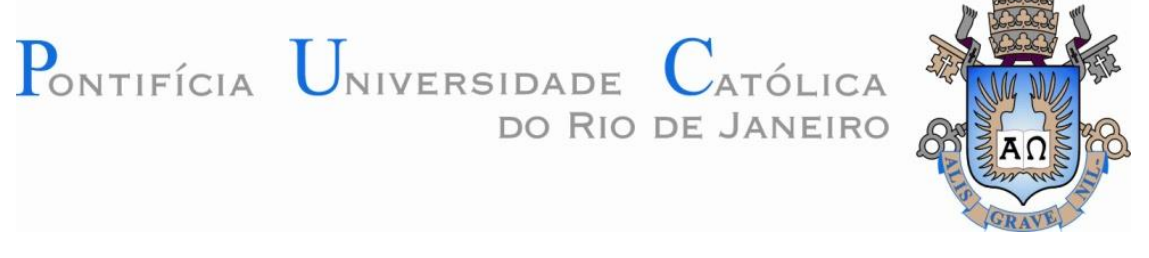

Silvia Regina dos Santos Gonçalves

\section{Metodologia para mensuração do impacto do potencial de geração fotovoltaica no planejamento da operação energética de médio prazo}

Dissertação apresentada como requisito parcial para obtenção do grau de Mestre pelo Programa de PósGraduação em Metrologia (Área de concentração: Metrologia para Qualidade e Inovação) da PUC-Rio. Aprovada pela Comissão Examinadora abaixo assinada.

Prof. Rodrigo Flora Calili

Orientador

Programa de Pós-Graduação em Metrologia - PUC-Rio

Prof. Reinaldo Castro de Souza Departamento de Engenharia Elétrica - PUC-Rio

Prof. Leonardo Lima Gomes Instituto de Administração e Gerência - IAG/PUC-Rio

Prof. José Francisco Moreira Pessanha Centro de Pesquisas de Energia Elétrica - CEPEL

Prof. Márcio da Silveira Carvalho Coordenador Setorial de Pós-Graduação do Centro Técnico Científico - PUC-Rio 
Todos os direitos reservados. É proibida a reprodução total ou parcial do trabalho sem autorização da universidade, da autora e do orientador.

\section{Silvia Regina dos Santos Gonçalves}

Formada em Engenharia de Produção pela Universidade do Estado do Rio de Janeiro, Brasil em 2008. Trabalha na Diretoria de Trading da empresa Enel Brasil.

Ficha Catalográfica

Gonçalves, Silvia Regina dos Santos

Metodologia para mensuração do impacto do potencial de geração fotovoltaica no planejamento da operação energética de médio prazo / Silvia Regina dos Santos Gonçalves; Orientador: Rodrigo Flora Calili. - 2017.

$141 \mathrm{f}$. : il. color. ; $30 \mathrm{~cm}$

Dissertação (mestrado) - Pontifícia Universidade Católica do Rio de Janeiro, Centro Técnico Científico, Programa de Pós-Graduação em Metrologia (Área de concentração: Metrologia para Qualidade e Inovação), 2017.

Inclui bibliografia

1. Metrologia - Teses. 2. Metrologia. 3. Níveis de irradiação solar. 4. Geração fotovoltaica. 5. Simulação bootstrap. 6. Planejamento da operação energética. I. Calili, Rodrigo Flora. II. Pontifícia Universidade Católica do Rio de Janeiro. Centro Técnico Científico. Programa de PósGraduação em Metrologia (Área de concentração: Metrologia para Qualidade e Inovação). III. Título.

CDD: 389.1 


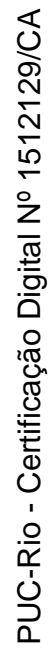

"O sol nasce, o sol se põe e se apressa em voltar ao lugar de onde nasce novamente". (Eclesiastes 1:5) 


\section{Agradecimentos}

Agradeço a Deus que dispensou todo seu cuidado sobre mim quando mais precisei e aos meus pais Davi e Regina pelo apoio e amor incondicional. Sem vocês eu não teria conseguido chegar até aqui.

Aos meus queridos amigos Neide Benchimol, Alex Almeida e Nathalie Mouron pelo incentivo relevante quando iniciei o curso de mestrado.

Aos professores Rodrigo Flora Calili e Maurício Frota pela oportunidade em realizar o curso na PUC-Rio, instituição que sempre estimei e respeitei e por todos ensinamentos. Vocês foram fundamentais para realização desse projeto.

Ao professor Reinaldo Castro e a professora Fátima Ludovico por todo aprendizado dispensado.

Às secretárias Márcia Ribeiro e Paula Molinari, pela dedicação e auxílio aos alunos.

Ao colega de curso Guilherme Fonseca Bassous, pela colaboração com a metodologia de tratamento do recurso solar disponibilizado pelo INMET.

À CAPES, pela bolsa concedida para realização do mestrado e à PUC-Rio pela oportunidade e formação de excelência.

A todos os professores, funcionários e amigos de classe do Programa de PósGraduação em Metrologia, pelo apoio e acompanhamento nesses dois anos de curso. 


\section{Resumo}

Gonçalves, Silvia Regina dos Santos. Calili, Rodrigo Flora (Orientador). Metodologia para mensuração do impacto do potencial de geração fotovoltaica no planejamento da operação energética de médio prazo. Rio de Janeiro, 2017. 141p. Dissertação de Mestrado - Programa de PósGraduação em Metrologia (Área de concentração: Metrologia para Qualidade e Inovação), Pontifícia Universidade Católica do Rio de Janeiro.

Nos últimos anos, o Brasil tem enfrentado frequentes desafios para garantir o suprimento de energia elétrica. A produção de energia fotovoltaica tem ganhado destaque, pois a fonte solar é um recurso abundante e renovável. No entanto, no âmbito do planejamento da operação energética de médio prazo, a estimativa proveniente dos parques geradores fotovoltaicos tem caráter determinístico. Quanto à geração fotovoltaica distribuída, pouco se sabe como é feita sua consideração para os próximos anos. Nesse contexto, essa dissertação propõe uma metodologia para mensuração do impacto do potencial de geração fotovoltaica residencial no planejamento da operação energética de médio prazo. Para alcançar tal objetivo, utilizou-se a metodologia Box \& Jenkins com simulação de cenários via Bootstrap, levando em consideração os níveis de irradiação solar, a área de telhado útil e a eficiência na conversão do recurso solar em eletricidade. Os principais resultados dessa dissertação são: custo total da operação, custo marginal de operação, energia armazenada, custo de déficit, risco de déficit, geração hidráulica, geração térmica, intercâmbio de energia e custo de vertimento. A consideração de cenários do potencial de geração fotovoltaica residencial reduziu o custo total da operação nos Programas Mensais da Operação Energética de janeiro/2015 e janeiro/2016, chegando a máxima redução de $(7,8 \%)$ e $(1,5 \%)$, respectivamente. Os demais resultados também foram impactados. Conclui-se que, a geração fotovoltaica residencial impacta, significativamente, o planejamento da operação energética de médio prazo, sendo necessário o desenvolvimento de outros estudos para avaliar a inserção e evolução dessa geração na matriz energética brasileira.

\section{Palavras-chave}

Metrologia; níveis de irradiação solar; geração fotovoltaica; simulação bootstrap; planejamento da operação energética. 


\section{Abstract}

Gonçalves, Silvia Regina dos Santos. Calili, Rodrigo Flora (Advisor). Methodology for measuring the impact of the photovoltaic generation potential to long-term energetic operation planning. Rio de Janeiro, 2017. 141p. Dissertação de Mestrado - Programa de Pós-Graduação em Metrologia (Área de concentração: Metrologia para Qualidade e Inovação), Pontifícia Universidade Católica do Rio de Janeiro.

In recent years, Brazil has faced frequent challenges to ensure the supply of electricity. The production of photovoltaic energy has gained prominence, because the solar source is an abundant and renewable resource. However, in the context of long-term energy operation planning, the estimation from photovoltaic generating parks is deterministic. As for distributed photovoltaic generation, little is known how its consideration is made for the next few years. In this context, this Master's thesis proposes a methodology for measuring the impact of the potential of residential photovoltaic generation in the planning of medium-term energy operation. In order to achieve this objective, the Box \& Jenkins methodology was simulated using Bootstrap scenarios, taking into account the levels of solar radiation, the useful roof area and the efficiency in the conversion of the solar resource into electricity. The main results of this dissertation are: total cost of operation, marginal cost of operation, stored energy, cost of deficit, deficit risk, hydraulic generation, thermal generation, energy exchange and delivery cost. The consideration of scenarios of the potential of residential photovoltaic generation reduced the total cost of operation in the Monthly Energy Operation Programs of January 2015 and January 2016, reaching the maximum reduction of $7.8 \%$ and 1.5 $\%)$, Respectively. The other results were also impacted. It is concluded that, residential photovoltaic generation significantly impacts medium-term energy operation planning, and it is necessary to develop other studies to evaluate the insertion and evolution of this generation in the Brazilian energy matrix.

\section{Keywords}

Metrology; levels of solar radiation; photovoltaic generation; bootstrap simulation; energetic operation planning. 


\section{Sumário}

1 Introdução 16

$\begin{array}{ll}1.1 \text { Definição do problema de pesquisa } & 18\end{array}$

$\begin{array}{ll}1.2 \text { Motivação } & 19\end{array}$

1.3 Objetivo 20

$\begin{array}{ll}1.4 \text { Metodologia da pesquisa } & 21\end{array}$

1.5 Estrutura do documento 24

2 Energia solar fotovoltaica e o planejamento da operação energética no Brasil $\quad 25$

2.1 Panorama energético mundial 25

2.2 Panorama energético brasileiro 28

2.3 A energia solar fotovoltaica 29

2.3.1 Mecanismos de incentivo à energia solar fotovoltaica na matriz energética brasileira 33

2.4 planejamento da operação energética no Brasil 35

2.4.1 O sistema elétrico brasileiro 36

2.4.2 O sistema interligado nacional 39

2.4.2.1 Desagregação do planejamento da operação em etapas 42

3 Simulação Bootstrap em séries temporais $\quad 49$

3.1 Modelos Box \& Jenkins 49

3.1.1 Modelos estacionários $\quad 50$

3.1.2 Modelos não-estacionários 52

3.1.3 Modelos sazonais 52

3.2 Técnica Bootstrap $\quad 53$

4 Metodologia $\quad 55$

4.1 Energia fotovoltaica residencial $\quad 55$

4.2 Metodologia proposta 56

4.2.1 Etapa 1: Mapeamento das informações 58

4.2.1.1 Mapeamento do recurso solar 58

4.2.1.2 Área útil total de telhado para instalação de sistemas
fotovoltaicos 
4.2.1.3 Eficiência na conversão da energia solar em eletricidade fotovoltaicos

4.2.2 Etapa 2: Simulação dos cenários do potencial de geração fotovoltaica residencial

4.2.2.1 Geração de cenários do potencial de energia fotovoltaica residencial

4.2.3 Etapa 3: Processamento do PMO 68

4.2.3.1 Cálculo dos cenários de carga global de energia 69

4.2.4 Etapa 4: Resultados da otimização 72

5 Resultados $\quad 74$

5.1 Curvas de irradiação solar 74

5.2 Área útil de telhado para instalação de sistemas fotovoltaicos 76

5.3 Cenários do potencial de geração fotovoltaica residencial e carga global de energia

81

5.4 Simulação do PMO janeiro/2015 e do PMO janeiro/2016 89

5.4.1 PMO janeiro/2015 90

5.4.1.1 Custo total da operação (CTO) 90

5.4.1.2 Custo marginal de operação (CMO) 91

5.4.1.3 Energia armazenada 94

5.4.1.4 Custo de déficit 95

5.4.1.5 Risco de déficit 96

5.4.1.6 Geração hidráulica (GH) 100

5.4.1.7 Geração térmica (GT) 102

5.4.1.8 Intercâmbio entre as regiões 105

5.4.1.9 Custo de vertimento 109

5.4.2 PMO janeiro/2016 110

5.4.2.1 Custo total da operação (CTO) 110

5.4.2.2 Custo marginal de operação (CMO) 112

5.4.2.3 Energia armazenada 114

5.4.2.4 Custo de déficit 115

5.4.2.5 Risco de déficit 116

5.4.2.6 Geração hidráulica $(\mathrm{GH}) \quad 120$

5.4.2.7 Geração térmica (GT) 122

$\begin{array}{ll}\text { 5.4.2.8 Intercâmbio entre as regiões } & 124\end{array}$ 
5.4.2.9 Custo de vertimento

6 Conclusões 129

6.1 Considerações e estudos futuros 132

7 Referências bibliográficas 134 


\section{Lista de tabelas}

Tabela 2.1 - Capacidade instalada na matriz elétrica brasileira (MW) 36

Tabela 4.1 - Eficiência de conversão de células solares

Tabela 5.1 - Agrupamento do recurso solar por região 75

Tabela 5.2 - \% de domicílio próprio por região

Tabela 5.3 - Projeção de domicílios (mil) de 2015 a 2020

Tabela 5.4 - Modelos Box \& Jenkins selecionados por região

Tabela 5.5 - Montantes anuais do potencial de geração fotovoltaica residencial (MW med)

Tabela 5.6 - Representação dos cenários do potencial de geração fotovoltaica residencial na carga global de energia (\%)

Tabela 5.7 - Variação média anual entre a carga global de energia do PMO janeiro/2015 e os casos de sensibilidade

Tabela 5.8 - Variação média anual entre a carga global de energia do PMO janeiro/2016 e os casos de sensibilidade

Tabela 5.9 - Variação média anual entre a carga global de energia dos casos de sensibilidade do PMO janeiro/2015

Tabela 5.10 - Variação média anual entre a carga global de energia dos casos de sensibilidade do PMO janeiro/2016

Tabela 5.11 - Custo total de operação e desvio-padrão

$\left(\${ }^{\wedge} 10^{6}\right)$ - Ref. PMO janeiro/2015

Tabela 5.12 - Custo de déficit e desvio-padrão

$\left(\${ }^{\wedge} 10^{6}\right)$ - Ref. PMO janeiro/2015

Tabela 5.13 - Custo do vertimento e desvio-padrão

$\left(\$ \wedge^{\wedge} 0^{6}\right)$ - Ref. PMO janeiro/2015

Tabela 5.14 - Custo total da operação e desvio-padrão

$\left(\${ }^{\wedge} 10^{6}\right)$ - Ref. PMO janeiro/2016

Tabela 5.15 - Custo de déficit e desvio-padrão

$\left(\${ }^{\wedge} 10^{6}\right)$ - Ref. PMO janeiro/2016

Tabela 5.16 - Custo do vertimento e desvio-padrão

$\left(\$ \wedge 10^{6}\right)$ - Ref. PMO janeiro/2016 


\section{Lista de figuras}

Figura 1.1 - Delimitação da pesquisa $\quad 21$

Figura 1.2 - Desenho da pesquisa 23

Figura 2.1 - Composição interna de energia no Brasil em $2015 \quad 28$

Figura 2.2 - Radiação solar global diária no Brasil (média anual) 32

Figura 2.3 - Parte do diagrama esquemático das usinas

hidrelétricas da região Sudeste/Centro-oeste

Figura 2.4 - Etapas de estudos do planejamento da operação energética

Figura 2.5 - Árvore de decisão do sistema hidrotérmico 44

Figura 2.6 - Custo do armazenamento da água 45

Figura 2.7 - Enfoque pente do NEWAVE 47

Figura 4.1 - Etapas da metodologia proposta 57

Figura 4.2 - Representação das estações do ano e do movimento da Terra em torno do Sol

Figura 4.3 - Energia armazenada verificada dos reservatórios equivalentes do SIN (\%)

Figura 4.4 - Carga global de energia oficial PMO janeiro/2015 e PMO janeiro/2016

Figura 4.5 - Metodologia Box \& Jenkins

Figura 5.1 - Evolução mensal da irradiação solar (jan/2009 a dez/2013)

Figura 5.2 - Representação do tipo de domicílio no Brasil 77

Figura 5.3 - Estimativa de área útil de telhado $\left(\mathrm{m}^{2}\right)$ por região $\quad 81$

Figura 5.4 - Cenários de irradiação solar - $\mathrm{kWh} / \mathrm{m}^{2} / \mathrm{mês}$

(jan/2014 a dez/2020)

Figura 5.5 - Cenários do potencial de energia fotovoltaica residencial no SIN

Figura 5.6 - Carga global de energia do SIN. PMO janeiro/2015 e casos de sensibilidade

Figura 5.7 - Carga global de energia do SIN. PMO janeiro/2016 e casos de sensibilidade

Figura 5.8 - Boxplot do custo total de operação $\left(\$ \times 10^{\wedge} 6\right)$.

PMO janeiro/2015 e casos de sensibilidade

Figura 5.9 - Custo marginal de operação (Sudeste).

PMO janeiro/2015 e casos de sensibilidade 
Figura 5.10 - Custo marginal de operação (Sul).

PMO janeiro/2015 e casos de sensibilidade

Figura 5.11 - Custo marginal de operação (Nordeste).

PMO janeiro/2015 e casos de sensibilidade

Figura 5.12 - Custo marginal de operação (Norte).

PMO janeiro/2015 e casos de sensibilidade

Figura 5.13 - Evolução do armazenamento do SIN -

Ref. PMO janeiro/2015

Figura 5.14 - Boxplot do custo de déficit $\left(\$ \times 10^{\wedge 6}\right)$.

PMO janeiro/2015 e casos de sensibilidade

Figura 5.15 - Risco de déficit - PMO janeiro/2015 97

Figura 5.16 - Risco de déficit - caso P5 (Ref. PMO janeiro/2015) 97

Figura 5.17 - Risco de déficit - caso P25 (Ref. PMO janeiro/2015) 98

Figura 5.18 - Risco de déficit - caso P50 (Ref. PMO janeiro/2015) 98

Figura 5.19 - Risco de déficit - caso P75 (Ref. PMO janeiro/2015) 99

Figura 5.20 - Risco de déficit - caso P95 (Ref. PMO janeiro/2015) 99

Figura 5.21 - Geração hidráulica (Sudeste/Centro-oeste) -

Ref. PMO janeiro/2015

100

Figura 5.22 - Geração hidráulica (Sul) - Ref. PMO janeiro/2015

Figura 5.23 - Geração hidráulica (Nordeste) -

Ref. PMO janeiro/2015

Figura 5.24 - Geração hidráulica (Norte) -

Ref. PMO janeiro/2015

102

Figura 5.25 - Geração térmica (Sudeste/Centro-oeste) -

Ref. PMO janeiro/2015

Figura 5.26 - Geração térmica (Sul) - Ref. PMO janeiro/2015 103

Figura 5.27 - Geração térmica (Nordeste) - Ref. PMO janeiro/2015 104

Figura 5.28 - Geração térmica (Norte) - Ref. PMO janeiro/2015 104

Figura 5.29 - Fluxo de intercâmbio Sudeste/Centro-oeste -

nó-fictício - Nordeste

106

Figura 5.30 - Intercâmbio Sudeste para Sul

(Ref. PMO janeiro/2015)

Figura 5.31 - Intercâmbio Sudeste para Nordeste

(Ref. PMO janeiro/2015)

Figura 5.32 - Intercâmbio Sudeste para nó-fictício

(Ref. PMO janeiro/2015)

Figura 5.33 - Intercâmbio Nordeste para nó-fictício

(Ref. PMO janeiro/2015) 
Figura 5.34 - Intercâmbio Norte para nó-fictício

(Ref. PMO janeiro/2015)

Figura 5.35 - Boxplot do custo de vertimento $\left(\$ \times 10^{\wedge 6}\right)$.

PMO janeiro/2015 e casos de sensibilidade

Figura 5.36 - Boxplot do custo de total de operação $\left(\$ \times 10^{\wedge 6}\right)$.

PMO janeiro/2016 e casos de sensibilidade

Figura 5.37 - Custo marginal de operação (Sudeste).

PMO janeiro/2016 e casos de sensibilidade

Figura 5.38 - Custo marginal de operação (Sul).

PMO janeiro/2016 e casos de sensibilidade

Figura 5.39 - Custo marginal de operação (Nordeste).

PMO janeiro/2016 e casos de sensibilidade

Figura 5.40 - Custo marginal de operação (Norte).

PMO janeiro/2016 e casos de sensibilidade

Figura 5.41 - Evolução do armazenamento do SIN - Ref. PMO janeiro/2016

Figura 5.42 - Boxplot do custo de déficit ( $\$ \times 10^{\wedge} 6$ ).

Figura 5.43 - Risco de déficit - PMO janeiro/2016

Figura 5.44 - Risco de déficit - caso P5 (Ref. PMO janeiro/2016)

Figura 5.45 - Risco de déficit - caso P25 (Ref. PMO janeiro/2016)

Figura 5.46 - Risco de déficit - caso P50 (Ref. PMO janeiro/2016)

Figura 5.47 - Risco de déficit - caso P75 (Ref. PMO janeiro/2016)

Figura 5.48 - Risco de déficit - caso P95 (Ref. PMO janeiro/2016)

Figura 5.49 - Geração hidráulica (Sudeste/Centro-oeste) -

Ref. PMO janeiro/2016

Figura 5.50 - Geração hidráulica (Sul) - Ref. PMO janeiro/2016

Figura 5.51 - Geração hidráulica (Nordeste) - Ref. PMO janeiro/2016

Figura 5.52 - Geração hidráulica (Norte) - Ref. PMO janeiro/2016

Figura 5.53 - Geração térmica (Sudeste) - Ref. PMO janeiro/2016

Figura 5.54 - Geração térmica (Sul) - Ref. PMO janeiro/2016 123

Figura 5.55 - Geração térmica (Nordeste) - Ref. PMO janeiro/2016 124

Figura 5.56 - Geração térmica (Norte) - Ref. PMO janeiro/2016 124

Figura 5.57 - Intercâmbio Sudeste para Sul (Ref. PMO janeiro/2016) 125

Figura 5.58 - Intercâmbio Sudeste para Nordeste

(Ref. PMO janeiro/2016) 
Figura 5.59 - Intercâmbio Sudeste para nó-fictício (Ref. PMO janeiro/2016)

Figura 5.60 - Intercâmbio Nordeste para nó-fictício (Ref. PMO janeiro/2016)

Figura 5.61 - Intercâmbio Norte para nó-fictício

(Ref. PMO janeiro/2016)

Figura 5.62 - Boxplot do custo de vertimento $\left(\$ \times 10^{\wedge 6}\right)$.

PMO janeiro/2016 e casos de sensibilidade 


\section{1. Introdução}

O século XXI será marcado pela busca mundial do suprimento energético que atenda ao crescimento da demanda de forma economicamente viável e sustentável. O crescimento por ações de eficiência energética e o desenvolvimento de novas tecnologias combinado com a redução gradativa de seus custos propiciam uma maior participação das fontes renováveis na matriz energética mundial.

Desde a Conferência Rio-92, quando foi criada a Convenção-Quadro das Nações Unidas sobre Mudança Climática (UNFCCC - United Nations Framework Convention on Climate Change), que se observa uma preocupação mundial com o meio ambiente. Recentemente, os aspectos climáticos ganharam atenção na $22^{\mathrm{a}}$ Conferência do Clima das Nações Unidas - COP 22, realizada em 2016 na cidade de Marrakesh, cuja missão era implementar o Acordo de Paris sobre o aquecimento global firmado em 2015 na COP 21.

As energias renováveis podem ser consideradas inesgotáveis à escala humana quando comparadas aos combustíveis fósseis. Seu impacto ambiental é menor do que o provocado pelas fontes de energia com origem nos combustíveis fósseis, uma vez que não produzem dióxido de carbono ou outros gases de efeito estufa (GEE). Além disso, as fontes de energia renováveis proporcionam a redução da dependência energética, conferindo autonomia a um país, uma vez que não dependem da importação de combustíveis. São exemplos de fontes renováveis: energia eólica, energia solar, energia hidráulica, energia maremotriz, energia geotérmica, energia à base de hidrogênio, biomassa, biogás, biocombustíveis, entre outras. Contudo, o custo das fontes renováveis ainda é um ponto desfavorável para sua adoção em larga escala, como por exemplo, a energia à base de hidrogênio.

Dentre as fontes renováveis, a que mais cresce no mundo é a energia solar fotovoltaica. O mundo contabilizou, ao final de 2014, uma potência instalada de geração de energia solar fotovoltaica de $180 \mathrm{GW}, 40,2 \mathrm{GW}$ a mais que em 2013, 
segundo o boletim "Energia Solar no Brasil e no Mundo" (MME, 2015), evidenciando um crescimento de mais de $22 \%$. A energia solar é uma fonte promissora, pois se trata de um recurso inesgotável e, principalmente, independente de importação. Além das condições atmosféricas (nebulosidade, umidade relativa do ar, entre outras), a disponibilidade da radiação solar depende da latitude local e do período do ano.

O Brasil tem um grande potencial energético solar visto que a maior parte de seu território está localizada relativamente próxima à linha do Equador, de forma que não se observam grandes variações nas características de insolação e radiação (Pereira et al., 2006). Contudo, a capacidade instalada de energia solar no país ainda é pouco representativa.

A produção de energia elétrica no Brasil é predominantemente de origem hidrelétrica, dependendo das chuvas para manter os níveis dos reservatórios. Em 2001, o Brasil sofreu o maior racionamento de energia elétrica de sua história. Já na última década, especialistas acreditam que o país tenha passado por um racionamento "técnico", quando em janeiro de 2015 o nível nos reservatórios da região Sudeste/Centro-oeste foi de 16,84\%. A escassez de chuva também está sendo percebida na região Nordeste desde 2013. O elevado despacho de usinas térmicas e a redução do nível armazenamento nos últimos anos indicam o agravamento da crise (Gonçalves \& Calili, 2015). Ainda nesse contexto, a falta de chuva não é a única causa responsável pelo agravamento no suprimento de eletricidade no Brasil. Os grandes aproveitamentos hidráulicos construídos nos últimos anos, em especial, na região Amazônica, são a fio d'água, ou seja, não apresentam reservatório. Esse novo tipo de construção auxiliou na perda do grau de regularização dos reservatórios do país e, por conseguinte, uma maior dependência do regime hidrológico.

Para efeito de planejamento da operação energética, a consideração da geração do conjunto de usinas não simuladas nos modelos de otimização energética (pequenas centrais hidrelétricas, pequenas centrais térmicas, usinas eólicas e fotovoltaicas) é de caráter determinístico, regulamentada atualmente pela Resolução Normativa ANEEL $n^{\circ} 476$ de 2012. A estimativa da geração dessas usinas é abatida da carga global de energia declarada no Programa Mensal da 
Operação Energética (PMO), resultando em uma carga líquida que é o requisito a ser atendido.

Já no caso da geração distribuída pouco se sabe como são realizadas as estimativas de geração para o futuro.

Essa dissertação apresenta uma abordagem conceitual do planejamento energético de médio prazo, simulação de séries temporais e otimização via modelo NEWAVE (CEPEL, 2012), tendo como objetivo propor uma metodologia para mensuração do impacto do potencial de geração fotovoltaica no planejamento da operação energética de médio prazo.

\section{1}

\section{Definição do problema de pesquisa}

No cenário atual de escassez de chuva, perda do grau de regularização dos reservatórios e inserção de novas fontes alternativas na matriz energética brasileira, dá-se origem a questão principal dessa dissertação: "Qual o impacto do potencial de geração fotovoltaica no planejamento da operação energética de médio prazo, considerando cenários a partir da simulação de séries?”. Com vistas a responder esta questão de pesquisa será proposta uma metodologia que busque mensurar esse impacto considerando o potencial brasileiro de geração fotovoltaica residencial, uma vez que existem lacunas na literatura sobre este tema. Cabe mencionar que as simulações propostas por essa dissertação consideraram um caso de "stress", onde todos os consumidores de domicílios próprios permanentes teriam um sistema solar fotovoltaico.

A atratividade econômica da micro e minigeração está relacionada às tarifas de energia elétrica convencional. Esse tipo de geração se apresenta como uma alternativa interessante para o consumidor de energia elétrica no Brasil, já que os reajustes nas tarifas estão sujeitos a grandes variações. Em algumas economias no mundo, os incentivos para geração distribuída foram dados para que as pessoas gerassem energia elétrica a partir de suas residências, utilizando sistemas fotovoltaicos conectados à rede elétrica. A classe residencial no Brasil representa 
uma parcela potencial significativa de geração fotovoltaica, uma vez que a quantidade de domicílios combinada às taxas de irradiação solar são fatores positivos para esse tipo de geração. Contudo, a viabilidade da implementação dessa fonte ainda é um ponto de grande discussão e passível de evoluções, principalmente nos aspectos relacionados a custo, tecnologia e regulamentação.

\section{2 \\ Motivação}

A escolha do tema foi motivada pela relevância e abrangência da inserção de novas fontes de energia alternativa, em especial, energia fotovoltaica, no planejamento energético de médio prazo. Segundo o Plano Decenal de Expansão de Energia 2024 (EPE, 2015), a capacidade instalada de energia solar passaria de praticamente nula em dezembro/2014 para 7 GW em dezembro/2024, representando $3,3 \%$ da matriz elétrica.

Outro fator importante para a decisão do tema foi a possibilidade dessa dissertação contribuir para o arcabouço bibliográfico nacional e internacional. Como o tema é recente no Brasil a literatura possui uma lacuna que, em partes, poderá ser preenchida por essa dissertação no intuito de contribuir, principalmente, pela proposição de uma metodologia para mensurar impactos da inserção da geração fotovoltaica no planejamento energético de médio prazo.

No âmbito acadêmico o tema está consoante com a linha de pesquisa de redes inteligente do Programa de Pós-Graduação em Metrologia para Qualidade e Inovação (Pós-MQI) na PUC-Rio, e espera-se com essa dissertação despertar o interesse de novos pesquisadores no desenvolvimento de trabalhos futuros que poderão contribuir no preenchimento das lacunas da bibliografia nacional e internacional, não só referente a mensuração do impacto do potencial de geração fotovoltaica no planejamento da operação energética de médio prazo, como também, dos diversos desafios proporcionados pela inserção da fonte fotovoltaica na matriz energética brasileira. 


\section{3 \\ Objetivo}

Consoante com o cenário atual de diversificação da matriz energética brasileira com novas fontes alternativas de energia limpa, em especial, a matriz elétrica, esta dissertação tem como objetivo principal propor uma metodologia para mensurar o impacto do potencial de geração fotovoltaica no planejamento da operação energética de médio prazo, considerando a geração de cenários do potencial de geração fotovoltaica residencial. Os objetivos específicos são:

- Avaliar a aplicabilidade dos modelos de séries temporais e técnicas de simulação no planejamento da operação energética no Brasil, considerando cenários de geração fotovoltaica;

- Identificar e descrever os estudos de simulação aplicados à geração fotovoltaica;

- Descrever as abordagens metodológicas utilizadas para análise do impacto do potencial de geração fotovoltaica no planejamento da operação energética de médio prazo;

- Gerar séries sintéticas de geração fotovoltaica, no âmbito do planejamento da operação energética, por meio de simulação;

- Selecionar cenários de geração fotovoltaica a partir da geração de séries sintéticas;

- Simular o Programa Mensal da Operação Energética (PMO) no Brasil via modelo NEWAVE, considerando cenários de geração fotovoltaica.

- Mensurar os impactos na política de geração hidrotérmica considerando cenários do potencial de geração fotovoltaica residencial. 


\section{4 \\ Metodologia da pesquisa}

A delimitação da pesquisa foi baseada em três pilares de acordo com a Figura 1.1:

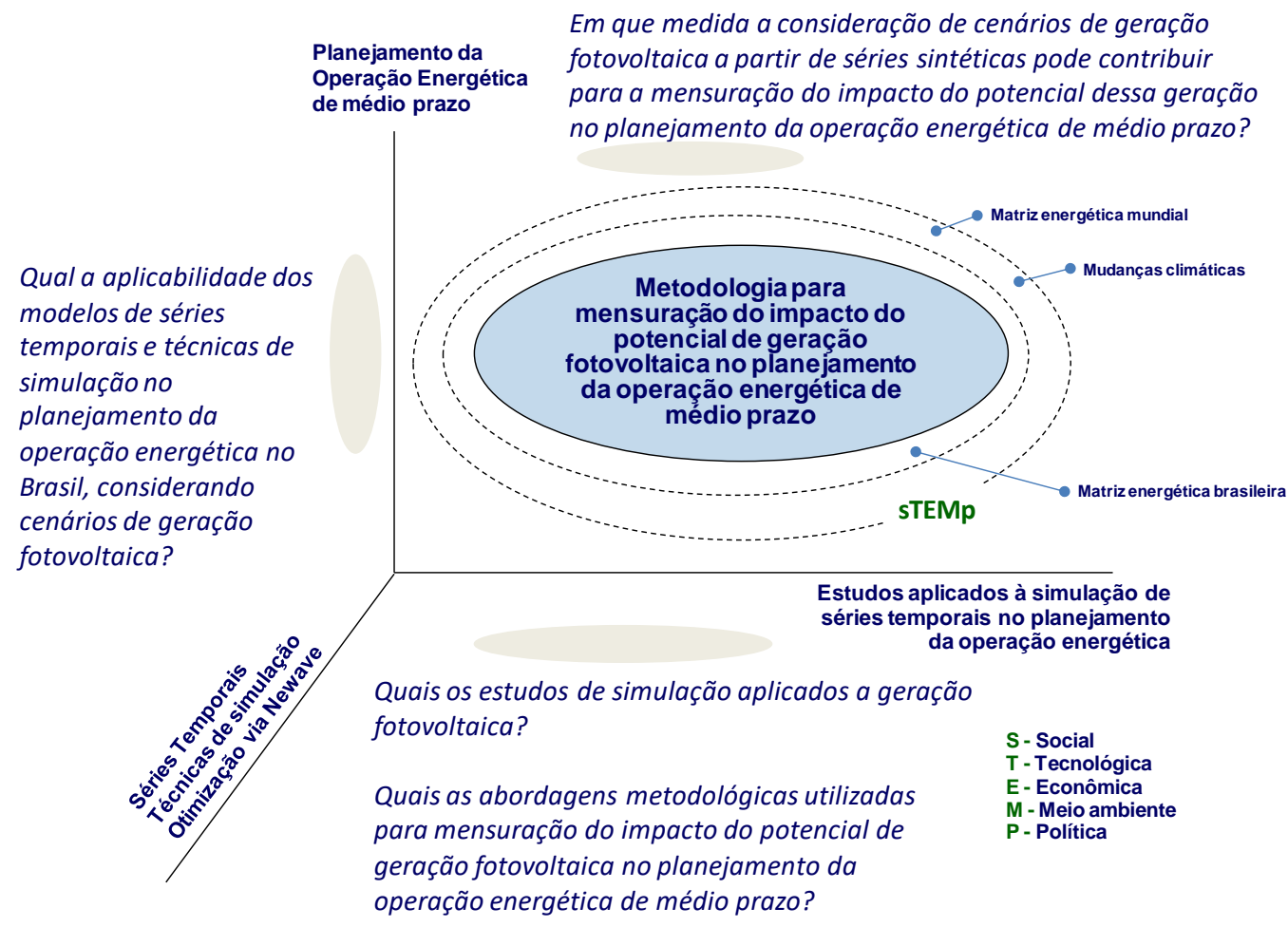

Figura 1.1 - Delimitação da pesquisa

Fonte: Elaboração própria

- Planejamento da operação energética de médio prazo: para o entendimento do problema foi feita uma contextualização sobre o planejamento da operação energética de médio prazo do Brasil, com o detalhamento das principais entidades envolvidas e suas atribuições, assim como os principais conjuntos de normas que norteiam o Setor Elétrico Brasileiro (SEB);

- Séries temporais/técnicas de simulação/otimização via NEWAVE: utilização da metodologia Box \& Jenkins para tratamento das séries temporais de irradiação solar das regiões Sudeste/Centro-Oeste, Sul, 
Nordeste e Norte. Emprego da simulação Bootstrap para criação de cenários sintéticos. Otimização via programa computacional NEWAVE, considerando os cenários do potencial de geração fotovoltaica residencial;

- Estudos aplicados à simulação de séries temporais no planejamento da operação energética: ampla pesquisa nas bases de dados para o entendimento do estado da arte de estudos aplicados à simulação de séries temporais no planejamento da operação energética.

A metodologia da pesquisa foi baseada na taxonomia proposta por Vergara (Vergara, 2007), que aborda a classificação da pesquisa em dois critérios: quanto aos fins e aos meios.

Quanto aos fins a pesquisa foi classificada como descritiva, pois descreve com detalhe a metodologia utilizada para estimar o potencial de geração fotovoltaica residencial; metodológica, pois utiliza a parte descritiva para a análise e manipulação dos dados; aplicada, pois há contribuição e geração de conhecimento com a aplicação prática.

Quanto aos meios a pesquisa foi classificada como bibliográfica, devido ao trabalho de pesquisa realizado nas bases de dados; experimental, por uma clara manipulação das variáveis que estão relacionadas com o objeto do estudo e por buscar o entendimento da metodologia atual através de métodos estatísticos e orientados. Por fim, essa pesquisa pode ser classificada como de natureza quantitativa, e foi dividida em três fases, conforme Figura 1.2. 

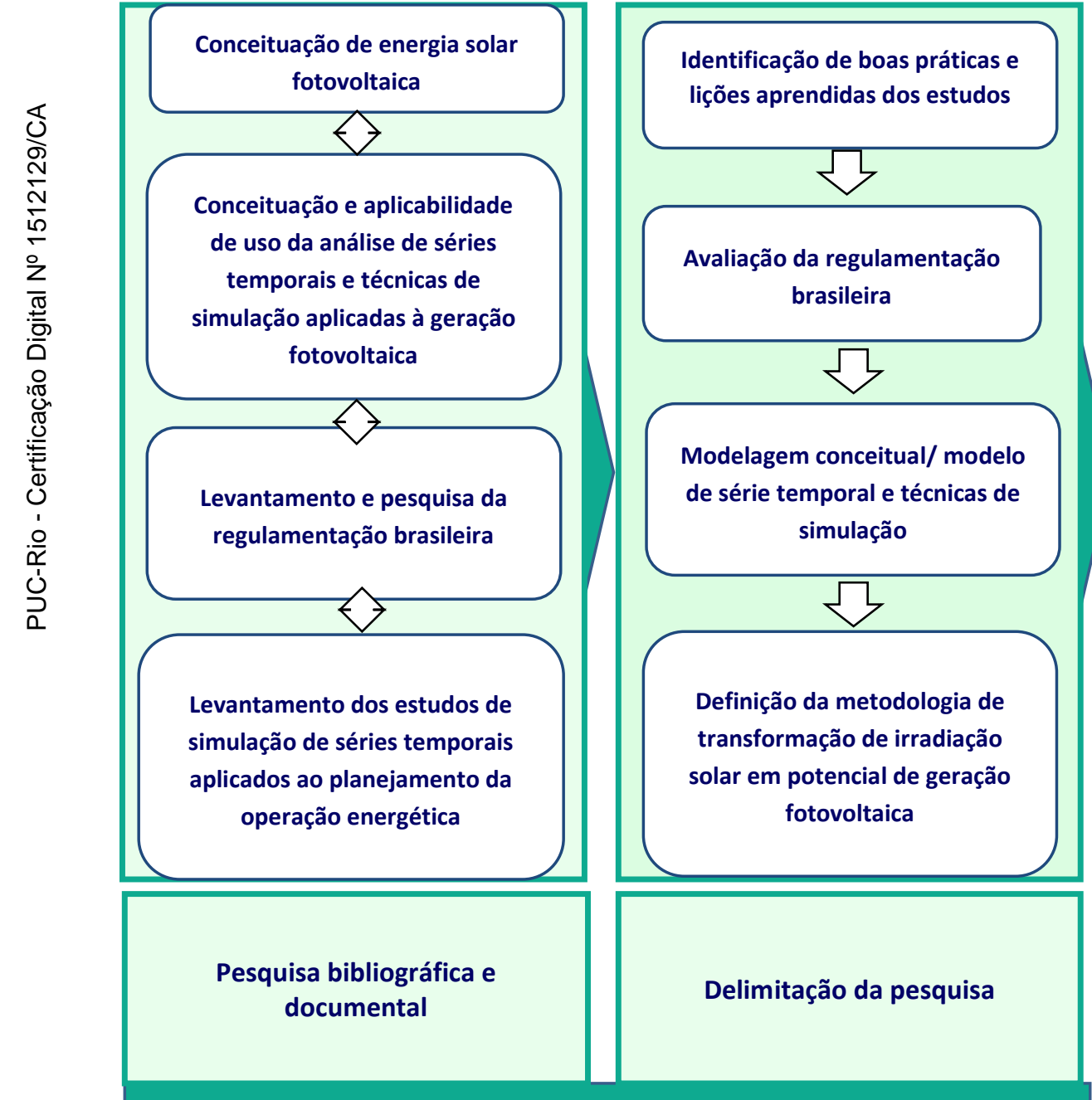

Fase 1 - Exploratória
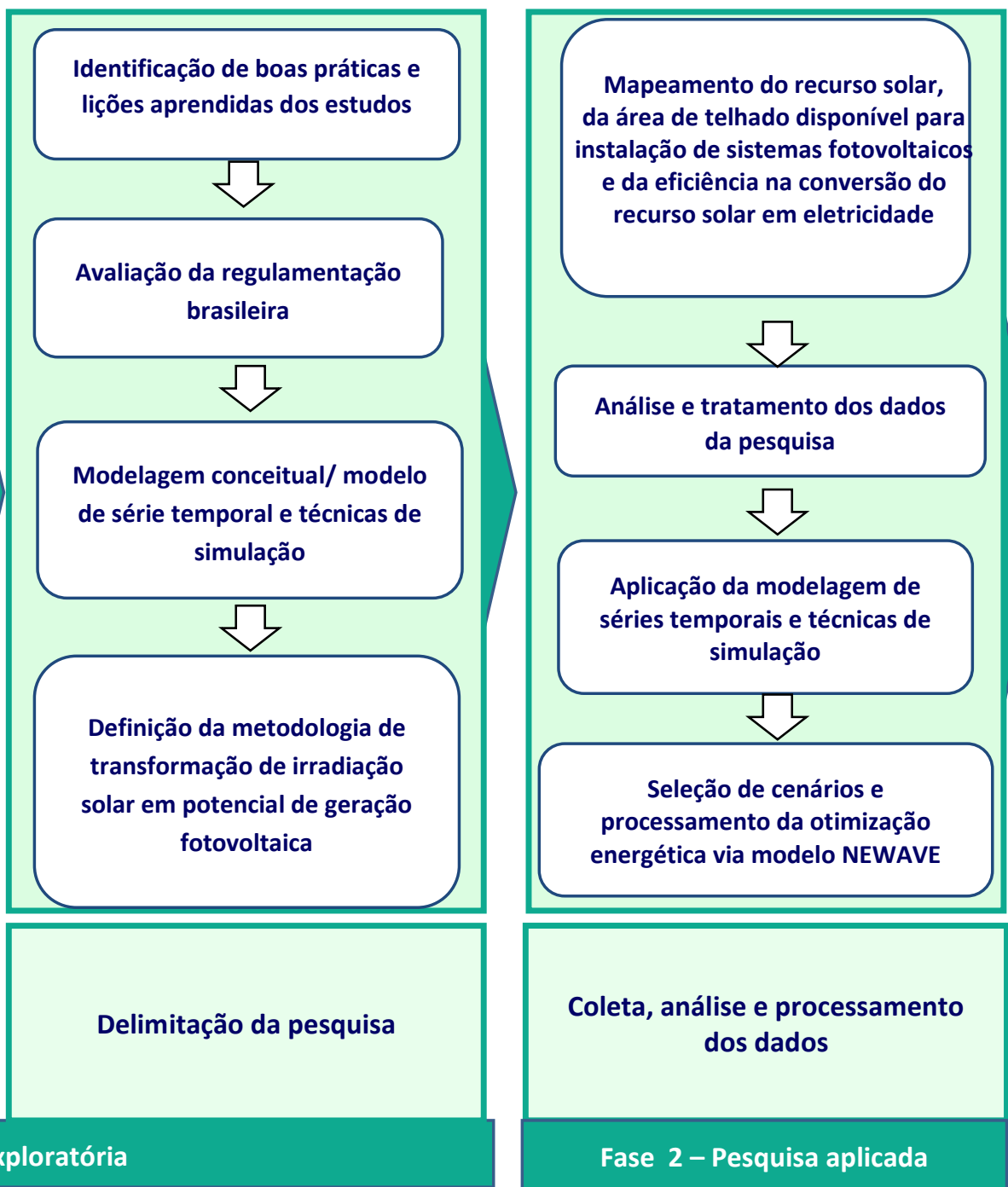

Coleta, análise e processamento dos dados

Fase 2 - Pesquisa aplicada

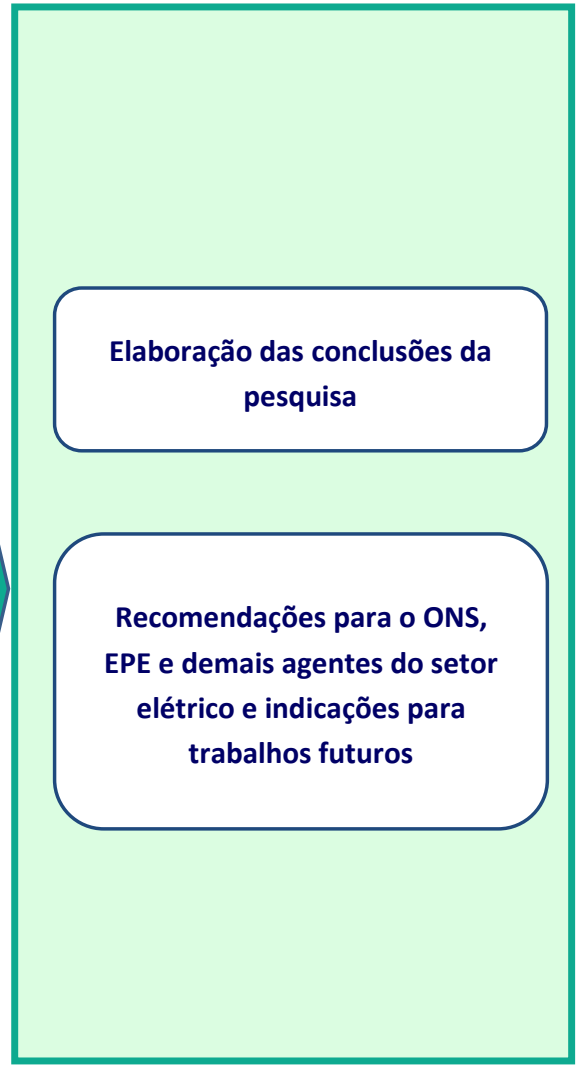

Elaboração das conclusões e recomendações

Fase 3-Conclusiva-propositiva

Figura 1.2 - Desenho da pesquisa

Fonte: Elaboração própria 


\section{5 \\ Estrutura do documento}

A dissertação é composta por seis capítulos. O Capítulo 1 apresenta o contexto do assunto, a definição do problema da pesquisa, a motivação pela escolha do tema, os objetivos a serem alcançados e a metodologia aplicada. No Capítulo 2 é feita a descrição da fonte de energia solar fotovoltaica e a ampla contextualização do planejamento da operação energética no Brasil. Em seguida, o Capítulo 3 descreve a técnica de simulação Bootstrap em séries temporais. A metodologia do trabalho é detalhada no Capítulo 4, objetivando alcançar o objetivo principal da pesquisa. O Capítulo 5 contempla os resultados da metodologia proposta, que utilizou como objeto de estudo o Programa Mensal da Operação Energética de janeiro de 2015 e janeiro de 2016. Os resultados contêm os impactos mensurados e os principais pontos de aprimoramento. Finalizando o trabalho, são apresentadas no Capítulo 6 as conclusões e as recomendações para possíveis trabalhos futuros, visando aprimorar a metodologia aqui proposta. 


\section{2. \\ Energia solar fotovoltaica e o planejamento da operação energética no Brasil}

Nesse capítulo serão contextualizados os temas energia solar fotovoltaica e planejamento da operação energética no Brasil, a fim de oferecer a base teórica que irá subsidiar o objetivo da pesquisa. A energia solar fotovoltaica refere-se à fonte e tecnologia que ganha destaque no cenário mundial por se apresentar como uma solução de energia limpa e abundante para alguns países. Já o planejamento da operação energética no Brasil abarca diversas premissas e cenários, utilizando a cadeia de modelos computacionais desenvolvida pelo Centro de Pesquisa de Energia Elétrica - CEPEL como apoio à tomada de decisão. Como o objetivo dessa dissertação não é aprofundar a pesquisa nesse tema, esse capítulo tem como objetivo oferecer uma revisão atual da literatura, demonstrando o estado da arte no cenário nacional e internacional.

\section{1 \\ Panorama energético mundial}

A lenha e o carvão vegetal foram praticamente os únicos energéticos utilizados no período pré-industrial. A partir da revolução industrial nos séculos XVIII e XIX, o carvão mineral passou a exercer papel preponderante na economia. Ao final do século XIX, os derivados de petróleo passaram a substituir o carvão mineral. O petróleo se tornou a energia dominante no século XX e sua evolução foi acelerada, o que provocou crises históricas no cenário mundial, envolvendo nações que objetivavam o domínio sobre o refino e a comercialização (Costa \& Prates, 2005). 
Durante os anos 70 os países adotaram estratégias para enfrentar os preços elevados do petróleo. Inovaram na exploração do petróleo em águas profundas e no aproveitamento do gás natural, desenvolveram tecnologia de suprimento de larga escala como a tecnologia nuclear e adotaram práticas de eficiência energética.

Segundo Agência Internacional de Energia (AIE, 2004), entre 1973 e 2002, a participação dos derivados de petróleo reduziu cerca de 10\%, sendo substituído basicamente pelo gás natural e energia nuclear. Em 2015, a matriz energética mundial teve aproximadamente $14 \%$ de participação das fontes renováveis, 5\% a mais que a Organização para a Cooperação e Desenvolvimento Econômico (OCDE).

A evolução histórica energética explica a predominância das fontes não renováveis na matriz energética. As crises mundiais desencadeadas pela fonte energética dominante, somadas à dependência da matriz energética e as consequências ambientais do uso em larga escala das fontes não renováveis, culminaram na necessidade de uma mudança radical na matriz energética mundial com forte aumento da participação das fontes renováveis.

Nesse início de século a humanidade tem se preocupado de forma geral com três grandes temas: meio ambiente, energia e economia global. Esses temas estão interligados e definem o cenário mundial, interferindo, principalmente, na mudança dos hábitos humanos e no comportamento econômico-político (Calili, 2013).

No contexto internacional, há diversos movimentos de promoção de energias renováveis. Os eventos de cunho ambiental têm ganhado relevância nos últimos anos. Desde a criação da Convenção-Quadro das Nações Unidas sobre Mudança Climática (UNFCCC - United Nations Framework Convention on Climate Change) na Conferência Rio-92 até os dias atuais a necessidade de redução do GEE tem sido discutida frequentemente.

Na Conferência de Quioto de dezembro de 1997, os países industrializados e economias em transição da antiga União Soviética assumiram compromissos de redução e limitação de emissões do GEE para o período 2008-2012, que foram prorrogados até 2020 . 
A Conferência Mundial sobre Desenvolvimento Sustentável realizada em Joanesburgo, no ano de 2002, deu destaque especial para as fontes renováveis. A proposta apresentada pelo Brasil de participação de $10 \%$ das fontes renováveis na matriz energética de cada país membro não foi aceita.

Em 2004, foi realizada na cidade de Bonn a Conferência Internacional sobre Energias Renováveis, reunindo 154 delegações de diferentes países. A conferência teve como um dos objetivos discutir políticas para o desenvolvimento de fontes renováveis de energia, com opções de financiamento para essas fontes e com o reforço da capacitação humana e institucional dos países.

Após 11 anos da Conferência de Bonn, ocorreu em Paris a COP-21, outro grande evento de cunho ambiental que buscava alcançar um novo acordo internacional sobre o clima, com participação de todos os países. E por último, a COP-22, realizada no ano de 2016, em Marrakesh, que teve como objetivo definir o chamado "livro de regras", que estabelecerá como será a implementação das obrigações assumidas em Paris.

Apesar da expressiva preocupação mundial com o meio ambiente, o desenvolvimento de novas fontes renováveis não se restringe ao cumprimento de metas ou obrigações ambientais, mas também visa novas descobertas tecnológicas. Outro ponto importante a destacar é que as novas fontes renováveis proporcionam a redução das diferenças regionais no que se refere ao acesso à energia. Mesmo com custos elevados quando comparados aos das fontes tradicionais, as novas fontes renováveis podem se tornar competitivas em comunidades isoladas (Miranda et al., 2013), por exemplo.

No entanto, a substituição do petróleo por outro energético não é uma tarefa simples, uma vez que o petróleo é uma fonte com conteúdo energético elevado, de fácil transporte e múltiplas aplicações. É fato que as energias renováveis nem sempre podem oferecer essas facilidades, além de serem fontes de energia consideradas intermitentes ${ }^{1}$.

\footnotetext{
${ }^{1}$ Energia intermitente é aquela energia que não pode ser fornecida continuamente, devido a fatores não controláveis, como o vento e radiação solar, por exemplo.
} 


\section{2 \\ Panorama energético brasileiro}

O Brasil se destaca dos demais países por apresentar grande participação em energia renovável em sua matriz energética. A matriz energética brasileira totalizou em 2015, conforme Figura 2.1, cerca de 40\% em energia renovável, comparada à média mundial de $14 \%$ e OCDE de $9 \%$. O Brasil tem, portanto, uma vantagem ímpar no cenário mundial.
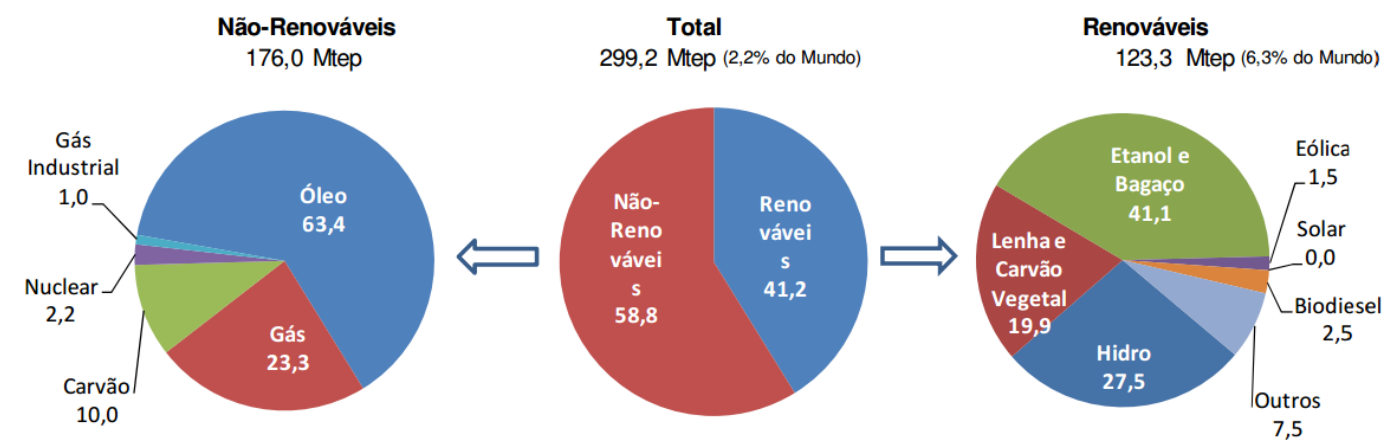

Figura 2.1 - Composição interna de energia no Brasil em 2015 Fonte: (EPE, 2016a)

Conforme o Balanço Energético Nacional (EPE, 2016a), a oferta interna de energia em 2015 reduziu 2,1\% em relação ao ano anterior. Parte dessa queda foi influenciada pelo comportamento da oferta interna de petróleo e derivados, que retraiu 7,2\% no período, devido ao superávit desses energéticos nos fluxos de exportação e importação. A outra parte sofreu influência da queda do Produto Interno Bruto (PIB).

As fontes renováveis da Figura 2.1 estão divididas em: etanol e bagaço de cana-de-açúcar; lenha e carvão vegetal; hidráulica; eólica; solar e biodiesel. Cabe destacar que, em 2015 a participação da fonte solar na matriz energética brasileira é ainda inexpressiva. Já o etanol e o bagaço são os mais representativos, com participação de $41,1 \%$.

Além do potencial energético, o país também apresenta indicadores de emissão de $\mathrm{CO}_{2}$ menores que da média mundial e de países desenvolvidos. Ainda 
conforme o BEN 2016, o Brasil apresentou em 2015, um indicador de 1,55 $\mathrm{tCO}_{2} /$ tep. Já a média mundial foi de 2,35 e a OCDE de 2,25 $\mathrm{tCO}_{2} /$ tep.

A Empresa de Pesquisa Energética (EPE, 2015) projeta para 2024 mais de 45\% de participação de energia renovável na matriz energética brasileira. No entanto, ainda são necessários aprimoramentos nos programas de incentivo a inserção de novas fontes alternativas. A EPE também projeta uma participação da energia solar fotovoltaica de 3,3\% na matriz elétrica brasileira, representando uma capacidade instalada de $7 \mathrm{GW}$.

\section{3 \\ A energia solar fotovoltaica}

O Sol é responsável pela origem de praticamente todas as outras fontes de energia. O aproveitamento da energia solar é inesgotável e é uma das alternativas energéticas mais promissoras no cenário energético atual.

A energia solar é proveniente da luz e do calor do Sol que é aproveitada por meio de diferentes tecnologias. Os métodos de captura da energia solar podem ser segundo CRESESB (2000):

- Direto - o método direto precisa de uma única etapa para capturar a energia do sol e transformá-la em energia a ser utilizada pelo homem, como por exemplo, a energia solar fotovoltaica. Esta atinge uma célula fotovoltaica se transformando em eletricidade;

- Indireto - precisa de duas ou mais etapas para converter a energia solar em energia utilizável. A energia solar heliotérmica serve como exemplo desse tipo de captura. A energia solar atinge os espelhos refletores que concentram o calor em um tubo a vácuo por onde passa água e, esta, quanto tiver sido transformada em vapor alimentará uma turbina para gerar energia elétrica; 
- Passivo - os sistemas passivos são normalmente diretos, como por exemplo, uma estufa que transfere o calor do sol para o ar mantendo o ambiente quente;

- Ativo - já os sistemas ativos, funcionam com o auxílio de dispositivos mecânicos para melhorar o desempenho da coleta da energia solar. O sistema de aquecimento solar que utiliza uma bomba para forçar a circulação de água dentro do sistema é um exemplo de sistema ativo.

Atualmente, os processos de aproveitamento da energia solar mais usados no mundo são o aquecimento de água e a geração fotovoltaica de energia elétrica.

Dada a importância desse tema na atualidade, o foco desse estudo será a geração fotovoltaica de energia elétrica. A energia solar fotovoltaica pode ser definida como uma fonte de energia renovável obtida pela conversão direta de energia luminosa em energia elétrica por meio de células fotovoltaicas (Green et al., 2000).

Para converter a energia solar em energia elétrica por meio de sistemas fotovoltaicos, é necessário conhecer a intensidade da radiação solar global ${ }^{2}$ incidente no plano coletor.

Conforme CRESESB (2000), a medição do recurso solar é feita comumente por meio dos seguintes instrumentos:

- Piranômetros e actinógrafos: medição de radiação global;

- Heliógrafos: medição do número de horas de insolação, e

- Piroheliômetros: medição de radiação direta normal.

Esses instrumentos utilizam sensores do tipo termopilhas, pares bi-metálicos ou fotocélulas.

\footnotetext{
${ }^{2}$ Radiação solar global é o somatório da radiação vinda diretamente do Sol e da radiação difundida pelas partículas e gases da atmosfera.
} 
O Brasil tem um grande potencial energético solar visto que a maior parte de seu território está localizada relativamente próxima à linha do Equador. A variação da incidência de radiação solar entre o Inverno e Verão é menor na região Norte do que nas regiões Sul e Sudeste. A região Norte recebe menor incidência de radiação solar durante o Verão, por ser um período muito úmido, ocorrendo o inverso no inverno. A região amazônica recebe maior radiação solar global (Pereira et al., 2006).

Os valores máximos de radiação solar global são observados na região oeste do Nordeste, no norte de Minas Gerais, no nordeste de Goiás e no sul de Tocantins.

Na região Sul do Brasil, são observados os menores valores de irradiação solar $^{3}$, devido as características de clima e a influência de sistemas frontais associados ao Anticiclone Polar Antártico que contribuem para o aumento da nebulosidade na região.

Apesar de o Brasil ser caracterizado pela variabilidade de irradiação solar ao longo das estações do ano e nas diversas regiões, pode-se observar na Figura 2.2 que a média anual de radiação global diária é bastante uniforme.

Contudo, a previsão de energia solar fotovoltaica no Brasil precisa superar os desafios inerentes à fonte, pois o desempenho da célula fotovoltaica está influenciado pelas condições do tempo, especialmente a radiação solar e a temperatura.

\footnotetext{
${ }^{3}$ Irradiação solar é uma determinada quantidade de radiação solar por unidade de área.
} 


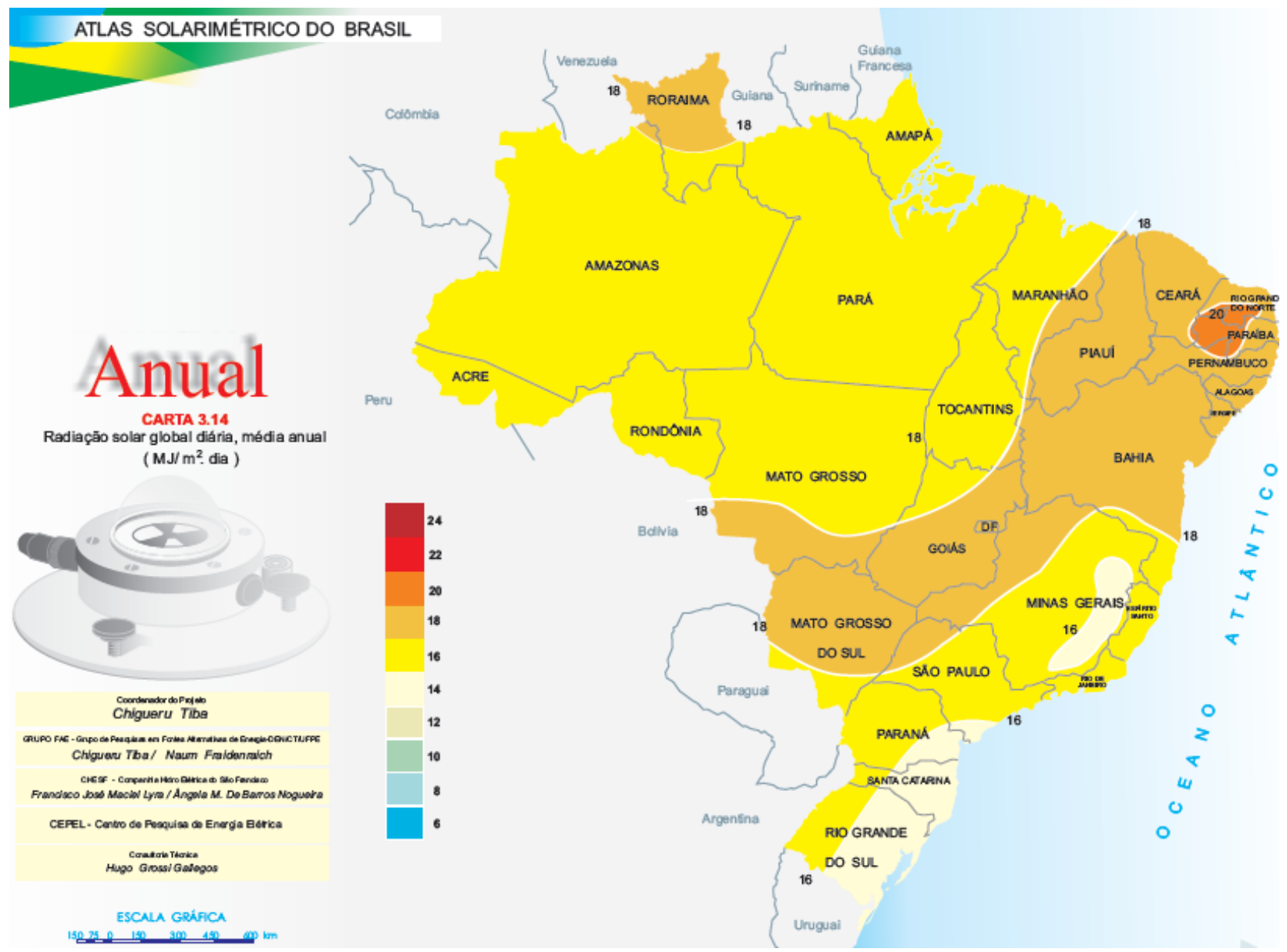

Figura 2.2 - Radiação solar global diária no Brasil (média anual) Fonte: (UFPE et al., 2000) 


\subsection{1 \\ Mecanismos de incentivo à energia solar fotovoltaica na matriz energética brasileira}

O Brasil tem tido nos últimos anos diversos estímulos à energia renovável. A primeira iniciativa que incorporou o uso da energia solar fotovoltaica em âmbito nacional foi o Programa de Desenvolvimento Energético de Estados e Municípios - PRODEEM. Segundo Galdino et al. (2002), o PRODEEM é um dos maiores programas de eletrificação rural que utilizou sistemas fotovoltaicos nos países em desenvolvimento.

A geração distribuída ${ }^{4}$ tem como vantagens: o adiamento de investimentos em expansão dos sistemas de transmissão e distribuição, o baixo impacto ambiental, a redução no carregamento das redes, a minimização das perdas e a diversificação da matriz energética.

Atualmente, existem diversos projetos de lei com o objetivo de promover a inserção das fontes renováveis na matriz energética brasileira. No que diz respeito à energia solar fotovoltaica, destacam-se os seguintes projetos de lei:

- Projeto de lei $\mathrm{n}^{0} 10.438$, de 2002 - cria o Programa de Incentivo às Energias Renováveis (PROINFA), e dá outras providências;

- Projeto de lei $n^{0} 3.831$, de 2004 - dispõe sobre incentivos à geração de energias alternativas e dá outras providências;

- Projeto de lei $\mathrm{n}^{0}$ 7.692, de 2006 - institui o Programa Brasileiro de Geração Descentralizada de Energia Elétrica e dá outras providências;

- Projeto de lei $n^{0}$ 523, de 2007 - institui a Política Nacional de Energias Alternativas e dá outras providências;

- Projeto de lei $n^{0} 1.563$, de 2007 - dispõe sobre fontes renováveis de energia, com o objetivo de promover a universalização, a geração distribuída e a racionalização energética. Altera a Lei $\mathrm{n}^{\circ} 10.438$, de 26 de abril de 2002, para modificar o Programa de Incentivo às Fontes Alternativas de Energia Elétrica (PROINFA) e aumentar a

\footnotetext{
${ }^{4}$ Geração distribuída (GD) pode ser definida por geração elétrica realizada junto ou próximo aos consumidores, normalmente a partir de fontes renováveis ou mesmo utilizando combustíveis fósseis (ANEEL, 2016).
} 
participação de fontes alternativas na matriz energética nacional, e dá outras providências;

- Projeto de lei $\mathrm{n}^{0} 2.737$, de 2008 - Estabelece incentivos à geração de energia a partir de fonte solar.

Em 17 de abril de 2012, entrou em vigor a Resolução Normativa ANEEL n ${ }^{\circ}$ 482/2012, que estabelece as condições para o acesso de microgeração e minigeração distribuída aos sistemas de distribuição de energia elétrica. Em dezembro do mesmo ano passa a vigorar a Resolução Normativa ANEEL n ${ }^{0}$ 517/2012, que altera a Resolução Normativa ANEEL no 482 de 2012 e o Módulo 3 dos Procedimentos de Distribuição - PRODIST, destacando-se por definir o sistema de compensação de energia elétrica e as regras para injeção de energia por parte dos geradores e distribuidora local. Em novembro de 2015, passa a vigorar a Resolução Normativa ANEEL $n^{0}$ 687/2015, que altera a Resolução $n^{0} 482 / 2012$. A nova resolução tem como objetivo propiciar um ambiente que busque a redução dos custos e tempos de conexão associados a micro e minigeração, assim como compatibilizar o sistema de compensação de energia elétrica com as condições de fornecimento, aumentar o público alvo e melhorar as informações na fatura.

Ainda como forma de incentivo à inserção da energia solar fotovoltaica, o Instituto Brasileiro de Metrologia, Normalização e Qualidade Industrial INMETRO, alinhado com a Lei n ${ }^{0}$ 10.295/2001 de Eficiência Energética, constituiu em 9 de fevereiro de 2002, dentro do escopo do Programa Brasileiro de Etiquetagem (PBE), o grupo de trabalho de sistemas fotovoltaicos. Esse grupo foi criado com o objetivo de estabelecer as normas para etiquetagem de sistemas fotovoltaicos e seus componentes, visando à contínua melhoria técnica destes produtos. O PBE Fotovoltaico tem marco regulatório vigente na portaria Inmetro $n^{0} 4$ de 2011 (INMETRO, 2013). A etiquetagem em sistemas fotovoltaicos é feita com base em sua capacidade de gerar energia (Galdino et al., 2005). Atualmente, os modelos etiquetados pelo PBE referentes ao sistema de energia fotovoltaico são:

- Módulos - os materiais dos módulos são o silício mono e poli cristalino;

- Baterias; 
- Inversores conectados à rede (On Grid);

- Inversores redes autônomas (Off Grid).

No âmbito do planejamento da operação energética, foram criadas a resolução normativa da ANEEL $n^{0} 440$, de 5 de julho de 2011 e a resolução normativa da ANEEL $n^{\circ} 476$, de 13 de março de 2012. A primeira estabelece os critérios para a consideração de usinas não simuladas individualmente nos modelos computacionais de planejamento da operação e formação de preço, conforme visto na seção 1. Já a segunda, altera o conteúdo da primeira, trazendo melhorias.

\section{4 \\ O planejamento da operação energética no Brasil}

O sistema elétrico brasileiro (SEB) é predominantemente hidroelétrico, cerca de $70 \%$ da capacidade instalada (EPE, 2016a). O SEB é caracterizado por grandes bacias hidrográficas e grandes interligações que representam o sistema interligado nacional (SIN). Aproximadamente, 98\% do mercado de energia brasileiro estão interligados. Cerca de $2 \%$ que ainda não foram interligados correspondem ao sistema isolado da Amazônia, que é atendido na sua maioria pelo parque térmico da região (ONS, 2017).

As principais linhas de transmissão interconectam as bacias hidrográficas aos principais centros de carga e as grandes interligações regionais Sul-Sudeste/CentroOeste, Norte-Nordeste e a Interligação Norte-Sul, que interligam os sistemas elétricos das regiões Sul e Sudeste/Centro-Oeste aos sistemas elétricos das regiões Norte e Nordeste.

O regime de chuvas brasileiro é torrencial e sazonal, por isso no passado as grandes construções de usinas hidrelétricas priorizavam os reservatórios de regularização. No entanto, os empreendimentos atuais são construídos com a prerrogativa de causar o mínimo impacto ao meio ambiente e à sociedade no seu entorno. Essa prerrogativa ambiental e social fez com que as novas usinas hidrelétricas fossem construídas a fio d'água, ou seja, que não dispõem de reservatório de água, apenas conta com a área do lago construída. 
Com o crescimento de usinas hidrelétricas a fio d'água, como por exemplo, os grandes projetos hidráulicos da região Amazônica, em detrimento da construção de usinas com reservatórios de regularização, o atendimento a demanda tornou-se um desafio para o planejador (EPE e ONS). Com isso, as novas fontes alternativas passaram a ganhar cada vez mais importância dentro do contexto nacional, conforme apresentado na Tabela 2.1.

Tabela 2.1 - Capacidade instalada ${ }^{5}$ na matriz elétrica brasileira (MW)

\begin{tabular}{lccc}
\hline Fonte & $\mathbf{2 0 1 5}$ & $\mathbf{2 0 1 4}$ & $\mathbf{\Delta 1 5 / 1 4}$ \\
Hidrelétrica & 91.650 & 89.193 & $2,80 \%$ \\
Térmica6 $^{6}$ & 39.564 & 37.827 & $4,60 \%$ \\
Nuclear & 1.990 & 1.990 & $0,00 \%$ \\
Eólica & 7.633 & 4.888 & $56,20 \%$ \\
Solar & 21 & 15 & $42,30 \%$ \\
Capacidade disponível & $\mathbf{1 4 0 . 8 5 8}$ & $\mathbf{1 3 3 . 9 1 4}$ & $\mathbf{5 , 2 0 \%}$ \\
\hline
\end{tabular}

Fonte: Elaboração própria (com base em EPE, 2016a)

Conforme mostrado na Tabela 2.1, a fonte hidrelétrica ainda é predominante, com cerca de $70 \%$ da capacidade instalada. Em seguida, a fonte térmica com aproximadamente $28 \%$ da capacidade instalada. Já as demais fontes como eólica $(5,4 \%)$, nuclear $(1,4 \%)$ e solar $(0,0 \%)$, representam participações mais reduzidas na matriz elétrica. Contudo, ao se comparar com o apurado em 2014, percebe-se um aumento das fontes eólica e solar de aproximadamente $60 \%$ e 40\%, respectivamente.

\subsection{1 \\ O sistema elétrico brasileiro}

A partir de meados da década de 60 o crescimento do consumo de energia elétrica e a necessidade do aumento da capacidade instalada em usinas geradoras e

${ }^{5}$ Não inclui geração distribuída.

${ }^{6}$ Inclui biomassa, gás, petróleo e carvão mineral. 
da malha de transmissão, exigiu que os sistemas elétricos brasileiros funcionassem de forma integrada (Pires et al., 1998), sendo os grandes empreendimentos da época realizados por empresas públicas federais e estaduais.

Logo, a expansão do setor produtivo estatal na área de energia favoreceu a ideia da criação do Ministério de Minas e Energia (MME) em 1960, sendo que em 1962 a Eletrobras foi fundada, passando a administrar o Fundo Federal de Eletrificação e a carteira de aplicações efetuadas pelo BNDES com as concessionárias de energia.

$\mathrm{Na}$ década de 70, outro marco importante ganhava destaque no setor. A viabilização de grandes empreendimentos como os aproveitamentos hidrelétricos de Itaipu e Tucuruí fizeram com que a Eletrobras exercesse as funções de coordenação do planejamento da expansão e da operação dos sistemas elétricos brasileiros, além do seu papel como principal agente de financiamento do setor (Gomes, 2012). Além disso, esta empresa deveria estruturar órgãos capazes de contribuir com estudos específicos para o setor, como por exemplo, a criação do Centro de Pesquisa de Energia Elétrica (CEPEL), que teve como objetivo promover uma infraestrutura científica e de pesquisa.

Nos anos 80, foi aprovada por resolução da Eletrobras a criação dos Grupos Coordenadores de Planejamento do Sistema Elétrico (GCPS) que tinha duas finalidades: estudar alternativas de desenvolvimento dos sistemas elétricos das concessionárias e elaborar pareceres e proposições para ajustar o programa de expansão das empresas (Gomes, 2012).

O funcionamento desses grupos tinha um caráter colaborativo por parte das empresas públicas de geração, transmissão e distribuição que foram componentes essenciais nas grandes conquistas desse modelo constituído, primordialmente, por um monopólio estatal. No entanto, não havia competição e mecanismos de incentivo à eficiência. As decisões da expansão do setor elétrico eram definidas com forte influência política. 
Em meados dos anos 80, devido ao agravamento da dívida externa brasileira, foram tomadas várias ações pelo Poder Concedente na tentativa de reestruturar o setor elétrico.

Na década de 90 foi aprovada a Lei ${ }^{\circ}$ 8.967, que regulamentou os preceitos de licitação para concessões, dando início à competição no setor, e em 1998 foi aprovada a Lei $n^{0} 9.648$ que introduziu as seguintes modificações na indústria de energia elétrica brasileira:

- Desverticalização dos segmentos de geração, transmissão e distribuição das empresas e a constituição do segmento de comercialização;

- Criação do segmento de transmissão como um negócio independente;

- Permissão da comercialização de energia elétrica entre geradores de distribuidores de diferentes pontos da rede;

- Criação do Operador Nacional do Sistema Elétrico (ONS), com objetivo de coordenar e controlar a operação da geração e da transmissão no âmbito do SIN;

- Criação do Mercado Atacadista de Energia Elétrica (MAE), com atribuição de disciplinar as transações de compra e venda de energia elétrica e efetuar a contabilização e a liquidação da energia de curto prazo.

O racionamento de energia elétrica ocorrido no Brasil entre 2001 e 2002 fez com que as privatizações do setor elétrico reduzissem e um novo modelo mais harmonioso e efetivo fosse implantado.

Nesse cenário, nascia o modelo atual do setor elétrico brasileiro, norteado pela Resolução CNPE $n^{0} 5$ de 2003, e tem como principais entidades/instituições, com suas respectivas atribuições:

- Conselho Nacional de Política Energética (CNPE) - assessoramento do presidente da República para a formulação de políticas nacionais e diretrizes de energia; 
- Ministério de Minas e Energia (MME) - monitoramento e acompanhamento do setor elétrico;

- Comitê de Monitoramento do Setor Elétrico (CMSE) acompanhamento e avaliação da continuidade e segurança do suprimento eletroenergético em todo o território nacional;

- Agência Nacional de Energia Elétrica (Aneel) - autarquia sob regime especial, cuja finalidade é regular e fiscalizar os serviços de geração, transmissão, distribuição e comercialização de energia elétrica;

- Empresa de Pesquisa Energética (EPE) - empresa vinculada ao MME, que tem por finalidade prestar serviços na área de estudos e pesquisas que subsidiem o planejamento do setor energético;

- Operador Nacional do Sistema Elétrico (ONS) - associação civil sem fins lucrativos, cuja finalidade é realizar atividades de coordenação e controle da operação das instalações de geração e da transmissão de energia elétrica participantes do SIN.

\section{4 .2 \\ O sistema interligado nacional}

A configuração atual e a evolução do SIN podem ser explicadas através do eixo de desenvolvimento econômico do país, das racionalidades econômicas e das características da natureza.

Os serviços de geração, transmissão e distribuição de energia elétrica foram organizados no Brasil inicialmente sob a forma de sistemas independentes e isolados, atendendo preferencialmente aos maiores centros urbanos.

A escassez de reservas de carbono de boa qualidade combinada à insuficiência de combustíveis fósseis, e a inexistência de tecnologia nuclear, fizeram com que as fontes de geração hidroelétrica se tornassem a principal opção para o atendimento do mercado de energia elétrica (Tolmasquim, 2016). 
As hidrelétricas construídas antes da década de 30 não dispuseram do conhecimento mais aprofundado das bacias hidrográficas. Somente a partir dos anos 30, foram dados os primeiros passos para a interligação da operação de usinas.

A região Sudeste, por ser a mais urbanizada e industrializada do País, foi a que deu maior contribuição para o crescimento do parque elétrico brasileiro. $\mathrm{Na}$ região Sul, o aproveitamento das fontes hidráulicas foi complementado por termoelétricas que consumiam o carvão local. Já as regiões Norte e Nordeste permaneceram servidas predominantemente por pequenas usinas térmicas movidas a óleo diesel.

Quanto às características da natureza, cabe destacar que a forte sazonalidade do regime hidrológico do país afeta diretamente a produção de energia elétrica e a dinâmica da utilização e planejamento dos demais recursos energéticos. A produção de energia elétrica nas usinas está diretamente ligada ao regime de chuvas. Em períodos chuvosos a produção de energia elétrica tende a ser abundante, sendo possível estocar os excedentes de água para o atendimento ao mercado consumidor. Por outro lado, nos períodos de estiagens, os rios tornam-se menos caudalosos e, como consequência, a produção de energia tende a ser menor, podendo ser necessária a utilização da água estocada nos reservatórios durante o(s) período(s) chuvoso(s) anterior(es), denominados de reservatórios de acumulação ou reservatórios de regularização.

O Brasil possui diversos rios extensos, perenes e caudalosos, alguns atravessando vários estados da federação (EPE, 2015). Muitos desses rios apresentam vários locais com grandes quedas d'água ao longo dos seus cursos ou com topografia local favorável à construção de grandes reservatórios de acumulação de água. Estas características potencializam o aproveitamento da energia hidroelétrica em vários sítios ao longo de um mesmo rio, os chamados aproveitamentos em cascata. Esses aproveitamentos em cascata dentro de um mesmo rio podem pertencer a proprietários diferentes, tornando a operação mais complexa, conforme exemplo apresentado na Figura 2.3. 


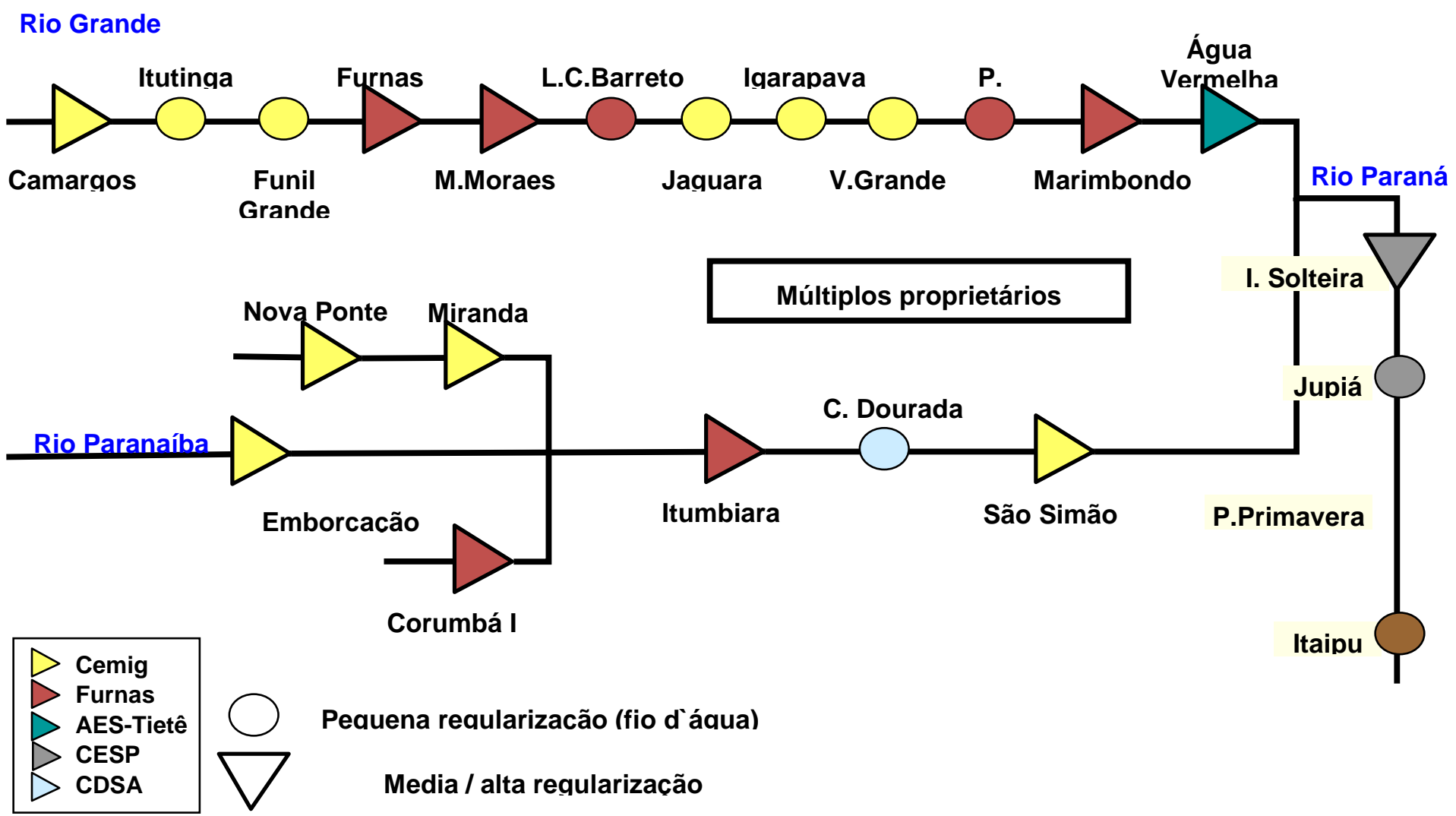

Figura 2.3 - Parte do diagrama esquemático das usinas hidrelétricas da região Sudeste/Centro-oeste Fonte: (ONS, 2000) 
O SIN apresenta, além das linhas de transmissão contidas em território nacional, as linhas de transmissão de importação e exportação envolvendo países vizinhos, logo, o papel do agente coordenador da operação é indispensável tanto para que o sistema seja eletricamente seguro quanto para que os recursos sejam aproveitados de forma eficiente (Gomes, 2012). Para isso é necessário encadear de forma harmoniosa todas as atividades que constituem o planejamento da operação.

O planejamento da operação se inicia com o levantamento dos recursos energéticos, requisitos de atendimento e restrições associadas.

\subsubsection{1}

\section{Desagregação do planejamento da operação em etapas}

O planejamento da operação energética é dividido em três momentos:

- Médio prazo - corresponde ao horizonte de cinco anos, discretizados em etapas mensais;

- Curto prazo - corresponde ao horizonte de até doze meses, discretizados em etapas semanais;

- Programação diária - corresponde ao horizonte de uma semana, discretizados em $1 / 2$ hora.

Em função da complexidade do SIN e das incertezas inerentes às informações para os períodos mais distantes, o planejamento é feito em etapas sucessivas, com horizontes decrescentes e grau de detalhamento crescente. O ONS dispõe da cadeia de modelos computacionais desenvolvida pelo CEPEL, conforme Figura 2.4, para otimização da operação em cada uma das etapas descritas acima, com exceção da etapa de programação diária, cujo modelo ainda se encontra em desenvolvimento. 


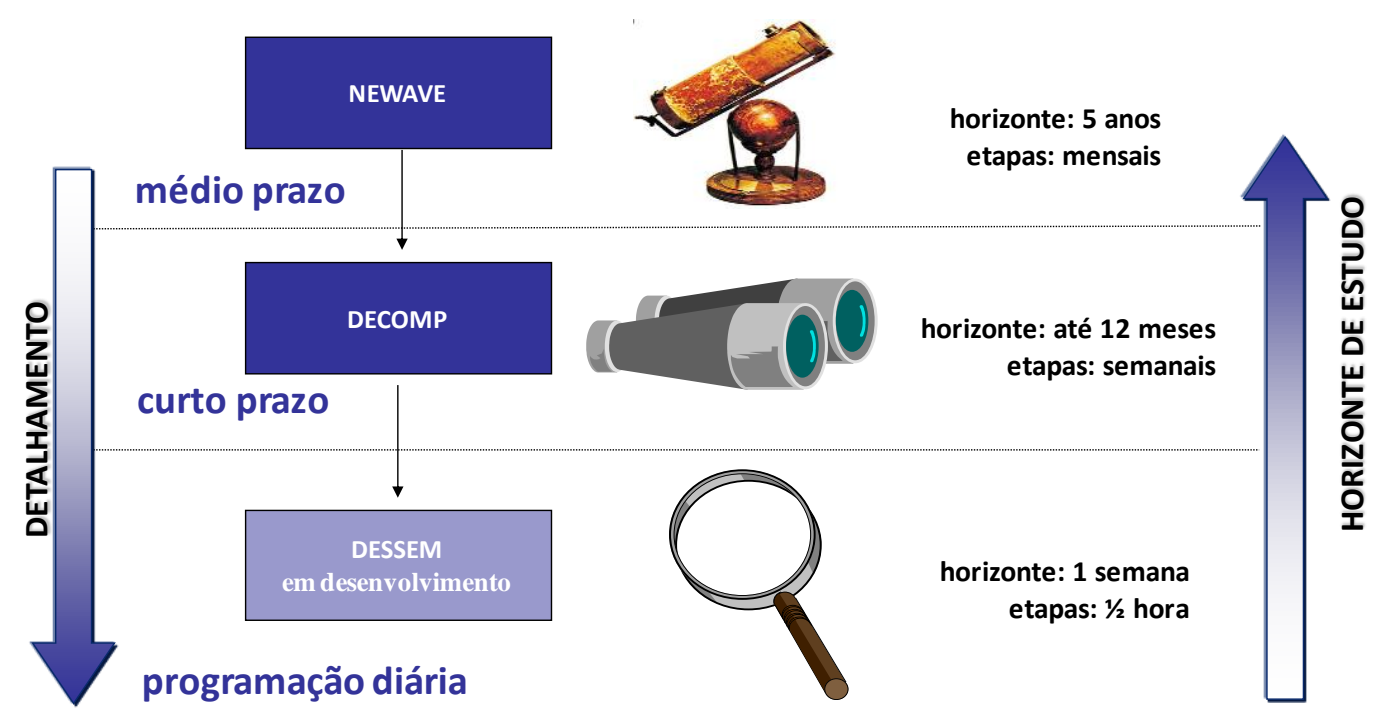

Figura 2.4 - Etapas de estudos do planejamento da operação energética

Fonte: Elaboração própria

O planejamento da operação energética visa construir uma política operativa mensal que tem como objetivo minimizar o custo total da operação para todo o horizonte de estudo. O custo total da operação é a soma dos custos variáveis de todos os recursos utilizados, ou seja, o custo de geração térmica e, caso parte da demanda não seja suprida, o custo associado à falta ou racionamento de energia elétrica, denominado custo de déficit.

A estratégia deve ser então definida visando alcançar o mínimo custo, cabendo gerenciar as decisões de geração hidroelétrica e termoelétrica por usina, de intercâmbio de energia entre as regiões do SIN e de corte de carga. Cabe ressaltar que devido à predominância da hidroeletricidade no sistema brasileiro, e por consequência, a interdependência no tempo, a função do custo futuro é influenciada pelas decisões tomadas no presente (Souza et al., 2012).

A disponibilidade da energia hidráulica é limitada pela capacidade de armazenamento dos reservatórios. Logo, existe uma relação entre a decisão da operação em um determinado estágio e as consequências desta decisão no futuro. Por exemplo, se a energia armazenada hidrelétrica é usada hoje e ocorrem períodos mais secos, pode ser necessário o uso de geração térmica sem o devido 
planejamento (opção mais cara), ou até mesmo interromper o fornecimento de energia, o que incorre em custos elevados de déficit. Caso os níveis dos reservatórios sejam preservados, através do uso de geração de energia térmica, e ocorrem elevados volumes de afluência no futuro, os reservatórios podem verter, ocasionando o desperdício de energia e custos operacionais aumentados. Essa árvore de decisão do sistema hidrotérmico é apresentada na Figura 2.5.

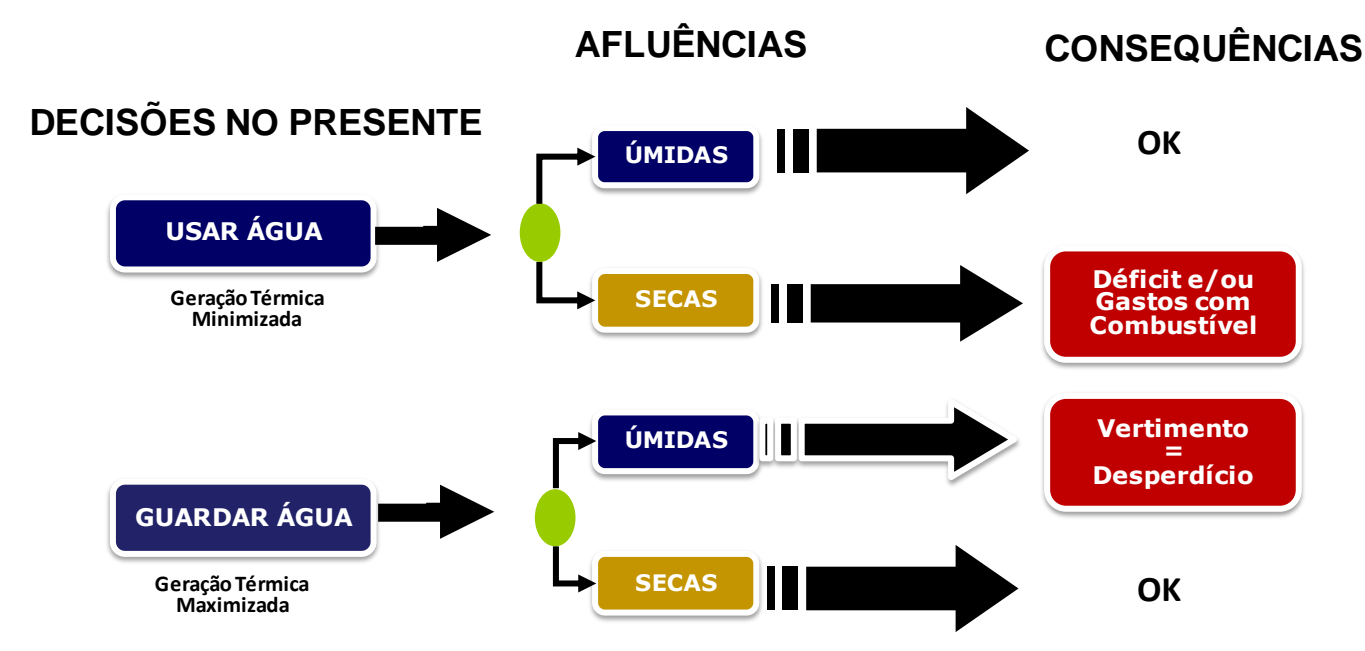

Figura 2.5 - Árvore de decisão do sistema hidrotérmico

Fonte: Elaboração própria

O custo total é representado por duas parcelas: a função do custo imediato (FCI) e a função do custo futuro (FCF), conforme Figura 2.6. A função de custo imediato está relacionada aos custos de geração térmica no estágio $t$. À medida que o armazenamento aumenta no final do período e há redução de água disponível para a produção de energia no estágio $t$, os custos imediatos se elevam devido à necessidade do aumento de geração térmica. Já a função de custo futuro (FCF) está associada aos custos esperados de geração térmica a partir do estágio $t+1$ até o final do planejamento. Logo, a FCF diminui quando o armazenamento final tende a aumentar, pois há maior quantidade de água disponível para o uso no futuro. $\mathrm{O}$ despacho energético que conduz ao menor custo total é obtido ao se equilibrar a geração hidráulica e térmica de forma a igualar a $\mathrm{FCF}$, que representa o valor da água, à FCI, associado ao custo de geração térmica mais cara que estiver sendo despachada (Maceira et al., 2002). 


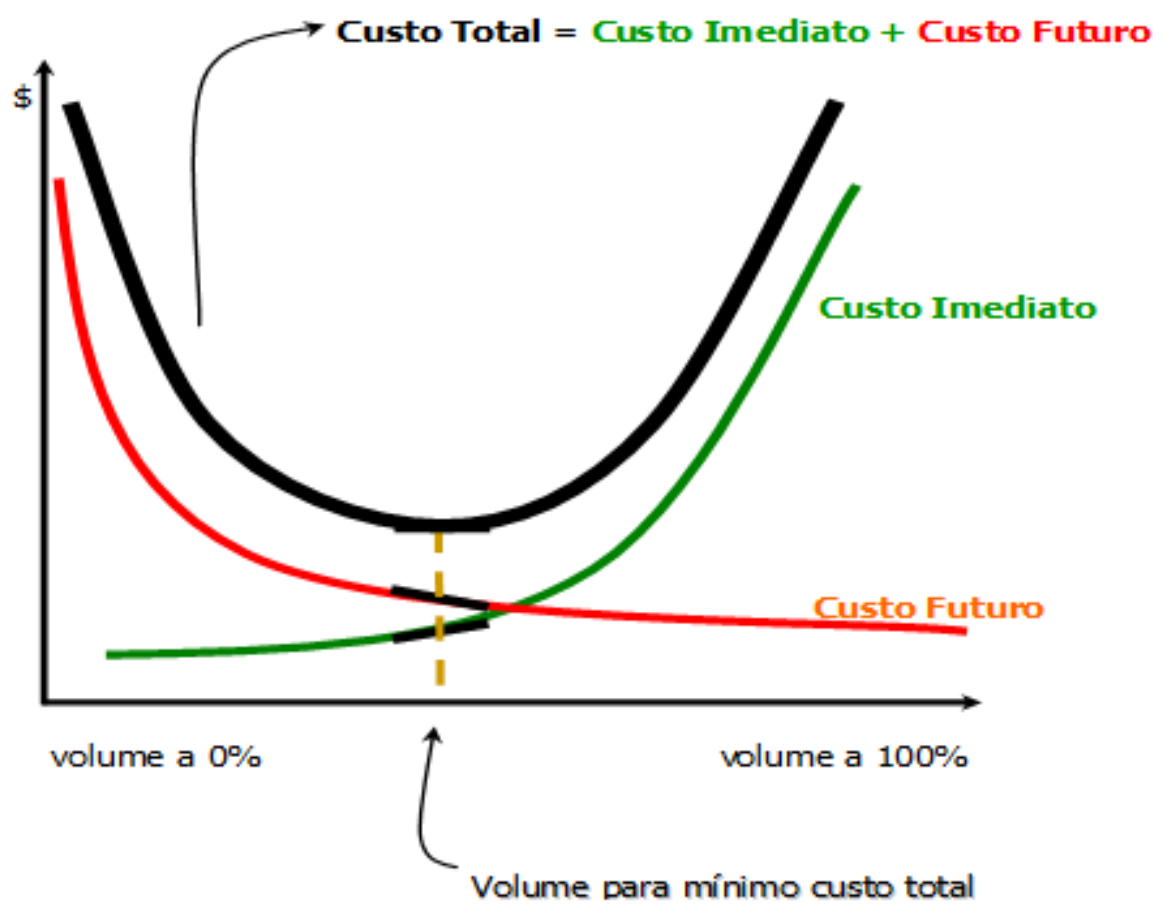

Figura 2.6 - Custo do armazenamento da água Fonte: Elaboração própria

Para o cálculo da minimização do custo total da operação é utilizado o modelo NEWAVE, correspondente ao planejamento de médio prazo. O modelo NEWAVE representa o parque hidroelétrico de forma agregada e o cálculo da política de operação baseia-se na Programação Dinâmica Dual Estocástica (PDDE). O objetivo da otimização via NEWAVE é determinar a estratégia de operação de médio prazo, de forma a minimizar o valor esperado do custo de operação ao longo do período de planejamento (CEPEL, 2012).

Devido a gama de varáveis considerada no planejamento de médio prazo, o sistema é representado de maneira simplificada. Assim, o armazenamento da energia é agrupado em quatro subsistemas ou reservatórios equivalentes: Sudeste/Centro-oeste, Sul, Nordeste e Norte.

Como visto anteriormente, a função de custo imediato é fácil de determinar, pois corresponde às despesas com o pagamento do combustível decorrentes das decisões presentes. Já a função de custo futuro depende do comportamento aleatório 
das vazões que é uma característica marcante de sistemas com predominância hidráulica. As vazões, da mesma forma que o clima, tem alto grau de incerteza.

Ao estudar o histórico de afluências desde 1931 a 2001, foram obtidos índices estatísticos como média, desvio-padrão, correlação temporal e espacial visando identificar um modelo estatístico que se ajustasse ao comportamento das afluências conhecidas. Definiu-se então para o tratamento das vazões no modelo NEWAVE a utilização do modelo estocástico periódico autorregressivo - PAR(p) - que é utilizado para representar a estocasticidade da energia armazenada em cada subsistema (Souza et al., 2012), ou seja, as afluências, por este modelo, dependem das afluências que ocorreram nos mesmos locais em até $\mathrm{p}$ meses anteriores. $\mathrm{O}$ caráter periódico do modelo está ligado à sazonalidade do regime hidrológico. Logo, para cada mês pode haver um valor diferente para o parâmetro p. Geralmente, afluências em meses iniciais do período chuvoso dependem de 1 a 2 lags passados. Já as afluências em meses iniciais do seco, dependem do que ocorreu em vários lags do período úmido imediatamente anterior (Maceira et al., 2006).

No caso do NEWAVE, estes modelos são ajustados às séries de vazões e/ou ENA (Energia Natural Afluente) de cada um dos subsistemas do SIN (Sudeste/Centro-oeste, Sul, Nordeste e Norte). Assim, conhecendo-se o modelo estocástico que represente as afluências, pode-se sortear um número grande de hipóteses, acompanhar a evolução do sistema nos próximos cinco anos para cada uma das trajetórias correspondentes a cada hipótese de afluência e calcular o custo médio de todas as hipóteses (Maceira et. al, 2002).

A versão atual do modelo NEWAVE utiliza a programação dinâmica dual estocástica, enunciada em 1962 pelo matemático J. F. Benders (Benders, 1962), para estudar a evolução do sistema trazendo as informações do futuro para o presente. A função de custo futuro então é utilizada na otimização da operação de cada uma das trajetórias, em cada uma das etapas, conforme representada pela Figura 2.7. O estado do sistema corresponde ao nível de armazenamento do reservatório de uma usina. Já a etapa corresponde ao intervalo de tempo, como por exemplo, a uma semana, a um mês ou outro intervalo de interesse (CEPEL, 2012). 


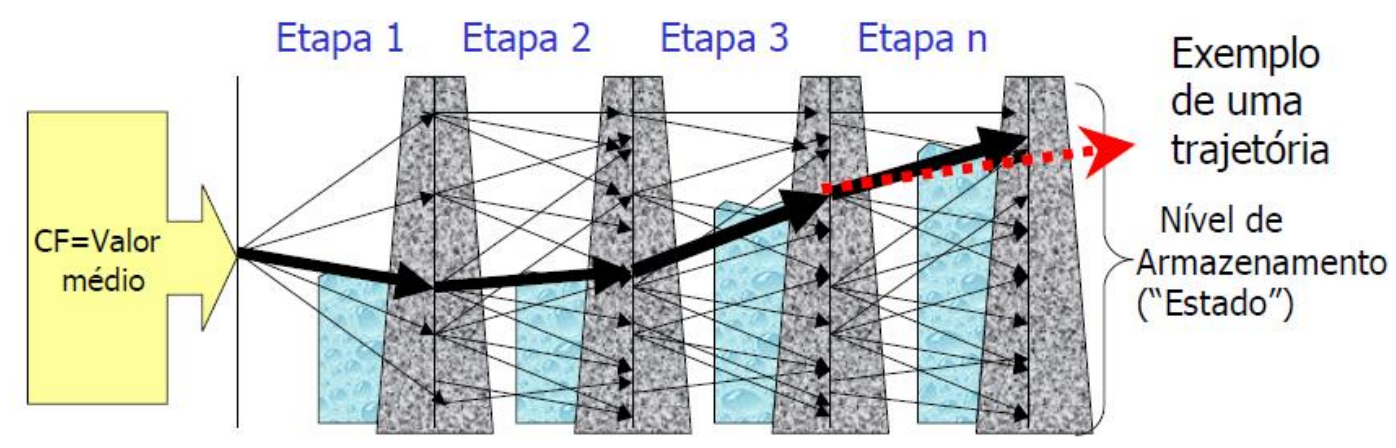

Figura 2.7 - Enfoque pente do NEWAVE

Fonte: (ONS, 2005)

No enfoque pente, utilizado pelo NEWAVE, todas as hipóteses se ramificam apenas a partir do início do horizonte, e cada hipótese tem a duração do horizonte de estudo.

$\mathrm{Na}$ formulação do problema de otimização, devem ser representadas todas as restrições elétricas e hidráulicas que possam impactar as decisões operativas. Para esse caso são adicionadas ao problema restrições através de novas inequações (Maceira et al., 2006). O problema clássico de um estágio de planejamento, utilizando sistemas equivalentes de energia, visa à minimização do valor esperado do custo total de operação (FCI + FCF), sujeito a:

- Equações de atendimento a demanda ${ }^{7}$;

- Equações do balanço de energia nos reservatórios;

- Equações de fechamento dos nós fictícios;

- Restrições de geração hidráulica máxima;

- Equações de função de custo futuro;

- Restrições operacionais.

Dentre os principais resultados do modelo NEWAVE estão a função de custo futuro (FCF), já detalhada anteriormente, e o custo marginal de operação (CMO).

\footnotetext{
${ }^{7}$ Cabe destacar ainda que o requisito de atendimento a demanda ou carga global de energia é abatido da estimativa de geração de usinas não simuladas pelo NEWAVE (Pequenas centrais hidráulicas, pequenas centrais térmicas, usinas eólicas e usinas solares) A demanda líquida resultante é o requisito que deverá ser atendido pela otimização.
} 
O CMO é o custo adicional que seria necessário para o atendimento a um incremento de carga em cada um dos quatro subsistemas equivalentes e sua unidade é o R\$/MWh.

As principais utilidades da função de custo futuro são:

- Análise da operação supondo a repetição do histórico conhecido e consolidado;

- Análise de caráter estatístico com as 2.000 séries de afluências de tamanho igual ao período do estudo;

- Acoplamento com o modelo DECOMP ${ }^{8}$.

O ONS disponibiliza mensalmente em seu site o Programa Mensal da Operação Energética (PMO), no qual é possível consultar todas as premissas consideradas no "deck de PMO" utilizadas no processamento do modelo NEWAVE para obtenção da função de custo futuro.

Cabe destacar ainda, que a geração solar fotovoltaica é considerada no grupo de geração de usinas não simuladas pelos modelos de otimização energética (NEWAVE e DECOMP), formado pelas pequenas centrais hidrelétricas, pequenas centrais térmicas, usinas eólicas e fotovoltaicas, como visto na seção 1. A representação da geração desse grupo de usinas no horizonte de planejamento é feita de forma determinística, conforme Resolução Normativa ANEEL nº 476 de 2012. Para a geração distribuída, a situação é ainda mais delicada, pois pouco se sabe como o planejador considera a projeção dessa geração no futuro.

Nesse contexto, essa dissertação fará uso do modelo computacional NEWAVE, no âmbito do planejamento da operação energética de médio prazo, para efetuar análises de caráter probabilístico.

\footnotetext{
${ }^{8}$ O DECOMP é um modelo da cadeia energética e seu processamento tem por objetivo determinar a estratégia de operação de curto prazo para sistemas hidrotérmicos interligados.

${ }^{9}$ Conjunto de arquivos que contém todas as premissas utilizadas no processamento do NEWAVE para a obtenção da função de custo futuro.
} 


\section{3. \\ Simulação Bootstrap em séries temporais}

\section{1 Modelos Box \& Jenkins}

Uma série temporal pode ser definida como qualquer conjunto de observações ordenadas no tempo (Morettin \& Toloi, 1987). As séries temporais são divididas em quatro elementos: tendência, ciclo, sazonalidade e ruído aleatório. A tendência indica o sentido de deslocamento da série ao longo do tempo. O elemento ciclo corresponde ao movimento ondulatório, que ao longo do tempo tende a ser periódico. A sazonalidade corresponde ao comportamento da série temporal que tende a se repetir a cada n períodos de tempo. Já o ruído consiste na variabilidade intrínseca aos dados e não podem ser modelados.

Um dos métodos mais aplicados para previsão e ajuste de séries temporais é a metodologia Box \& Jenkins, em que uma das características principais consiste na interpretação de uma dada série temporal como sendo a realização de um vetor aleatório multivariado, com dimensão definida pela própria série temporal estudada (Box \& Jenkins, 1976).

A modelagem Box \& Jenkins se utiliza do princípio da parcimônia e da construção de modelos através de um ciclo iterativo. Um modelo parcimonioso deve ser aquele com o menor número de parâmetros possíveis. Já o ciclo iterativo é uma estratégia de seleção de modelos que deve ser desenvolvida até que se encontre o modelo satisfatório. Espera-se que uma série temporal apresente correlação serial ao longo do tempo (Souza et al., 2004). Os modelos desenvolvidos pelos autores Box e Jenkins são também conhecidos como modelos ARIMA (Auto Regressive Integrated Moving Average).

Os modelos ARIMA são modelos matemáticos, cujo objetivo é identificar o comportamento da correlação serial ou autocorrelação entre os valores da série temporal (Hamilton, 1994). Com base nesse comportamento identificado pelas 
autocorrelações é possível realizar previsões e simulações satisfatórias. Esses modelos resultam da combinação de três componentes que estão associados aos parâmetros dos modelos chamados "filtros": componente autorregressivo (AR); componente de integração (I); e, por último, componente de médias móveis (MA) (Souza et al., 2004).

As etapas de construção de um modelo Box \& Jenkins são: identificação, estimação e verificação (Souza et al., 2004). A etapa identificação tem por objetivo identificar qual versão do modelo representa a série temporal, sendo feita principalmente através da análise do comportamento da função de autocorrelação $\left(\mathrm{FAC}^{10}\right)$ e da função de autocorrelação parcial $\left(\mathrm{FACP}^{11}\right)$. A segunda etapa consiste em estimar os parâmetros $\phi$ e $\Phi$ do componente autorregressivo, os parâmetros $\theta$ e $\Theta$ do componente de médias móveis e a variância de $\varepsilon t$. E por último, a verificação consiste em avaliar a adequabilidade do modelo estimado.

Os modelos são subdivididos em estacionários, não-estacionários e sazonais e serão brevemente detalhados nos itens a seguir.

\subsection{1 Modelos estacionários}

São aqueles que assumem que o processo está em equilíbrio. Quando uma série temporal é estacionária significa dizer que o comportamento da série não se altera ao longo do tempo, ou seja, quando a média e a variância são dependentes do tempo. Para detectar a não-estacionariedade de uma série temporal é necessário aplicar testes estatísticos de raiz unitária, como por exemplo, o teste Dickey-Fuller (Dickey \& Fuller, 1979).

\footnotetext{
${ }^{10} \mathrm{~A}$ função de autocorrelação mede o grau de correlação de uma variável com ela mesma, em um dado instante e em um instante de tempo posterior. Ela permite que se analise o grau de irregularidade de um sinal. Pode ser definida como a razão entre a autocovariância e a variância para um conjunto de dados.

${ }^{11} \mathrm{~A}$ função de autocorrelação parcial de atraso $\mathrm{k}$ corresponde à autocorrelação de uma variável com ela mesma em um dado instante de tempo e em um instante de tempo posterior, que não é explicada pelos atrasos de 1 até o lag $k$.
} 
Os modelos estacionários são: modelo autorregressivo (AR) e modelo de médias móveis (MA). No modelo autorregressivo (AR), a série $Z t$ é descrita por seus valores passados regredidos e pelo ruído aleatório $\varepsilon t$. A equação do modelo de ordem $p$ ou $\operatorname{AR}(p)$ é dada por:

$$
\hat{Z}_{t}=\phi_{1} \hat{Z}_{t-1}+\phi_{2} \hat{Z}_{t-2}+\ldots+\phi_{p} \hat{Z}_{t-p}+\varepsilon_{t}
$$

Onde:

- $\hat{Z}_{t}=\hat{Z}_{t-\mu}$

- $\phi i=$ parâmetro que descreve como $\hat{Z} t$ se relaciona com o valor $\hat{Z} t-i$, para $i=1,2, \ldots, p$.

No modelo de médias móveis (MA), a série $Z t$ é resultado da combinação dos ruídos do período atual com os ocorridos em períodos anteriores. Logo, o modelo de médias móveis de ordem q ou MA (q) segue a equação abaixo.

$$
\hat{Z}_{t}=\varepsilon_{t}+\theta_{1} \varepsilon_{t-1}+\theta_{2} \varepsilon_{t-2}+\ldots+\theta_{q} \varepsilon_{t-q}
$$

Onde:

- $\hat{Z}_{t}=\hat{Z}_{t-\mu}$

- $\theta i=$ parâmetro que descreve como $\hat{Z} t$ se relaciona com o valor $\hat{Z} t-i$, para $i=1,2, \ldots, q$.

Ainda sobre os modelos estacionários, temos o modelo autorregressivo de médias móveis (ARMA). Em algumas ocasiões é necessário o uso de um grande número de parâmetros em modelos que são puramente AR ou MA. Para esses casos é aconselhável combinar os componentes dos dois modelos gerando um modelo $\operatorname{ARMA}(p, q)$. A equação do modelo é dada por: 


$$
\hat{Z}_{t}=\phi_{1} \hat{Z}_{t-1}+\ldots+\phi_{p} \hat{Z}_{t-p}+\varepsilon_{t}-\theta_{1} \varepsilon_{t-1}-\ldots-\theta_{q} \varepsilon_{t-q}
$$

\subsection{2}

\section{Modelos não-estacionários}

A série temporal é dita não-estacionária quando a média e a variância são dependentes do tempo (Souza et al., 2004). Para detectar a não-estacionariedade de uma série temporal é necessário aplicar testes estatísticos de raiz unitária, como por exemplo, o teste Dickey-Fuller (ADF).

Quando a série é não-estacionária é necessário transformá-la. A transformação mais comum é aquela que realiza diferenças sucessivas da série original até obter uma série estacionária.

O número de diferenças necessárias para tornar a série estacionária é definido como ordem de integração. A consideração do termo de ordem de integração $(d)$ permite que sejam utilizados os modelos $\operatorname{ARIMA}(p, d, q)$ dados pela equação abaixo.

$$
w_{t}=\phi_{1} w_{t-1}+\ldots+\phi_{p} w_{t-p}+\varepsilon_{t}-\theta_{1} \varepsilon_{t-1}-\theta_{q} \varepsilon_{t-q}
$$

\subsection{3}

\section{Modelos sazonais}

Os modelos sazonais, que serão utilizados como ferramenta probabilística nessa dissertação, contemplam as séries que apresentam autocorrelação sazonal e são conhecidos como SARIMA. Esses modelos contêm uma parte não sazonal com parâmetros $(p, d, q)$ e outra parte sazonal com parâmetros $(P, D, Q)$. O modelo SARIMA mais geral, segundo Souza et al. (2004), é dado pela equação abaixo.

$$
\begin{aligned}
& (1-\phi 1 L-\ldots-\phi p L p)(1-\Phi 1 L s-\ldots-\Phi P L P s)(1-L) d(1-L s) D Z t \\
= & (1-\theta 1 L-\ldots-\theta q L q)(1-\Theta 1 L s \ldots-\Theta Q L Q s) \varepsilon t
\end{aligned}
$$


Onde:

- $\quad(1-\phi 1 L-\ldots-\phi p L p)=$ parte autorregressiva não sazonal de ordem $\mathrm{p}$;

- $\quad(1-\Phi 1 L s-\ldots$ - $\Phi P L P S)=$ parte autorregressiva sazonal de ordem $\mathrm{P}$ e estação sazonal s;

- $\quad(1-L) d=$ parte de integração não-sazonal de ordem d;

- $\quad(1-L s) D=$ parte de integração sazonal de ordem D e estação sazonal s;

- $\quad(1-\theta 1 L-\ldots-\theta q L q)=$ parte não-sazonal de médias móveis de ordem q;

- $(1-\Theta 1 L s-\ldots-\Theta Q L Q s)=$ parte sazonal de médias móveis de ordem Q e estação sazonal s.

\section{2.}

\section{Técnica Bootstrap}

A técnica de computação intensiva Bootstrap é uma técnica não paramétrica. O Bootstrap consiste em uma alternativa de reamostragem, baseada em retirar sucessivamente amostras repetidas de tamanho igual à amostra original. Nesse método a informação da amostra é reciclada para se chegar às distribuições amostrais das estatísticas de interesse, onde se realiza a amostragem aleatória das observações amostrais de cada rodada de cálculo (Oliveira, 2010).

Conforme Neto (1996), a técnica Bootstrap para séries temporais foi utilizada a partir de 1984 nos estudos dos autores Freedman e Peters, no contexto de previsão de demanda para o mercado de energia americano. A técnica tem sido utilizada em séries temporais desde então se mostrando robusta.

Os métodos de reamostragem que podem ser utilizados em modelos de regressão são: o Bootstrap residual e Bootstrap de pares (Freedman et al., 1981).

Nessa dissertação será aplicada a técnica Bootstrap nos resíduos da série temporal de irradiação solar. Logo, será apresentado brevemente a seguir o método de reamostragem Bootstrap residual.

Os principais passos deste método aplicados nessa dissertação são: 
- Aplicar decomposição STL (Seasonal and Trend Decomposition Using Loess) em cada série original a fim de separar a estrutura principal da série do resíduo, também conhecido como Remainder. Cabe explicitar que a decomposição STL é um procedimento de filtragem no qual a série temporal é decomposta em três componentes: Tendência, Sazonalidade e Remainder. Este último é resultado da diferença entre a soma dos dois primeiros e a série temporal;

- Considerar $\mathrm{R}_{1}, \ldots, \mathrm{R}_{\mathrm{N}}$ como o ruído branco obtido da decomposição STL realizada e B o número de séries residuais a serem geradas (2.000 séries);

- Gerar B séries residuais por reamostragem com reposição da série residual original;

- Obter B séries Bootstrap que representa a soma da estrutura principal da série com B séries residuais geradas no passo anterior;

- Realizar a previsão das B séries Bootstrap com o Modelo SARIMA correspondente a cada série original. 


\section{4. \\ Metodologia}

Nesta seção, são apresentadas a metodologia adotada e as contribuições dadas por esta dissertação. Na primeira etapa é contextualizada a energia fotovoltaica residencial no Brasil. Na segunda etapa, é definida a metodologia proposta, assim como os parâmetros e as variáveis utilizadas para alcançar o objetivo principal da dissertação.

\section{1.}

\section{Energia fotovoltaica residencial}

O Brasil possui enorme potencial fotovoltaico, por ter maior incidência solar que os demais países. A irradiação média anual varia entre 1.200 e 2.400 $\mathrm{kWh} / \mathrm{m}^{2} / \mathrm{ano}$, bem acima da média registrada em outros países.

Em novembro de 2015, passou a vigorar a Resolução Normativa ANEEL $n^{0}$ 687/2015 que altera a Resolução $n^{\circ} 482 / 2012$. A nova resolução teve como objetivo propiciar um ambiente que busque a redução dos custos e tempos de conexão associados à micro e minigeração, assim como compatibilizar o sistema de compensação de energia elétrica com as condições de fornecimento, aumentar o público alvo e melhorar as informações na fatura. Há um balanço realizado pelas concessionárias no momento do faturamento das contas de energia, no qual os créditos acumulados compensam os débitos. (Landeira, 2013).

O sistema de net metering ${ }^{12}$ adotado no Brasil ainda não oferece a mesma atratividade proporcionada por outros mecanismos empregados nos outros países, $\operatorname{logo}$ a inserção da energia fotovoltaica residencial torna-se dependente da capacidade da própria fonte se viabilizar economicamente, tornando o processo de inserção mais lento do que o esperado.

12 Sistema de compensação de energia elétrica. 
No planejamento da operação energética, é considerada a estimativa da geração solar proveniente dos leilões de energia ocorridos em 2014 e 2015: $1^{\circ}$ LER de 2014 e $2^{\circ}$ LER 2015 e o crescimento da geração fotovoltaica distribuída. Ambas as considerações têm caráter determinístico. No caso da energia proveniente dos leilões, existem diretrizes que constam nas resoluções normativas da ANEEL $\mathrm{n}^{0}$ 440/2011 e no 476/2012, conforme citadas na seção 2. Já para o crescimento da geração fotovoltaica distribuída, pouco se sabe como é considerada. Poucos estudos foram encontrados sobre o assunto. Conforme nota técnica EPE 035/2016 Avaliação e compatibilização das informações de geração, carga e consumo de energia elétrica no SIN - a geração conectada na rede de distribuição, que não é modelada na CCEE, é informada ao ONS pelo agente de distribuição (EPE, 2016b). A CCEE, para este caso, apura a carga medida das distribuidoras abatida da geração não modelada. Contudo, as informações indicadas nessa nota técnica apresentam poucos detalhes sobre o cálculo para a consideração da geração na carga global do SIN.

Visto que a participação da geração fotovoltaica residencial ganha destaque em 2020 (AIE, 2010), e que apesar do Brasil apresentar grande potencial para essa geração, a sua consideração no planejamento da operação energética de médio prazo ainda é pouco conhecida e pouco detalhada. Assim, essa dissertação tem como objetivo propor uma metodologia para mensurar o impacto do potencial de geração fotovoltaica no planejamento da operação energética de médio prazo, utilizando o potencial técnico proveniente das residências.

É importante destacar que a mensuração e avaliação do impacto da inserção ou evolução de uma fonte de energia na matriz energética são de extrema relevância, pois serve de apoio à tomada de decisão das instituições que planejam e operam o sistema elétrico.

\section{2. \\ Metodologia proposta}

Para facilitar o encadeamento das ideias, a metodologia proposta foi dividida em quatro etapas, conforme apresentado na Figura 4.1. 


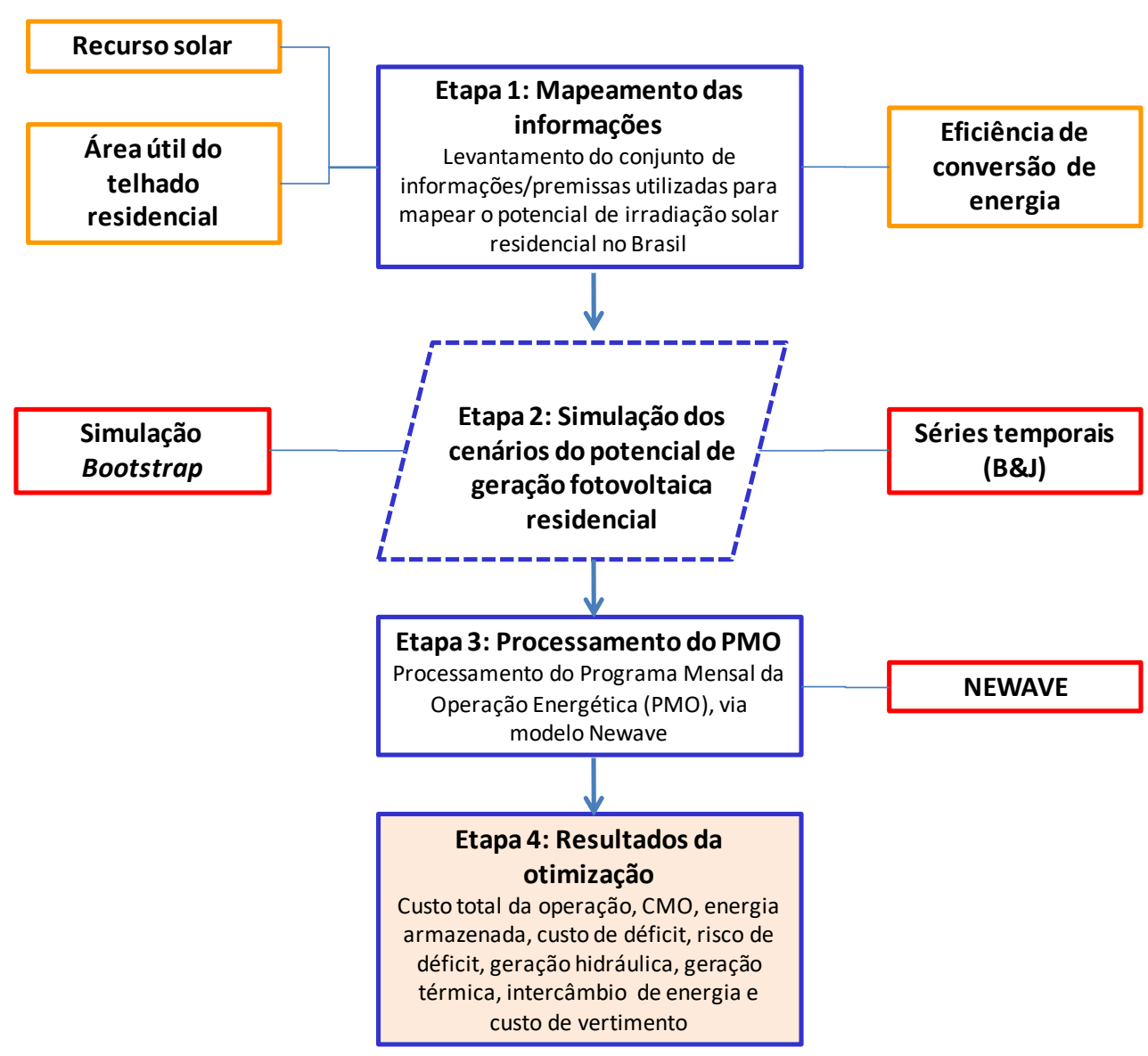

Figura 4.1 - Etapas da metodologia proposta Fonte: Elaboração própria

- Etapa 1: Mapeamento das informações - refere-se ao levantamento do conjunto de informações e premissas utilizadas para mapear o potencial de irradiação solar residencial no Brasil;

- Etapa 2: Simulação dos cenários do potencial de geração fotovoltaica residencial - refere-se ao processamento das informações obtidas na etapa anterior. Nessa etapa serão descritas as técnicas de simulação e o arcabouço matemático/estatístico utilizado para obtenção de cenários de geração fotovoltaica residencial para o horizonte do planejamento de médio prazo (cinco anos);

- Etapa 3: Processamento do PMO - nessa etapa será descrito o processamento do Programa Mensal da Operação Energética (PMO) de janeiro/2015 e janeiro/2016, via modelo NEWAVE, conforme 
visto na seção 2.4.2.1, utilizando os cenários de geração fotovoltaica residencial, obtidos na etapa anterior e definidos quais variáveis resultantes da otimização energética serão analisadas.

- Etapa 4: Resultados da otimização - nessa etapa são analisados os resultados do processamento dos programas mensais da operação selecionados.

Cada uma das quatro etapas listadas anteriormente será melhor detalhada nas subseções que se seguem.

\subsection{1 \\ Etapa 1: Mapeamento das informações}

Segundo Lange (2012), o levantamento da energia fotovoltaica residencial se baseia em três fatores preponderantes: o mapeamento do recurso solar, como por exemplo, os níveis de irradiação solar no país; a área útil total de telhado para instalação de sistemas fotovoltaicos; e a eficiência na conversão do recurso solar em eletricidade.

\subsubsection{1 Mapeamento do recurso solar}

Como foi visto na seção 2, a nebulosidade, a umidade relativa do ar e outras condições atmosféricas, assim como a disponibilidade de radiação solar, dependem da latitude e da posição no tempo (Pereira et al., 2006). Isso se deve à inclinação do eixo imaginário em torno do qual a Terra realiza o movimento de rotação e à trajetória que a Terra realiza ao redor do Sol, conforme apresentado na Figura 4.2. 


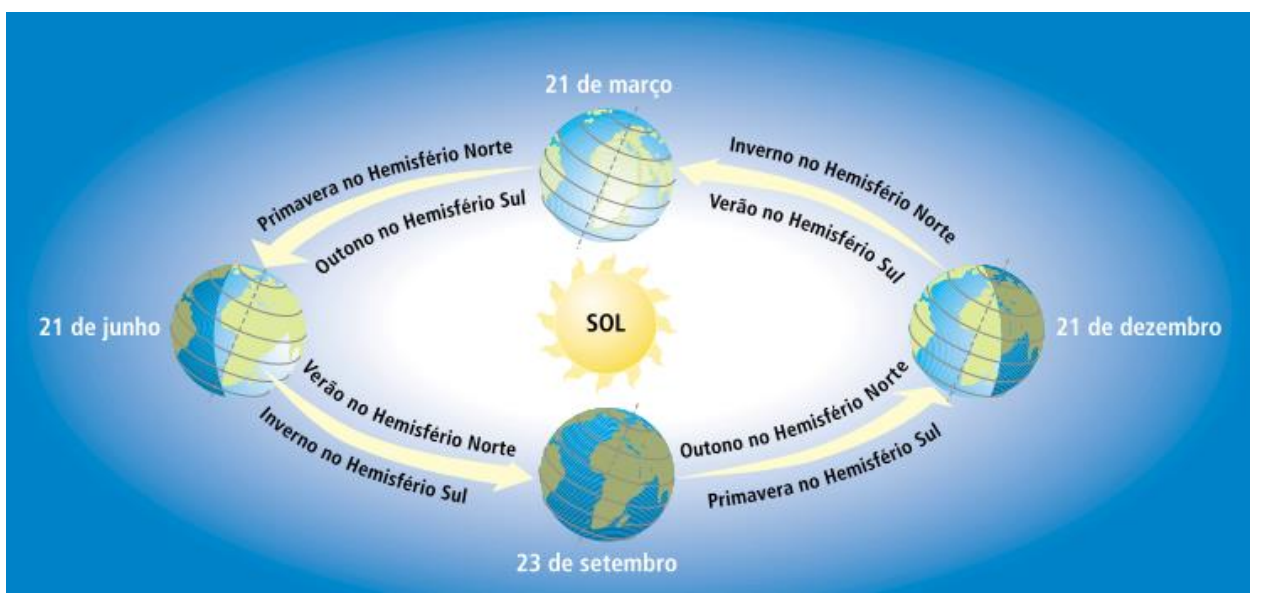

Figura 4.2 - Representação das estações do ano e do movimento da Terra em torno do Sol Fonte: (ANEEL, 2005)

Para essa dissertação, definiu-se como recurso solar a irradiação solar, que é a quantidade de radiação solar por unidade de área. A sua unidade de medida é o watt hora por metro quadrado $\left(\mathrm{Wh} / \mathrm{m}^{2}\right)$. O mapeamento desse recurso considerou os dados de radiação solar global $(\mathrm{kJ} / \mathrm{m} 2)$ disponibilizados pelo Instituto Nacional de Meteorologia (INMET) e, na sequência, a conversão da radiação solar global $(\mathrm{kJ} / \mathrm{m} 2)$ em irradiação solar $(\mathrm{kWh} / \mathrm{m} 2)$, utilizando o seguinte fator de conversão: $1 \mathrm{~J}($ Joule $)=2,77 \times 10-7 \mathrm{kWh}$ (quilowatt-hora).

Os dados disponibilizados corresponderam à medição horária do período janeiro/2009 a dezembro/2013 e foram classificados por cada capital brasileira que tem estação meteorológica automática. Para compatibilizar os dados coletados nessa primeira etapa da metodologia com os subsistemas equivalentes do modelo NEWAVE, mencionado na seção 2, adotou-se o agrupamento das capitais em quatro regiões do país (Sudeste/Centro-oeste, Sul, Nordeste e Norte).

Ao analisar os dados observaram-se anomalias na medição, a saber: dados faltantes e erros identificados visualmente; e Outliers.

Para o tratamento das anomalias identificadas foi adotada a metodologia desenvolvida e aplicada ao estudo de Bassous (2015). A substituição dos dados faltantes foi feita automaticamente através de um código desenvolvido em VBA, que consistiu basicamente na substituição desses dados pela média da região do país 
para aquele dia e hora. Caso não houvesse essa média devido à ausência de todos os dados correspondentes àquele horário, a substituição se deu por zeros.

Para o tratamento dos outliers, adotou-se o teste de Grubbs ${ }^{13}$, por apresentar maior robustez e maior eficiência na identificação dos outliers (Souza et al., 2007). O teste de Grubbs empregado nesse caso foi o bilateral, pois é possível que haja tanto valores muito altos quanto valores muito baixos. Conforme Oliveira (2008), quando o $\mathrm{n}$ da amostra for grande demais e não esteja na Tabela de Grubbs, a hipótese nula é rejeitada se:

$$
G>\frac{(n-1)}{\sqrt{n}} \times \sqrt{\frac{\left(t^{2}\right)}{n-2+t^{2}}}
$$

Onde:

- $\quad n$ : número de observações na amostra;

- $t$ : valor crítico da distribuição $t$ de Student com (n-2) graus de liberdade para um nível de confiança $\alpha / 2$, no caso, 0,025 .

Após a identificação do outlier o algoritmo passou a substituí-lo pela média entre a hora anterior e a hora seguinte. Ainda no caso desse novo valor encontrado continuar sendo um outlier, a substituição passa ser feita pela média da mesma hora anterior e seguinte do dia antecedente a ocorrência. Há ainda duas possíveis exceções, o primeiro e o último dado da série temporal e a média da hora anterior e seguinte serem outliers. Para esses casos decidiu-se por substituir valores pela média das observações. Apesar da perda do valor estatístico desses dados, não foi observado impacto significativo proveniente dessa solução.

\footnotetext{
${ }^{13} \mathrm{O}$ teste de Grubbs é definido para a hipótese nula $\mathrm{HO}$ de que não há outliers na amostra e serve para detecção de outliers em amostras que seguem uma distribuição aproximadamente normal.
} 


\subsubsection{2 \\ Área útil total de telhado para instalação de sistemas fotovoltaicos}

A área dos telhados dos domicílios é um dado importante para a identificação do potencial fotovoltaico de uma região, pois essa área corresponde ao espaço que pode ser usado para instalar os painéis solares. Estudos como de Zheng et al. (2014) e Cellura et al. (2012) tem como dados de entrada os mapas vetoriais dos domicílios, e utilizam, para estimar a área do telhado, ferramentas de sistemas de informação geográfica e técnicas de sensoriamento remoto. Já Lange (2012) e Miranda et al. (2015) utilizam como dados de entrada informações estatísticas sobre o número de domicílios (IBGE, 2010) e as áreas médias de telhado dos mesmos (Ghisi et al., 2006).

Com o intuito de considerar possíveis limitações no uso das áreas do telhado, ou pela forma ou pelo uso da área para outros fins, autores como Izquierdo et al. (2008), Miranda et al. (2015) e Wiginton et al. (2010) utilizaram coeficientes de redução sobre as áreas do telhado estimadas. A aplicação do coeficiente visa estimar a quantidade de área real do telhado disponível para a instalação dos sistemas fotovoltaicos.

No estudo desenvolvido por essa dissertação, para obter a área útil total de telhado para fins de sistemas fotovoltaicos, considerou-se o produto entre o número de domicílios próprios permanentes e a área útil por tipo de domicílio (casa e apartamento) a partir da estimativa do número de domicílios de 2015 a 2020 feita pela EPE (2015b) e da análise dos dados do censo demográfico 2010 (IBGE, 2010). Dentro da amostra de domicílios particulares permanentes do censo demográfico 2010 foi selecionada a sub-amostra de domicílios particulares permanentes próprios, pois foram considerados nessa dissertação aqueles domicílios em que o investimento para instalação dos painéis se justificassem. A partir da análise dos dados do censo demográfico 2010, adotou-se, para o período 2015 a 2020, a representação do tipo de domicílio para cada região. Como era esperado, o domicílio tipo casa teve a maior participação em todas as regiões, sendo que no Sudeste/Centro-oeste observou-se a maior representação do domicílio tipo apartamento e no Norte a menor representação desse mesmo tipo. Esse comportamento está associado às questões ligadas ao desenvolvimento 
demográfico de cada região e outros aspectos regionais, que acabam contribuindo no mapeamento do recurso solar feito nessa dissertação e nos demais estudos citados anteriormente.

Como referência para a estimação da área útil de telhado por domicílio utilizou-se o estudo de Ghisi et al. (2006), que teve como resultado a área de telhado média de $85 \mathrm{~m}^{2}$ para domicílio tipo casa e $15 \mathrm{~m}^{2}$ para domicílio tipo apartamento. Além dos estudos de Ghisi et al. (2006) foram considerados para encontrar a área útil de telhado por domicílio os estudos de Izquierdo et al. (2008) e Wiginton et al. (2010), que adotaram um coeficiente de redução de área adequado para cada tipo de domicílio e uma taxa de aproveitamento.

Os coeficientes de redução da área do telhado foram: 0,5 para o domicílio tipo casa e 1,0 para domicílio tipo apartamento. Para o domicílio tipo casa é razoável considerar o coeficiente de 0,5 que representa a instalação dos painéis solares sobre um dos lados de cada telhado, por apresentar melhor exposição à radiação solar do que o outro lado. Para o caso domicílio tipo apartamento, onde os telhados são, em geral, superfícies planas, o nível de irradiação solar recebida é igual em toda sua superfície, portanto, o coeficiente do telhado para este tipo de domicilio foi considerado igual a 1,0 (Izquierdo et al., 2008).

Após a aplicação do coeficiente de redução da área útil de telhado por domicílio, obteve-se a área útil total final de telhado por região multiplicando a área útil total de telhado pela taxa de aproveitamento de 30\%, conforme estudos apresentados na nota técnica EPE (2014).

\subsubsection{3 \\ Eficiência na conversão da energia solar em eletricidade}

Nos cálculos para estimar o potencial de geração fotovoltaica residencial também foi considerado o fator de eficiência na conversão da energia fotovoltaica em energia elétrica (eficiência dos módulos e Performance Ratio ${ }^{14}$ ).

\footnotetext{
${ }^{14}$ É uma das unidades de medida mais importantes para a avaliação da eficiência de um sistema fotovoltaico. Representa a relação entre a possível produção de energia real e teórica.
} 
O desempenho da célula fotovoltaica é altamente influenciado pela condições do tempo (radiação solar e temperatura). O silício está entre os materiais mais adequados para a conversão da radiação solar em energia elétrica. A eficiência de conversão das células solares é medida pela proporção da radiação solar incidente sobre a superfície da célula que é convertida em energia elétrica (ANEEL, 2005).

Conforme Green et al. (2000), atualmente, as melhores células apresentam um índice de eficiência de laboratório entre $25 \%$ a $30 \%$. No entanto, quando esses valores são traduzidos em escala comercial há uma redução significativa nos valores, conforme apresentado na Tabela 4.1.

Tabela 4.1 - Eficiência de conversão de células solares

\begin{tabular}{cccc}
\cline { 2 - 4 } & \multicolumn{3}{c}{ Eficiência (\%) } \\
\hline Tipo de célula de silício & Teórica & Laboratório & Comercial \\
cristal simples & 30,0 & 24,7 & 12 a 14 \\
concentrado & 27,0 & 28,2 & 13 a 15 \\
policristalino & 25,0 & 19,8 & 11 a 13 \\
amorfo 17 & 13,0 & 4 a 7 & 3 a 5 \\
\hline
\end{tabular}

Fonte: Adaptado de (Green et al., 2000)

O silício policristalino torna-se interessante dentre as opções de célula de silício, pois se apresenta como opção mais barata que os cristais únicos de silício, monocristais, e como um processo de produção mais simples, eliminando o processo de corte dos lingotes ${ }^{15}$ de silício, e todos os custos associados, sendo assim a tecnologia mais utilizada no mercado. Por esse motivo, foi considerado nessa dissertação o valor médio do intervalo de eficiência comercial do silício policristalino (12\%), conforme mostrado na Tabela 4.1 .

\footnotetext{
${ }^{15}$ Lingote é uma massa de metal ou de um material condutor, que após ter sido aquecida a uma temperatura superior ao seu ponto de fusão, é vertida num molde, tomando uma forma que torna mais fácil o seu manuseamento, geralmente uma barra ou um bloco.
} 


\section{2 .2 \\ Etapa 2: Simulação dos cenários do potencial de geração fotovoltaica residencial}

Nessa etapa utilizou-se o insumo resultante da etapa anterior (séries de irradiação solar e área útil de telhado por região) para a geração dos cenários do potencial de energia fotovoltaica residencial.

\subsubsection{1}

\section{Geração de cenários do potencial de energia fotovoltaica residencial}

O primeiro passo para se alcançar um dos objetivos da dissertação que é mensurar os impactos na política de geração hidrotérmica considerando cenário de geração fotovoltaica do setor residencial, é tornar a curva determinística da geração dessa fonte em uma curva estocástica, adequando um processo estocástico a esta. A justificativa para se considerar incertezas nesse tipo de geração é que se faz necessário prover novas informações, dado que pouco se sabe sobre a consideração dessa geração no planejamento da operação energética de médio prazo e em outros instrumentos que norteiam o planejamento energético no Brasil. Além disso, qualquer processo de planejamento energético tem incertezas envolvidas, haja vista que outras variáveis podem influenciar na adoção de novas tecnologias que possam impactar o consumo e geração de energia.

Analisando as curvas de irradiação solar encontradas na primeira etapa dessa dissertação, verifica-se que estas têm um comportamento bastante sazonal e estacionário na média e variância. Devido a essas caraterísticas, optou-se por utilizar o modelo SARIMA, da família Box \& Jenkins, conforme visto na seção 3.

Segundo Souza et al. (2004), a previsão com modelos de séries temporais é um procedimento que visa estender aos valores futuros o modelo ajustado aos valores passados e ao valor presente da variável. Para Moreira (1998), existe a necessidade de se planejar para cinco ou dez anos à frente, tanto quanto para os próximos dias ou semanas. Porém, a certeza de um dado previsto e o horizonte de planejamento são inversamente proporcionais, ou seja, quanto maior o período a ser previsto menor a precisão dos dados. 
Como um dos objetivos específicos da dissertação é simular o Programa Mensal da Operação Energética, considerando cenários do potencial de geração fotovoltaica residencial, a fim de mensurar os principais impactos, foram selecionados o PMO de janeiro/2015 e o PMO janeiro/2016, pois a situação energética no Brasil no início de 2015 estava bastante crítica. Os níveis dos principais reservatórios encontravam-se baixos e a carga global de energia elevada. O reservatório equivalente da região Sudeste/Centro-oeste registrou em dezembro de 2014 19,35\% de energia armazenada. No PMO janeiro/2016, houve uma piora nos níveis de armazenamento dos reservatórios da região Nordeste e Norte, registrando em dezembro de 2015 , respectivamente, $5,15 \%$ e $15,38 \%$ da energia armazenada. Já a região Sudeste apresentou melhora, porém continuou com baixo desempenho, registrando $29,82 \%$, de energia armazenada, conforme mostrado na Figura 4.3.

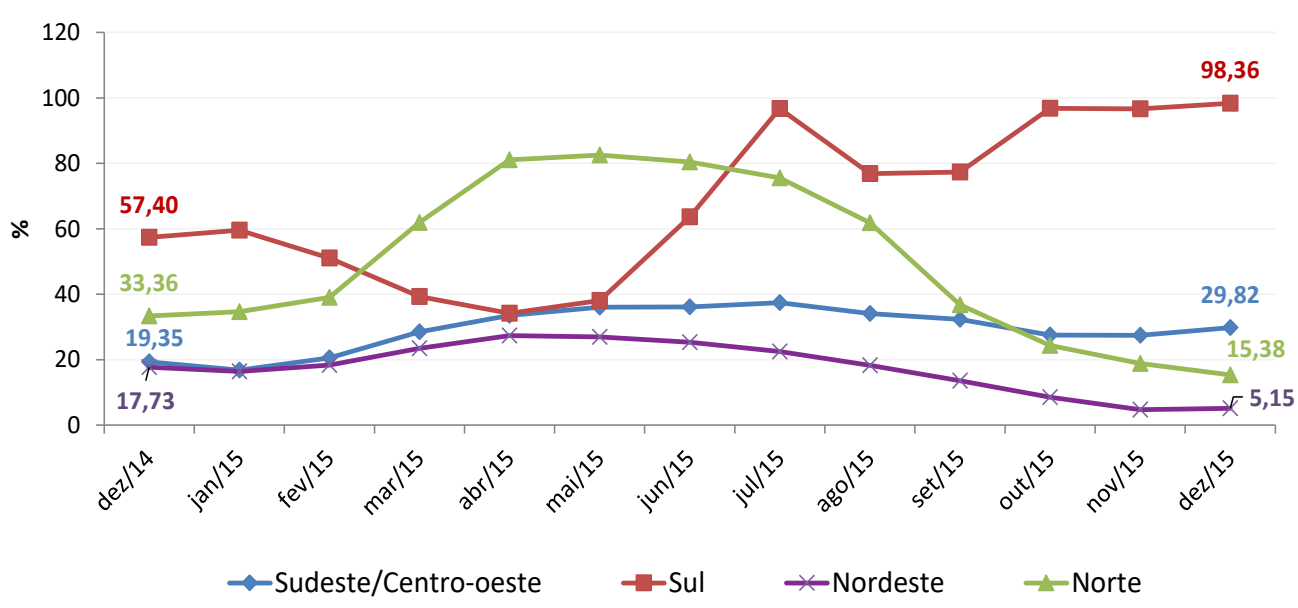

Figura 4.3 - Energia armazenada verificada dos reservatórios equivalentes do SIN (\%) Fonte: Elaboração própria com base em (ONS, 2017)

Contudo, a carga global de energia para o período de planejamento do PMO janeiro/2016 era mais baixa que a considerada no PMO de janeiro/2015. A previsão da carga foi reduzida em 4,0\% para o ano de 2016. O período 2016 a 2019 sofreu redução média de 3,9\%, conforme apresentado na Figura 4.4. 


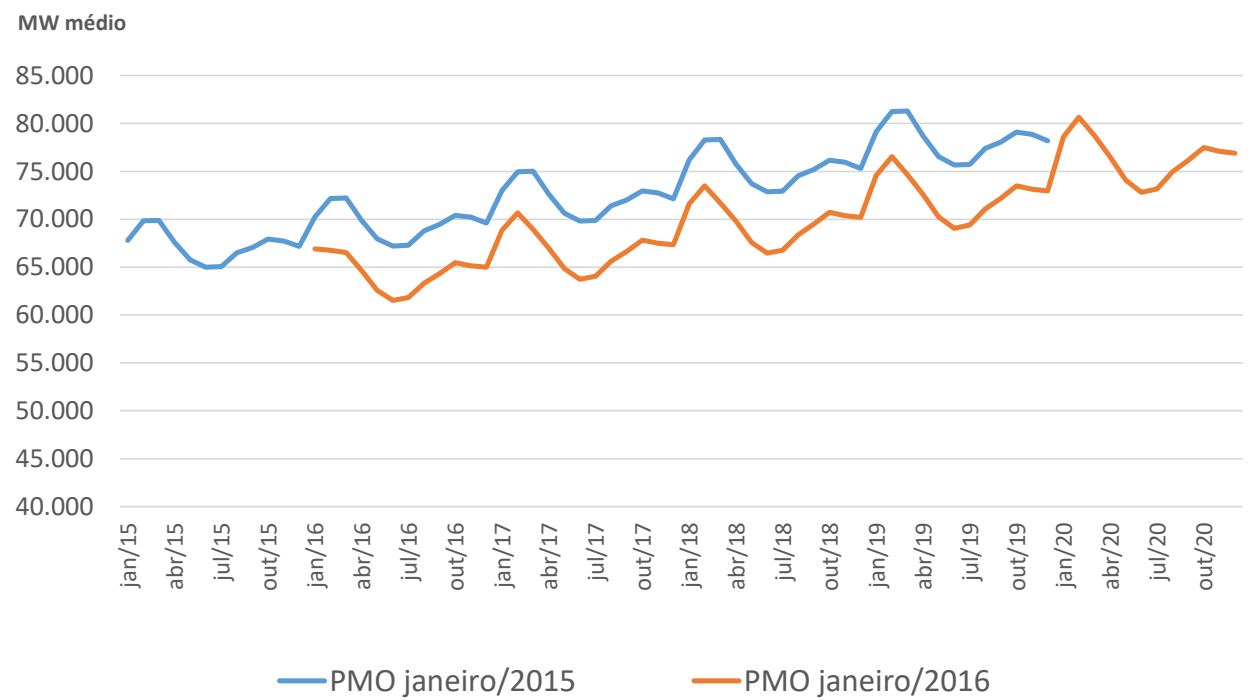

Figura 4.4 - Carga global de energia oficial PMO janeiro/2015 e PMO janeiro/2016 Fonte: Elaboração própria com base em (ONS, 2017)

Como o período de informação do recurso solar utilizado se estendia até dezembro/2013, foi necessário criar modelos de previsão, a partir da metodologia Box \& Jenkins para estimar a irradiação solar no período janeiro/2015 a dezembro/2019 e no período janeiro/2016 a dezembro/2020, atendendo ao horizonte de planejamento (cinco anos) dos dois programas mensais selecionados.

A metodologia Box \& Jenkins empregada é dividida em três fases, indicada na Figura 4.5. 


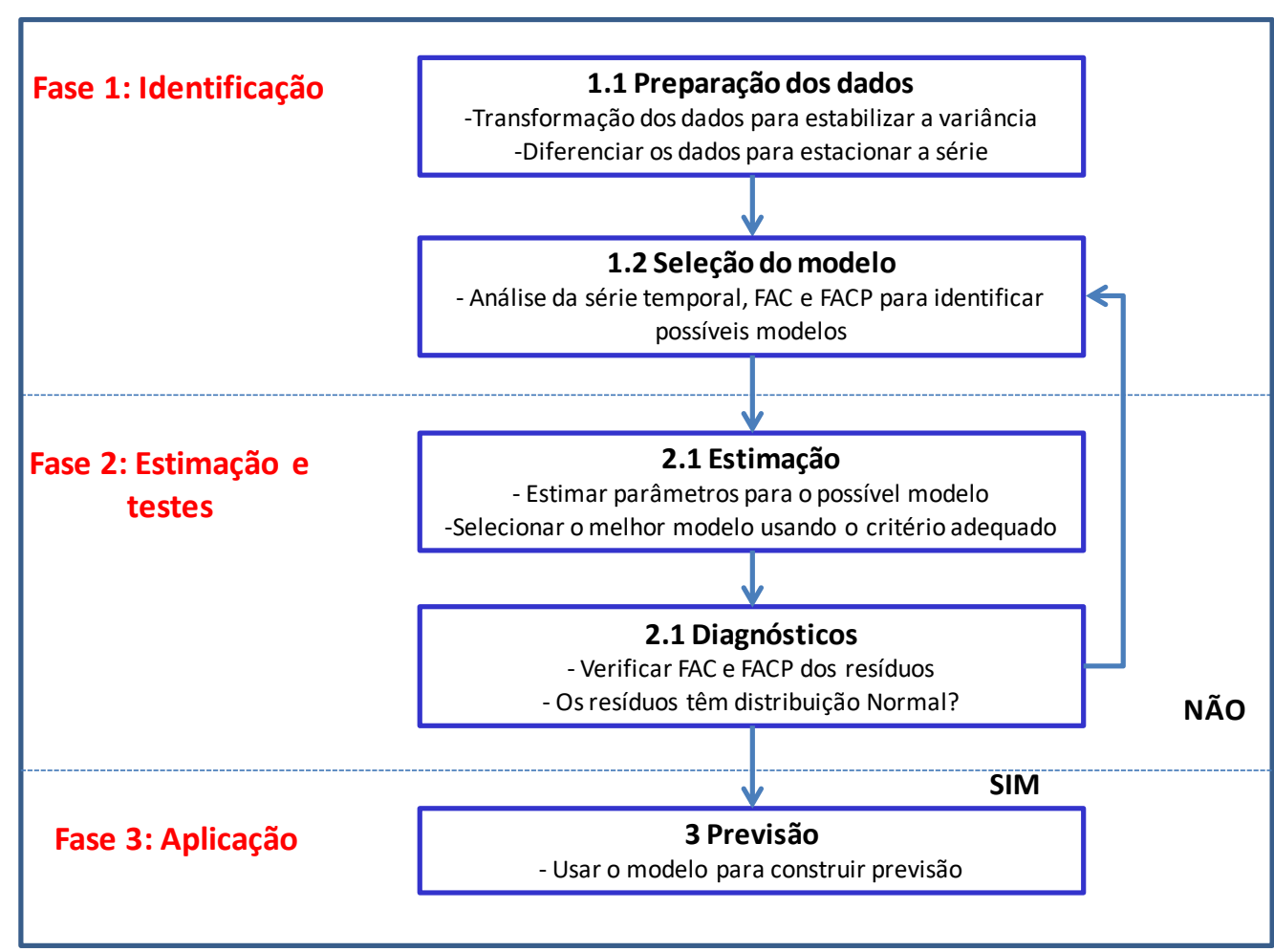

Figura 4.5 - Metodologia Box \& Jenkins Fonte: Elaboração própria com base em (Souza et al., 2004)

Ao modelo de previsão selecionado para cada região aplicou-se a técnica de computação intensiva Bootstrap, apresentada na seção 3, a fim de criar cenários do potencial de geração fotovoltaica residencial. Originalmente, foram criados 2.000 cenários de irradiação solar, conforme passo-a-passo a seguir.

1. Aplicação da decomposição STL (Seasonal and Trend Decomposition Using Loess) em cada série original de irradiação solar a fim de separar a estrutura principal da série do resíduo;

2. Geração de B (2.000 séries) séries residuais por reamostragem com reposição da série residual original;

3. Obtenção de B séries Bootstrap que representa a soma da estrutura principal da série com B séries residuais geradas no passo anterior;

4. Previsão de $\mathrm{B}$ séries Bootstrap com o Modelo SARIMA correspondente a cada série original de irradiação solar; 
A partir da nuvem de 2.000 séries foram aplicados os percentis $5 \%, 25 \%$, $50 \%, 75 \%$ e $95 \%$, mês a mês a fim de se obter cenários de curvas estocásticas de irradiação solar. Os percentis foram adotados devido ao tempo de processamento para cada simulação de, aproximadamente, três horas. Portanto, um número muito grande de simulações poderia inviabilizar o estudo.

De posse dos cenários de irradiação solar, da área útil de telhado residencial e do fator de eficiência na conversão da energia fotovoltaica, vistos na seção 4, foram construídas as curvas estocásticas do potencial de geração fotovoltaica residencial para cada região do país, a fim de serem consideradas no processamento do modelo Newave.

\subsection{3}

\section{Etapa 3: Processamento do PMO}

Nesta penúltima etapa da metodologia foram calculados os cenários de carga global de energia, considerando o abatimento dos cenários do potencial de energia fotovoltaica residencial, definidos na etapa anterior e processada a otimização energética do PMO janeiro/2015 e janeiro/2016, considerando os cenários de carga global de energia, para obtenção dos principais resultados selecionados por essa dissertação: custo total da operação, custo marginal de operação, energia armazenada, custo de déficit, risco de déficit, geração hidráulica, geração térmica, intercâmbio de energia e custo de vertimento.

Cabe explicar nessa seção que o Programa Mensal da Operação Energética (PMO) é elaborado pelo Operador Nacional do Sistema Elétrico (ONS) com a participação dos agentes do setor envolvidos. Os estudos realizados em base mensal, sendo o primeiro mês discretizado em etapas semanais, por patamar de carga, e revistos semanalmente, fornecem metas e diretrizes a serem seguidas pelos órgãos executivos da programação diária da operação e da operação em tempo real. As etapas do processo de programação mensal da operação energética estão preconizadas no submódulo 7.3 dos procedimentos de rede do ONS, aprovado pela Agência Nacional de Energia Elétrica (ANEEL). 


\subsubsection{1}

\section{Cálculo dos cenários de carga global de energia}

A carga global de energia esperada para o Brasil nos próximos cinco anos está disponível no "deck de preços". Essa carga é publicada mensalmente e revisada quadrimestralmente pelo ONS. Apesar dessa carga, segundo ONS, já contabilizar o crescimento da geração distribuída fotovoltaica, pouco se sabe quais são os valores estimados e como são calculados, conforme mencionado na seção 4.1.

Na modelagem matemática do NEWAVE, o planejamento energético é projetado de modo que o sistema hidrotérmico possa atender à carga global de energia de forma segura e econômica (CEPEL, 2012). No entanto, as incertezas no valor da carga global de energia não são consideradas pelo modelo, uma vez que o problema considera apenas as incertezas presentes nas afluências, logo, a carga de energia é considerada determinística. Isso significa que, para representar diferentes possíveis cenários de carga, o modelo NEWAVE deve ser executado $n$ vezes de acordo com cada cenário de carga considerado.

Assim, definiu-se como caso referência (1) o PMO janeiro/2015, e os casos de sensibilidade, considerando os cenários de geração fotovoltaica residencial, associados a esse PMO, deu-se o nome de: Caso P5, Caso P25, Caso P50, Caso P75 e Caso P95.

O PMO janeiro/2016 foi definido como caso referência (2), e aos casos de sensibilidade, considerando os cenários de geração fotovoltaica residencial, associados a esse PMO, deu-se o nome de: Caso P5, Caso P25, Caso P50, Caso P75 e Caso P95.

Como visto na seção 3, a simulação do planejamento da operação energética de médio prazo, via modelo Newave, tem como objetivo minimizar o custo total da operação em todo o horizonte de estudo, através de decisões de despacho de geração hidráulica, despacho de geração térmica, intercâmbio entre regiões e corte de carga (déficit).

O problema de operação hidrotérmica em sistemas equivalentes de energia que é resolvido a cada estágio é descrito a seguir: 


$$
Z_{t}=\operatorname{Min}\left[\sum_{k=1}^{N S} \sum_{j=1}^{N U T_{k}} C T_{j} \cdot G T_{t, j}+\frac{1}{1+\beta} \alpha_{t+1}\right]
$$

Equação de balanço hídrico

$$
\begin{aligned}
& E A_{t+1}(k)=F D I N_{t}(k) E A_{t}(k)+F C_{t}(k) E C_{t}(k)-G H_{t}(k)-E V T_{t}(k) \\
& -E V M_{t}(k)-E V P_{t}(k)-E M_{t}(k)-E D V C_{t}(k) ; k=1, \ldots, N S
\end{aligned}
$$

Equação de atendimento à demanda

$$
\begin{aligned}
& G H_{t}+\sum_{j=1}^{N U T_{k}} G T_{t, j}+\sum_{j=1}^{\Omega_{k}}\left(F_{t, i, k}-F_{t, k, i}\right)+D E F_{t, k}-E X C_{t}(k)=D_{t, k} \\
& -E V M_{t}(k)-E F I O_{t}(k)-\sum_{j=1}^{N U T_{k}} G T M I N_{t, j}-E D V F_{t}(k) ; k=1, \ldots, N S
\end{aligned}
$$

Limites na geração térmica

$$
0 \leq G T_{t, j} \leq \overline{G T}_{t, j} \quad, \quad \forall j \in N U T_{k}, k=1, \ldots, N S
$$

Limites na capacidade de intercâmbio

$$
\left|F_{t, i, k}\right| \leq \bar{F}_{t, i, k} \quad, \quad i=1, \ldots, N S \text { e } k=1, \ldots, N S
$$

Limites na capacidade de armazenamento

$$
0 \leq \operatorname{FDIN}_{t+1}(k) \cdot E A_{t+1}(k) \leq E A M A X_{t+1}(k), k=1, \ldots, N S
$$

Geração hidráulica máxima

$$
G H_{t}(k)+E F I O_{t}(k)+E V M_{t}(k) \leq \operatorname{GHMAX}_{t}(k), \quad k=1, \ldots, N S
$$

Limites operativos

$$
\begin{aligned}
& \operatorname{EAMIN}_{t+1}(k)+\operatorname{FDIN}_{t+1}(k) \cdot \operatorname{EARM}_{t+1}(k) \leq \operatorname{EAVEMAX}_{t+1}(k), \\
& k=1, \ldots, N S
\end{aligned}
$$

Função de custo futuro 


$$
\begin{aligned}
& \alpha_{t+1}-\sum_{k=1}^{N S} \pi \cdot E A_{1, t+1}(k) \cdot E A_{t+1}(k) \geq \delta_{1, t+1} \\
& \cdots \\
& \alpha_{t+1}-\sum_{k=1}^{N S} \pi \cdot E A_{q, t+1}(k) \cdot E A_{t+1}(k) \geq \delta_{q, t+1}
\end{aligned}
$$

Equação de subsistemas fictícios

$$
\sum_{j=1}^{\Omega_{k}}\left(F_{t, i, k}-F_{t, k, i}\right)=0 \quad, \quad k=1, \ldots, N F I C
$$

Onde:

- $Z_{t}$

- $\beta$

- $\alpha_{t+1}$

- $E A_{t}(i)$

- $\operatorname{EAMAX}_{t}(i)$

- $G H_{t}(i)$

- $\operatorname{GHMAX}_{t}(i)$

- $E V T_{t}(i)$

- $E X C_{t}(i)$

- $E C_{t}(i)$

- $E_{t} O_{t}(i)$

- $\operatorname{EVP}_{t}(i)$

- $E M_{t}(i)$

- $E V_{t}(i)$

- $G T_{t}(j)$ valor esperado do custo total de operação do estágio $t$ até o final do período de planejamento;

taxa de desconto;

variável escalar que representa o valor esperado do custo futuro associado a decisão tomada no instante $t$; energia armazenada no subsistema $i$ no início do estágio $t$

limite máximo de armazenamento do subsistema $i$ no início do estágio $t$; energia hidráulica controlável gerada pelo subsistema $i$ no estágio $t$; limite máximo de geração hidráulica do subsistema $i$ no estágio $t$;

energia vertida no subsistema $i$ no estágio $t$; excesso de energia a fio d'água, energia de vazão mínima, geração térmica mínima, geração de pequenas usinas e energia de submotorização no subsistema $i$ durante o estágio $t$; energia controlável afluente ao sistema $i$ durante o estágio $t$ (está incluída a energia de vazão mínima); energia fio d'água afluente ao sistema $i$ durante o estágio $t$

energia evaporada no subsistema $i$ durante o estágio $t$; energia de enchimento de volume morto no subsistema $i$ durante o estágio $t$; energia de vazão mínima afluente ao subsistema $i$ durante o estágio $t$; energia gerada pela usina térmica $j$ do subsistema $i$, no estágio $t$ 
- $\overline{G T}_{t}(j)$

- $\operatorname{GTMIN}_{t}(j)$

- $F_{t}(i, k)$

- $\bar{F}_{t}(i, k)$

- $E D V C_{t}(i)$

- $E D V F_{t}(i)$

- $D_{t}(i)$

- $D E F_{t, i}$

- $C T(j)$

- $\Omega_{j}$

- $N S$

- $N F I C$

- $\operatorname{EAMIN}_{t}(i)$

- $\operatorname{EAVEMAX}_{t}(i)$

- $\operatorname{FDIN}_{t}(i)$

- $F C_{t}(i)$

- $q$

- $\pi \cdot E A_{t+1}(i)$

- $\delta_{t+1}$ limite máximo de geração térmica da usina $j$ no estágio $t$, descontando-se o limite mínimo de geração térmica dessa usina;

limite mínimo de geração térmica da usina $j$ no estágio $t$; intercâmbio de energia do subsistema $i$ para o subsistema $k$, no estágio $t$; capacidade de intercâmbio de energia do subsistema $i$ para o subsistema $k$, no estágio $t$; energia de desvio de água a ser abatida da energia controlável no subsistema $i$ durante o estágio $t$; energia de desvio de água a ser abatida da energia fio d'água no subsistema $i$ durante o estágio $t$; demanda de energia do subsistema $i$ no estágio $t$, descontadas a geração de pequenas usinas e a energia de submotorização;

déficit de energia do subsistema i no estágio $t$; custo de geração associado a usina térmica $j$; conjunto de subsistemas diretamente conectados ao subsistema $j$; número de subsistemas reais; número de subsistemas fictícios; limite mínimo de armazenamento do subsistema $i$ no início do estágio $t$;

limite máximo de armazenamento do subsistema $i$ no início do estágio $t$ por restrição de volume de espera; correção da energia armazenada no sistema $i$ devido a mudança de configuração no estágio $t$; fator de correção da energia controlável do sistema $i$ durante o estágio $t$; número de segmentos da função de custo futuro; derivada da função objetivo $Z_{t}$ com relação à energia armazenada no subsistema $i$ no início do estágio $t+1$; termo constante da restrição linear.

\subsection{4}

\section{Etapa 4: Resultados da otimização}

Os resultados do processamento do PMO selecionados por essa dissertação são:

- Custo total da operação (CTO) - corresponde ao custo dos cinco anos de planejamento (\$); 
- Custo marginal de operação (CMO) - incremento de $1 \mathrm{MW}$ de geração térmica para suprir o requisito de carga $(\mathrm{R} \$ / \mathrm{MWh})$;

- Energia armazenada final (Earf) - corresponde ao \% de energia armazenada no reservatório equivalente no final de cada mês;

- Custo de déficit - custo associado à interrupção de energia, conhecido como o custo do corte de carga ( $\mathrm{R} \$ \mathrm{MWh})$;

- Risco de déficit - associado ao risco de falta de suprimento de energia por profundidade de carga (\%).

- Geração térmica - geração das usinas termelétricas (MW médio);

- Geração hidráulica - geração das usinas hidrelétricas (MW médio);

- Intercâmbio de energia - transferência de energia entre as regiões (MW médio);

- Custo de vertimento - custo associado a não utilização da água que passa pelo reservatório, ou seja, energia não turbinável.

Os resultados referentes a cada caso elaborado serão comparados ao caso de referência (PMO janeiro/2015 e PMO janeiro/2016). 


\section{5. Resultados}

Nesta seção, são apresentados os principais resultados da dissertação. Primeiramente, na seção 5.1, elaborou-se as curvas de irradiação solar para as regiões Sudeste/Centro-oeste, Sul, Nordeste e Norte, correspondentes ao período janeiro de 2009 a dezembro de 2013. Em seguida, na seção 5.2, foi realizada a estimativa de área útil de telhado para a instalação de sistemas fotovoltaicos. $\mathrm{Na}$ seção 5.3, são apresentados os cenários do potencial de geração fotovoltaica residencial para os períodos janeiro de 2015 a dezembro de 2019 e janeiro de 2016 a dezembro de 2020, assim como os novos cenários de carga global de energia para o mesmo período. Por fim, na seção 5.4, são mostrados os resultados alcançados com a simulação do Programa Mensal da Operação Energética (PMO) de janeiro/2015 e janeiro/2016.

\section{1. \\ Curvas de irradiação solar}

A partir dos dados de radiação solar global, disponibilizados pelo INMET, foram construídas as séries de irradiação solar para as regiões Sudeste/Centro-oeste, Sul, Nordeste e Norte. Os dados disponibilizados estavam discretizados por hora e por capital do país, totalizando 25 capitais que apresentam estação meteorológica automática. Esses dados foram agrupados em dados médios por região e por mês para fins de compatibilização com a otimização feita pelo modelo NEWAVE, cujo resultado será apresentado na seção 5.4.

Na Tabela 5.1 é apresentada a localização agrupada por região das medições de irradiação utilizadas. 
Tabela 5.1 - Agrupamento do recurso solar por região

\begin{tabular}{c|c|c|c}
\hline $\begin{array}{c}\text { Sudeste/Centro- } \\
\text { oeste }\end{array}$ & Sul & Nordeste & Norte \\
\hline Belo Horizonte & Curitiba & Aracaju & Belém \\
Brasília & Florianópolis & Fortaleza & Boa Vista \\
Campo Grande & Porto Alegre & João Pessoa & Manaus \\
Goiânia & & Maceió & Palmas \\
Rio de Janeiro & & Natal & Porto Velho \\
São Paulo & & Recife & Rio Branco \\
Vitória & & Salvador & \\
& & São Luís & \\
& & Teresina & \\
\hline
\end{tabular}

Fonte: Elaboração própria

Conforme visto na seção 4, utilizou-se o tratamento dos dados faltantes e outliers para ajustar os dados, desenvolvido por (Bassous, 2015). Em seguida, os dados horários de radiação solar $\left(\mathrm{kJ} / \mathrm{m}^{2}\right)$ foram agrupados em dados mensais e transformados em irradiação solar $\left(\mathrm{kWh} / \mathrm{m}^{2} / \mathrm{mês}\right)$, conforme fórmula (4.1) mostrada na seção 4.2.1.1. Na Figura 5.1, são apresentadas as séries resultantes da metodologia empregada no tratamento do recurso solar.

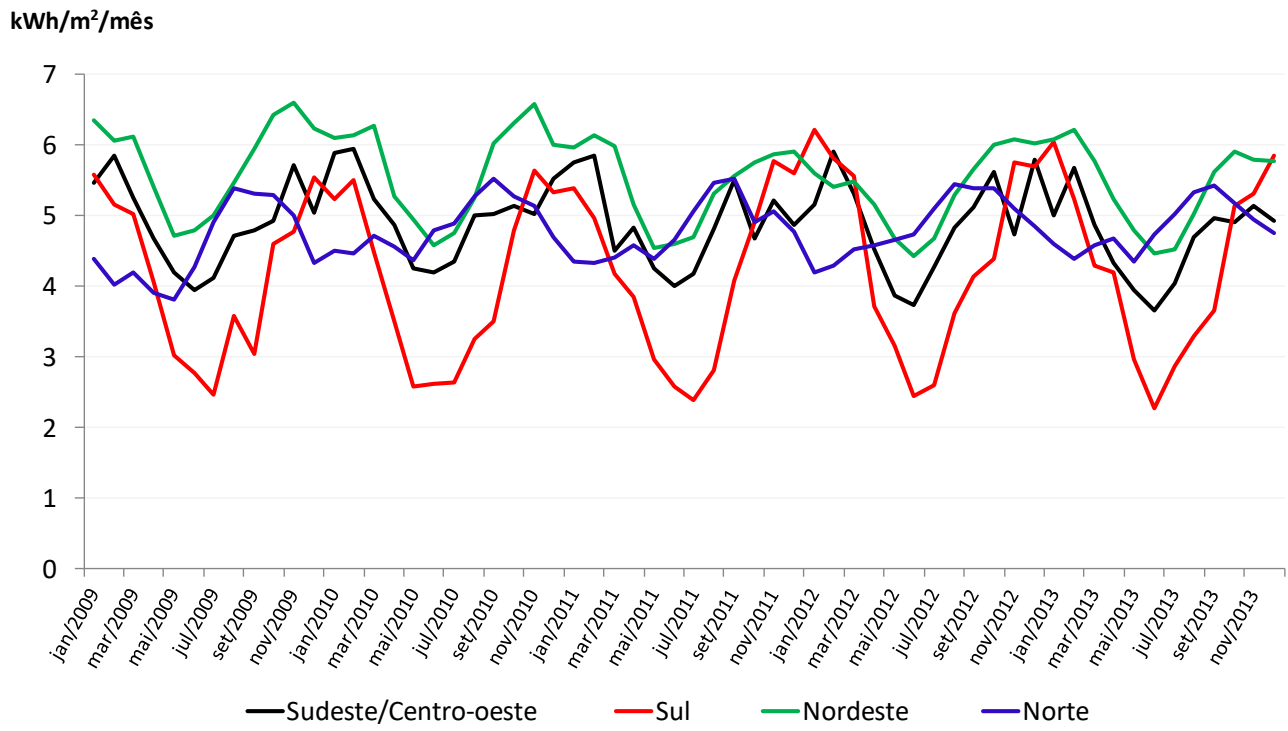

Figura 5.1 - Evolução mensal da irradiação solar (jan/2009 a dez/2013) Fonte: Elaboração própria 
As regiões Sudeste/Centro-oeste, Nordeste e Norte, apresentaram pouca variabilidade entre as estações do ano. Do ponto de vista do planejamento da operação energética essa característica é positiva, visto que há mais energia solar a ser aproveitada ao longo do ano. A região Nordeste, se destaca como a região mais interessante para o investimento de sistemas fotovoltaicos, uma vez que apresenta maiores registros de irradiação solar, em praticamente, todo o ano. Já na região Sul, a variabilidade entre as estações do ano é bastante marcante, chegando a variações da ordem de $40 \%$ entre o máximo e mínimo de irradiação solar.

\section{2. \\ Área útil de telhado para instalação de sistemas fotovoltaicos}

Para a estimativa da área útil de telhado para instalação de sistemas fotovoltaicos, utilizou-se como base o censo demográfico 2010 (IBGE, 2010) e a projeção do crescimento do número de domicílios da série estudos de demanda da EPE (EPE, 2015). Cabe destacar que essa estimativa considerou um caso de "stress", onde todos os domicílios próprios permanentes teriam um sistema solar fotovoltaico.

Quanto às informações do censo demográfico 2010 utilizadas, é importante detalhar que foram considerados:

- A representatividade do tipo de domicílio de 2001 a 2009, nas regiões Sudeste/Centro-oeste, Sul, Nordeste e Norte. Viu-se que a mesma se manteve igual em todos os anos para todas as regiões.

- O percentual de domicílios particulares próprios do total de domicílios particulares permanentes.

Foram adotados na metodologia os percentuais da representatividade de domicílios, conforme apresentado na Figura 5.2. Pode-se verificar que os domicílios com a tipologia de casa são os de maior representatividade em todas as regiões do Brasil. 

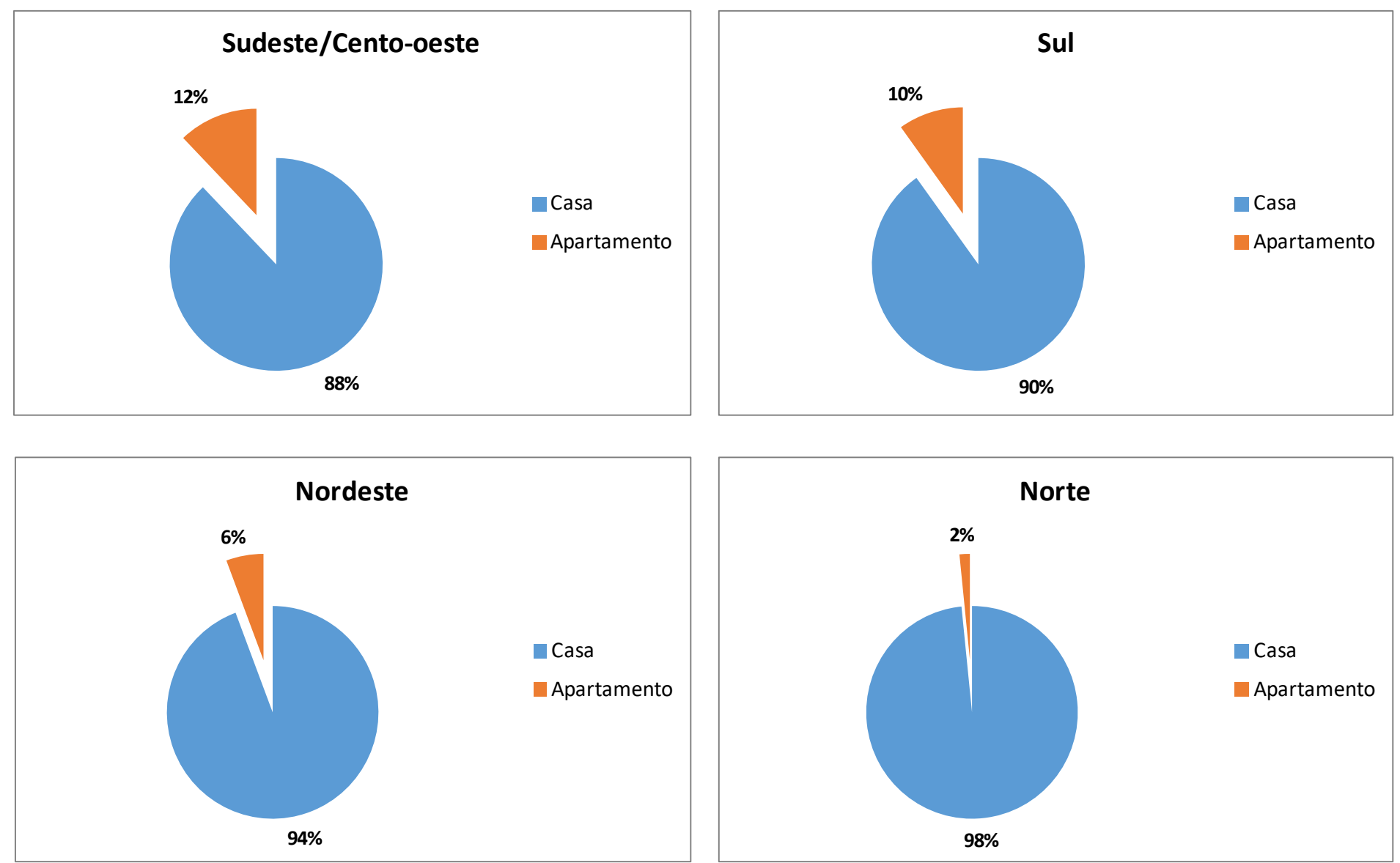

Figura 5.2 - Representação do tipo de domicílio no Brasil Fonte: Elaboração própria com base em (IBGE, 2010) 
Na Tabela 5.2 são apresentados os domicílios próprios declarados no censo demográfico de 2010. A escolha desse tipo de domicílio é justificada pela maior viabilidade para investimento em painéis solares que os demais domicílios (alugados, cedidos e outros).

Tabela 5.2 - \% de domicílio próprio por região

\begin{tabular}{c|c}
\hline Região & \% de domicílio próprio \\
\hline Sudeste/Centro-oeste & $71 \%$ \\
\hline Sul & $75 \%$ \\
\hline Nordeste & $77 \%$ \\
\hline Norte & $73 \%$ \\
\hline
\end{tabular}

Fonte: Elaboração própria em (IBGE, 2010)

Vale mencionar que os valores encontrados na Tabela acima foram considerados para todos os anos de projeção da área útil de telhado.

Quanto à previsão do número de domicílios até 2020, feita pela EPE (2015), destaca-se que foi considerada a taxa de crescimento anual indicada pela nota técnica DEA no 03 de 2015 da EPE para o período 2015 a 2020, obtendo-se como resultado os valores mostrados na Tabela 5.3.

Tabela 5.3 - Projeção de domicílios (mil) de 2015 a 2020

\begin{tabular}{r|cccc}
\hline Ano & $\begin{array}{c}\text { Sudeste/ } \\
\text { Centro-oeste }\end{array}$ & Sul & Nordeste & Norte \\
\hline $\mathbf{2 0 1 5}$ & 33.149 & 9.938 & 16.582 & 4.514 \\
$\mathbf{2 0 1 6}$ & 33.303 & 9.978 & 16.648 & 4.537 \\
$\mathbf{2 0 1 7}$ & 33.457 & 10.018 & 16.715 & 4.561 \\
$\mathbf{2 0 1 8}$ & 33.613 & 10.058 & 16.782 & 4.585 \\
$\mathbf{2 0 1 9}$ & 33.918 & 10.137 & 16.914 & 4.631 \\
$\mathbf{2 0 2 0}$ & 37.166 & 11.612 & 18.316 & 5.136 \\
\hline
\end{tabular}

Fonte: Elaboração própria com base em (EPE, 2015) 
O número total domicílios próprios por tipo de domicílio no ano para cada região $i$ é calculado pela fórmula a seguir.

$$
\begin{aligned}
& \text { Total dom tipo-região (i) }=(\text { Tipo dom região (i) }) \times\left[\left(\text { Dom }_{\text {permanente-próprio-região (i) })} x\right.\right. \\
& \text { (Total dom estimado (i))] }
\end{aligned}
$$

Onde:

- $\quad$ Total dom tipo-região $(i)=$ total de domicílios por ano e por região;

- Tipo dom região $(i)=\%$ do tipo de domicílio (casa ou apartamento) por ano e por região;

- Dom permanente-próprio-região $=\%$ domicílio permanente próprio por ano e por região;

- $\quad$ Total dom estimado $(i)=$ total domicílio estimado por ano.

A área total útil de telhados $\left(\mathrm{m}^{2}\right)$ por tipo e domicílio é dada pelas equações a seguir.

$$
\text { Área útil região (i) }=\Sigma \text { [Total dom tipo-região (i) } x \text { Área aproveitada tipo] } x \mathrm{Fa}
$$

Sendo que:

$$
\text { Área aproveitada tipo }=\left[\text { Área estimada tipo } x \mathrm{Ca}_{\text {tipo }}\right]
$$

Onde:

- Área útil região(i) = área total útil de telhado por ano e por região;

- Total dom tipo-região $(i)=$ total de domicílios por ano e por região;

- Área aproveitada tipo = área de telhado aproveitada por tipo de domicílio;

- Área estimada tipo = área de telhado estimada por tipo de domicílio;

- $\mathrm{Fa}^{16}=30 \%$ (fator de aproveitamento);

\footnotetext{
16 Variação entre 22\% a 95\%. Esta grande variação se deve principalmente à localização da
} amostra e sua respectiva configuração espacial. 
- Ca tipo = coeficiente de aproveitamento: casa $(0,5)$ e apartamento $(1,0)$.

Com base nas equações 5.1, 5.2 e 5.3 anteriormente explicitadas, é calculada na Figura 5.3 a estimativa de área útil de telhado $\left(\mathrm{m}^{2}\right)$ por região no período 2015 a 2020. A região Sudeste/Centro-oeste é aquela que apresenta maior área útil de telhado $\left(\mathrm{m}^{2}\right)$, seguida da região Nordeste, Sul e Norte. Isso se deve porque a região Sudeste/Centro-oeste é a região mais populosa com 94,3 milhões de pessoas, representando 49,5\% do total de habitantes do país, segundo (IBGE, 2010).

A segunda região com maior número de habitantes é o Nordeste, com 53 milhões de pessoas, o que equivale a $27,8 \%$ do total.

A região Sul e Norte totalizam, respectivamente, 27,8 milhões de habitantes $(14,4 \%)$ e 15,8 milhões de habitantes $(8,3 \%)$.

O estudo sobre a estimativa do número de domicílios permanentes feito pela EPE (2015) e considerado nessa dissertação indicou um aumento significativo no período 2015-2020. O número de domicílios é estimado através da relação habitante/domicílio. Nos últimos anos, observou-se uma tendência decrescente nessa relação, devido às alterações no perfil sociodemográfico das famílias brasileiras. Logo, o aumento da renda, o estímulo ao financiamento habitacional, a urbanização e o envelhecimento populacional são fatores que influenciaram no aumento da expectativa do número de domicílios, em especial, na região Sudeste/Centro-oeste no ano de 2020. Cabe destacar que o envelhecimento populacional nos últimos anos aumentou a taxa de independência dos indivíduos, o que proporcionou maior autonomia para aquisição de residências e o aumento do número de domicílios com um único habitante. 


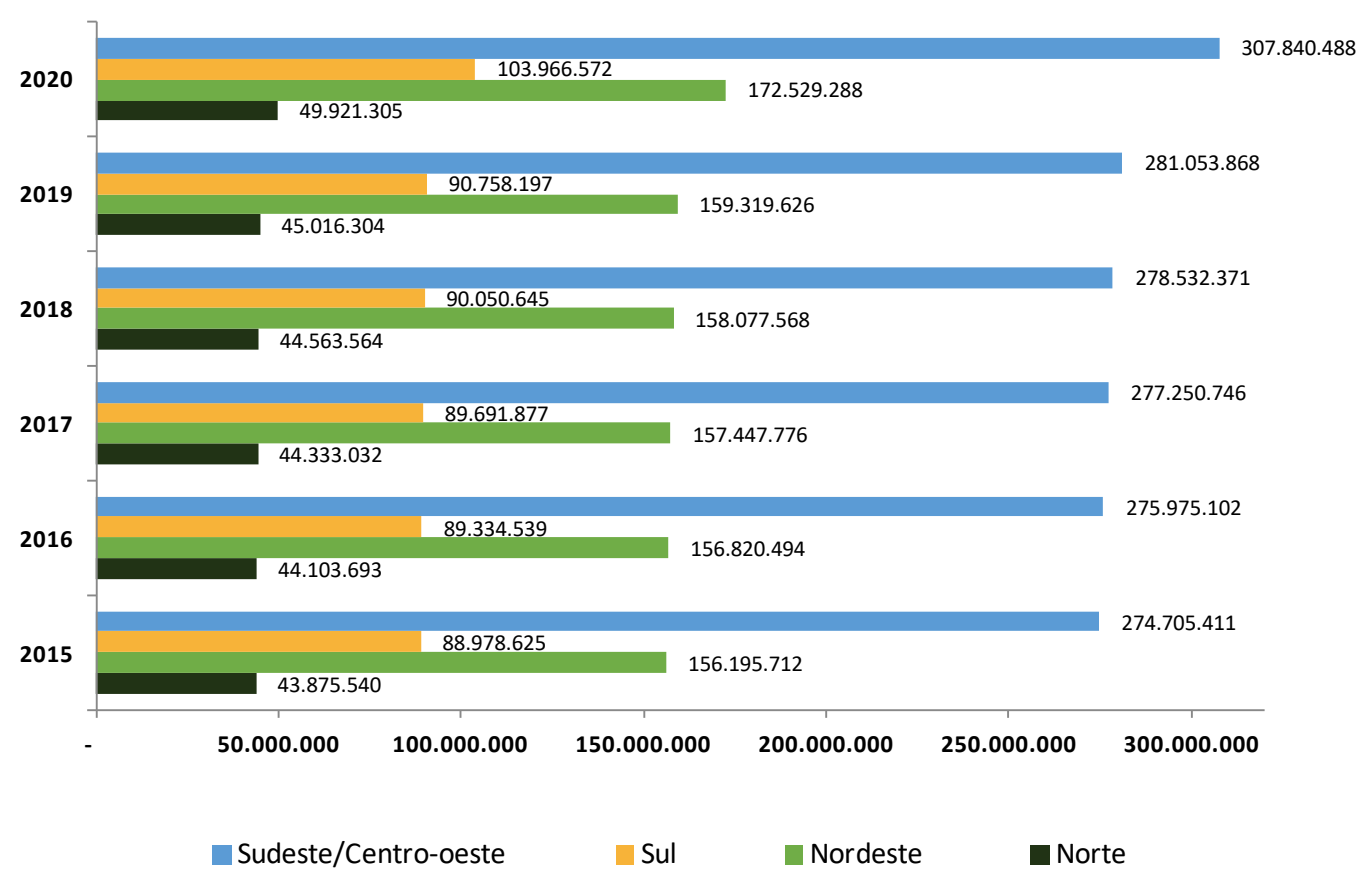

Figura 5.3 - Estimativa de área útil de telhado $\left(\mathrm{m}^{2}\right)$ por região Fonte: Elaboração própria

\section{3. \\ Cenários do potencial de energia fotovoltaica residencial e carga global de energia}

Conforme visto na seção 4, para obtenção de curvas estocásticas do potencial de energia fotovoltaica residencial empregou-se a metodologia Box \& Jenkins e a técnica de computação intensiva Bootstrap. A modelagem de séries temporais foi desenvolvida na linguagem estatística R, versão 3.2.2 (R Core Team, 2015).

O objetivo nessa etapa é criar cenários do potencial de geração fotovoltaica para o período 2015 a 2020, a partir das séries de irradiação solar por região encontradas na seção 5.1. A seguir cada uma das etapas da metodologia Box \& Jenkins e da computação intensiva Bootstrap aplicadas as séries de irradiação solar descritas são sumarizadas abaixo:

- Seleção do tipo de modelo que melhor representa cada série;

- Decomposição STL (estrutura da série + resíduos) 
- Após garantir a independência dos resíduos dos modelos encontrados, obteve-se a geração das 2.000 séries sintéticas a partir da aplicação da técnica Bootstrap, utilizando os parâmetros do modelo original e os resíduos Bootstrap (Oliveira, 2010). O período considerado foi o mesmo da amostra original (janeiro/2009 a dezembro/2013).

- Seleção dos percentis 5\%, 25\%, 50\%, 75\% e 95\%. Tais percentis foram selecionados para observar quais eram os resultados do processamento do PMO, quando considerados diferentes níveis de geração fotovoltaica residencial;

- Previsão dos percentis selecionados de janeiro/2014 a dezembro/2020.

A Figura 5.4 ilustra um exemplo da aplicação das etapas descritas acima, considerando a série de irradiação solar da região Sudeste/Centro-oeste.

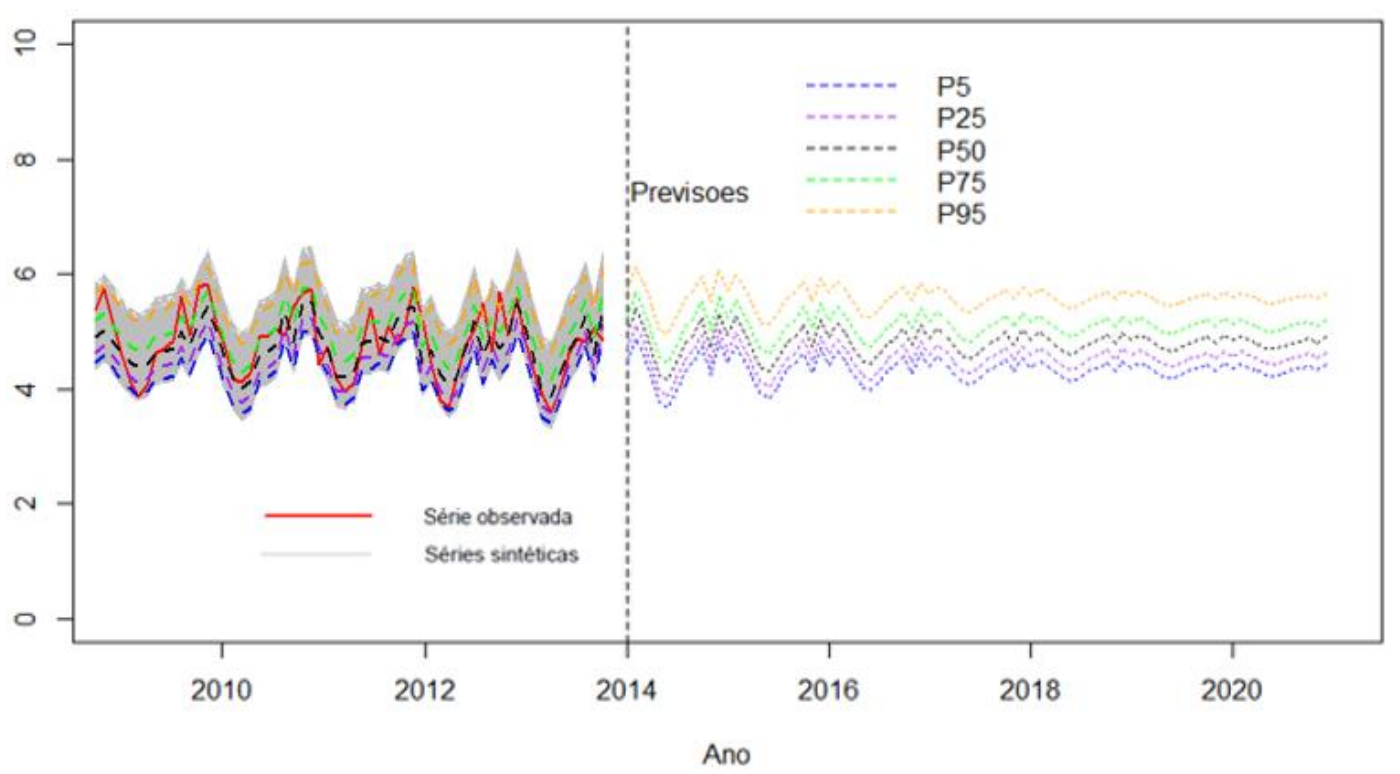

Figura 5.4 - Cenários de irradiação solar - kWh/m²/mês (jan/2014 a dez/2020) Fonte: Elaboração própria

Os modelos Box \& Jenkins encontrados para cada região do país são modelos Sazonais Autoregressivos Integrados à Média Móvel (SARIMA). Estes modelos são importantes, pois consideram a sazonalidade estocástica dos dados. Quando o 
período sazonal é igual a 12, o modelo denominado SARIMA de ordem $(\mathrm{p}, \mathrm{d}, \mathrm{q}) \times$ $(\mathrm{P}, \mathrm{D}, \mathrm{Q})_{12}$, é dado por (Morettin \& Toloi, 2004):

$$
\varphi(X) \Phi\left(X^{12}\right) \Delta^{d} \Delta^{D}{ }_{12} Z t=\theta(X) \Theta(X) a t
$$

Onde:

- $\varphi(X)$ : é o operador autorregressivo (AR) de ordem $\mathrm{p}$

- $\theta(X)$ : é o operador de médias móveis (MA) de ordem q

- $\Phi(X)$ : é o operador AR-sazonal de ordem P

- $\Theta(X)$ : é o operador MA-sazonal de ordem $\mathrm{Q}$

- $\Delta^{d}$ : é operador de diferença

- $\Delta^{D}{ }_{12}$ : é operador de diferença sazonal e

- $a t$ : é um ruído branco ${ }^{17}$

O modelo encontrado para a região Sudeste/Centro-oeste é aquele que tem o operador $\Phi(\mathrm{X})$ AR-sazonal de ordem $\mathrm{P}=1$. Já os modelos das regiões Sul, Nordeste e Norte são aqueles que apresentam o operador $\varphi(X)$ autorregressivo (AR) de ordem $\mathrm{p}=1$ e o operador $\Phi(\mathrm{X})$ AR-sazonal de ordem $\mathrm{P}=1$. Os coeficientes de cada modelo e suas respectivas informações estatísticas estão na Tabela 5.4.

Tabela 5.4 - Modelos Box \& Jenkins selecionados por região

\begin{tabular}{c|c|c|c|c|c|c|c|c|c}
\hline \multirow{2}{*}{ Região } & \multirow{2}{*}{ Modelo } & \multicolumn{2}{|c|}{ Coeficientes e Variância } & \multicolumn{5}{c}{ Índices de avaliação } \\
\cline { 4 - 11 } & & AR1 & SAR1 & $\sigma^{2}$ & AIC & BIC & RMSE & MAE & MAPE \\
\hline Sudeste/Centro-oeste & SARIMA $(0,0,0)(1,0,0)_{12}$ & - & 0,768 & 0,151 & 71,580 & 77,860 & 0,382 & 0,312 & 6,403 \\
\hline Sul & SARIMA $(1,0,0)(1,0,0)_{12}$ & 0,414 & 0,826 & 0,239 & 103,250 & 111,630 & 0,476 & 0,409 & 10,251 \\
\hline Nordeste & SARIMA $(1,0,0)(1,0,0)_{12}$ & 0,682 & 0,810 & 0,051 & 10,540 & 18,910 & 0,221 & 0,184 & 3,363 \\
\hline Norte & SARIMA $(1,0,0)(1,0,0)_{12}$ & 0,624 & 0,732 & 0,041 & $-6,110$ & 2,270 & 0,198 & 0,160 & 3,412 \\
\hline
\end{tabular}

Fonte: Elaboração própria

\footnotetext{
17 Uma série temporal é chamada de ruído branco se for uma sequência de variáveis aleatórias
} independentes e identicamente distribuída com média zero e variância finita (Souza et al., 2004). 
Onde,

- AR1: coeficiente autoregressivo de ordem $\mathrm{p}=1$;

- SAR1: coeficiente AR-sazonal de ordem $\mathrm{P}=1$;

- $\quad$ 2: variância do modelo;

- AIC: critério de informação de Akaike;

- BIC: critério de informação de Bayesiano;

- RMSE: raiz quadrada do erro médio;

- MAE: erro médio absoluto;

- MAPE: erro percentual absoluto médio.

Por fim, o cálculo do potencial de energia fotovoltaica é dado pela fórmula (5.5). A unidade de medida, para fins de planejamento da operação energética, é o MW médio.

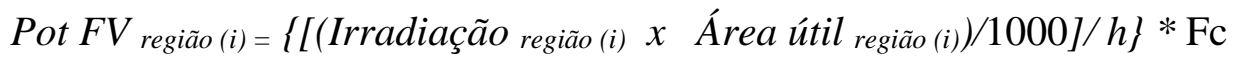

Onde,

- Pot FV região $(i)=$ potencial de energia fotovoltaica por região e por mês;

- Irradiação região $(i)=$ irradiação solar por região e por mês;

- Área útil região $(i)$ = área total útil de telhado por região e por mês;

- $\mathrm{h}=$ horas do mês;

- $\mathrm{Fc}=12 \%$ (fator de conversão).

Os cenários do potencial de energia fotovoltaica encontrados para o Sistema Interligado Nacional estão apresentados na Figura 5.5. 


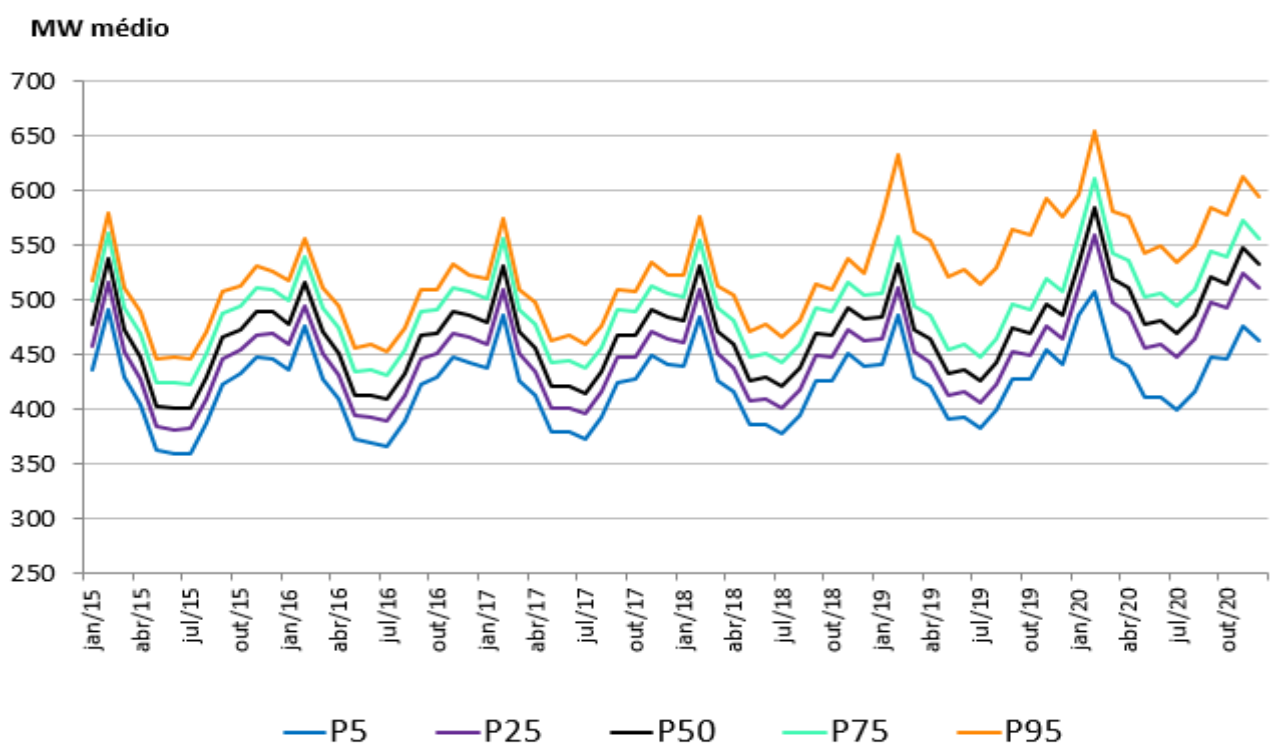

Figura 5.5 - Cenários do potencial de energia fotovoltaica residencial no SIN Fonte: Elaboração própria

O potencial máximo e o mínimo de geração fotovoltaica residencial correspondem, respectivamente, ao cenário P95 (654 MW médio) em fev/2020 e ao cenário P5 (359 MW médio) em jul/2015. Na Tabela 5.5 são indicados os montantes anuais do potencial de geração fotovoltaica residencial de cada cenário elaborado.

Tabela 5.5 - Montantes anuais do potencial de geração fotovoltaica residencial (MW med)

\begin{tabular}{llllll}
\hline Ano & P5 & P25 & P50 & P75 & P95 \\
\hline $\mathbf{2 0 1 5}$ & 415 & 437 & 457 & 479 & 499 \\
$\mathbf{2 0 1 6}$ & 416 & 438 & 458 & 480 & 500 \\
$\mathbf{2 0 1 7}$ & 419 & 442 & 462 & 484 & 504 \\
$\mathbf{2 0 1 8}$ & 421 & 444 & 464 & 486 & 508 \\
$\mathbf{2 0 1 9}$ & 425 & 448 & 468 & 491 & 559 \\
$\mathbf{2 0 2 0}$ & 446 & 492 & 515 & 539 & 579 \\
\hline
\end{tabular}

Fonte: Elaboração própria

Na Tabela 5.6 é indicada a representação dos cenários do potencial de geração fotovoltaica residencial na carga global de energia. 
Tabela 5.6 - Representação dos cenários do potencial de geração fotovoltaica residencial na carga global de energia (\%)

\begin{tabular}{c|c|c|c|c|c}
\hline Horizonte de planejamento & P5 & P25 & P50 & P75 & P95 \\
\hline PMO jan/2015 (2015-2019) & $0,6 \%$ & $0,6 \%$ & $0,6 \%$ & $0,7 \%$ & $0,7 \%$ \\
\hline PMO jan/2016 (2016-2020) & $0,6 \%$ & $0,6 \%$ & $0,7 \%$ & $0,7 \%$ & $0,8 \%$ \\
\hline
\end{tabular}

Fonte: Elaboração própria

A carga global de energia do SIN correspondente ao PMO janeiro/2015 e janeiro/2016, e a carga global líquida ${ }^{18}$ dos casos elaborados por essa dissertação são mostradas nas Figuras 5.6 e 5.7.

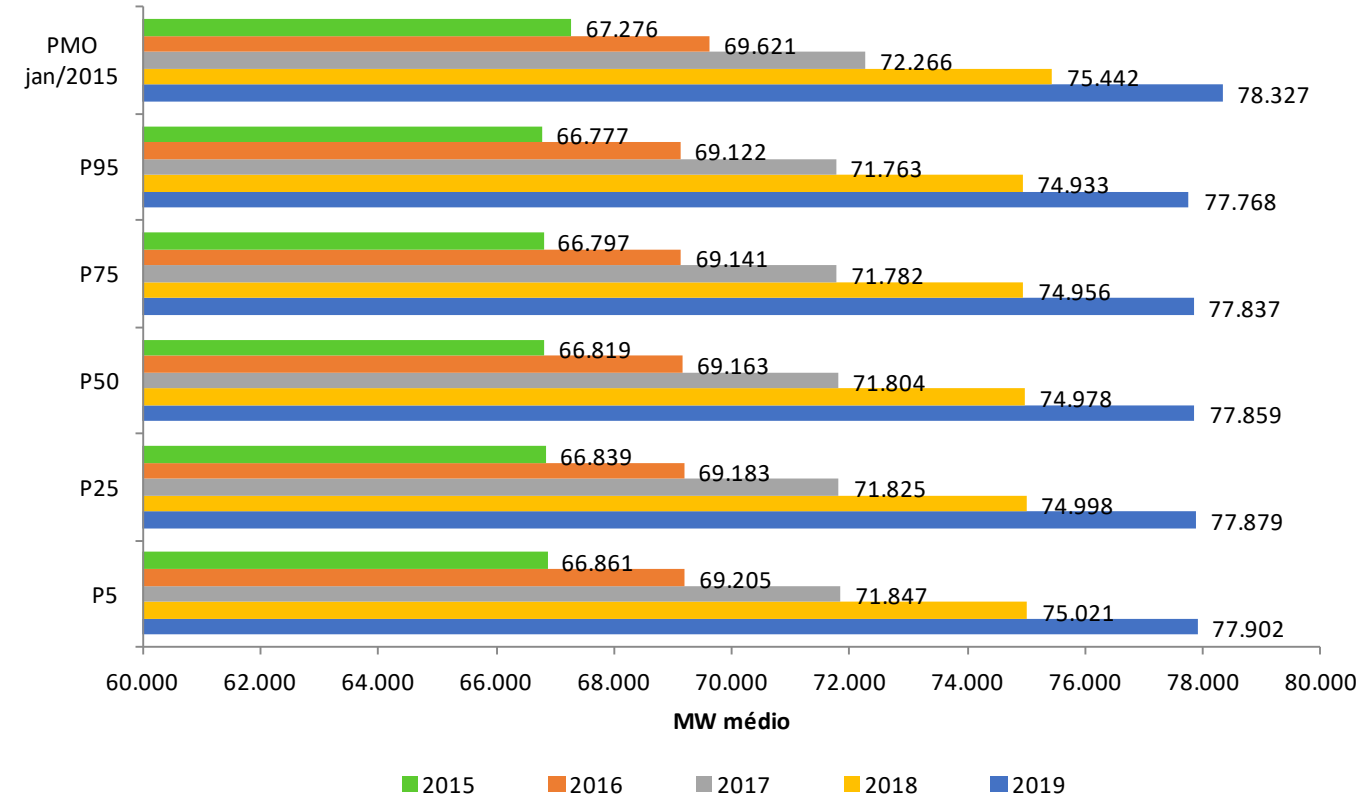

Figura 5.6 - Carga global de energia do SIN. PMO janeiro/2015 e casos de sensibilidade Fonte: Elaboração própria

${ }^{18}$ Carga global de energia dos casos referências (PMO janeiro/2015 e PMO janeiro/2016) abatida dos cenários de geração fotovoltaica residencial. 


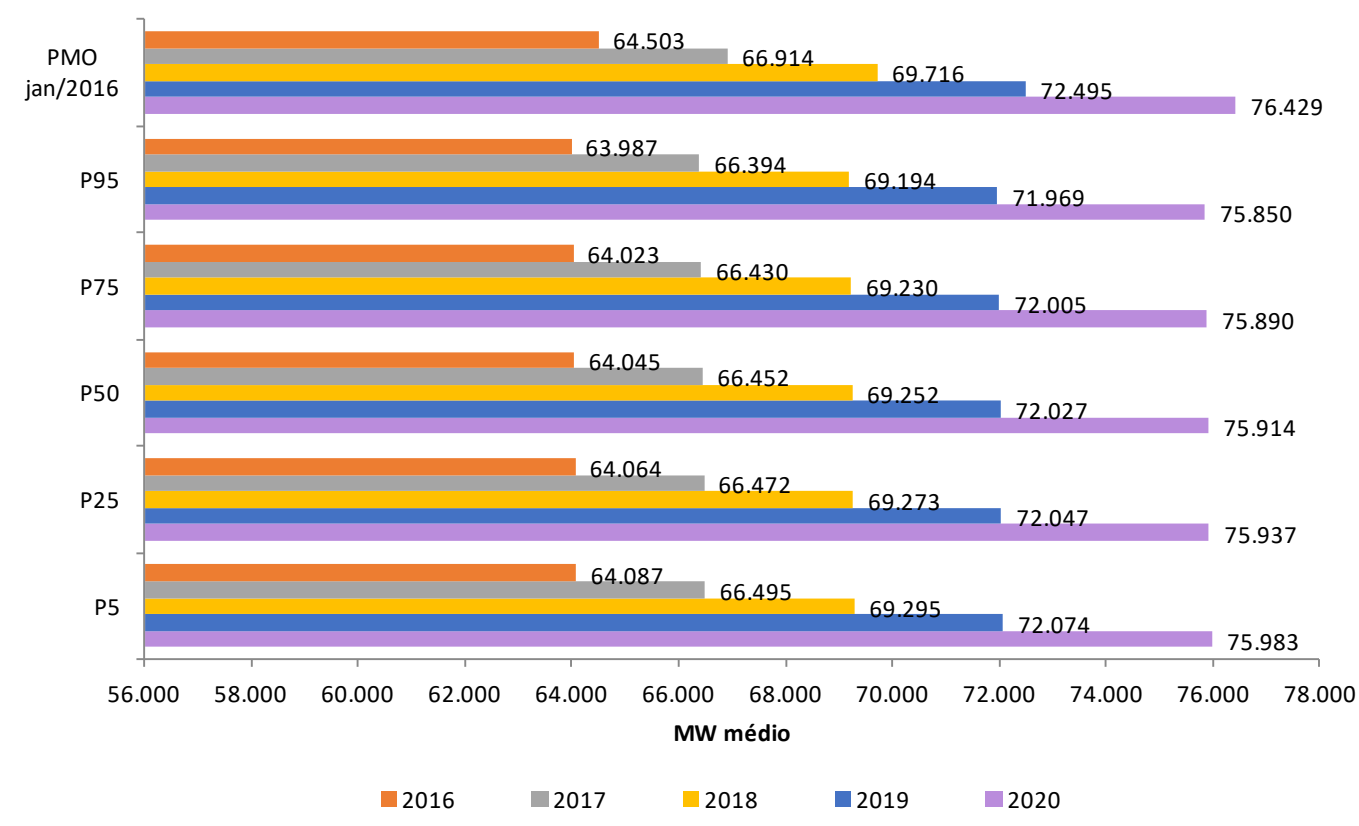

Figura 5.7 - Carga global de energia do SIN. PMO janeiro/2016 e casos de sensibilidade Fonte: Elaboração própria

A variação média anual entre a carga global de energia do PMO janeiro/2015 e a carga de energia global resultante da consideração dos cenários de geração fotovoltaica residencial são mostradas na Tabela 5.7. A maior contribuição de redução da carga, comparando com o caso referência PMO janeiro/2015, ocorreu no caso P95 (2015), registrando 0,74\% de redução (499 MW médio).

Tabela 5.7 - Variação média anual entre a carga global de energia do PMO janeiro/2015 e os casos de sensibilidade

\begin{tabular}{cccccc}
\hline Ano & PMO jan-2015/P5 & PMO jan-2015/P25 & PMO jan-2015/P50 & PMO jan-2015/P75 & PMO jan-2015/P95 \\
\hline $\mathbf{2 0 1 5}$ & $-0,62 \%$ & $-0,65 \%$ & $-0,68 \%$ & $-0,71 \%$ & $-0,74 \%$ \\
$\mathbf{2 0 1 6}$ & $-0,60 \%$ & $-0,63 \%$ & $-0,66 \%$ & $-0,69 \%$ & $-0,72 \%$ \\
$\mathbf{2 0 1 7}$ & $-0,58 \%$ & $-0,61 \%$ & $-0,64 \%$ & $-0,67 \%$ & $-0,70 \%$ \\
$\mathbf{2 0 1 8}$ & $-0,56 \%$ & $-0,59 \%$ & $-0,62 \%$ & $-0,64 \%$ & $-0,67 \%$ \\
$\mathbf{2 0 1 9}$ & $-0,54 \%$ & $-0,57 \%$ & $-0,60 \%$ & $-0,63 \%$ & $-0,71 \%$ \\
\hline
\end{tabular}

Fonte: Elaboração própria

A variação média anual entre a carga global de energia do PMO janeiro/2016 e a carga de energia global resultante da consideração dos cenários de geração fotovoltaica residencial são mostradas na Tabela 5.8. A maior contribuição de 
redução da carga, comparando com o caso referência PMO janeiro/2016, ocorreu no caso P95 no ano 2016, registrando 0,80\% (515 MW médio) de redução.

Tabela 5.8 - Variação média anual entre a carga global de energia do PMO janeiro/2016 e os casos de sensibilidade

\begin{tabular}{lccccc}
\hline Ano & PMO jan-2016/P5 & PMO jan-2016/P25 & PMO jan-2016/P50 & PMO jan-2016/P75 & PMO jan-2016/P95 \\
\hline $\mathbf{2 0 1 6}$ & $-0,64 \%$ & $-0,68 \%$ & $-0,71 \%$ & $-0,74 \%$ & $-0,80 \%$ \\
$\mathbf{2 0 1 7}$ & $-0,63 \%$ & $-0,66 \%$ & $-0,69 \%$ & $-0,72 \%$ & $-0,78 \%$ \\
$\mathbf{2 0 1 8}$ & $-0,60 \%$ & $-0,64 \%$ & $-0,67 \%$ & $-0,70 \%$ & $-0,75 \%$ \\
$\mathbf{2 0 1 9}$ & $-0,58 \%$ & $-0,62 \%$ & $-0,65 \%$ & $-0,68 \%$ & $-0,73 \%$ \\
$\mathbf{2 0 2 0}$ & $-0,58 \%$ & $-0,64 \%$ & $-0,67 \%$ & $-0,71 \%$ & $-0,76 \%$ \\
\hline
\end{tabular}

Fonte: Elaboração própria

A contribuição de redução da carga global de energia dos casos de sensibilidade gerados nessa dissertação pode ser considerada expressiva, uma vez que a redução da carga em um cenário de condições hidrológicas desfavoráveis impacta significativamente a decisão do despacho hidrotérmico.

No entanto, ao comparar a contribuição de redução da carga global de energia entre os casos de sensibilidade gerados nessa dissertação, percebe-se que a variação é pouco expressiva, conforme mostrado nas Tabelas 5.9 e 5.10. Isso indica que há pouca variação entre os cenários criados, contudo todos os cenários causam impactos relevantes nos casos de referência selecionados (PMO janeiro/2015 e PMO janeiro/2016).

Tabela 5.9 - Variação média anual entre a carga global de energia dos casos de sensibilidade do PMO janeiro/2015

\begin{tabular}{lllllllllll}
\hline Ano & P5/P25 & P5/P50 & P5/P75 & P5/95 & P25/P50 & P25/P75 & P25/P95 & P50/P75 & P50/P95 & P75/P95 \\
\hline $\mathbf{2 0 1 5}$ & $-0,03 \%$ & $-0,06 \%$ & $-0,10 \%$ & $-0,13 \%$ & $-0,03 \%$ & $-0,06 \%$ & $-0,09 \%$ & $-0,03 \%$ & $-0,06 \%$ & $-0,03 \%$ \\
$\mathbf{2 0 1 6}$ & $-0,03 \%$ & $-0,06 \%$ & $-0,09 \%$ & $-0,12 \%$ & $-0,03 \%$ & $-0,06 \%$ & $-0,09 \%$ & $-0,03 \%$ & $-0,06 \%$ & $-0,03 \%$ \\
$\mathbf{2 0 1 7}$ & $-0,03 \%$ & $-0,06 \%$ & $-0,09 \%$ & $-0,12 \%$ & $-0,03 \%$ & $-0,06 \%$ & $-0,09 \%$ & $-0,03 \%$ & $-0,06 \%$ & $-0,03 \%$ \\
$\mathbf{2 0 1 8}$ & $-0,03 \%$ & $-0,06 \%$ & $-0,09 \%$ & $-0,12 \%$ & $-0,03 \%$ & $-0,06 \%$ & $-0,09 \%$ & $-0,03 \%$ & $-0,06 \%$ & $-0,03 \%$ \\
$\mathbf{2 0 1 9}$ & $-0,03 \%$ & $-0,06 \%$ & $-0,08 \%$ & $-0,17 \%$ & $-0,03 \%$ & $-0,05 \%$ & $-0,14 \%$ & $-0,03 \%$ & $-0,12 \%$ & $-0,09 \%$ \\
\hline
\end{tabular}


Tabela 5.10 - Variação média anual entre a carga global de energia dos casos de sensibilidade do PMO janeiro/2016

\begin{tabular}{ccccccccccc}
\hline Ano & P5/P25 & P5/P50 & P5/P75 & P5/95 & P25/P50 & P25/P75 & P25/P95 & P50/P75 & P50/P95 & P75/P95 \\
\hline $\mathbf{2 0 1 6}$ & $-0,04 \%$ & $-0,07 \%$ & $-0,10 \%$ & $-0,16 \%$ & $-0,03 \%$ & $-0,07 \%$ & $-0,12 \%$ & $-0,03 \%$ & $-0,09 \%$ & $-0,06 \%$ \\
$\mathbf{2 0 1 7}$ & $-0,03 \%$ & $-0,06 \%$ & $-0,10 \%$ & $-0,15 \%$ & $-0,03 \%$ & $-0,06 \%$ & $-0,12 \%$ & $-0,03 \%$ & $-0,09 \%$ & $-0,05 \%$ \\
$\mathbf{2 0 1 8}$ & $-0,03 \%$ & $-0,06 \%$ & $-0,09 \%$ & $-0,15 \%$ & $-0,03 \%$ & $-0,06 \%$ & $-0,11 \%$ & $-0,03 \%$ & $-0,08 \%$ & $-0,05 \%$ \\
$\mathbf{2 0 1 9}$ & $-0,04 \%$ & $-0,06 \%$ & $-0,10 \%$ & $-0,15 \%$ & $-0,03 \%$ & $-0,06 \%$ & $-0,11 \%$ & $-0,03 \%$ & $-0,08 \%$ & $-0,05 \%$ \\
$\mathbf{2 0 2 0}$ & $-0,06 \%$ & $-0,09 \%$ & $-0,12 \%$ & $-0,18 \%$ & $-0,03 \%$ & $-0,06 \%$ & $-0,11 \%$ & $-0,03 \%$ & $-0,08 \%$ & $-0,05 \%$ \\
\hline
\end{tabular}

Fonte: Elaboração própria

\section{4 . Simulação do PMO janeiro/2015 e do PMO janeiro/2016}

Conforme visto na seção 4.2.3, o processamento do PMO janeiro/2015 e do PMO janeiro/2016 foi realizado via modelo NEWAVE. A carga global de energia informada em cada PMO foi substituída pelos cenários de carga líquida (carga do caso referência abatida dos cenários de geração fotovoltaica residencial) apresentados na seção 5.3.

Para fins de convergência do modelo NEWAVE, foi selecionado para os casos de sensibilidade (P5, P25, P50, P75 e P95) o mesmo número de iterações do caso base de referência. Nas simulações que utilizaram como referência o PMO janeiro/2015 foram selecionadas 16 iterações. Já nas simulações que utilizaram como referência o PMO janeiro/2016, foram selecionadas 15 iterações. Os casos processados foram nomeados de acordo com a consideração do percentil do potencial de geração fotovoltaica residencial selecionados nessa dissertação.

Foram utilizadas as versões dos modelos compatíveis com as utilizadas nos programas oficiais. Para os casos cuja referência é o PMO janeiro/2015 foi utilizada a versão do modelo NEWAVE 19. Já para os casos cuja referência é o PMO janeiro/2016, foi utilizada a versão 22 do modelo.

Os resultados da consideração do potencial de geração fotovoltaica residencial no PMO janeiro/2015 e no PMO janeiro/2016, para cada subsistema equivalente de energia (Sudeste/Centro-oeste, Sul, Nordeste e Norte), foram: custo total da operação, custo marginal de operação, energia armazenada, custo de déficit, 
risco de déficit, geração hidráulica, geração térmica, intercâmbio entre as regiões e custo de vertimento.

Cabe destacar nessa seção que os casos de sensibilidade elaborados nessa dissertação são considerados estatisticamente semelhantes, uma vez que a dispersão dos dados em torno da média amostral, indicada pelo desvio-padrão, coloca os resultados bem próximos uns dos outros. Logo, alguns resultados da otimização, via Newave, podem parecer pouco lógicos quando analisados. No entanto, a solução ótima encontrada para todos os casos são razoáveis e podem ser explicadas por um conjunto de variáveis utilizadas na otimização, conforme serão apresentadas nas próximas subseções.

\section{4 .1 \\ PMO janeiro/2015}

\subsubsection{1}

Custo total da operação (CTO)

O custo total da operação (CTO) é o somatório dos custos de geração térmica, do déficit de energia, do vertimento, do excesso de energia, da violação da evaporação, do intercâmbio, da violação de intercâmbio mínimo, do vertimento fio não turbinável e da violação de geração hidráulica mínima. O CTO apresentou redução máxima de 7,8\% nos casos de sensibilidade P75 e P95. Na Tabela 5.11 são mostrados os custos e devio-padrão para cada caso processado.

Tabela 5.11 - Custo total da operação e desvio-padrão $\left(\$ \wedge 10^{6}\right)$ - Ref. PMO janeiro/2015

\begin{tabular}{lcc}
\hline Casos Newave & Custo total da operação $\left(\mathbf{\$} \wedge \mathbf{1 0}^{\mathbf{6}}\right)$ & Desvio padrão $\left(\mathbf{\$} \mathbf{\wedge} \mathbf{1 0}^{\mathbf{6}}\right)$ \\
\hline PMO jan15 Oficial & 45.267 & 1.053 \\
Caso P5 & 42.280 & 996 \\
Caso P25 & 42.455 & 1.000 \\
Caso P50 & 42.213 & 988 \\
Caso P75 & 41.984 & 999 \\
Caso P95 & 42.003 & 990 \\
\hline
\end{tabular}

Fonte: Elaboração própria 
O PMO de janeiro/2015 apresentou custos marginais de operação elevados no início do período de planejamento, devido às condições hidrológicas desfavoráveis e a carga elevada, conforme visto na seção 4.2.2.1. A Figura 5.8 indica que o custo total de operação do PMO janeiro/2015 é um outlier quando comparado aos casos de sensibilidade e que os casos apresentam dispersão bastante baixa, conforme indica a amplitude interquartílica Q1 e Q3.

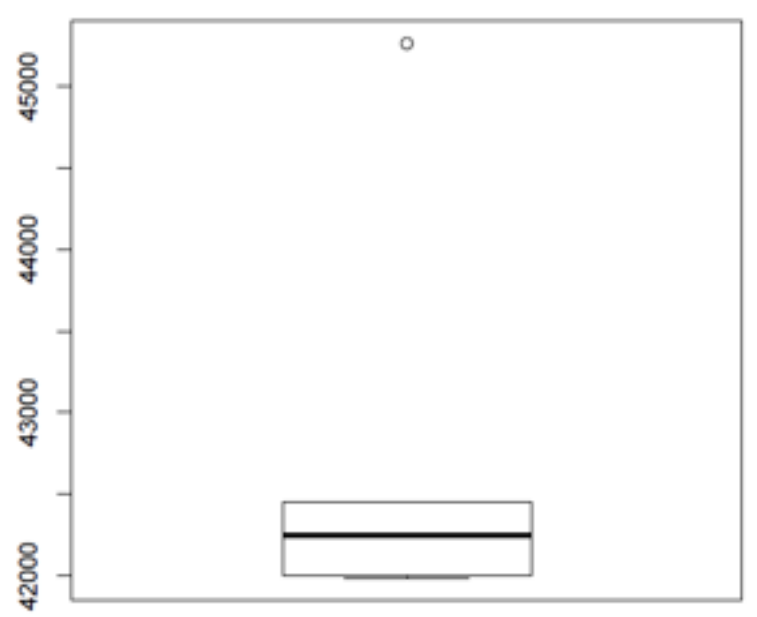

Figura 5.8 - Boxplot do custo total de operação $\left(\$\right.$ x $\left.10^{\wedge 6}\right)$. PMO janeiro/2015 e casos de sensibilidade Fonte: Elaboração própria

\subsubsection{2}

\section{Custo marginal de operação (CMO)}

O PMO de janeiro/2015 apresentou custos marginais de operação elevados no início do período de planejamento, devido às condições hidrológicas desfavoráveis e a carga elevada, conforme visto na seção 4.2.2.1. A consideração do potencial de geração fotovoltaica residencial reduziu o custo marginal de operação, significativamente, em todos os quatro subsistemas equivalentes do SIN, com redução máxima de aproximadamente $\mathrm{R} \$$ 50/MWh nas regiões Sudeste/Centro-oeste e Sul, R\$ 31/MWh no Nordeste e R\$ 24/MWh no Norte. Todas as reduções máximas ocorreram no caso de sensibilidade P95 (2016). O 
efeito da geração fotovoltaica no CMO pode ser observado na sequência de Figuras abaixo (Figura 5.9 a Figura 5.12).

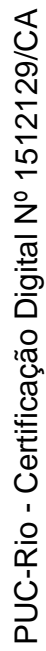

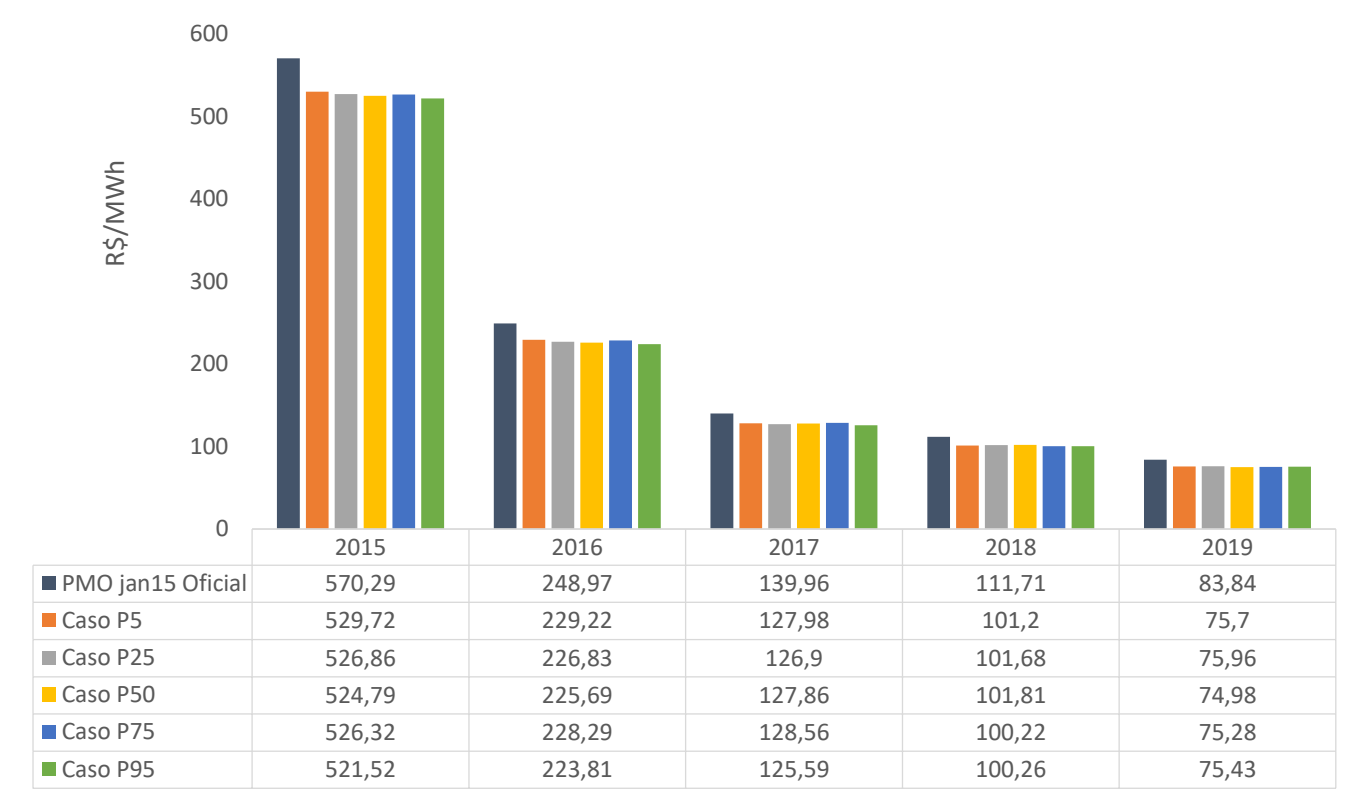

Figura 5.9 - Custo marginal de operação (Sudeste). PMO janeiro/2015 e casos de sensibilidade Fonte: Elaboração própria

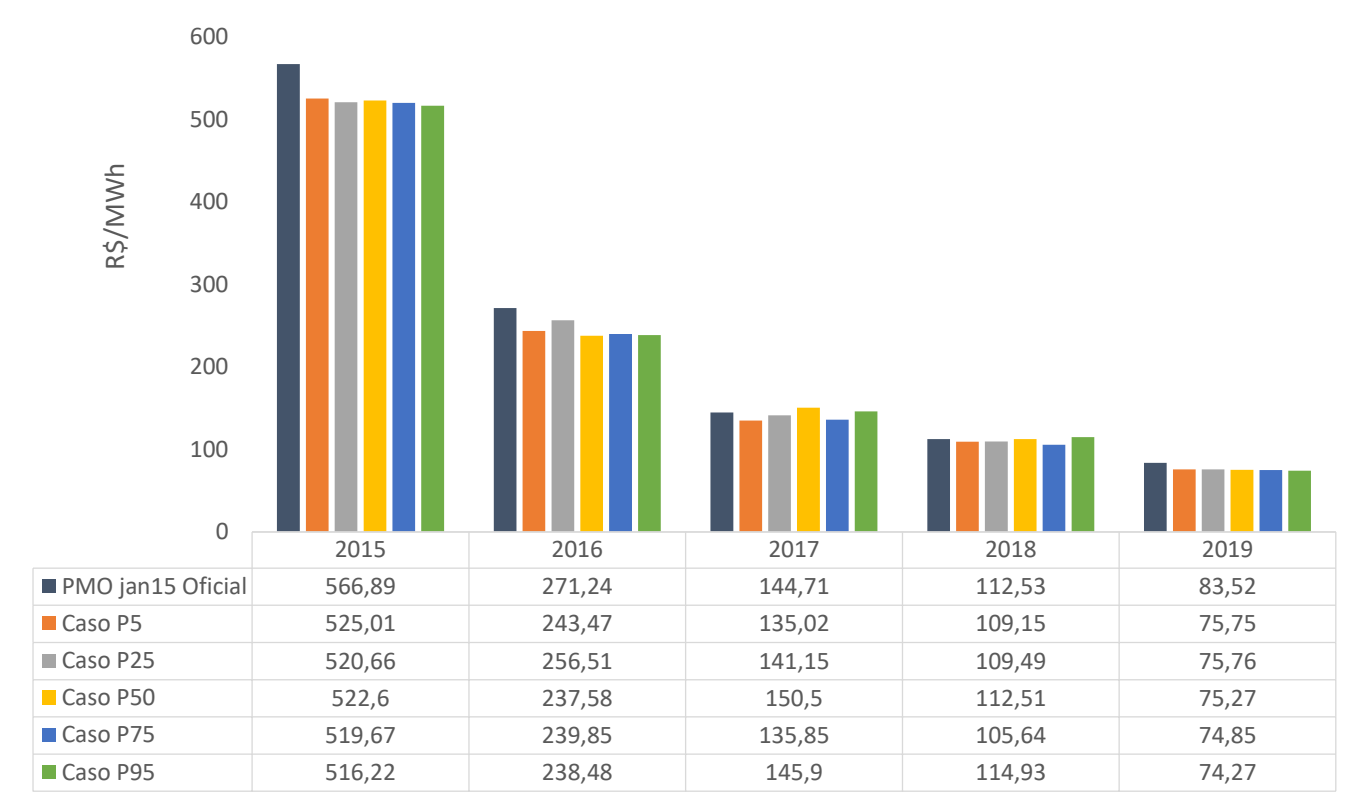

Figura 5.10 - Custo marginal de operação (Sul). PMO janeiro/2015 e casos de sensibilidade Fonte: Elaboração própria 


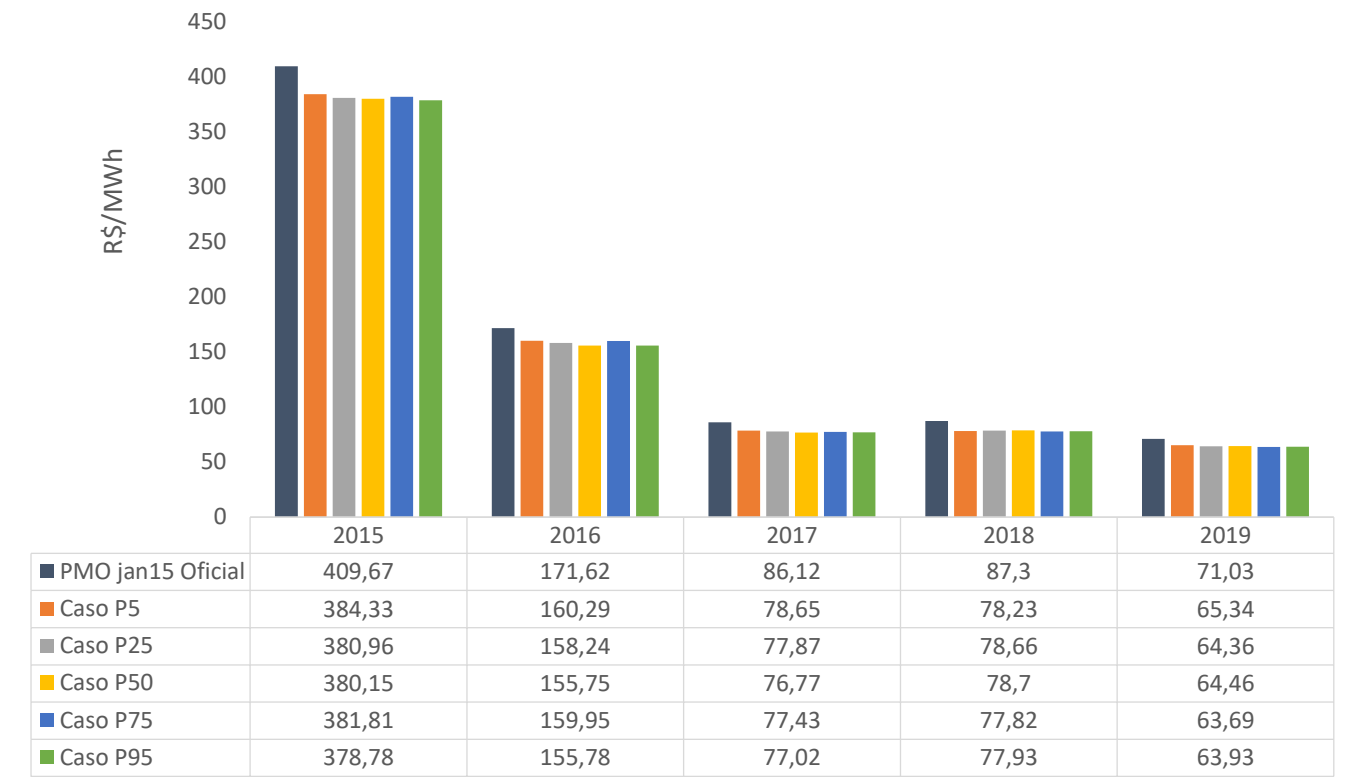

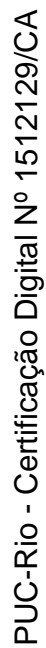

Figura 5.11 - Custo marginal de operação (Nordeste). PMO janeiro/2015 e casos de sensibilidade Fonte: Elaboração própria

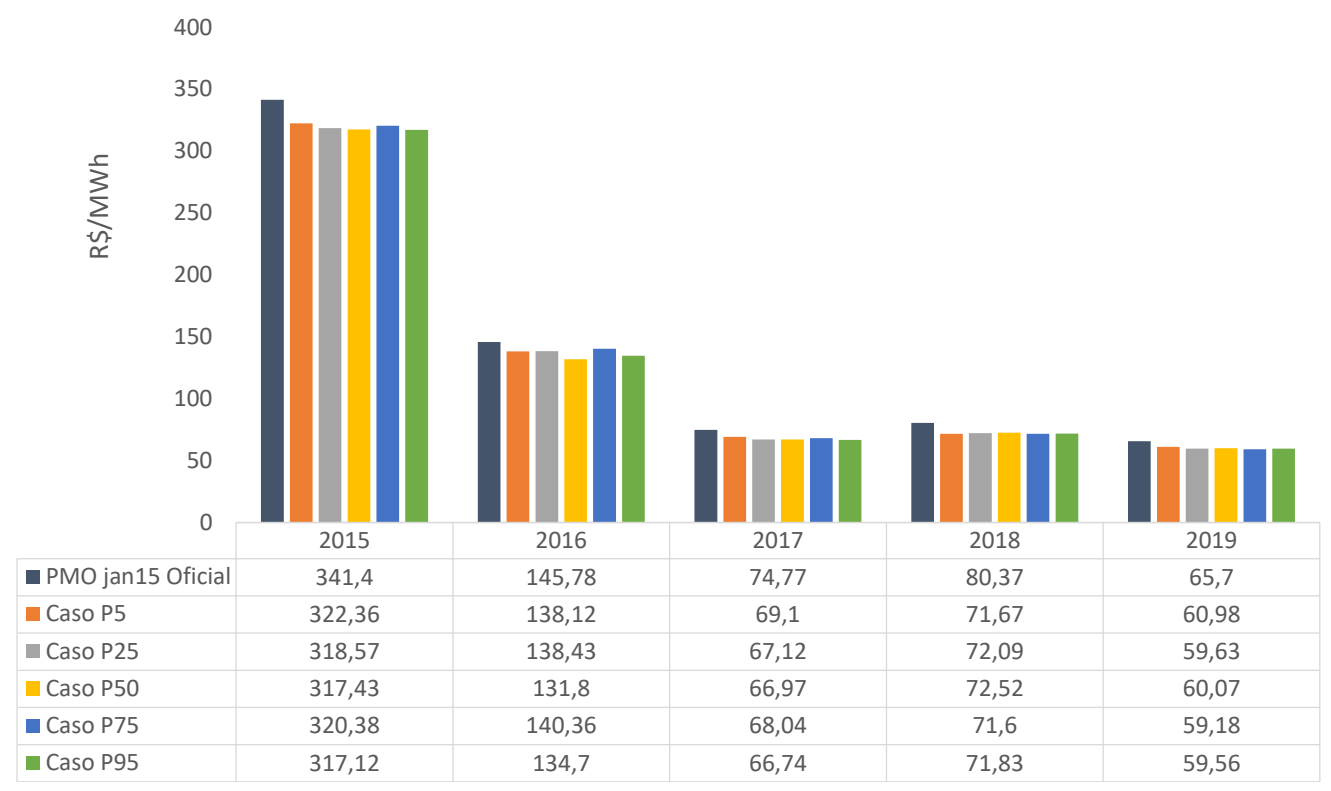

Figura 5.12 - Custo marginal de operação (Norte). PMO janeiro/2015 e casos de sensibilidade. Fonte: Elaboração própria 


\subsubsection{3 \\ Energia armazenada}

A energia armazenada inicial do SIN considerada pelo modelo Newave para o PMO janeiro/2015 foi de $21 \%$. A evolução do armazenamento ao longo do período de planejamento é apresentada pela Figura 5.13. A consideração do potencial de geração fotovoltaica contribuiu pouco para alcançar níveis de reservatórios equivalentes mais expressivos que os níveis alcançados pelo PMO janeiro/2015, pois a carga elevada fez com que a escolha da otimização priorizasse o despacho hidráulico, a fim de garantir o suprimento de energia, uma vez que os riscos de déficit a serem tratados na seção 5.4.1.5 foram bastante elevados. A máxima contribuição da geração fotovoltaica na energia armazenada do SIN se deu no caso P5, registrando 0,9\% de aumento da energia armazenada no final de novembro/2017. Importante destacar que a contribuição da geração fotovoltaica na energia armazenada ocorre de forma diferente entre os subsistemas equivalentes, pois a representatividade do nível do reservatório desses subsistemas no SIN se dá da seguinte forma: Sudeste/Centro-oeste (70\%); Sul (7\%); Nordeste (18\%) e Norte $(5 \%)$.

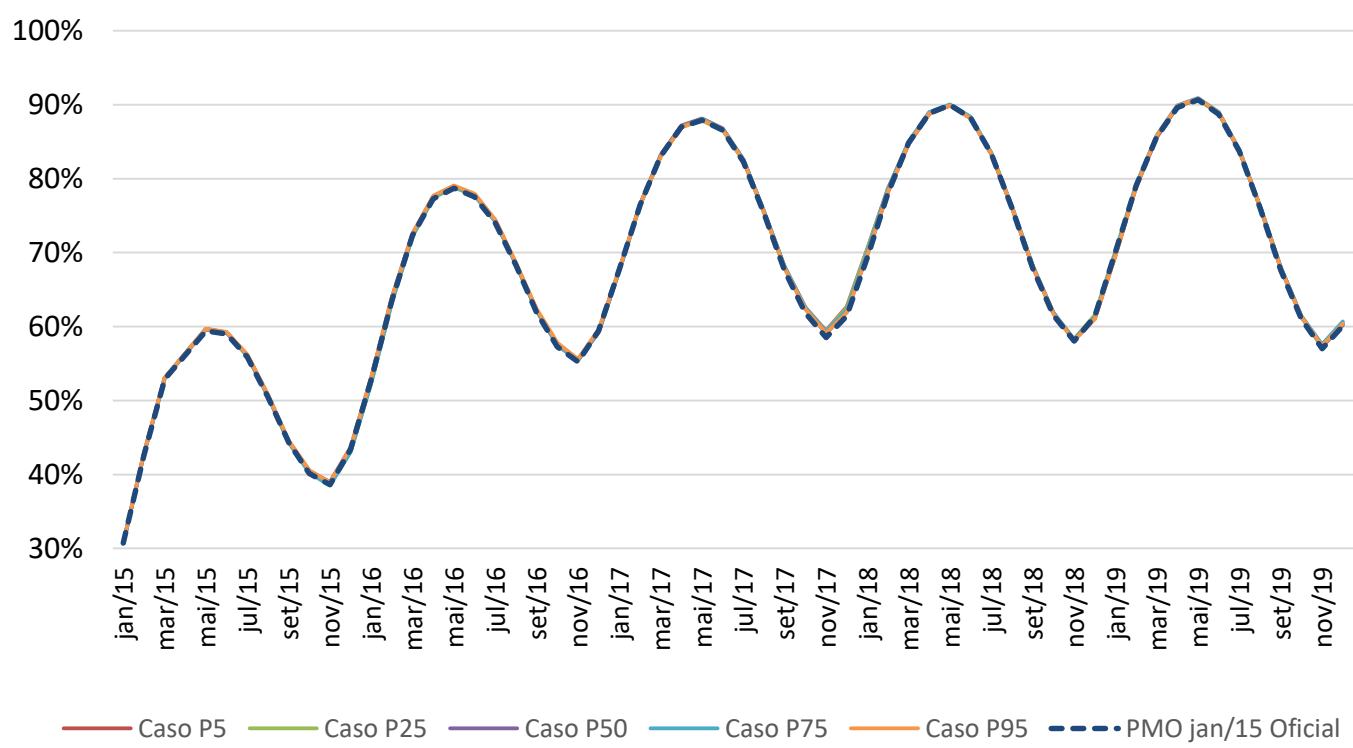

Figura 5.13 - Evolução do armazenamento do SIN - Ref. PMO janeiro/2015

Fonte: Elaboração própria 
O despacho acentuado da geração hidráulica explica os baixos níveis mantidos nos reservatórios do SIN. Em contrapartida, o despacho térmico tende a ser menor quando da exploração acentuada dos reservatórios. Como o custo da água é considerado zero no modelo Newave, o custo marginal da operação também tende a ser menor com a consideração dessa política de operação, conforme visto na subseção anterior.

\subsubsection{4}

\section{Custo de déficit}

A Tabela 5.12 indica o custo de déficit correspondente ao horizonte de planejamento (cinco anos) e o desvio padrão referente a esse custo. Ao considerar cenários do potencial de geração fotovoltaica no planejamento da operação de médio prazo o custo de déficit reduziu expressivamente quando comparado ao caso de referência (PMO janeiro/2015), registrando máxima redução de 14\% no caso P95.

Tabela 5.12 - Custo de déficit e desvio-padrão $\left(\$ \wedge 10^{6}\right)$ - Ref. PMO janeiro/2015

\begin{tabular}{lcc}
\hline Casos Newave & Custo de déficit $\left(\mathbf{\$} \mathbf{\wedge} \mathbf{1 0}^{\mathbf{6}}\right)$ & Desvio padrão $(\mathbf{\$} \mathbf{1 0} \mathbf{6})$ \\
\hline PMO jan15 Oficial & 8.140 & 659 \\
Caso P5 & 7.187 & 607 \\
Caso P25 & 7.270 & 610 \\
Caso P50 & 7.247 & 604 \\
Caso P75 & 7.153 & 614 \\
Caso P95 & 7.141 & 601 \\
\hline
\end{tabular}

Fonte: Elaboração própria

A Figura 5.14 indica que o custo de déficit do PMO janeiro/2015 é um outlier quando comparado aos casos de sensibilidade e que os casos apresentam dispersão bastante baixa, conforme indica a amplitude interquartílica Q1 e Q3. 


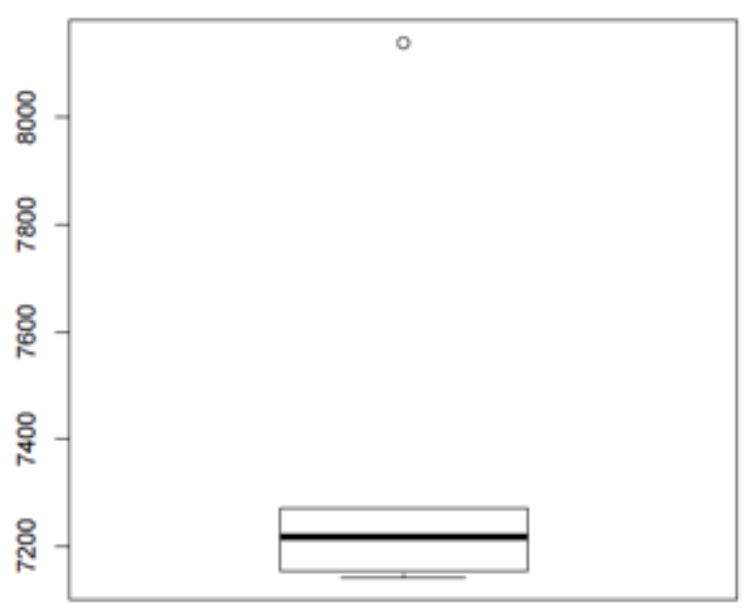

Figura 5.14 - Boxplot do custo de déficit $\left(\$ \times 10^{\wedge 6}\right)$. PMO janeiro/2015 e casos de sensibilidade Fonte: Elaboração própria

\subsubsection{5}

\section{Risco de déficit}

O risco de déficit é o percentual possível do risco de falta de atendimento a carga. Ele pode ser associado ao grau de profundidade da carga, podendo ser um classificado como:

- Qualquer déficit (QQ. déficit) - risco de déficit associado a qualquer profundidade da carga;

- $1,0 \%$ da carga - risco de déficit associado a 1,0\% de profundidade da carga;

- $2,5 \%$ da carga - risco de déficit associado a 2,5\% de profundidade da carga;

- 5,0\% da carga - risco de déficit associado a 5,0\% de profundidade da carga;

- $10 \%$ da carga - risco de déficit associado a $10,0 \%$ de profundidade da carga.

O risco de qualquer déficit do PMO janeiro/2015 registrou valores superiores a $20 \%$ nas regiões Sudeste/Centro-oeste e Sul, devido às condições hidrológicas desfavoráveis e a carga elevada no período, conforme mencionado na seção 4.2.2.1. A consideração de cenários do potencial de geração fotovoltaica residencial reduziu 
o risco de qualquer déficit em até $2 \%$ no Sudeste/Centro-oeste, $4 \%$ no Sul, $2 \%$ no Nordeste e $1 \%$ no Norte. O impacto da geração fotovoltaica residencial no risco de déficit está apresentado nas Figuras 5.15 a 5.20.

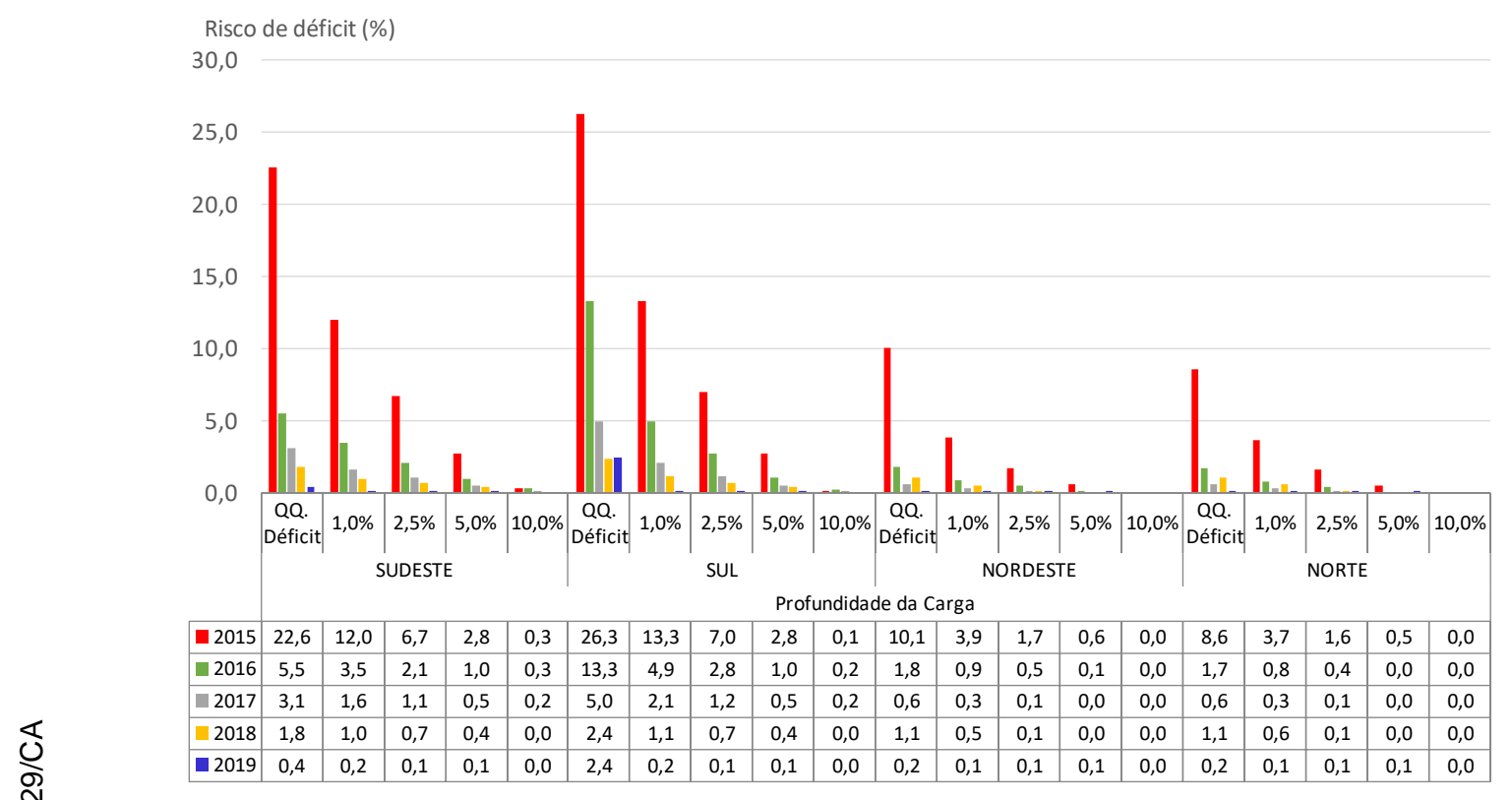

Figura 5.15 - Risco de déficit - PMO janeiro/2015

Fonte: Elaboração própria

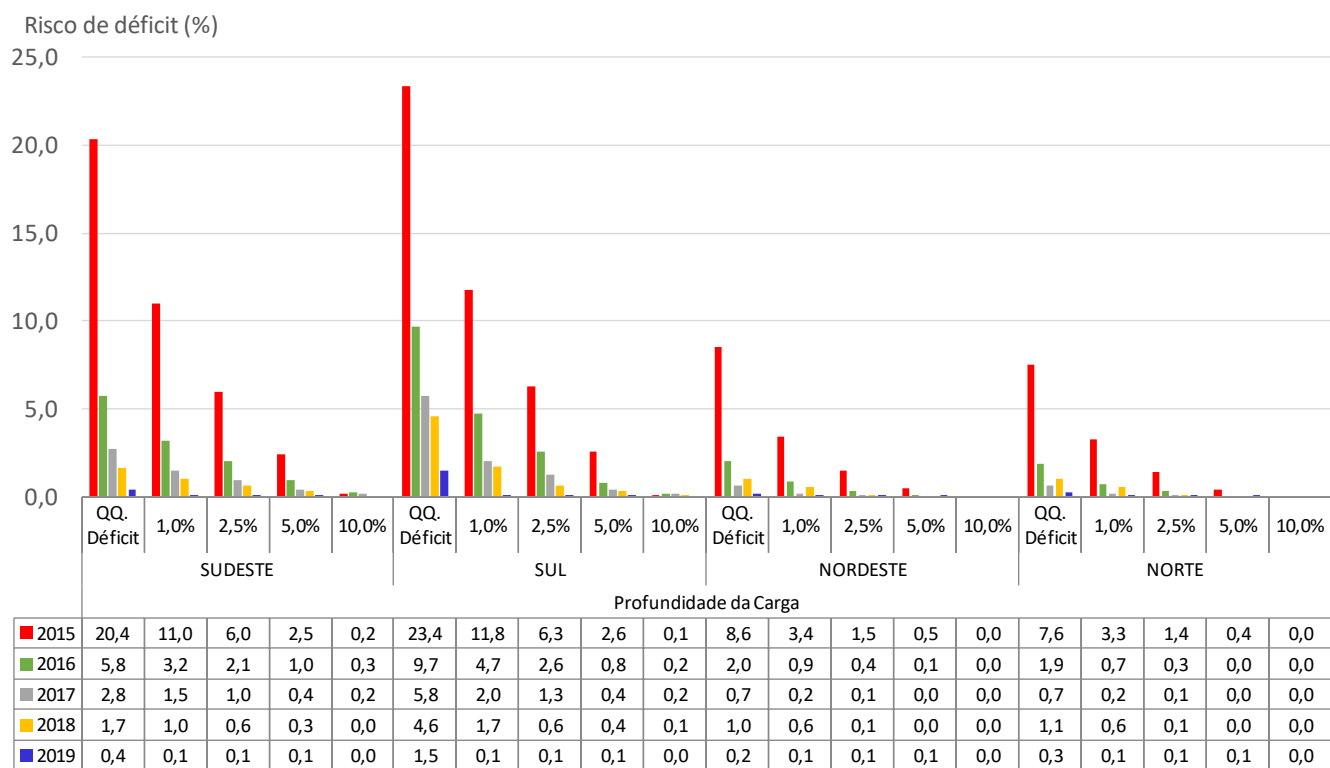

Figura 5.16 - Risco de déficit - caso P5 (Ref. PMO janeiro/2015)

Fonte: Elaboração própria 


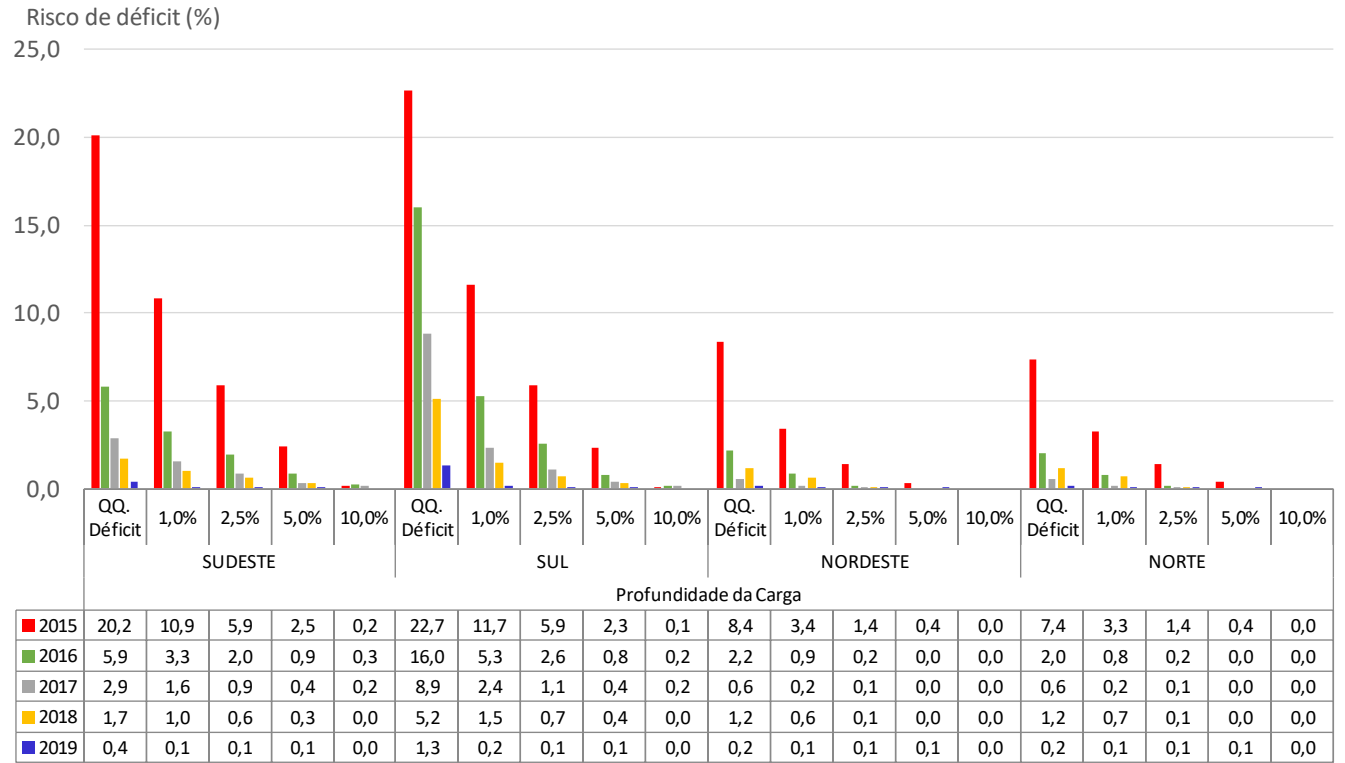

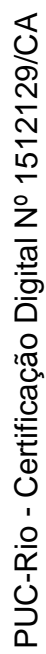

Figura 5.17 - Risco de déficit - caso P25 (Ref. PMO janeiro/2015) Fonte: Elaboração própria

Risco de déficit (\%)

25,0

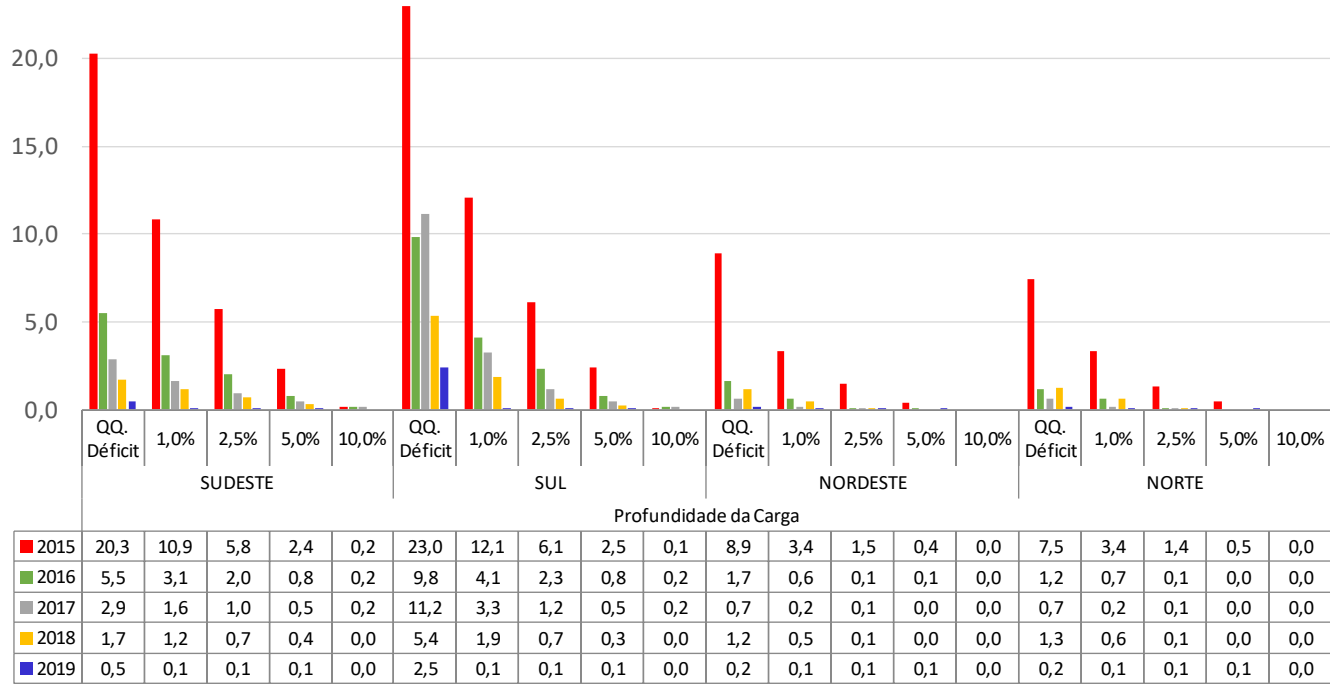

Figura 5.18 - Risco de déficit - caso P50 (Ref. PMO janeiro/2015)

Fonte: Elaboração própria 
Risco de déficit (\%)

25,0

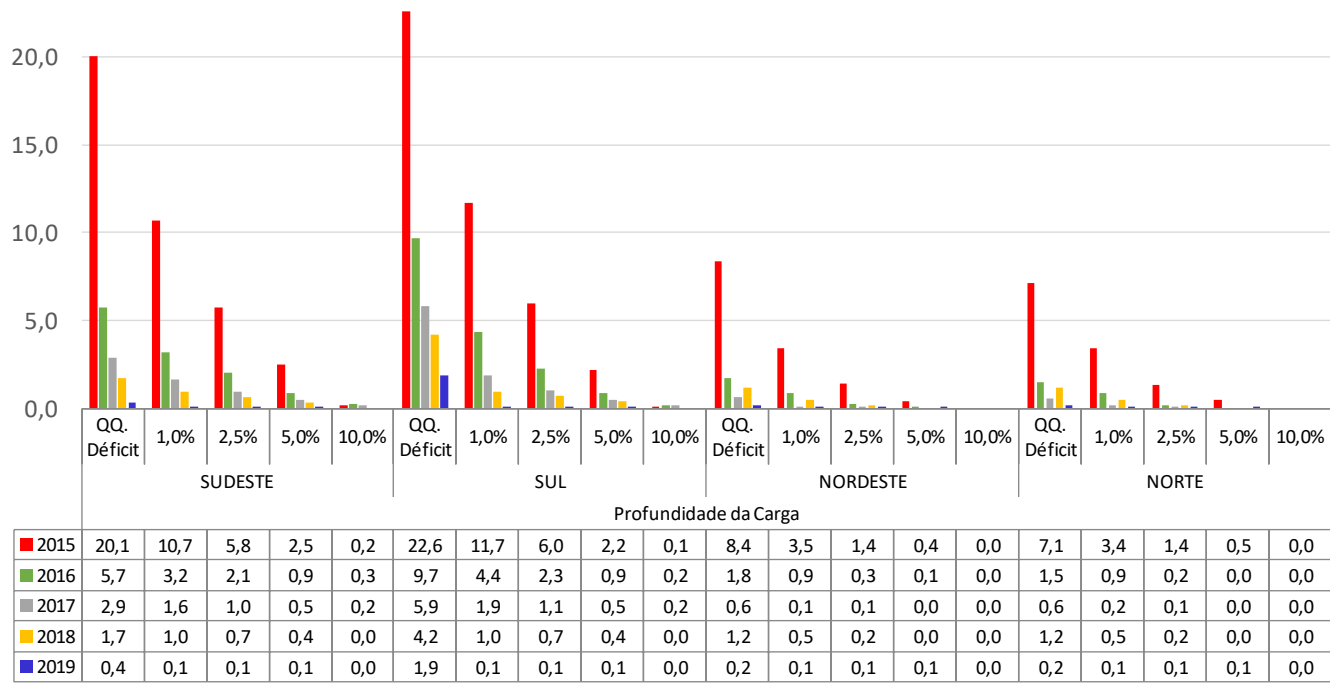

Figura 5.19 - Risco de déficit - caso P75 (Ref. PMO janeiro/2015)

Fonte: Elaboração própria

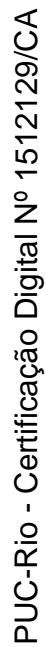

Risco de déficit (\%)

25,0

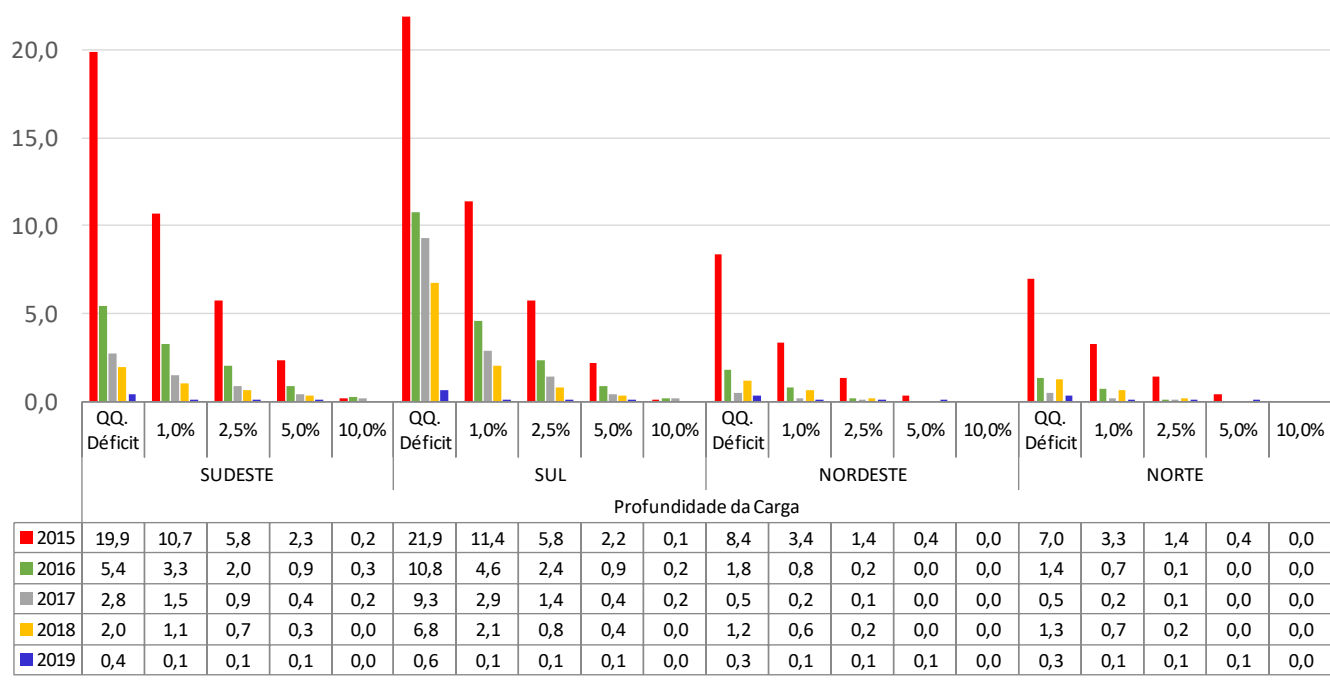

Figura 5.20 - Risco de déficit - caso P95 (Ref. PMO janeiro/2015) Fonte: Elaboração própria 


\subsubsection{6}

\section{Geração hidráulica (GH)}

A geração hidráulica da maioria dos casos de sensibilidade ficou abaixo da geração registrada no caso referência (PMO janeiro/15), com exceção de alguns meses, devido à escolha feita pela decisão de despacho hidrotérmico do modelo, conforme indicado nas Figuras 5.21 a 5.24.

Cabe destacar ainda nessa seção, a marcante sazonalidade da geração hidráulica nos quatro subsistemas equivalentes do SIN. As regiões Sudeste/Centrooeste, Nordeste e Norte são complementadas hidraulicamente pela região Sul, ou seja, no período dezembro a abril, quando são esperados maiores volumes de chuva no Sudeste/Centro-oeste, Nordeste e Norte, a região Sul tende a apresentar menores volumes de chuva. Já no período maio a novembro, quando são esperados maiores volumes de chuva no Sudeste/Centro-oeste, Nordeste e Norte, a região Sul tende a ser mais seca.

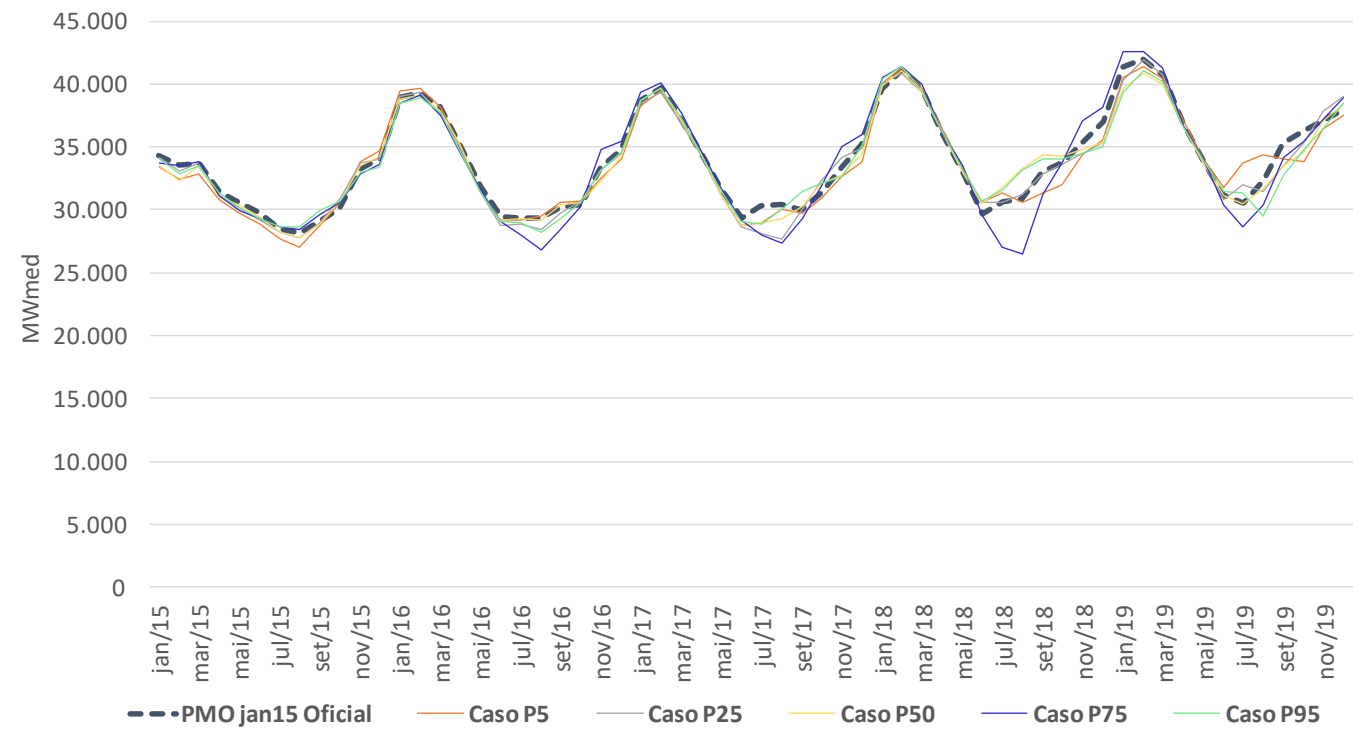

Figura 5.21 - Geração hidráulica (Sudeste/Centro-oeste) - Ref. PMO janeiro/2015 Fonte: Elaboração própria 


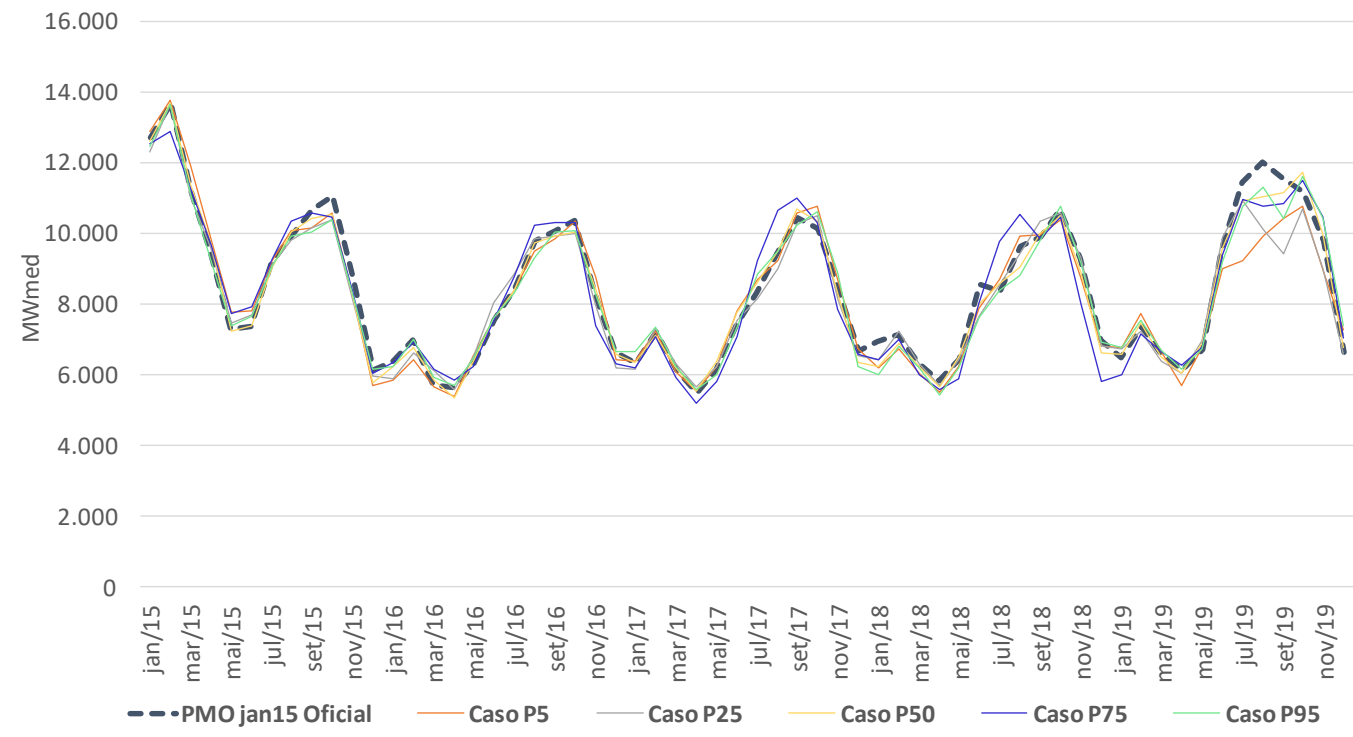

Figura 5.22 - Geração hidráulica (Sul) - Ref. PMO janeiro/2015

Fonte: Elaboração própria

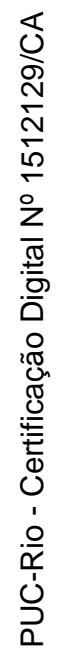

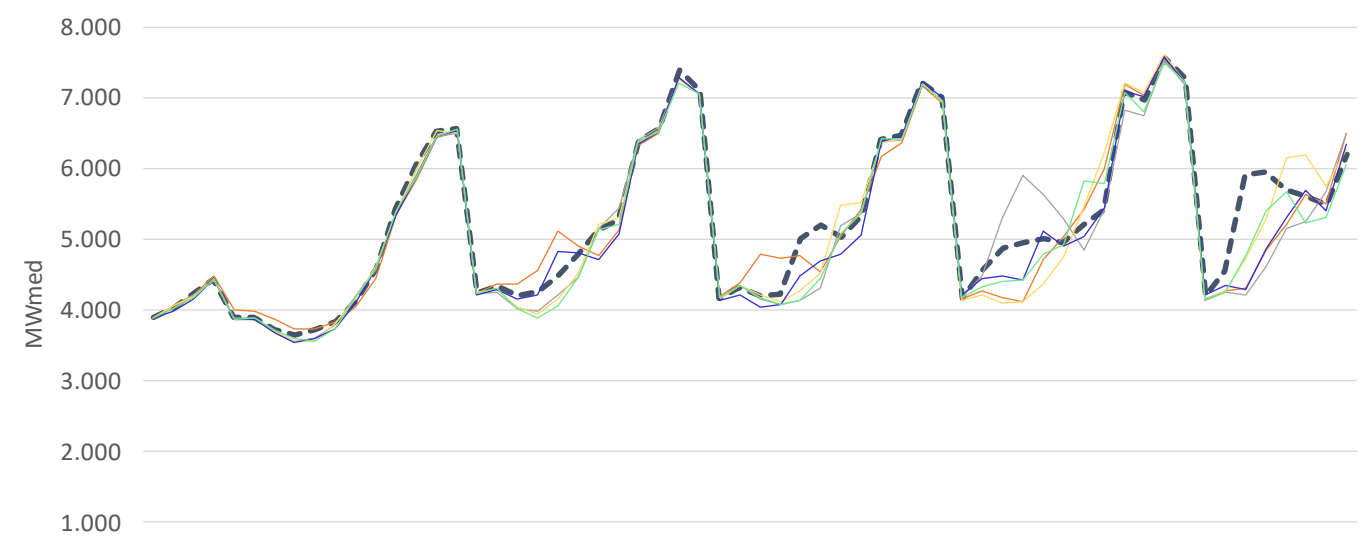

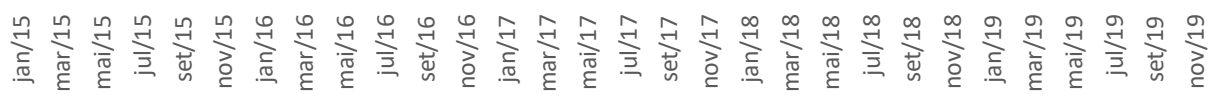

- -PMO jan15 Oficial Caso P5—Caso P25—Caso P50-Caso P75-Caso P95

Figura 5.23 - Geração hidráulica (Nordeste) - Ref. PMO janeiro/2015

Fonte: Elaboração própria 


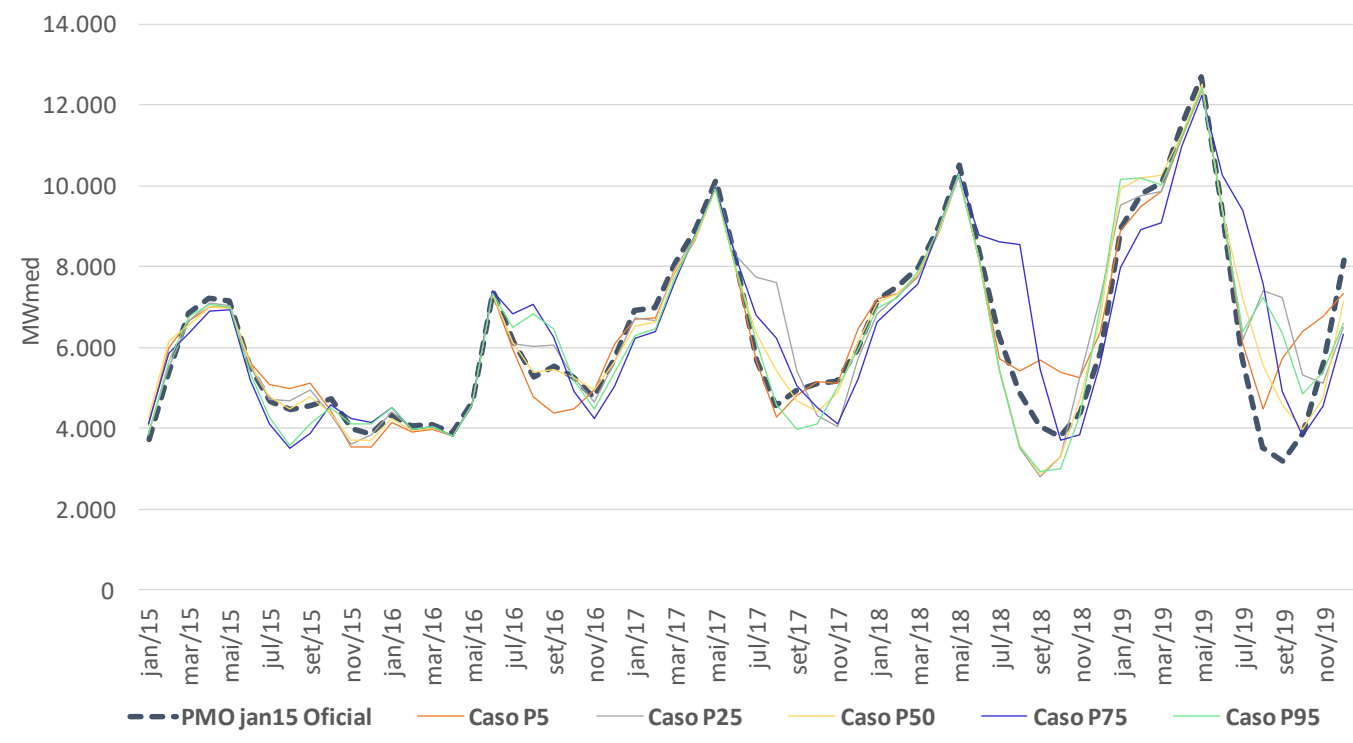

Figura 5.24 - Geração hidráulica (Norte) - Ref. PMO janeiro/2015

Fonte: Elaboração própria

\subsubsection{7 \\ Geração térmica (GT)}

A geração térmica de todos os casos de sensibilidade ficou abaixo da geração registrada no caso referência (PMO janeiro/15). Esse resultado impactou na redução do CMO, conforme visto na seção 5.4.1.2. O comportamento da geração térmica é mostrado nas Figuras 5.25 a 5.28.

São destaques dessa seção a máxima geração térmica nos primeiros meses do período de planejamento (cinco anos) nos subsistemas equivalentes Sudeste/Centro-oeste, Sul e Nordeste, devido às condições energéticas desfavoráveis e a carga elevada, conforme visto na seção 4.2.2.1. Já no subsistema Norte, observou-se uma elevação da geração térmica ao longo dos anos. Esse comportamento da região Norte é explicado pela elevação de geração térmica mínima na região durante o período de planejamento. 


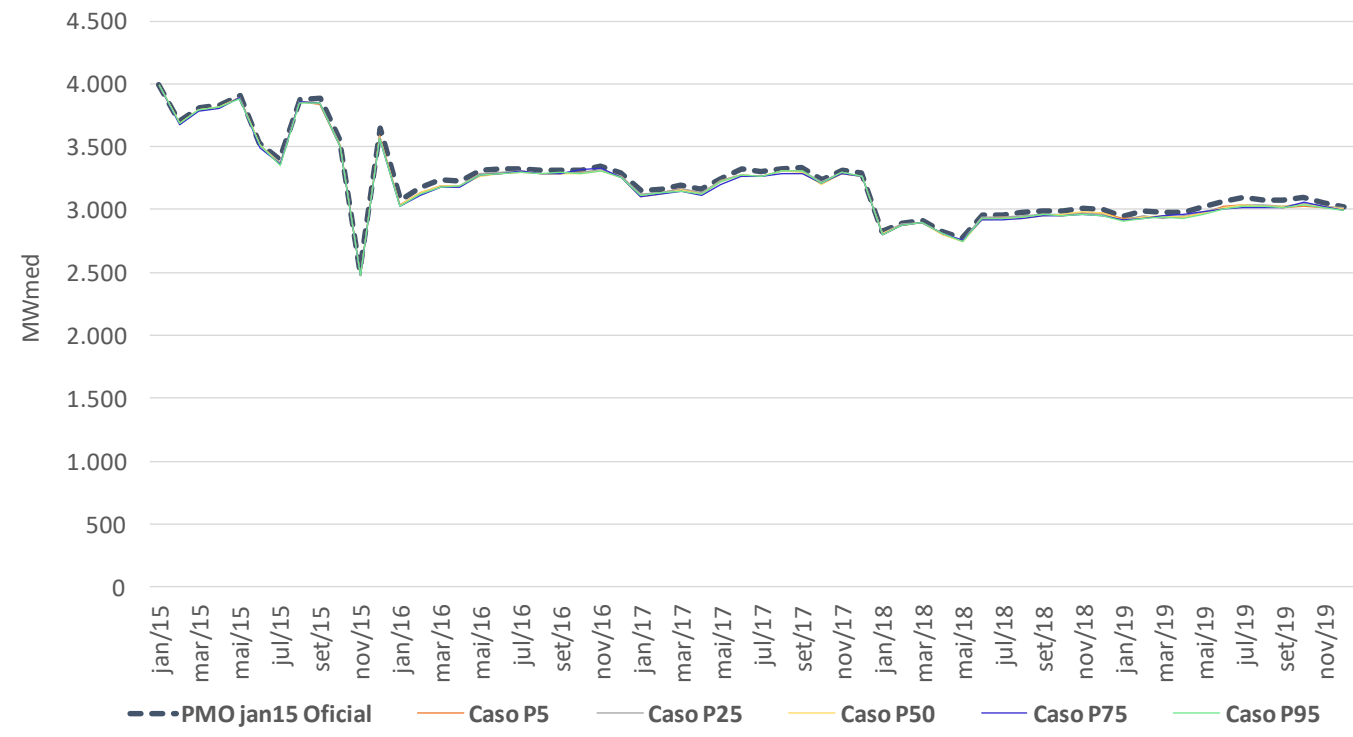

Figura 5.25 - Geração térmica (Sudeste/Centro-oeste) - Ref. PMO janeiro/2015 Fonte: Elaboração própria

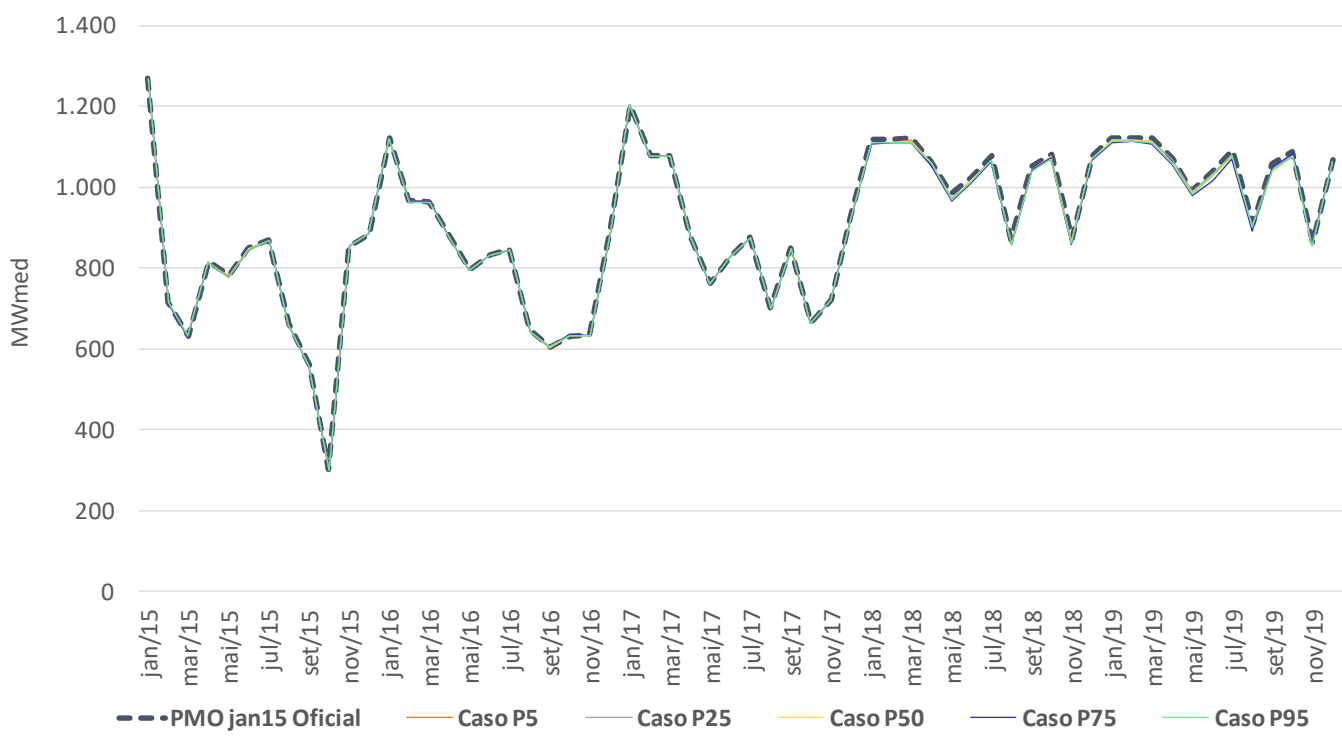

Figura 5.26 - Geração térmica (Sul) - Ref. PMO janeiro/2015

Fonte: Elaboração própria 


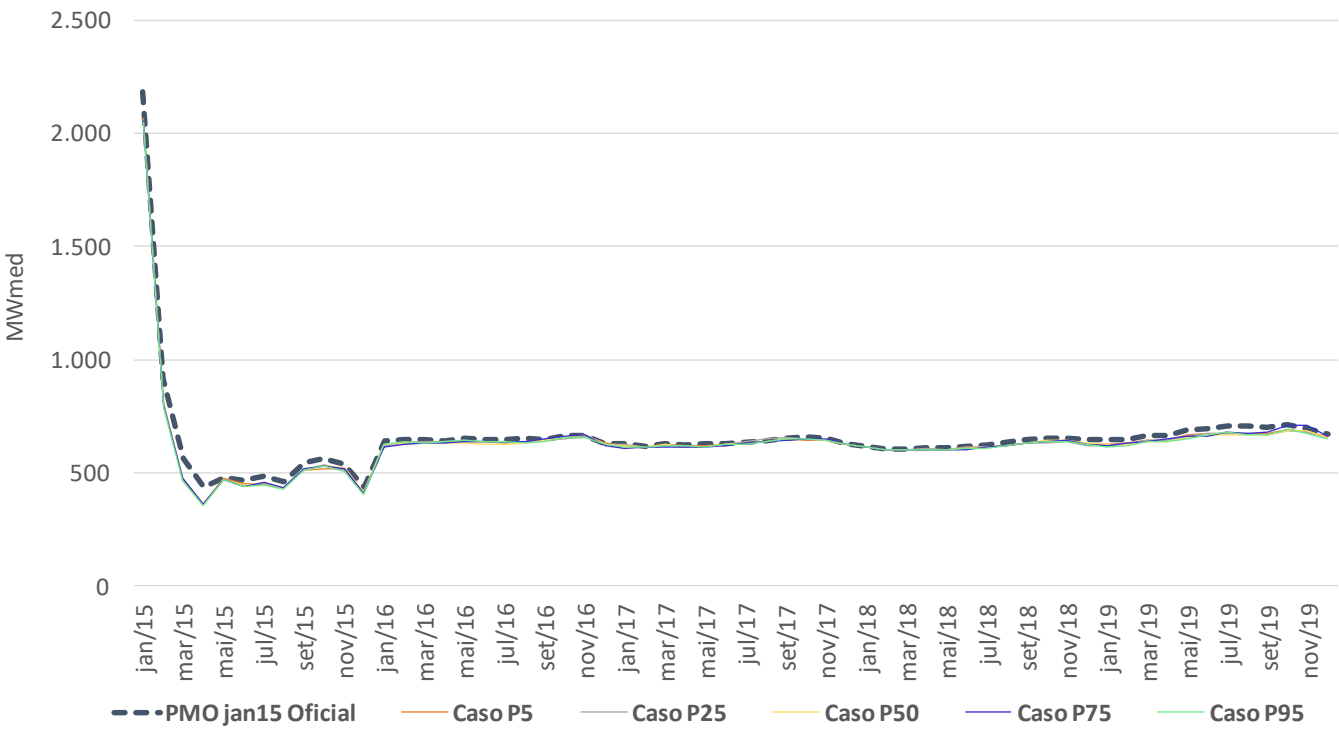

Figura 5.27 - Geração térmica (Nordeste) - Ref. PMO janeiro/2015

Fonte: Elaboração própria

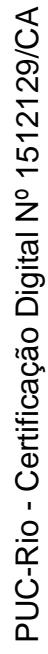

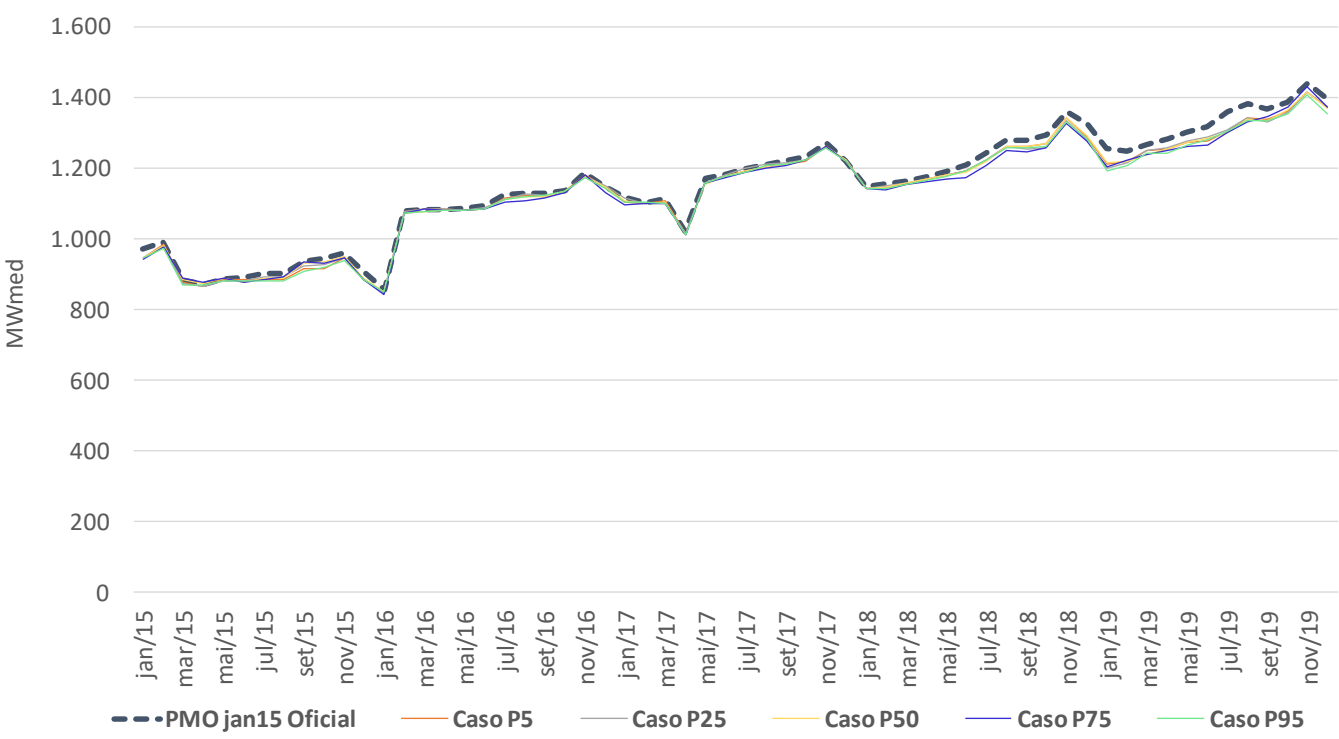

Figura 5.28 - Geração térmica (Norte) - Ref. PMO janeiro/2015

Fonte: Elaboração própria 


\subsubsection{8}

\section{Intercâmbio entre as regiões}

A modelagem energética dos intercâmbios inter-regionais adotada no PMO de janeiro/2015 segue as premissas a seguir:

- Intercâmbios com o Norte: Recebimento do Norte restrito pela necessidade de 5 máquinas sincronizadas na UHE Tucuruí (5 x 240 MW); exportação limitada pela capacidade de escoamento do nó de Imperatriz;

- Intercâmbios Sul-Sudeste/Centro-oeste: Geração típica de Itaipu 60 $\mathrm{Hz}$ abatida do limite elétrico de recebimento pelo Sudeste/Centrooeste;

- Recebimento pelo Nordeste sazonalizado: (jan-jun) Norte fornecedor prioritário; (jul-dez) Sudeste/Centro-oeste fornecedor prioritário;

- Exportação do Nordeste sazonalizado: (jan-ago) Sudeste/Centrooeste recebedor prioritário; (set-dez) Norte recebedor prioritário;

- Intercâmbios Sudeste/Centro-oeste - Nordeste - Imperatriz: Limites elétricos de intercâmbio Sudeste/Centro-oeste $\leftrightarrow$ Nordeste, Nordeste $\leftrightarrow$ Imperatriz e Sudeste/Centro-oeste $\leftrightarrow$ Imperatriz;

- Limites de exportação e recebimento do Nordeste, de exportação do Sudeste/Centro-oeste para o Norte/Nordeste e de exportação de Imperatriz para o Sudeste/Centro-oeste e Nordeste.

Os intercâmbios respeitam os fluxos bidirecionais listados abaixo. Quando a ordem desses fluxos é inversa, o sinal fica negativo.

- Sudeste/Centro-oeste para Sul;

- Sudeste/Centro-oeste para Nordeste; 
- Sudeste/Centro-oeste para nó-fictício (imperatriz);

- Nordeste para nó-fictício (imperatriz);

- Norte para nó-fictício (imperatriz).

O nó-fictício (imperatriz) representa o ponto de intercâmbio do fluxo de energia entre o Sudeste/Centro-oeste, Nordeste e Norte, ou seja, através desse nó fictício a região Sudeste/Centro-oeste pode enviar energia ao Norte e Nordeste assim como receber energia dessas regiões, conforme apresentado pela Figura 5.29.

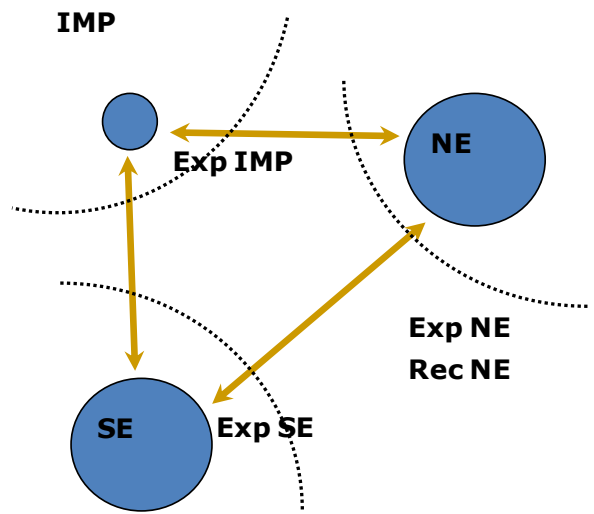

Figura 5.29 - Fluxo de intercâmbio Sudeste/Centro-oeste - nó-fictício - Nordeste Fonte: (ONS, 2015)

Cabe ressaltar que em nenhum dos casos gerados houve mudança de sentido do intercâmbio anual. As alterações percebidas são somente relacionadas ao montante de energia enviado de uma região para outra. É importante destacar ainda que, em todos os fluxos de intercâmbio o sentido de envio da energia foi mantido para todo o horizonte de planejamento. A região Sudeste/Centro-oeste foi exportadora de energia para a região Sul e importou energia da região Nordeste e Norte (através do nó-fictício). Apesar dos baixos níveis dos reservatórios do Nordeste e Norte nesse período, a política de intercâmbio priorizou o envio de energia para a região Sudeste/Centro-oeste, uma vez que a carga do Nordeste/Norte é bastante inferior quando comparada com a região importadora.

A sequência de Figuras a seguir (Figura 5.30 a Figura 5.34) ilustra o comportamento da política de intercâmbio do caso referência (PMO janeiro/2015) e dos casos de sensibilidade, considerando os cenários do potencial de geração fotovoltaica residencial. 


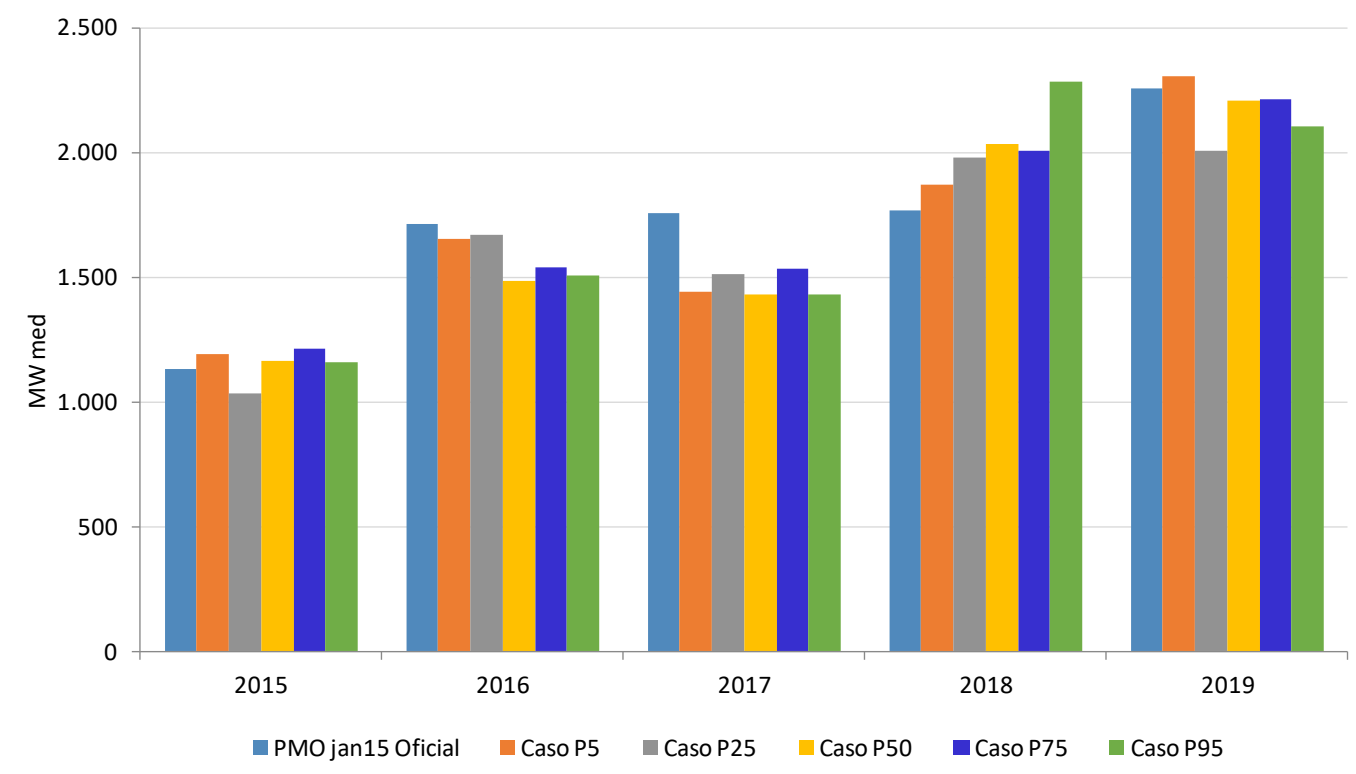

Figura 5.30 - Intercâmbio Sudeste para Sul (Ref. PMO janeiro/2015) Fonte: Elaboração própria

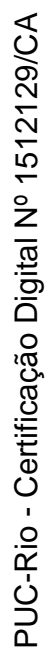

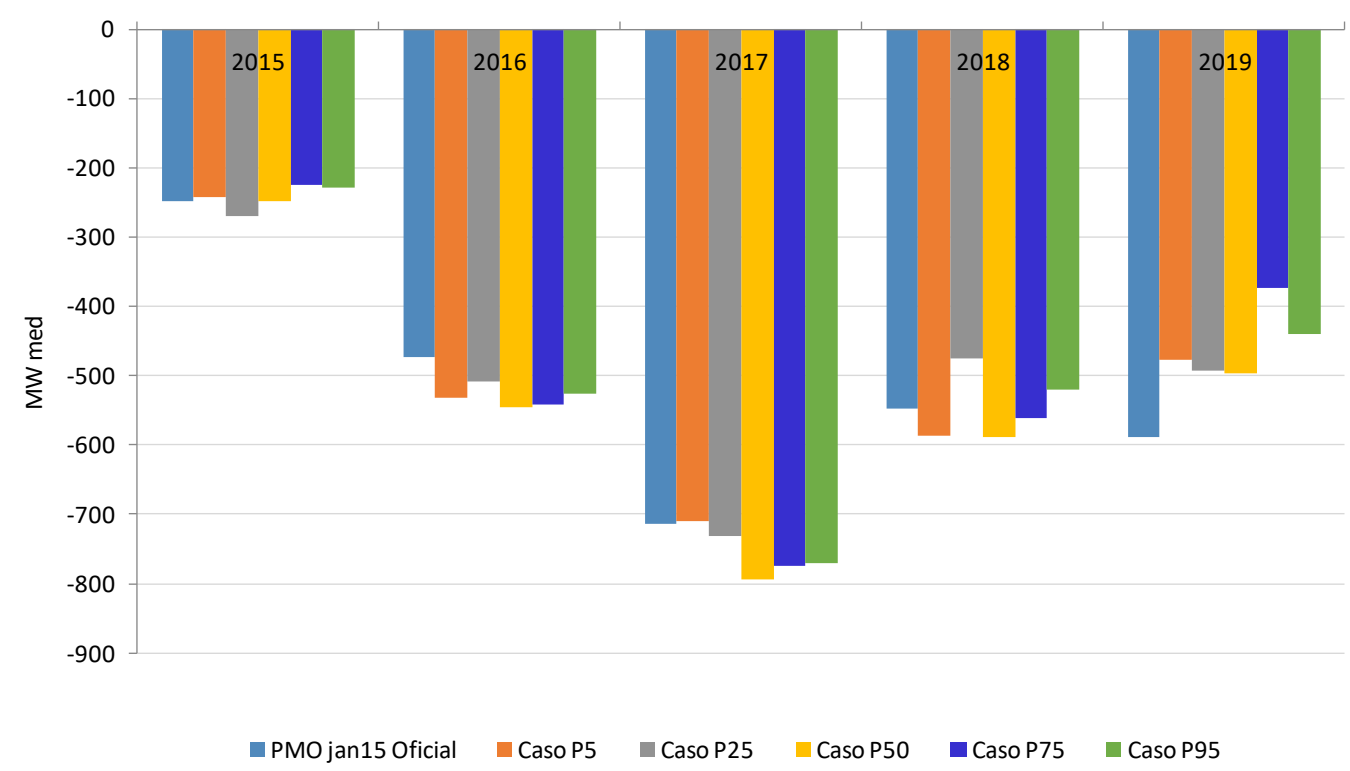

Figura 5.31 - Intercâmbio Sudeste para Nordeste (Ref. PMO janeiro/2015) Fonte: Elaboração própria 


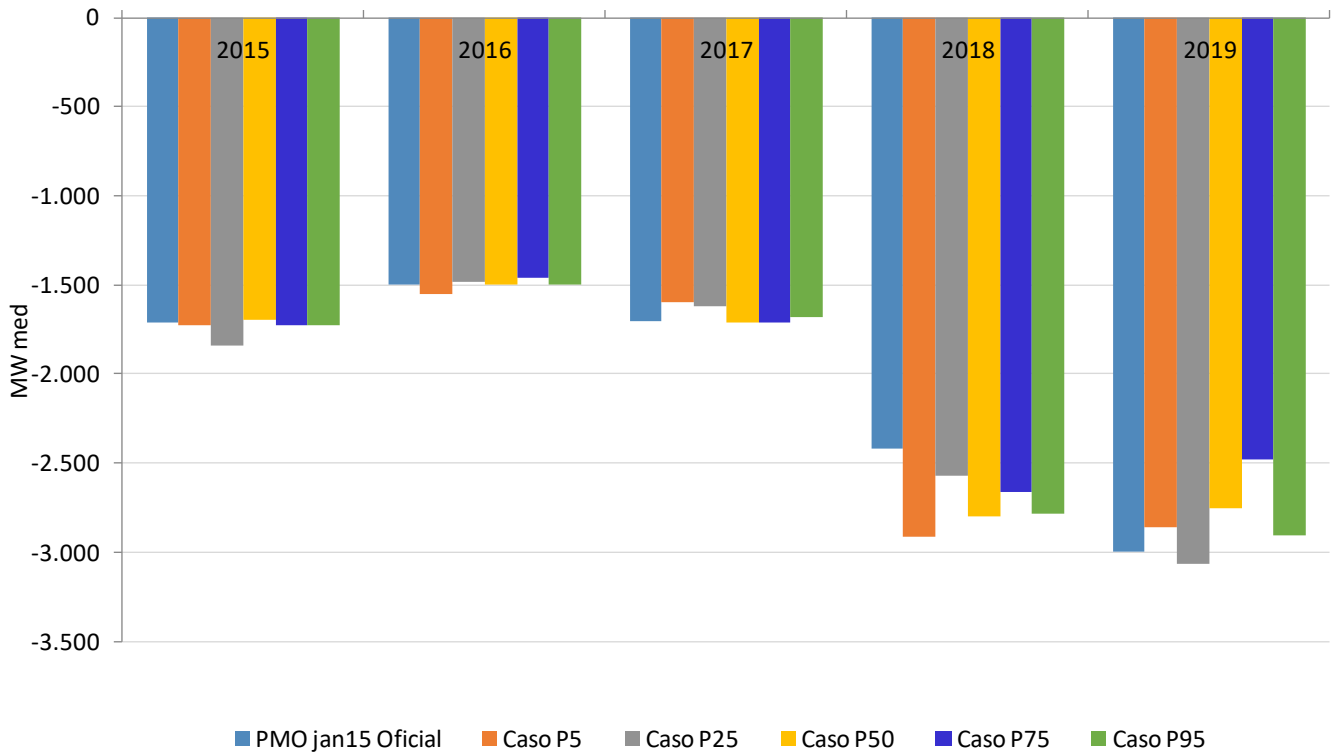

Figura 5.32 - Intercâmbio Sudeste para nó-fictício (Ref. PMO janeiro/2015)

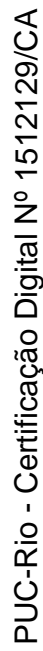

Fonte: Elaboração própria

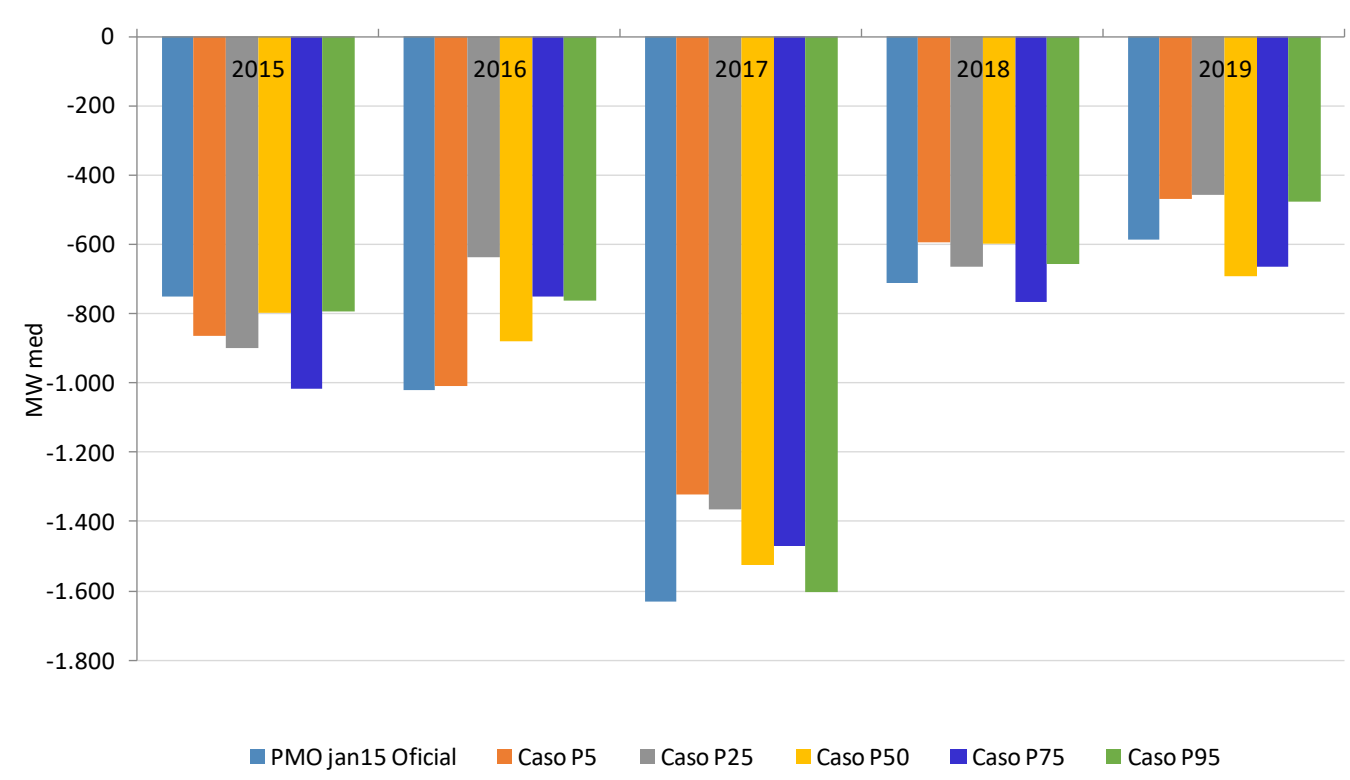

Figura 5.33 - Intercâmbio Nordeste para nó-fictício (Ref. PMO janeiro/2015) Fonte: Elaboração própria 


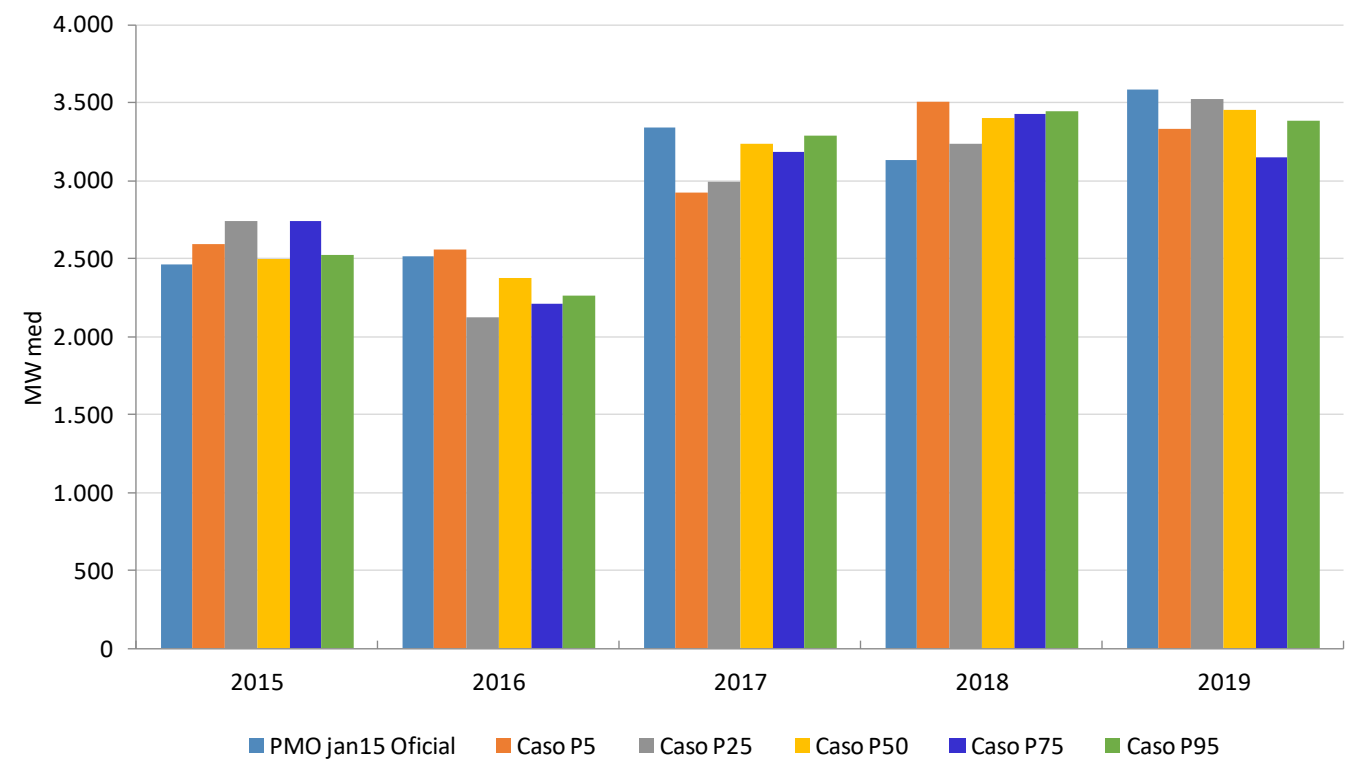

Figura 5.34 - Intercâmbio Norte para nó-fictício (Ref. PMO janeiro/2015) Fonte: Elaboração própria

\subsubsection{9 \\ Custo de vertimento}

O vertimento corresponde ao desperdício do recurso hídrico na geração de energia elétrica, ou seja, é a parcela da água que não é turbinada pela unidade geradora e que, por conseguinte, não gera energia elétrica. Os custos associados aos vertimentos variam pouco com a consideração do potencial de geração fotovoltaica residencial. A variação máxima ocorrida elevou os custos de vertimento em $0,02 \$$ $\wedge 10^{6}$ no caso P95, conforme Tabela 5.13.

Tabela 5.13 - Custo do vertimento e desvio-padrão $\left(\$ \wedge 10^{6}\right)$ - Ref. PMO janeiro/2015

\begin{tabular}{lcc}
\hline Casos Newave & Vertimento $\left(\mathbf{\$} \wedge \mathbf{1 0}^{\mathbf{6}}\right)$ & Desvio padrão $\left(\mathbf{\$} \mathbf{1} \mathbf{0}^{\mathbf{6}}\right)$ \\
\hline PMO jan15 Oficial & 1 & 0 \\
Caso P5 & 1 & 0 \\
Caso P25 & 1 & 0 \\
Caso P50 & 1 & 0 \\
Caso P75 & 1 & 0 \\
Caso P95 & 1 & 0 \\
\hline
\end{tabular}

Fonte: Elaboração própria 
A Figura 5.35 indica que na variável custo de vertimento não houve outlier e que nesse caso as regiões Q2 e Q3 se sobrepõe, ou seja, que a mediana e o terceiro quartil, respectivamente, são bem próximos, indicando variação ínfima e/ou nula entre os casos.

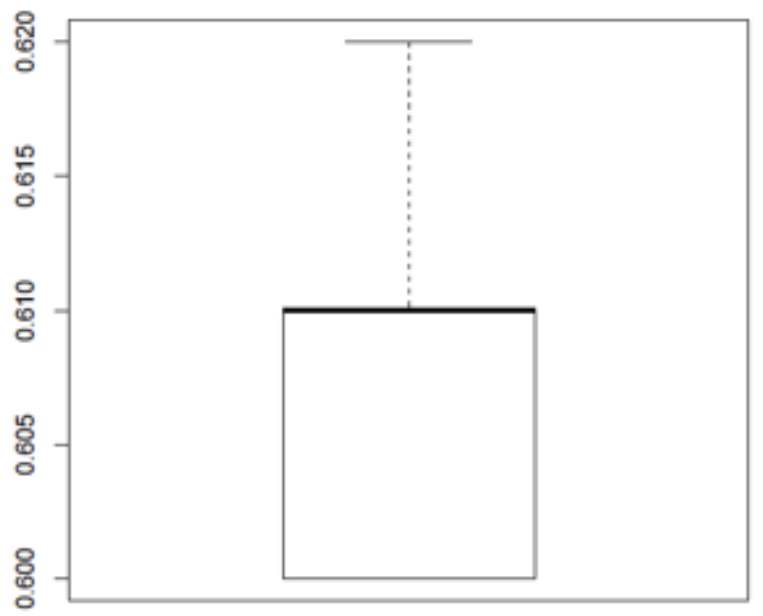

\footnotetext{
Figura 5.35 - Boxplot do custo de vertimento $\left(\$ \times 10^{\wedge 6}\right)$. PMO janeiro/2015 e casos de sensibilidade Fonte: Elaboração própria
}

\section{4 .2}

\section{PMO janeiro/2016}

\subsubsection{1}

\section{Custo total da operação (CTO)}

Como no PMO janeiro/2016 a carga global de energia já era bastante reduzida quando comparada a carga do PMO janeiro/2015, os resultados das simulações ficaram ainda mais semelhantes que o observado na seção 5.4.1, conforme apresentado na Tabela 5.14. Observou-se também, que no caso P75 o custo total da operação ultrapassou o caso referência (PMO janeiro/2016), sendo classificado como um resultado pouco intuitivo. No entanto, cabe destacar que nesse caso os custos de violação de evaporação mínima e violação de geração hidráulica mínima foram maiores que os custos do caso referência (PMO janeiro/2016), em 3\% e 82\%, 
respectivamente. A elevação dos custos obtidos na otimização do caso P75 explicam os resultados.

Tabela 5.14 - Custo total da operação e desvio-padrão $\left(\$ \wedge 10^{6}\right)$ - Ref. PMO janeiro/2016

\begin{tabular}{lcc}
\hline Casos Newave & Custo total da operação $(\mathbf{\$} \mathbf{1 0})$ & Desvio padrão $\left(\mathbf{\$} \wedge \mathbf{1 0}^{\mathbf{6}}\right)$ \\
\hline PMO jan16 Oficial & 31.511 & 754 \\
Caso P5 & 31.273 & 735 \\
Caso P25 & 31.165 & 737 \\
Caso P50 & 31.357 & 743 \\
Caso P75 & 32.080 & 747 \\
Caso P95 & 31.044 & 737 \\
\hline
\end{tabular}

Fonte: Elaboração própria

A Figura 5.36 indica que o custo total de operação do PMO janeiro/2016 é um outlier quando comparado aos casos de sensibilidade e que os casos apresentam dispersão bastante baixa, conforme indica a amplitude interquartílica Q1 e Q3.

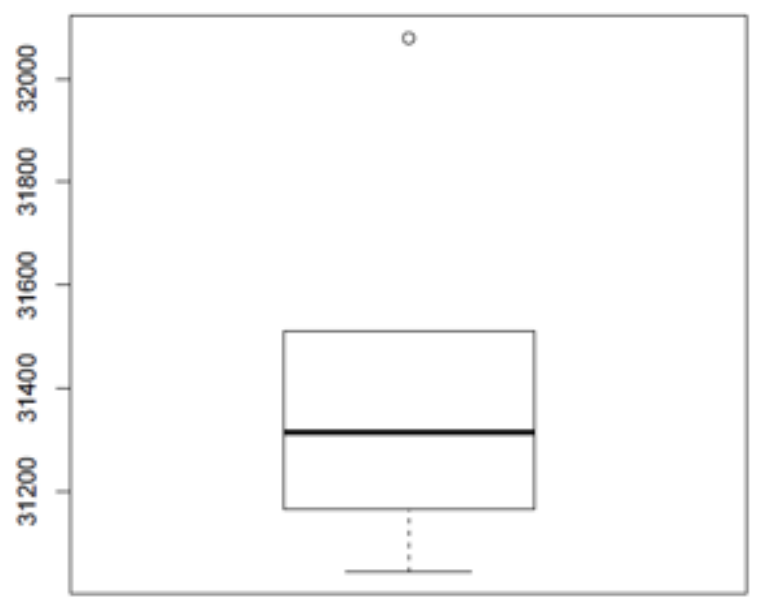

Figura 5.36 - Boxplot do custo de total de operação $\left(\$ \times 10^{\wedge 6}\right)$. PMO janeiro/2016 e casos de sensibilidade

Fonte: Elaboração própria 


\subsubsection{2}

\section{Custo marginal de operação (CMO)}

O PMO de janeiro/2016 apresentou custos marginais de operação bem menores que os custos do PMO janeiro/2015. As condições hidrológicas do reservatório equivalente Sudeste/Centro-Oeste, no PMO janeiro/2016, apresentou melhora de aproximadamente 10\% quando comparadas ao PMO de janeiro/2015. Além disso, a carga global de energia era bastante inferior àquela utilizada no PMO janeiro/2015, conforme visto na seção 4.2.2.1. A consideração do potencial de geração fotovoltaica residencial nesse PMO janeiro/2016 também proporcionou redução do custo marginal de operação em todos os quatro subsistemas equivalentes do SIN, com redução máxima de aproximadamente $\mathrm{R} \$ 14 / \mathrm{MWh}$ nas regiões Sudeste/Centro-oeste, Sul e Nordeste e R\$11/MWh na região Norte. Todas as reduções máximas ocorreram no caso de sensibilidade P95 (2016). O efeito da geração fotovoltaica no CMO pode ser observado na sequência de Figuras abaixo (Figura 5.37 a Figura 5.40).

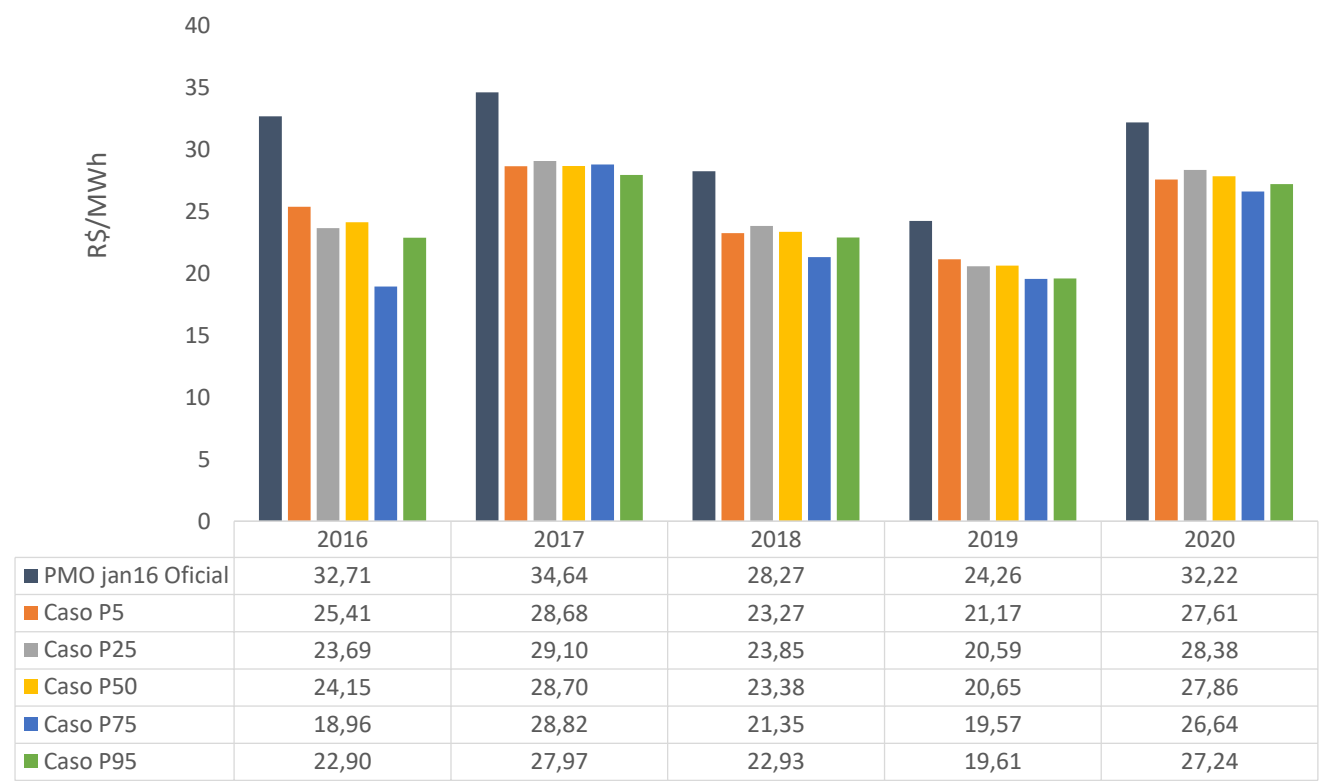

Figura 5.37 - Custo marginal de operação (Sudeste). PMO janeiro/2016 e casos de sensibilidade Fonte: Elaboração própria 


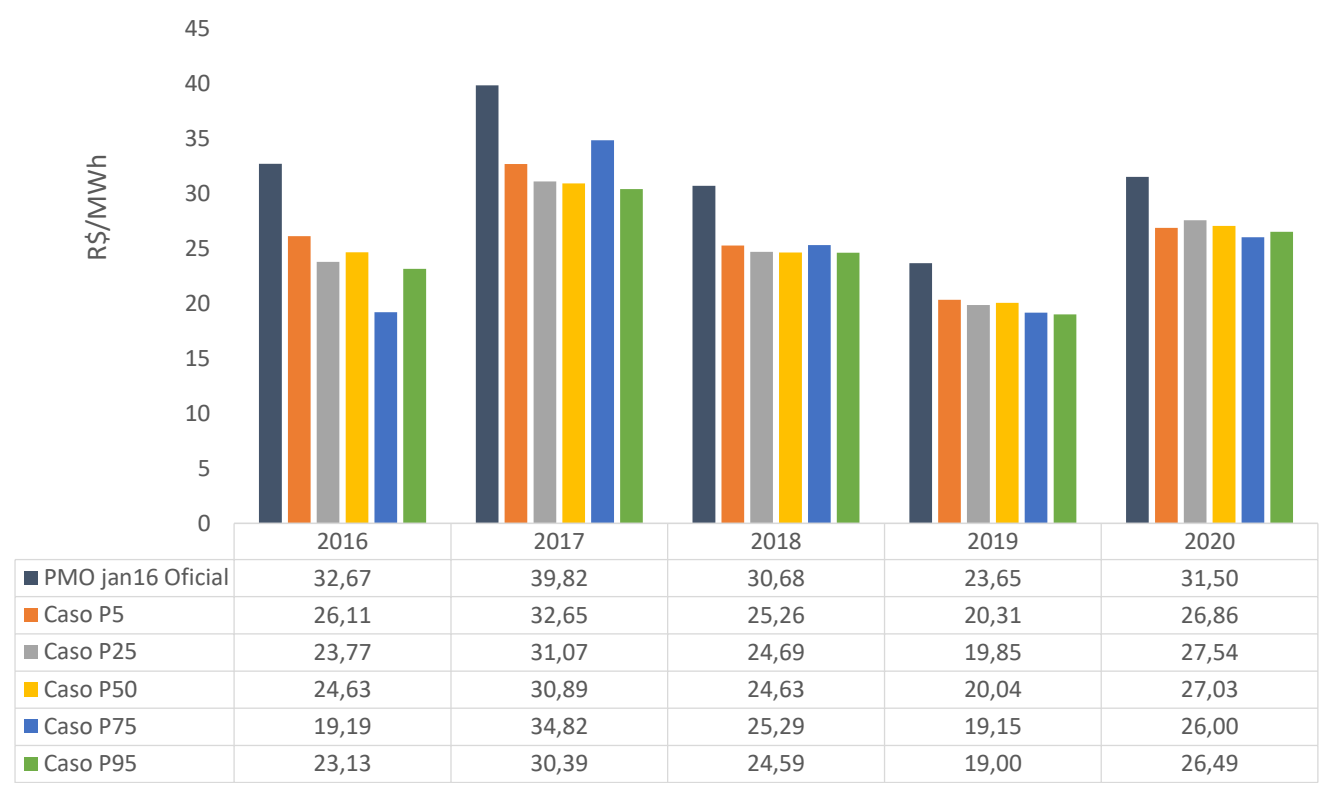

Figura 5.38 - Custo marginal de operação (Sul). PMO janeiro/2016 e casos de sensibilidade Fonte: Elaboração própria

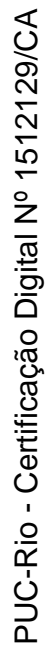

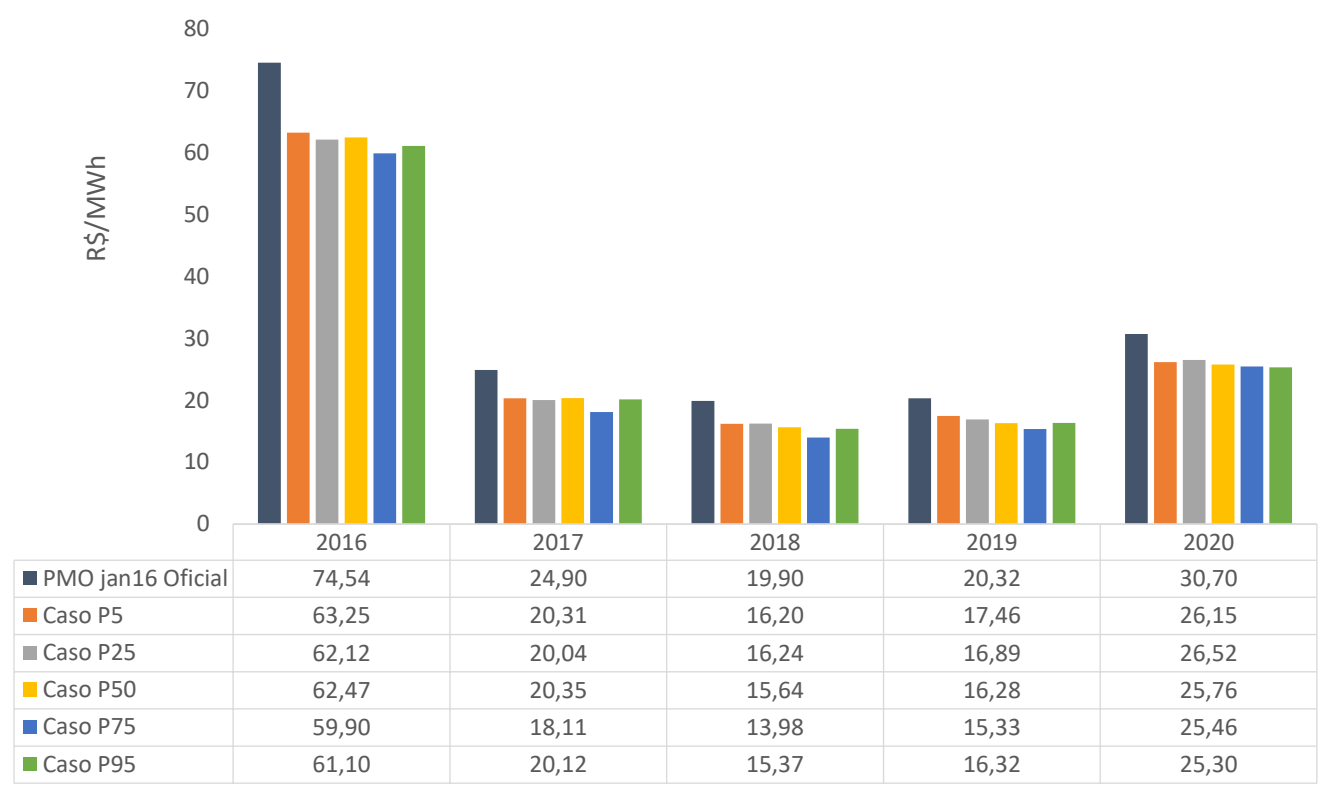

Figura 5.39 - Custo marginal de operação (Nordeste). PMO janeiro/2016 e casos de sensibilidade Fonte: Elaboração própria 


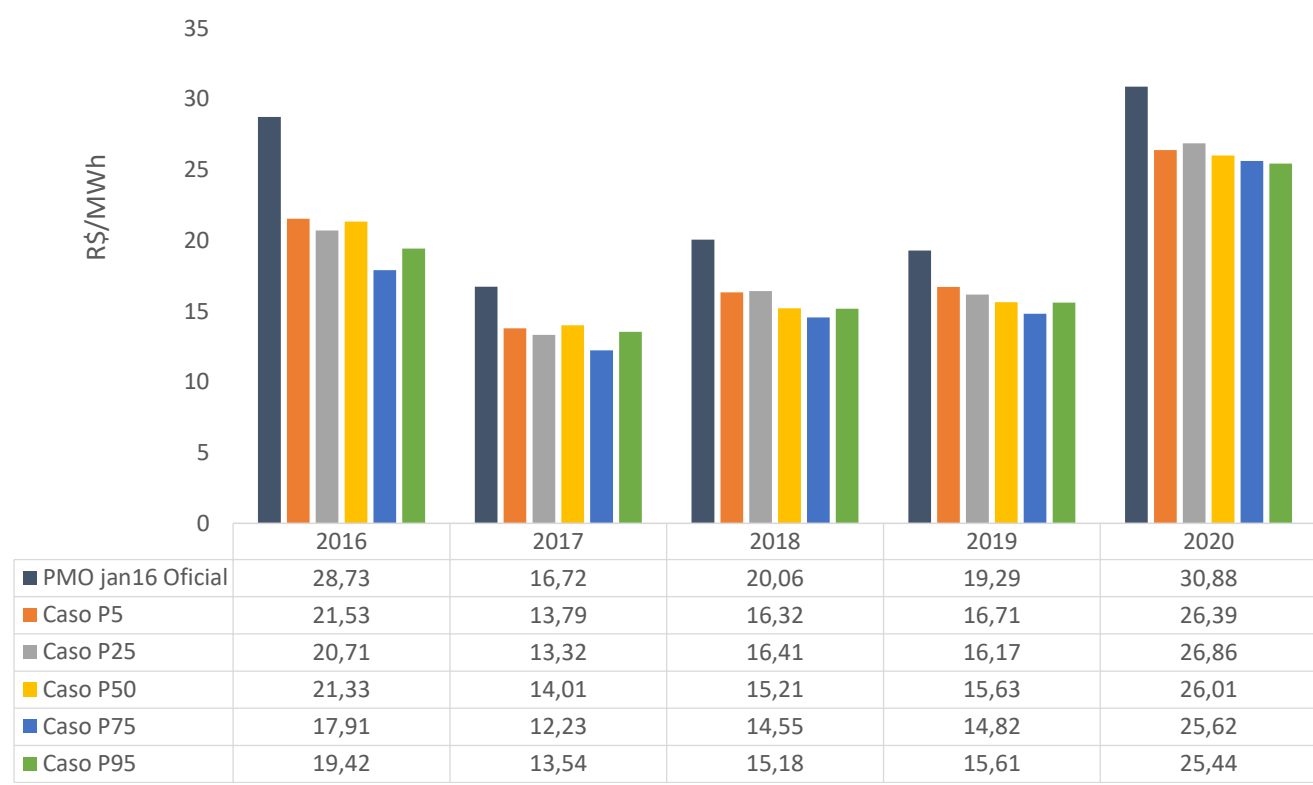

Figura 5.40 - Custo marginal de operação (Norte). PMO janeiro/2016 e casos de sensibilidade Fonte: Elaboração própria

\subsubsection{3 \\ Energia armazenada}

A energia armazenada inicial do SIN considerada pelo modelo Newave para o PMO janeiro/2016 foi de 29\%, $8 \%$ maior que a do PMO janeiro/2015. A consideração do potencial de geração fotovoltaica também contribuiu pouco para alcançar níveis de reservatórios equivalentes mais expressivos que os níveis alcançados pelo PMO janeiro/2016, conforme apresentado na Figura 5.41. Contudo, nesse PMO a carga global de energia a ser atendida era menor que a carga do PMO janeiro/2015, logo, a energia armazenada do SIN tende a ser maior no PMO janeiro/2016. A máxima contribuição da geração fotovoltaica na energia armazenada do SIN se deu no caso P5, registrando 1,3\% de aumento da energia armazenada no final de novembro/2017. 


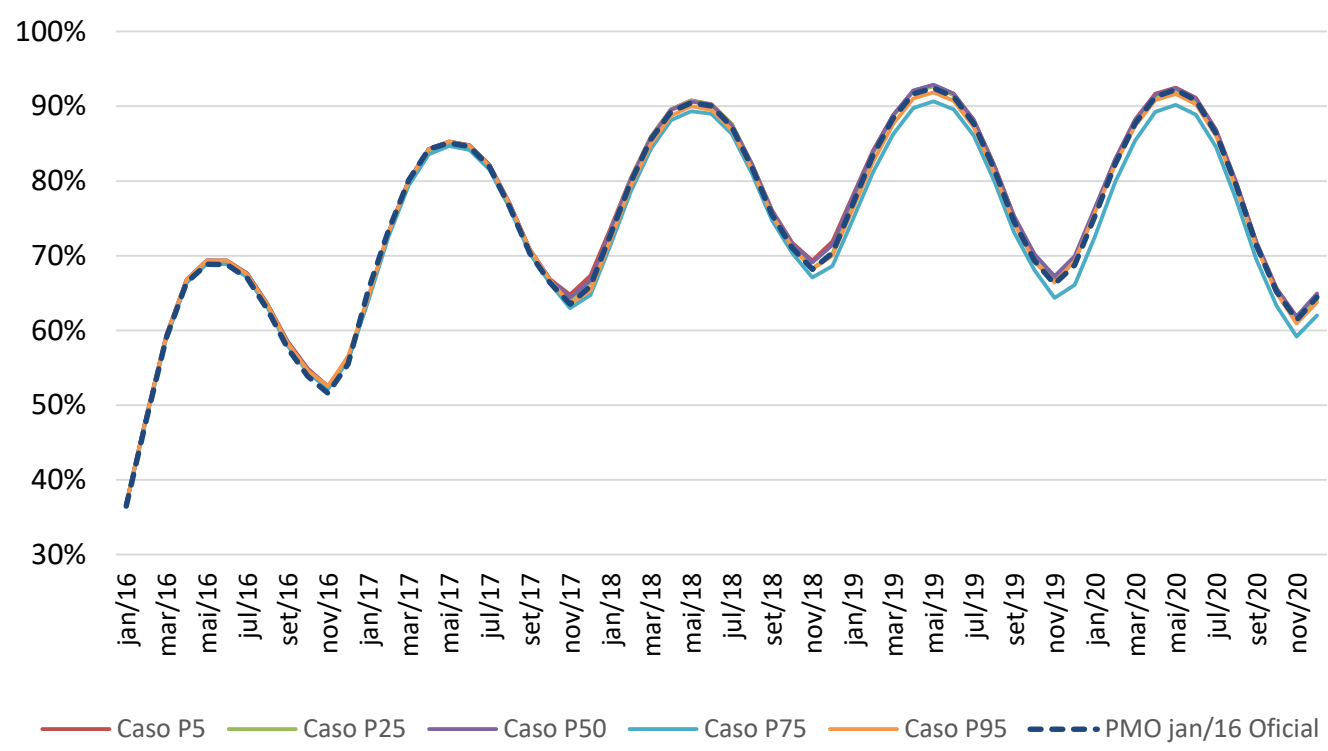

Figura 5.41 - Evolução do armazenamento do SIN - Ref. PMO janeiro/2016 Fonte: Elaboração própria

\subsubsection{4 Custo de déficit}

A Tabela 5.15 apresenta o custo de déficit do horizonte de planejamento (cinco anos) e o desvio padrão referente a esse custo. Ao considerar os cenários do potencial de geração fotovoltaica residencial no planejamento da operação de médio prazo, o custo de déficit reduziu expressivamente quando comparado ao caso de referência (PMO janeiro/2016), registrando máxima redução de 19\% no caso $\mathrm{P} 25$.

Tabela 5.15 - Custo de déficit e desvio-padrão $\left(\$ \wedge 10^{6}\right)$ - Ref. PMO janeiro/2016

\begin{tabular}{lcc}
\hline Casos Newave & Custo de déficit $\left(\mathbf{\$} \mathbf{\wedge} \mathbf{1 0}^{\mathbf{6}}\right)$ & Desvio padrão $\left(\mathbf{\$} \mathbf{\wedge} \mathbf{1 0}^{\mathbf{6}}\right)$ \\
\hline PMO jan16 Oficial & 824 & 170 \\
Caso P5 & 759 & 159 \\
Caso P25 & 694 & 154 \\
Caso P50 & 768 & 162 \\
Caso P75 & 806 & 151 \\
Caso P95 & 744 & 157 \\
\hline
\end{tabular}

Fonte: Elaboração própria 
A Figura 5.42 indica que na variável custo de déficit não houve outlier quando comparado e que os casos apresentam dispersão bastante baixa, conforme indica a amplitude interquartílica Q1 e Q3.

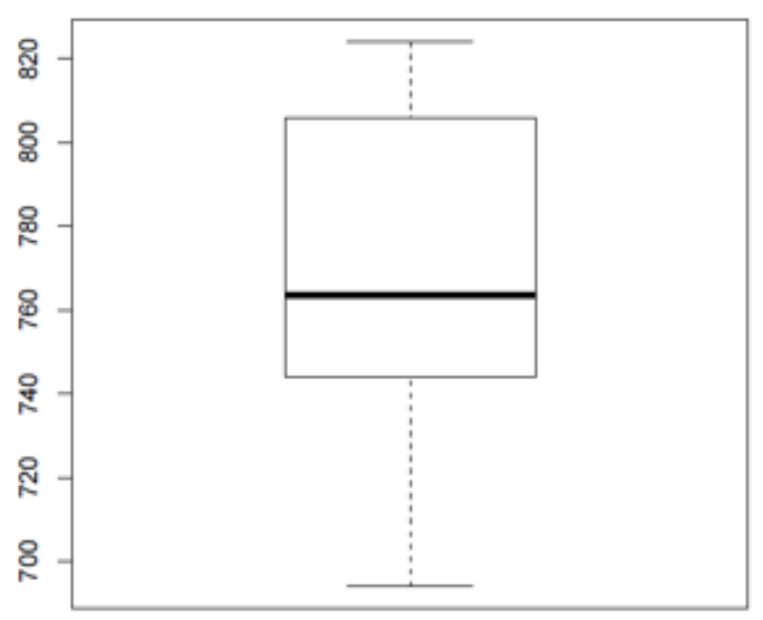

Figura 5.42 - Boxplot do custo de déficit $\left(\$ \times 10^{\wedge 6}\right)$. PMO janeiro/2016 e casos de sensibilidade Fonte: Elaboração própria

\subsubsection{5}

\section{Risco de déficit}

Conforme visto na seção 5.4.1.5, os riscos de déficit correspondem ao risco de não atendimento por profundidade da carga. $\mathrm{O}$ risco de qualquer déficit do PMO janeiro/2016 foi abaixo de 5\% para todos os subsistemas equivalentes do SIN, durante todo o horizonte de planejamento, diferente do observado no PMO janeiro/2015. Conforme visto na seção 4.2.2.1, as condições hidrológicas e o montante de carga global de energia em 2016 proporcionaram resultados menos negativos que àqueles observados no PMO janeiro/2015.

A consideração de cenários do potencial de geração fotovoltaica residencial no PMO janeiro/2016 reduziu o risco de déficit, aproximadamente, em $0,5 \%$ no Sudeste/Centro-oeste (2017) e 1,0\% no Sul (2017). Os riscos de déficit são mostrados na sequência de Figuras a seguir (Figura 5.43 a Figura 5.48). 


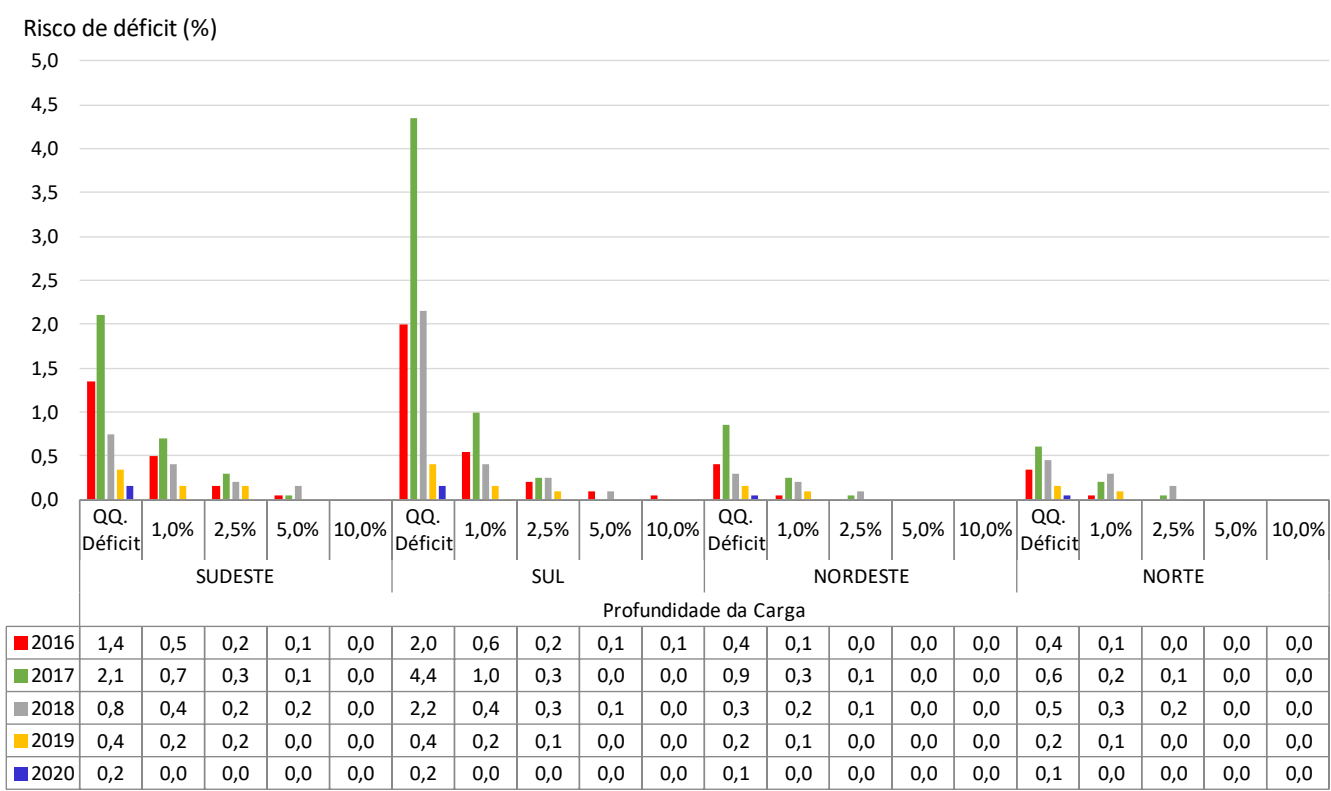

Figura 5.43 - Risco de déficit - PMO janeiro/2016

Fonte: Elaboração própria

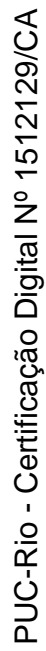

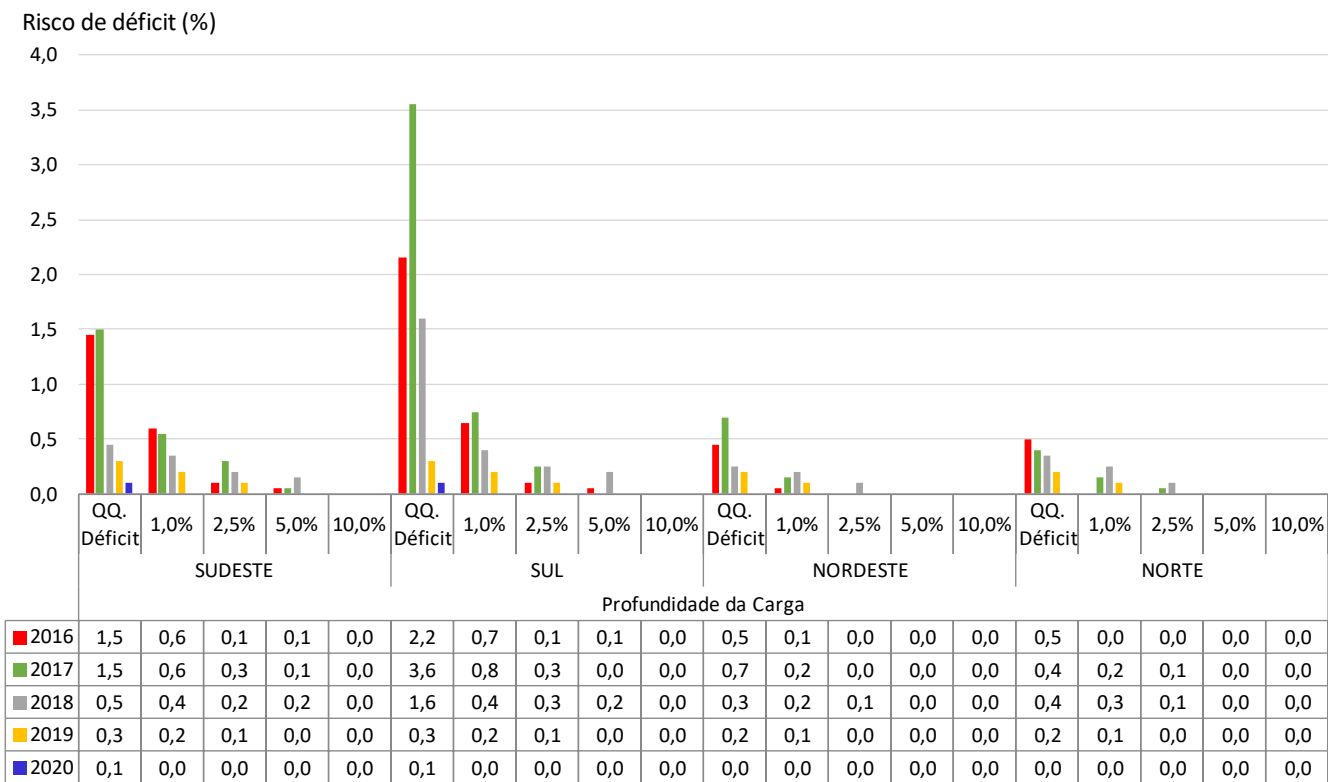

Figura 5.44 - Risco de déficit - caso P5 (Ref. PMO janeiro/2016)

Fonte: Elaboração própria 


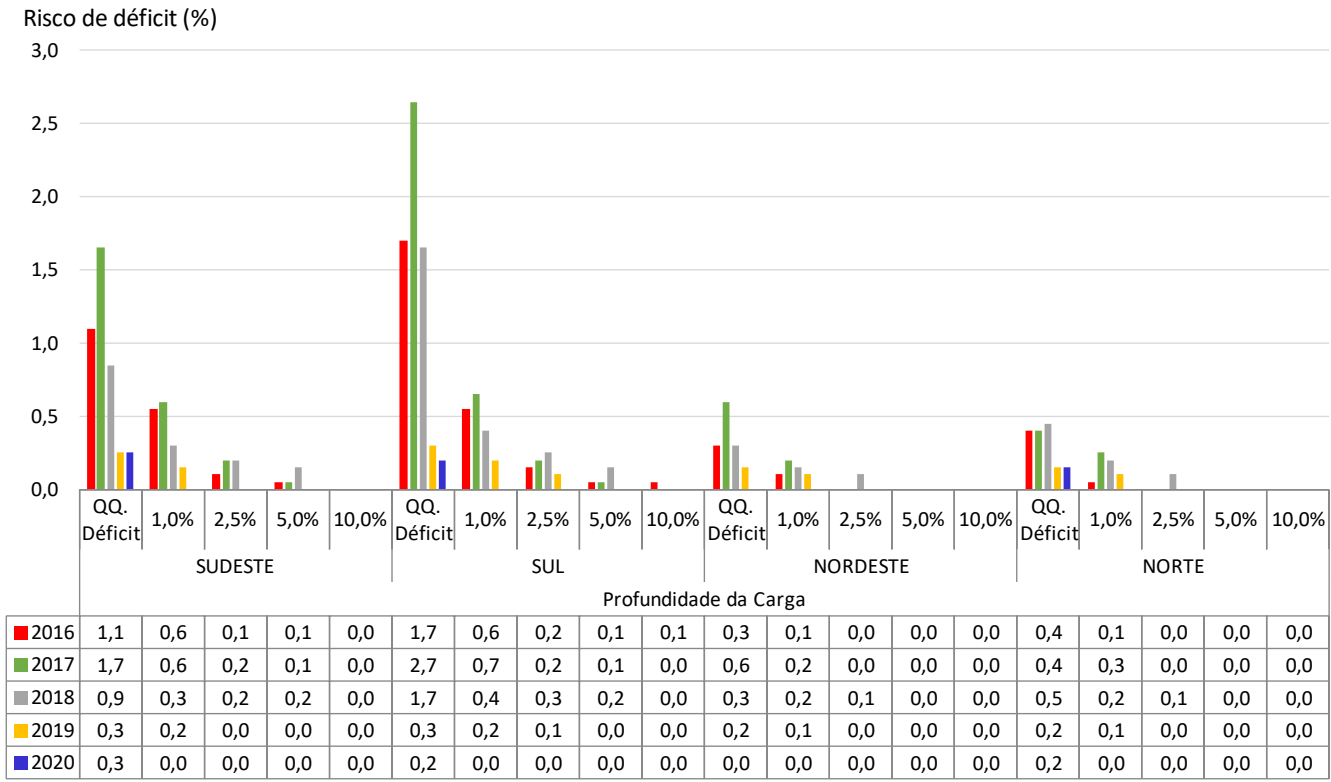

Figura 5.45 - Risco de déficit - caso P25 (Ref. PMO janeiro/2016) Fonte: Elaboração própria

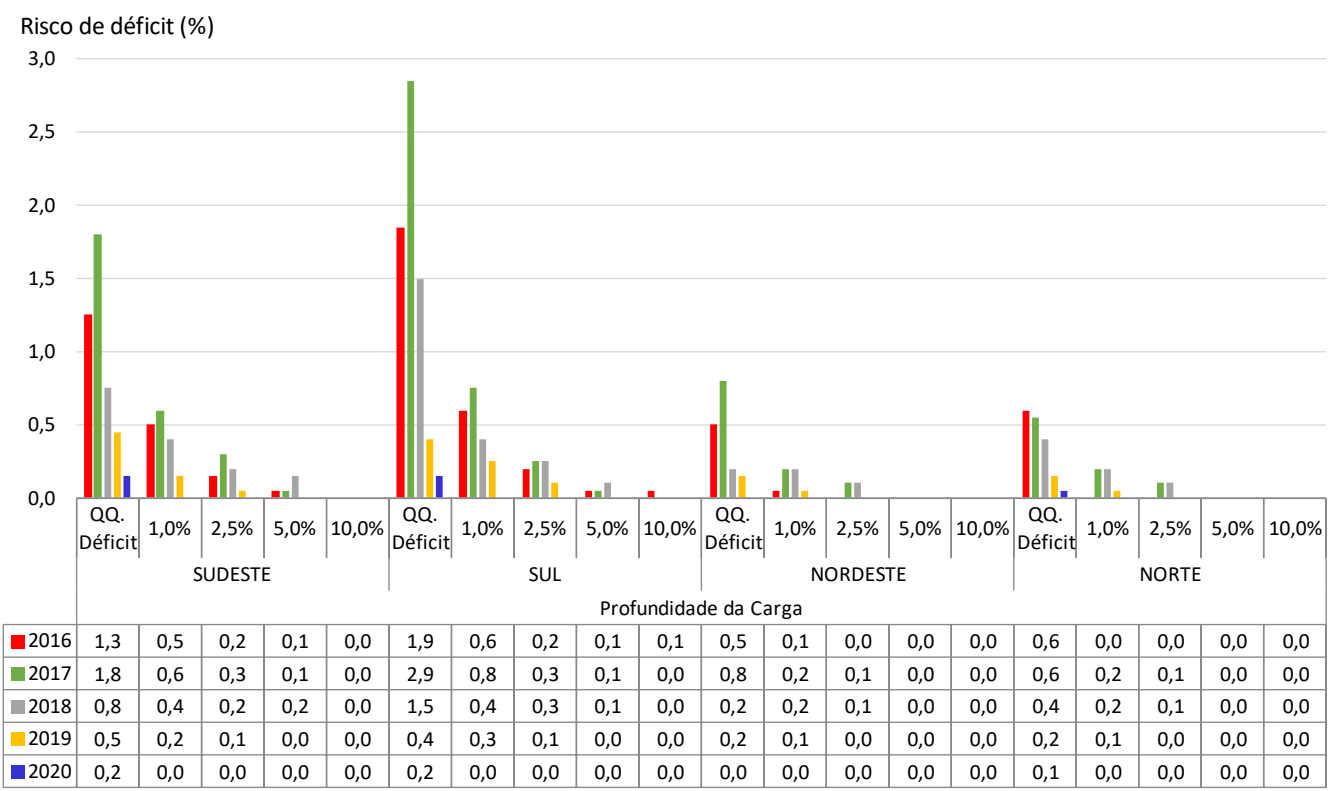

Figura 5.46 - Risco de déficit - caso P50 (Ref. PMO janeiro/2016) Fonte: Elaboração própria 


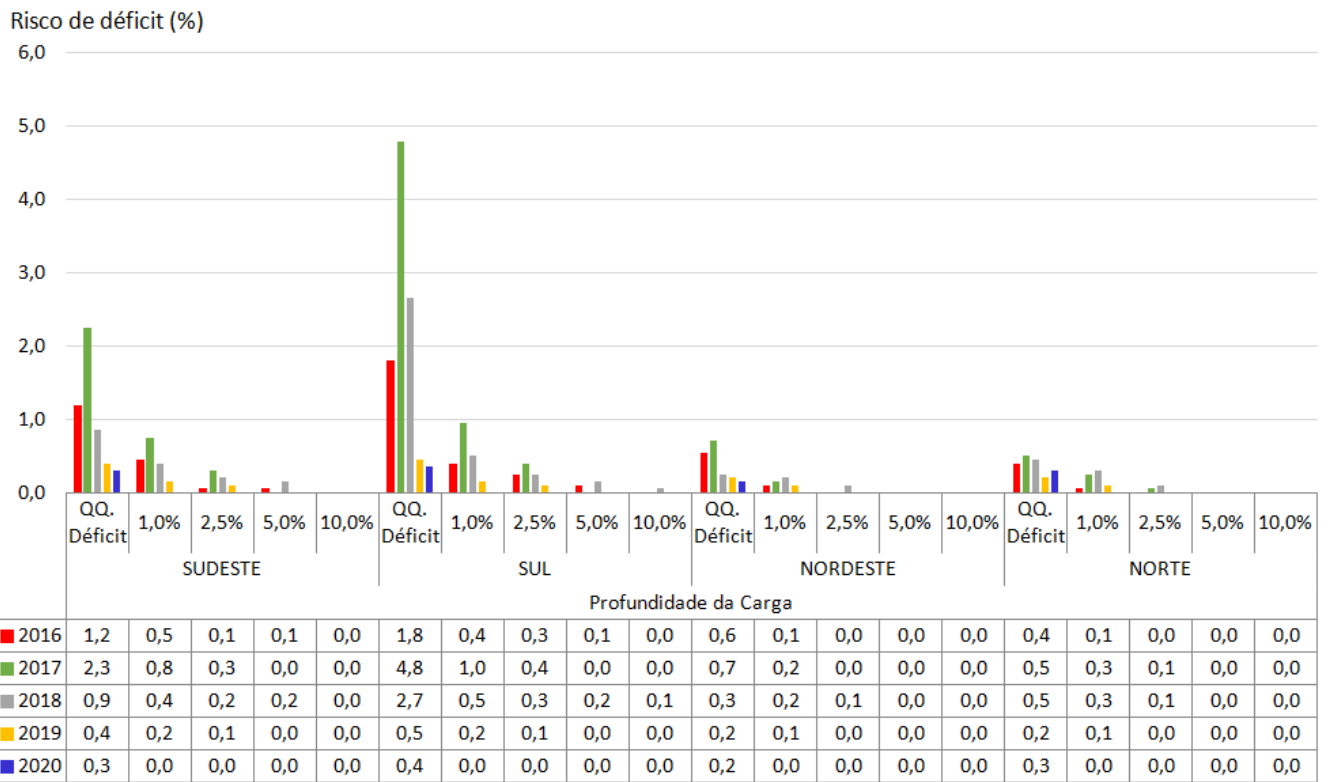

Figura 5.47 - Risco de déficit - caso P75 (Ref. PMO janeiro/2016)

Fonte: Elaboração própria

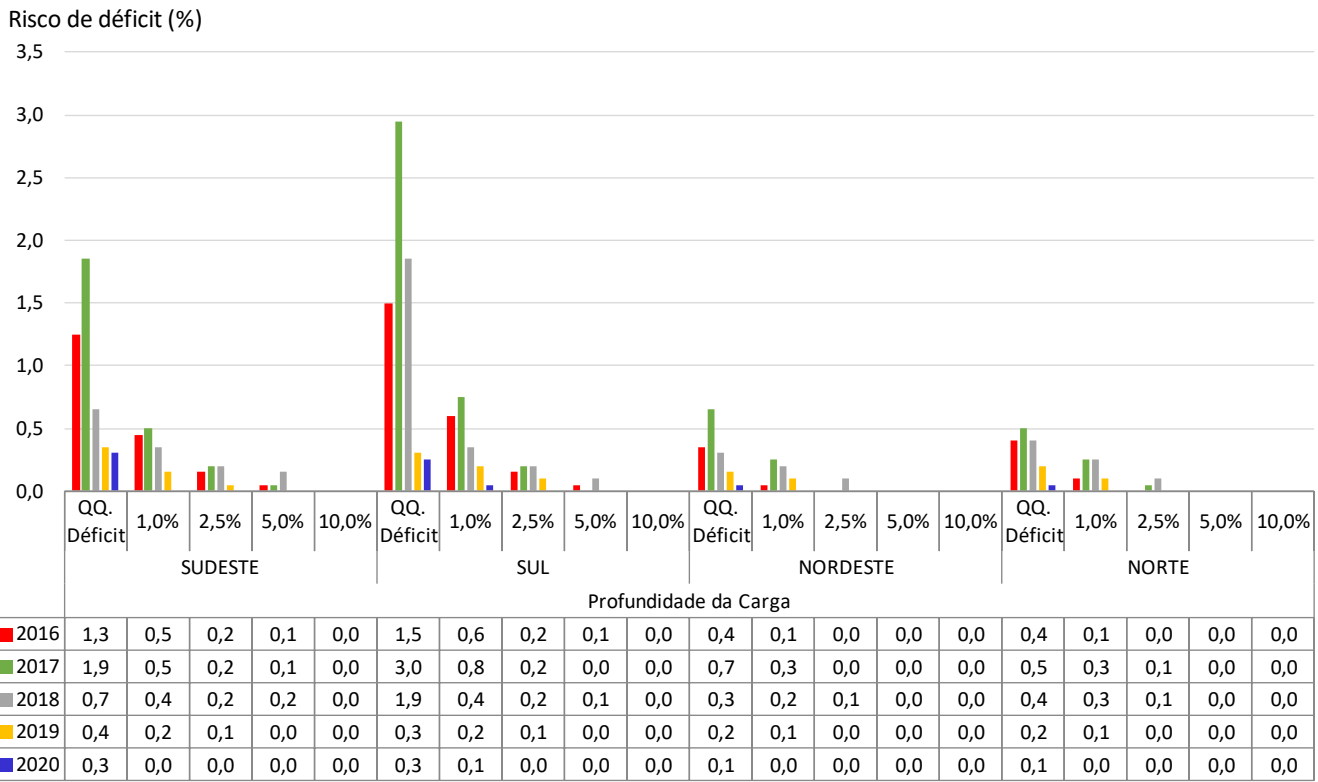

Figura 5.48 - Risco de déficit - caso P95 (Ref. PMO janeiro/2016)

Fonte: Elaboração própria 


\subsubsection{6}

\section{Geração hidráulica (GH)}

A geração hidráulica da maioria dos casos de sensibilidade ficou abaixo da geração hidráulica do caso referência (PMO janeiro/16), com exceção de alguns meses, devido à escolha feita pela política de despacho hidrotérmico, conforme indicado nas Figuras 5.49 a 5.52 .

Cabe destacar ainda, a marcante sazonalidade da geração hidráulica nos quatro subsistemas equivalentes do SIN, conforme mencionada na seção 5.4.1.6.

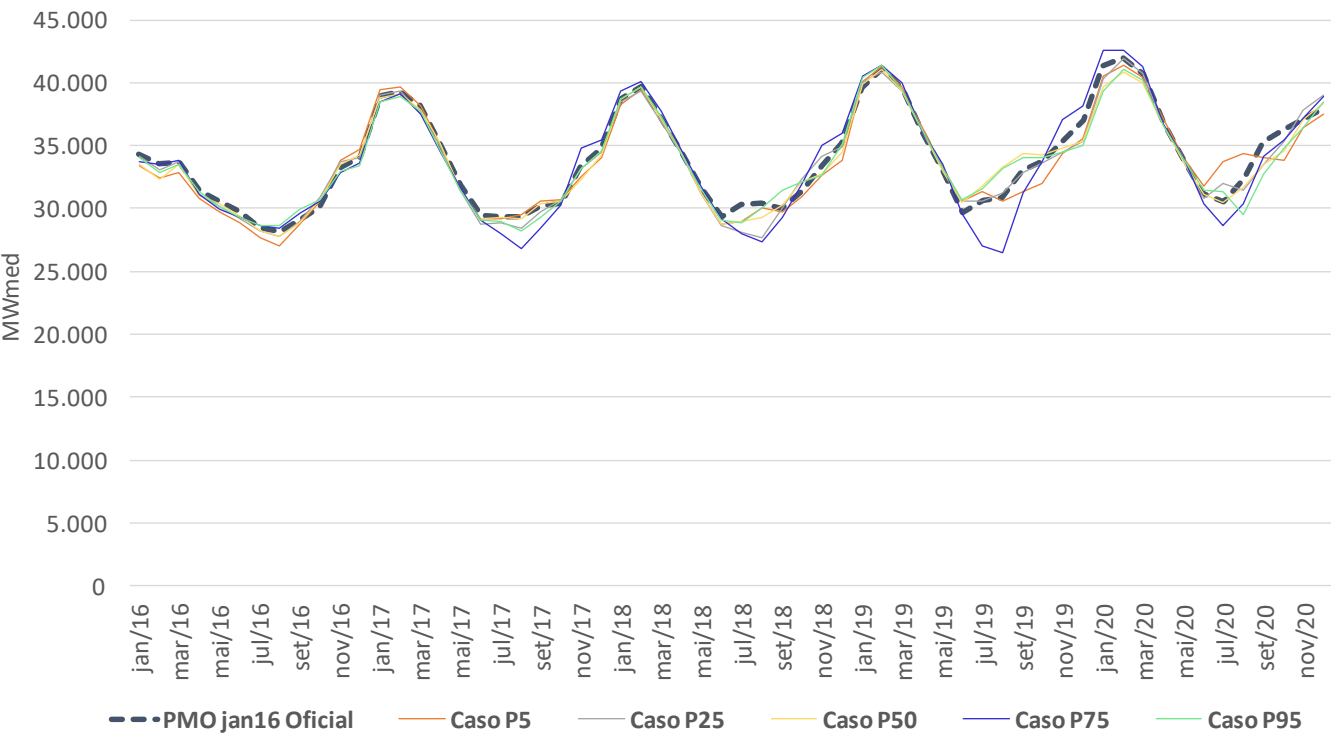

Figura 5.49 - Geração hidráulica (Sudeste/Centro-oeste) - Ref. PMO janeiro/2016 Fonte: Elaboração própria 


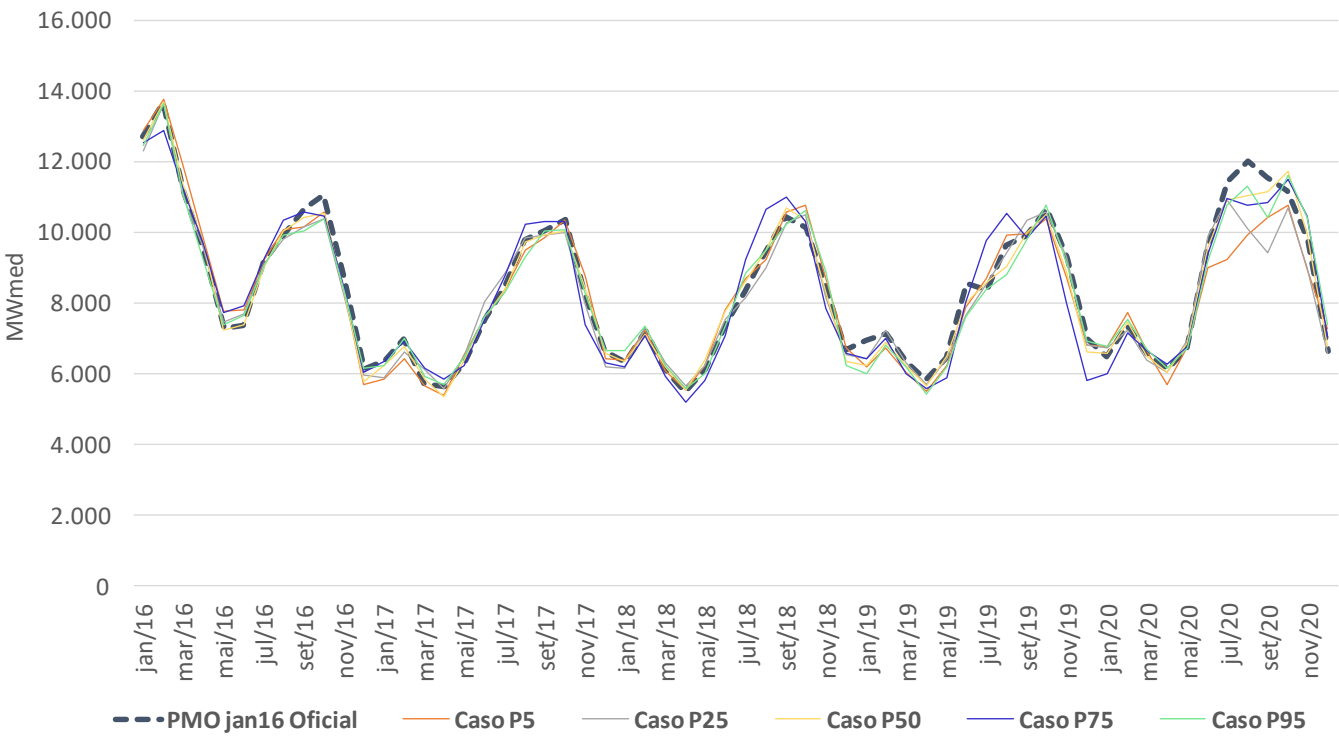

Figura 5.50 - Geração hidráulica (Sul) - Ref. PMO janeiro/2016

Fonte: Elaboração própria

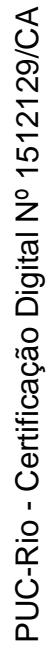

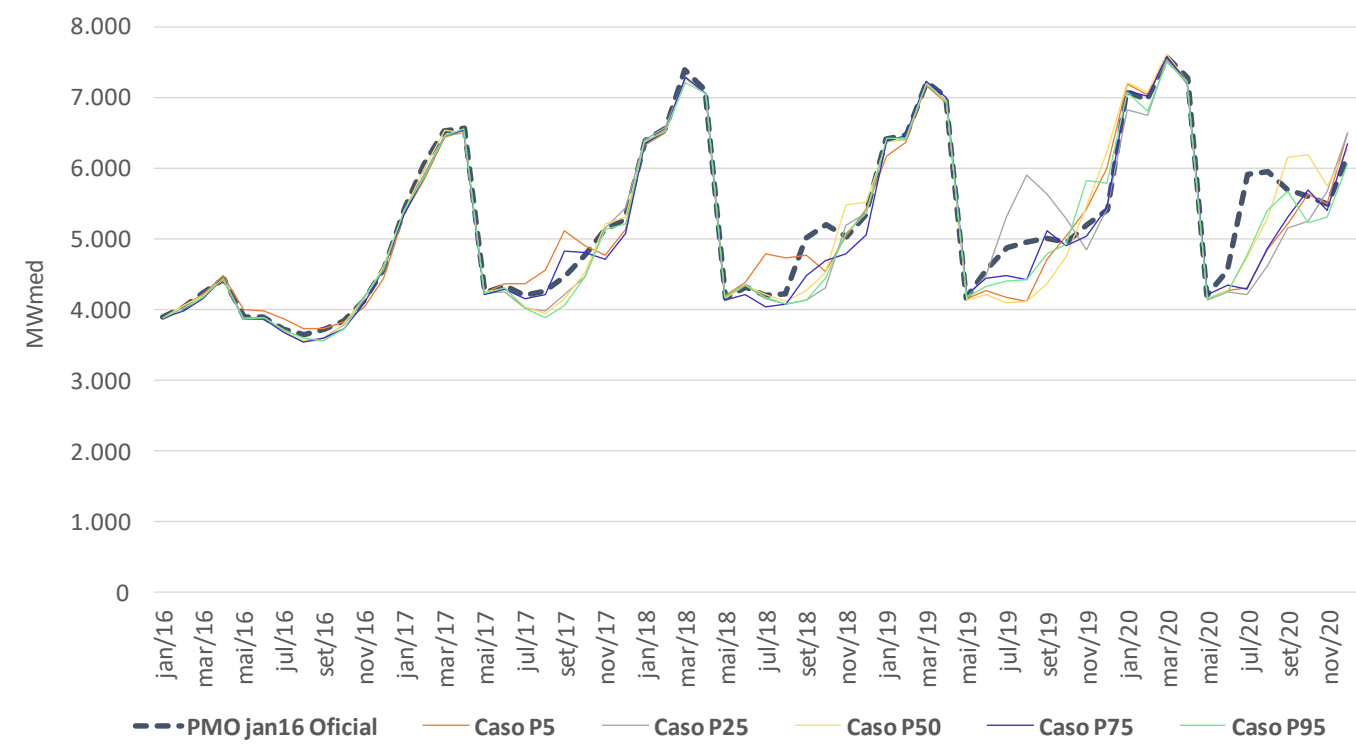

Figura 5.51 - Geração hidráulica (Nordeste) - Ref. PMO janeiro/2016

Fonte: Elaboração própria 


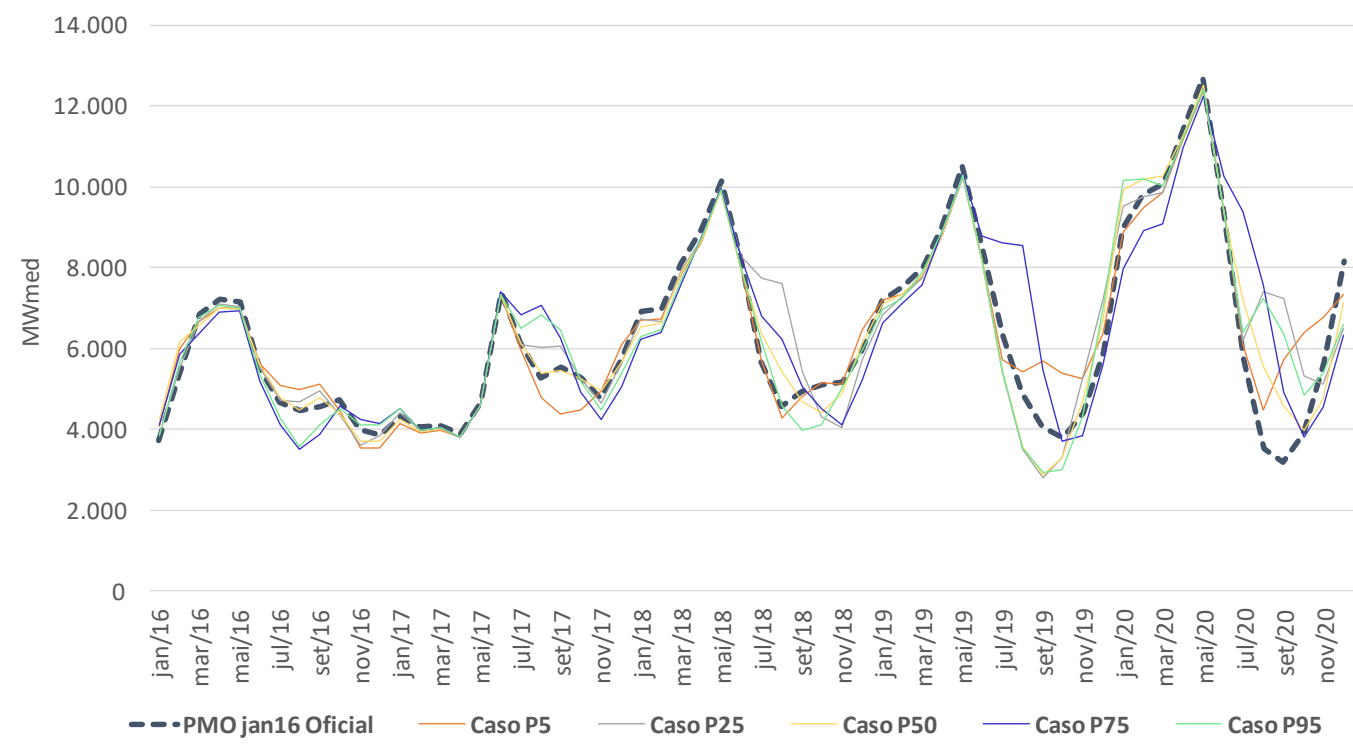

Figura 5.52 - Geração hidráulica (Norte) - Ref. PMO janeiro/2016

Fonte: Elaboração própria

\subsubsection{7 \\ Geração térmica (GT)}

A geração térmica de todos os casos de sensibilidade ficou abaixo da geração térmica do caso referência (PMO janeiro/16). Esse resultado impactou na redução do CMO, conforme visto na seção 5.4.2.2.

Os resultados de geração térmica desse PMO apresentam o mesmo destaque indicado na seção 5.4.1.7, que indica a máxima geração térmica nos primeiros meses do período de planejamento (cinco anos) nos subsistemas equivalentes Sudeste/Centro-oeste, Sul e Nordeste, devido à permanência das condições energéticas desfavoráveis, porém atenuada pela carga mais baixa que àquela utilizada no PMO janeiro/2016, conforme visto na seção 4.2.2.1. Já no subsistema Norte, observou-se uma elevação da geração térmica ao longo dos anos, explicada pela elevação de geração térmica mínima na região durante o período de planejamento, conforme visto na seção 5.4.1.7. O comportamento da geração térmica é mostrado na sequência de Figuras abaixo (Figura 5.53 a Figura 5.56). 


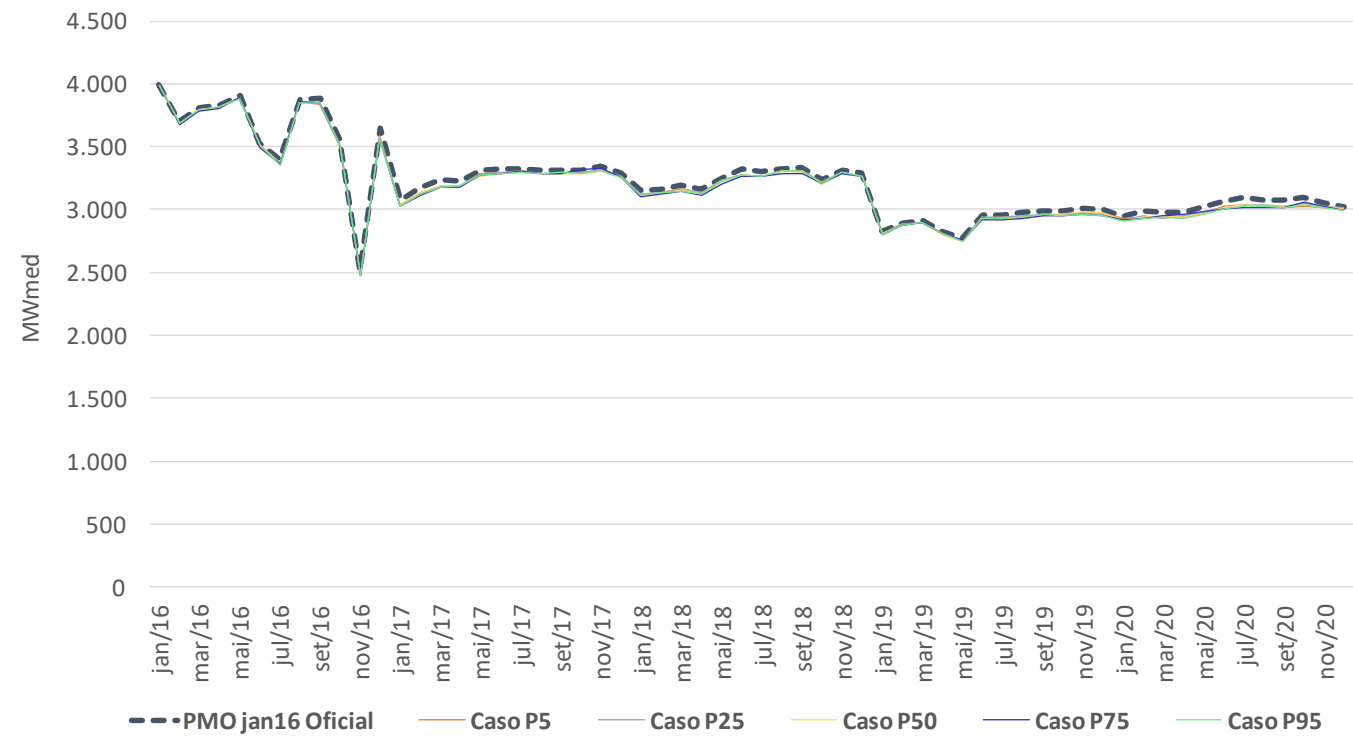

Figura 5.53 - Geração térmica (Sudeste) - Ref. PMO janeiro/2016

Fonte: Elaboração própria

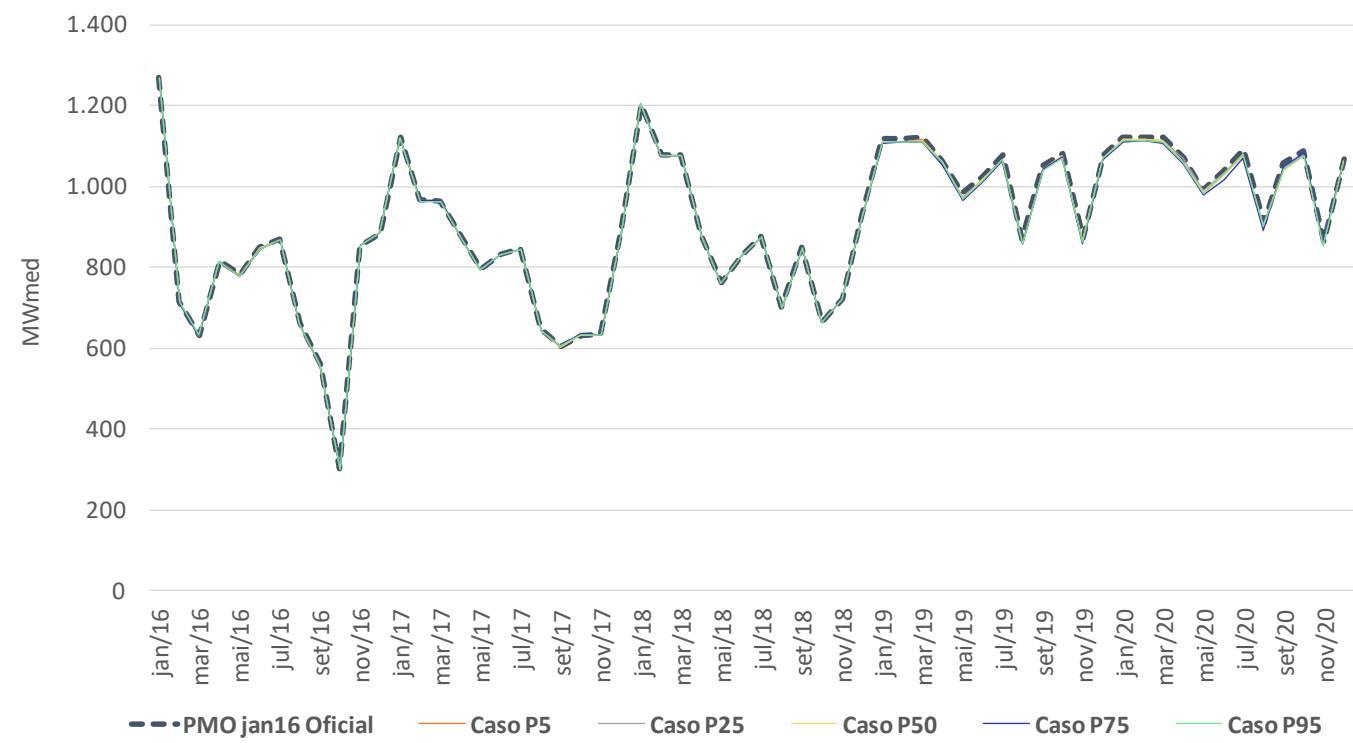

Figura 5.54 - Geração térmica (Sul) - Ref. PMO janeiro/2016

Fonte: Elaboração própria 


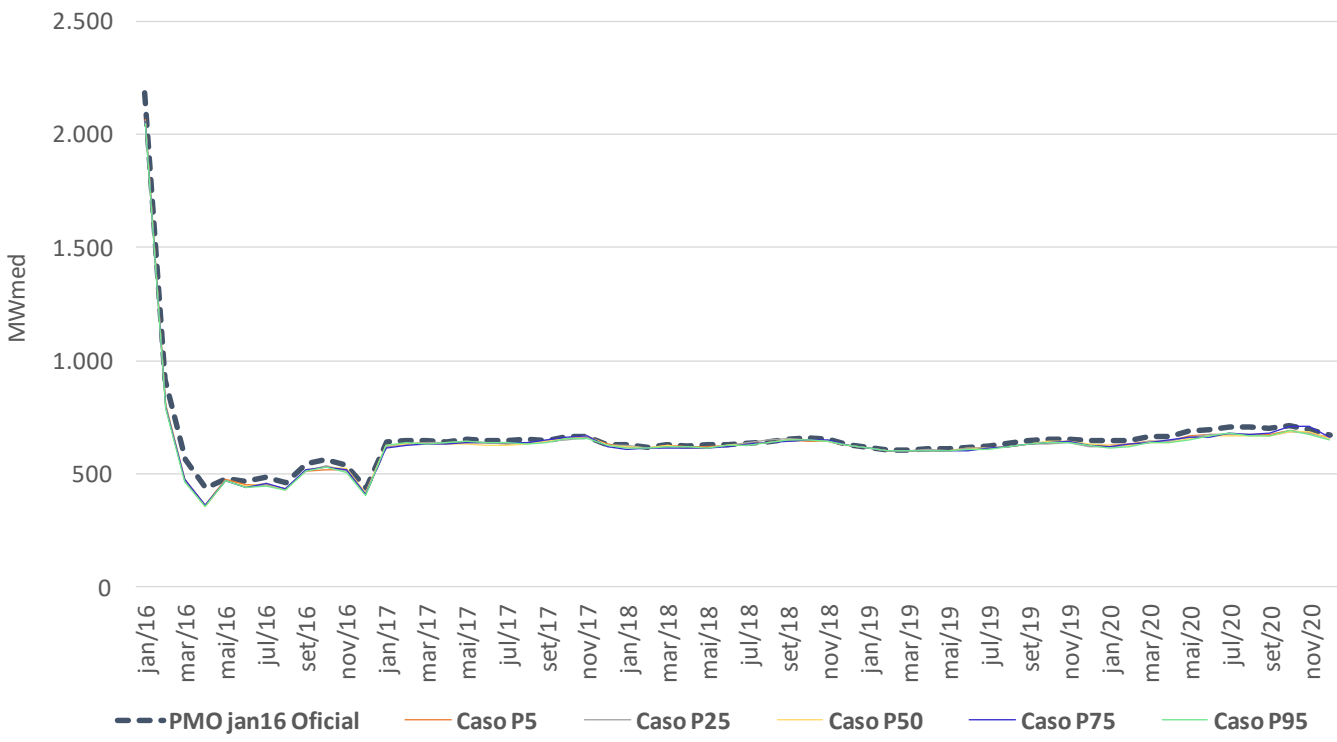

Figura 5.55 - Geração térmica (Nordeste) - Ref. PMO janeiro/2016

Fonte: Elaboração própria

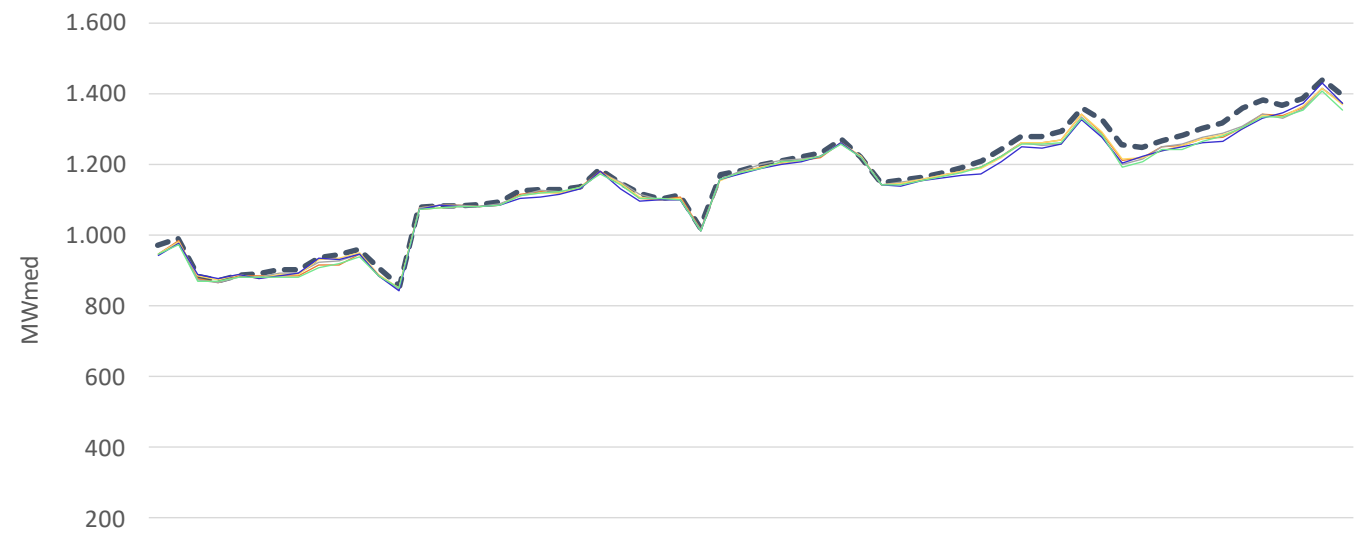

5.4.2.8

Intercâmbio entre regiões

A modelagem energética dos intercâmbios inter-regionais adotada no PMO de janeiro/2016 segue as mesmas premissas mostradas na seção 5.4.1.8. 
Cabe ressaltar que em nenhum dos casos gerados houve mudança de sentido do intercâmbio anual. As alterações percebidas são somente relacionadas ao montante de energia enviado de uma região para outra. É importante destacar ainda que, no primeiro ano de planejamento do PMO janeiro/2016 a região Sudeste/Centro-oeste foi recebedora de energia da região Sul, no entanto nos demais anos a região tornou-se exportadora. Para o mesmo ano, a região Sudeste/Centro-oeste foi exportadora para o Nordeste e nos demais anos recebedora. Esse comportamento é explicado pela existência de excedentes energéticos na região Sul em 2016 e a necessidade de importação de energia pela região Sudeste/Centro-oeste, uma vez que os níveis dos reservatórios nesse período ainda eram bastante baixos. Parte da energia que o Sudeste/Centro-oeste importou da região Sul foi transferida para o Nordeste, pois essa região também se encontrava com níveis de reservatórios críticos. A região Norte foi exportadora de energia para o nó-fictício (imperatriz) em todos os anos de planejamento. O comportamento do intercâmbio de energia está representado pelas Figuras 5.57 a 5.61.

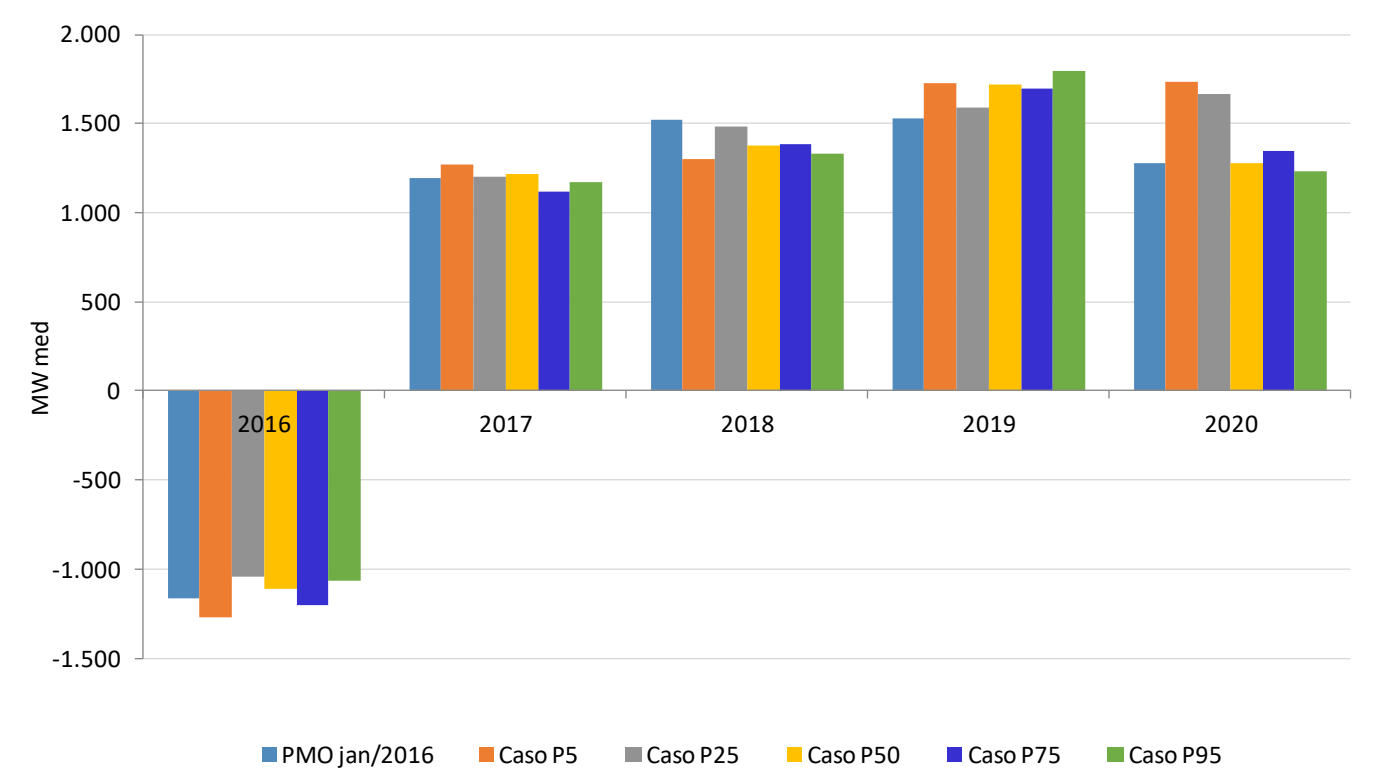

Figura 5.57 - Intercâmbio Sudeste para Sul (Ref. PMO janeiro/2016) Fonte: Elaboração própria 


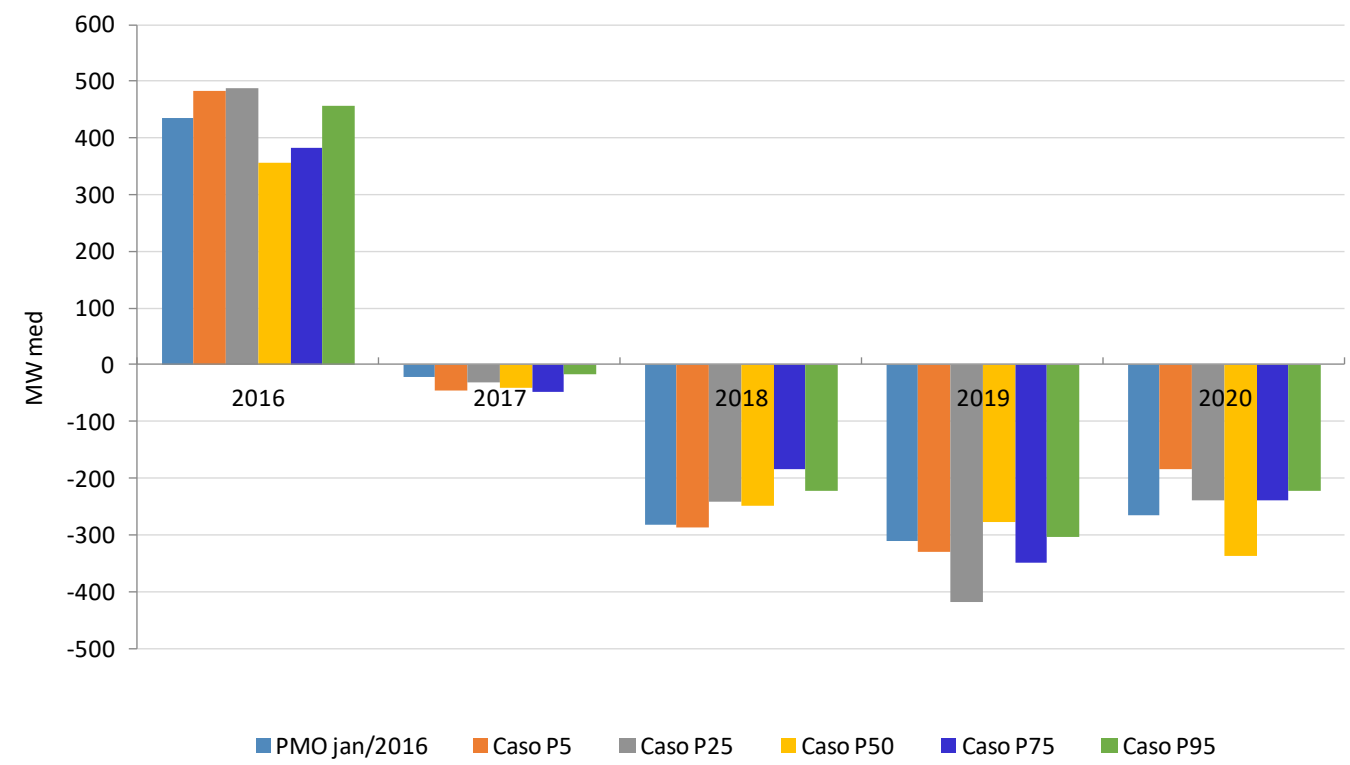

Figura 5.58 - Intercâmbio Sudeste para Nordeste (Ref. PMO janeiro/2016) Fonte: Elaboração própria

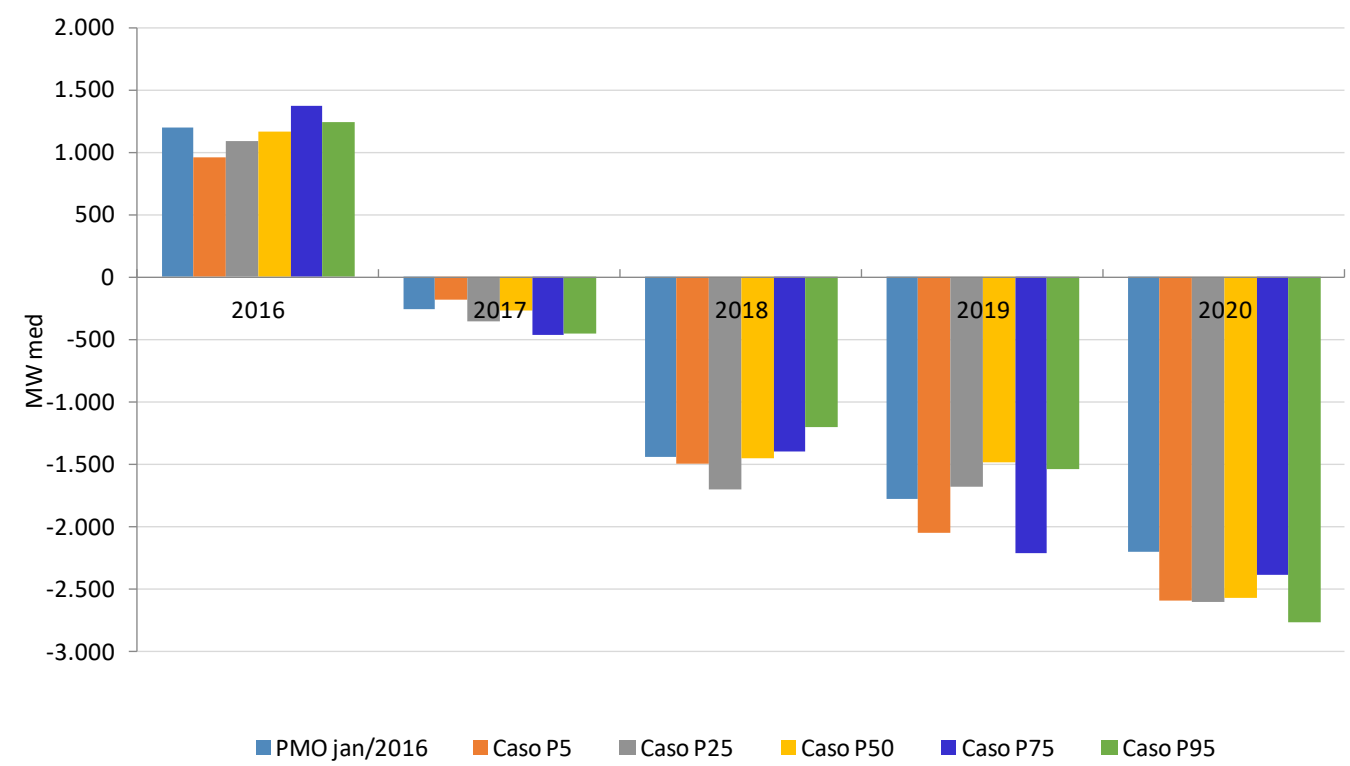

Figura 5.59 - Intercâmbio Sudeste para nó-fictício (Ref. PMO janeiro/2016) Fonte: Elaboração própria 


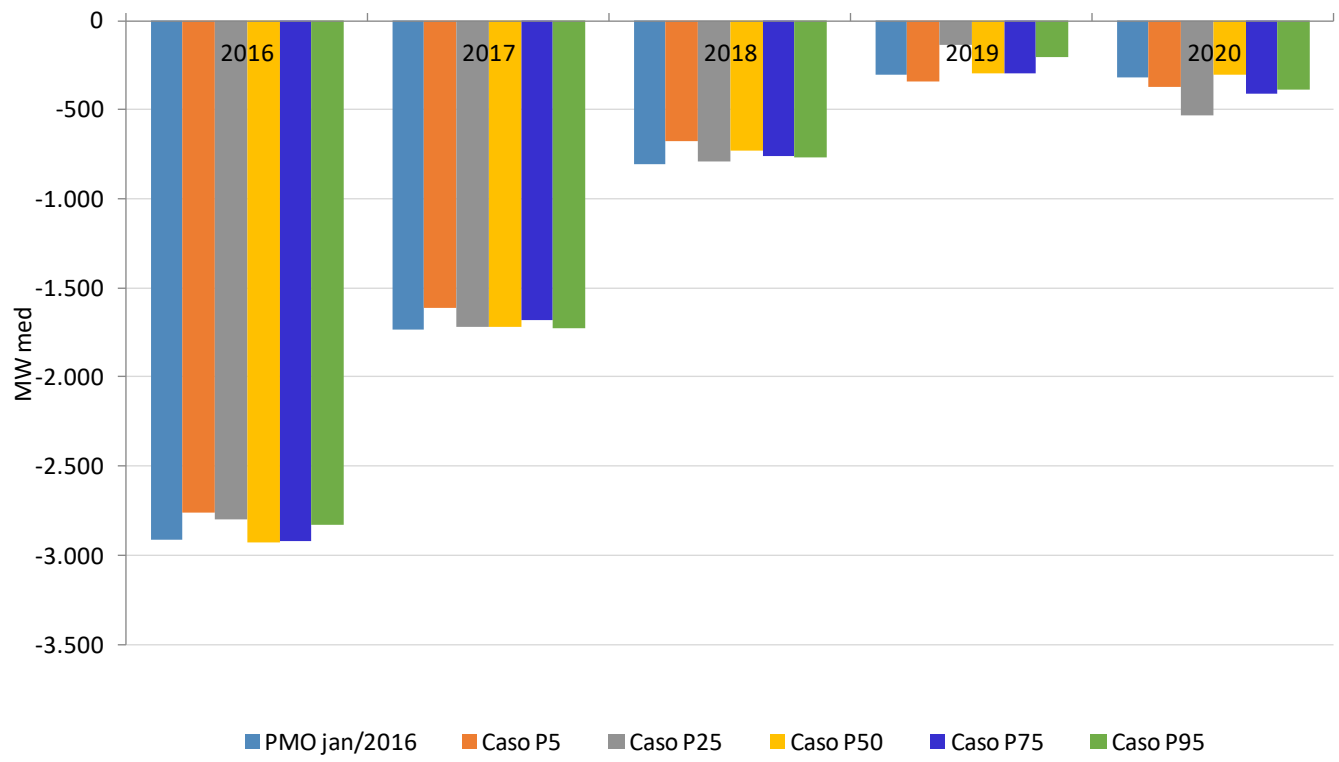

Figura 5.60 - Intercâmbio Nordeste para nó-fictício (Ref. PMO janeiro/2016) Fonte: Elaboração própria

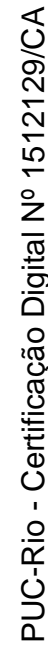

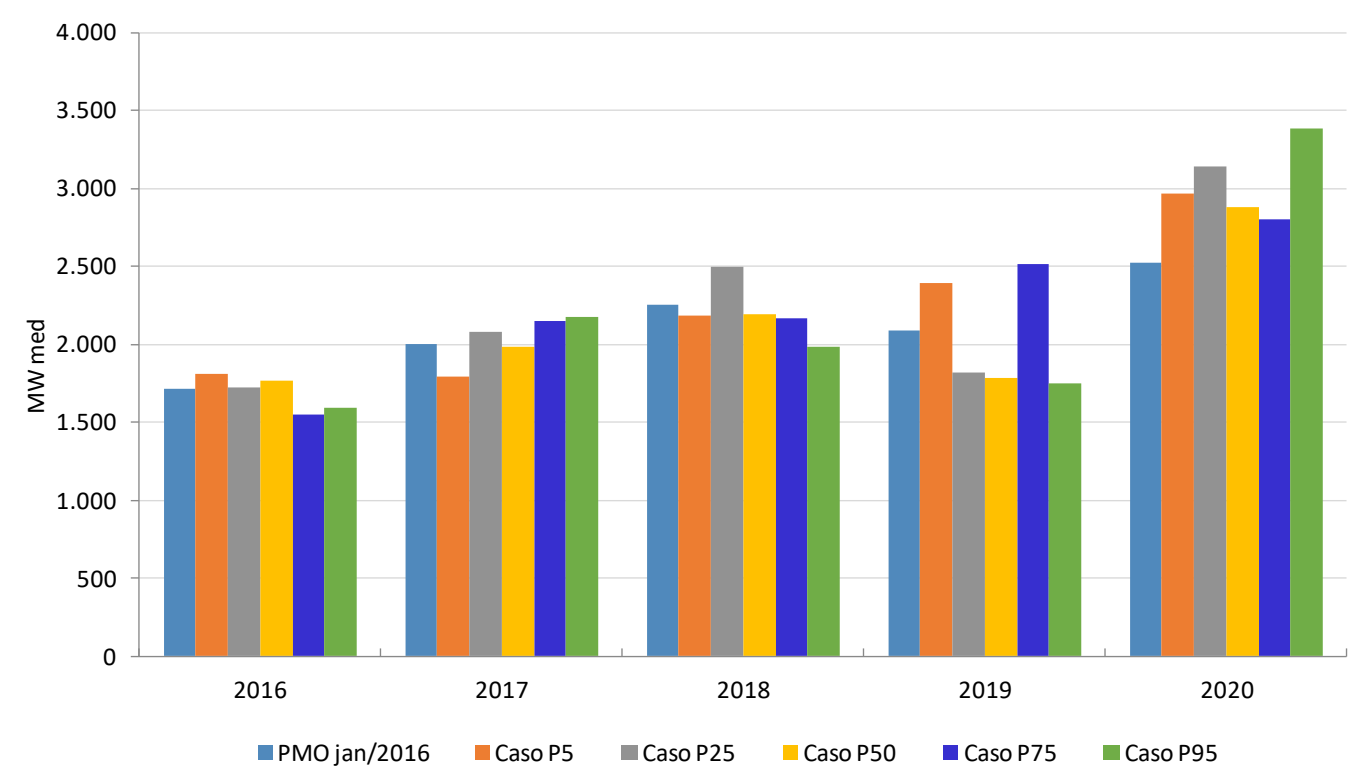

Figura 5.61 - Intercâmbio Norte para nó-fictício (Ref. PMO janeiro/2016) Fonte: Elaboração própria 


\subsubsection{9}

\section{Custo de vertimento}

Apesar da variação dos custos associados aos vertimentos não ter sido expressiva, ela se apresenta maior que a variação observada no PMO janeiro/2015. A variação máxima ocorrida elevou os custos de vertimento em $0,05 \$^{\wedge} 10^{6}$ no caso P95, conforme Tabela 5.16.

Tabela 5.16 - Custo do vertimento e desvio-padrão $\left(\$ \wedge 10^{6}\right)$ - Ref. PMO janeiro/2016

\begin{tabular}{lcc}
\hline Casos Newave & Vertimento $\left(\mathbf{\$} \mathbf{1 0 ^ { 6 }}\right)$ & Desvio padrão $\left(\mathbf{\$} \mathbf{1 0}^{\mathbf{6}}\right)$ \\
\hline PMO jan16 Oficial & 1 & 0 \\
Caso P5 & 1 & 0 \\
Caso P25 & 1 & 0 \\
Caso P50 & 1 & 0 \\
Caso P75 & 1 & 0 \\
Caso P95 & 1 & 0 \\
\hline
\end{tabular}

Fonte: Elaboração própria

A Figura 5.62 indica que na variável custo de vertimento não houve outlier e que a região Q2 (mediana) está mais próxima da região Q3 (terceiro quartil). Além disso, a dispersão entre os casos é bastante baixa.

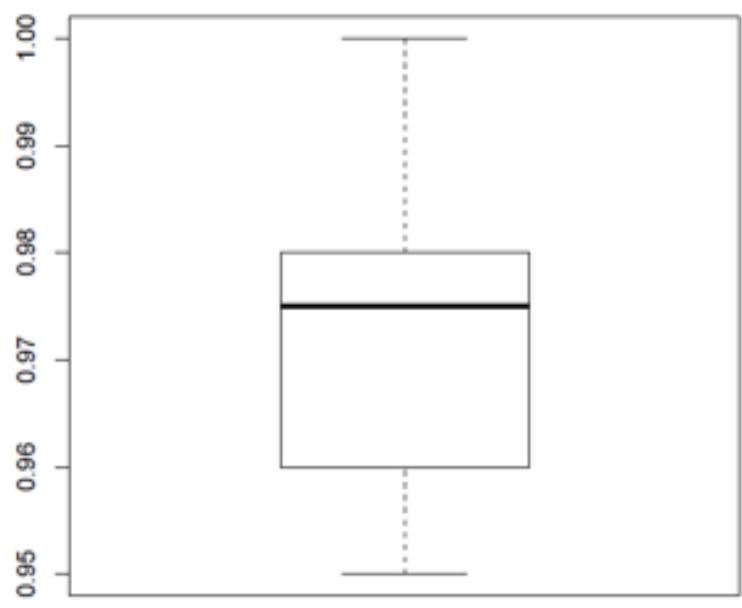

Figura 5.62 - Boxplot do custo de vertimento $\left(\$ \times 10^{\wedge 6}\right)$. PMO janeiro/2016 e casos de sensibilidade

Fonte: Elaboração própria 


\section{6. \\ Conclusões}

A inserção da fonte solar fotovoltaica na matriz energética do Brasil, em especial, na mátria elétrica, é extremamente positiva e está em linha com o que está sendo praticado por outros países.

Espera-se com a inserção dessa fonte a diversificação do parque gerador, a redução do custo da energia com a mitigação do despacho térmico e outros benefícios importantes como redução da emissão dos GEE e suprimento de energia em áreas isoladas.

Contudo, existe variação nas quantidades produzidas de acordo com a situação climática, além da produção somente durante o dia, já que a noite não existe produção dessa fonte. Outro ponto que merece destaque é que consideração da geração distribuída dessa fonte no planejamento da operação energética de médio prazo ainda não é clara ou conhecida.

Nesse intuito, o objetivo principal desta dissertação que era propor uma metodologia para mensuração do impacto do potencial de geração fotovoltaica residencial no planejamento da operação energética de médio prazo foi totalmente alcançado.

Após a apresentação da metodologia foi realizada sua aplicação no Programa Mensal da Operação Energética, utilizando como referência o PMO janeiro/2015 e o PMO janeiro/2016. Os resultados das simulações dos casos de sensibilidade, considerando o potencial de geração fotovoltaica residencial (P5, P25, P50, P75 e P95), foram comparados aos resultados obtidos nos casos de referência. Pode-se concluir que a consideração do potencial de geração fotovoltaica residencial apresentou impacto na maioria das variáveis operativas analisadas.

Houve redução do custo total da operação e do custo marginal de operação no curto e longo prazo. Além disso, houve também redução dos custos de déficit. 
Quanto ao risco de déficit, houve redução nos anos de planejamento, no entanto, no PMO janeiro/2015, quando a condição energética era mais desfavorável, não foi possível reduzir o risco para valores inferiores a $5 \% .^{19}$ Portanto, o PMO de janeiro/2015 indica a não garantia do suprimento de energia de qualquer déficit de carga até 2,5\% de profundidade da carga para as regiões Sudeste/Centro-oeste e Sul e de qualquer déficit da carga para as regiões Nordeste e Norte.

A dinâmica do despacho da geração hidráulica e térmica foi alterada em alguns meses. Em geral, a geração hidráulica diminuiu quando houve aumento da geração fotovoltaica residencial, com exceções de poucos meses. Já a geração térmica foi menor todas as vezes que se considerou o potencial de geração fotovoltaica residencial.

Observou-se, como esperado, que o custo total da operação e o custo marginal da operação nos dois programas reduziram quando introduzidos os cenários do potencial de geração fotovoltaica residencial. No PMO janeiro/2015 essa redução foi mais expressiva, pois naquele momento havia a combinação de condições energéticas desfavoráveis e carga global de energia elevada. Este resultado é importante, pois com a inserção da fonte de energia fotovoltaica na matriz, pode-se reduzir consideravelmente o custo marginal de operação, especialmente em momentos de crise hídrica ou iminência de racionamento.

Isso ficou claro no caso P75 e P95 do PMO janeiro/2015, onde apresentou máxima redução do custo total de operação de $7,8 \%$, quando comparado ao custo total da operação do caso de referência (PMO janeiro/2015). Os custos marginais de operação para o primeiro ano de planejamento apresentaram máxima redução no caso P95. Essas reduções corresponderam a aproximadamente R $\$$ 50/MWh nos subsistemas equivalentes Sudeste/Centro-oeste e Sul, R\$ 31/MWh no Nordeste e R\$ 24 /MWh no Norte.

Quanto aos resultados referentes à aplicação da metodologia no PMO janeiro/2016, a máxima redução do custo total da operação foi de 1,5\% no caso P95,

${ }^{19}$ Critério de segurança do Sistema Interligado Nacional. 
quando comparado ao custo total da operação do caso de referência (PMO janeiro/2016), uma vez que os patamares de CMO já eram baixos, devido as melhores condições hidrológicas, com exceção do subsistema Nordeste e a carga era menor que aquela utilizada no PMO janeiro/2015. Os custos marginais de operação para o primeiro ano de planejamento apresentaram máxima redução no caso P75. Essas reduções corresponderam a aproximadamente R \$ 14/MWh nos subsistemas equivalentes Sudeste/Centro-oeste, Sul e Nordeste e R $\$ 11 / \mathrm{MWh}$ no no Norte. Para esse PMO alguns resultados não se mostraram tão intuitivos quanto os vistos no PMO janeiro/2015. O desvio-padrão do custo total de operação encontrado para os casos do PMO de janeiro/2016 indicaram que os resultados são mais semelhantes que os casos do PMO de janeiro/2015.

Para ambos os programas, o impacto da geração fotovoltaica residencial na energia armazenada não foi observado diretamente, pois a situação energética do período era muito crítica. Sendo assim, a política de operação do modelo NEWAVE priorizou o uso da água dos reservatórios. A priorização da geração hidráulica, em alguns estágios da otimização, reduziu o despacho térmico, proporcionando custos marginais de operação menores que aqueles encontrados pelos casos de referência (PMO janeiro/2015 e PMO janeiro/2016). A combinação da redução da carga de energia global, devido à crise econômica, com a consideração de geração fotovoltaica residencial, fez com que o modelo NEWAVE poupasse a água dos reservatórios no PMO janeiro/2016. Logo os níveis dos reservatórios do SIN referentes ao horizonte de planejamento 2016 a 2020 foram maiores que os níveis resultantes do horizonte de planejamento 2015 a 2019.

Houve também redução no custo de déficit, registrando máxima redução de 14\% no PMO janeiro/2015 e 19\% no PMO janeiro/2016 e redução em alguns casos do risco de déficit. Nesse caso, observou-se uma alternância entre redução e aumento do risco, conforme decisões feitas pela política de operação do modelo Newave.

Por último, o sentido do fluxo dos intercâmbios de energia não foi alterado ao considerar a geração fotovoltaica residencial. O que se observou foi alterações no volume transferido de uma região para outra. Quanto ao custo de vertimento, não houve praticamente contribuição da geração fotovoltaica. 
A metodologia aplicada nos Programas Mensais da Operação Energética selecionados se demonstrou consistente e foi possível responder as questões de pesquisa propostas.

\section{1.}

\section{Considerações e estudos futuros}

As análises e proposições realizadas nesse trabalho demonstraram a complexidade do tema e o quão oportuno é para o momento de inserção da fonte solar fotovoltaica no contexto brasileiro, merecendo ser tratado de forma tão ou mais aprofundada em outros trabalhos e estudos acadêmicos.

A primeira recomendação de estudos futuros é atualizar a base de medição solarimétrica e aprimorar as técnicas para tratamento dos dados faltantes e outliers.

Como segunda recomendação, é necessário o aprofundamento da metodologia de estimação da área de telhado útil para aplicação de sistemas fotovoltaicos, principalmente no que diz respeito aos fatores de aproveitamento de área útil, a premissa de área útil para domicílio tipo casa e tipo apartamento e a estimativa de número de domicílios para o horizonte de planejamento selecionado.

A terceira recomendação é avaliar outras metodologias de simulação de séries temporais e comparar os resultados com os cenários escolhidos.

A quarta recomendação é propor ao CEPEL, através da participação das forças-tarefas de evolução e aprimoramento do modelo NEWAVE, a possibilidade de representar a carga global de energia por patamar de carga (leve, médio e pesado) para que seja possível avaliar a consideração do potencial de geração fotovoltaica residencial no patamar médio, que corresponde ao período de disponibilidade do recurso solar.

Dada a importância cada vez maior sobre o tema, sugere-se como quinta recomendação o estudo sobre modelos que levam em consideração a inserção de geração fotovoltaica com capacidade de armazenamento (banco de baterias). 
A sexta recomendação é a consideração da tendência de cluster de geração fotovoltaica, constituído de múltiplas unidades consumidoras e geração compartilhada, já previsto pela Resolução Normativa ANEEL nº 687/2015.

Como sétima recomendação, é indicado o desenvolvimento de estudos que proponham uma metodologia para o cálculo mais factível do potencial de domicílios que teriam sistemas fotovoltaicos.

Por fim, devido ao desenvolvimento dessa modalidade, em especial, nos Estados Unidos e Alemanha, a oitava e última recomendação é a consideração da Blockchain $^{20}$ no conceito de geração fotovoltaica distribuída rumo à descentralização, proporcionando a dissociação entre centralização e confiabilidade para o consumo de eletricidade.

${ }^{20}$ Blockchain é a estrutura de dados que representa uma entrada de contabilidade financeira ou um registro de uma transação. Cada transação é digitalmente assinada com o objetivo de garantir sua autenticidade e garantir que ninguém a adultere, de forma que o próprio registro e as transações existentes dentro dele sejam considerados de alta integridade. 


\section{7. Referências bibliográficas}

AIE. Agência Internacional de Energia (2004). Key world energy statistics. Paris. Renewable energy: market \& policy trends in IEA countries.

AIE. Agência Internacional de Energia. (2010). Technology Roadmap: Solar photovoltaic energy. Organization for Economic Cooperation \& Development.

ANEEL. Agência Nacional de Energia Elétrica (2005). Atlas de energia elétrica do Brasil. Brasília.

ANEEL. Agência Nacional de Energia Elétrica. Resolução Normativa $\mathbf{n}^{\circ}$ 440, 5 de julho de 2011. Estabelece os critérios para a consideração de usinas não simuladas individualmente nos modelos computacionais de planejamento da operação e formação de preço. Acesso em 20 de 11 de 2015. Disponível em: http://www.aneel.gov.br.

ANEEL. Agência Nacional de Energia Elétrica. Resolução Normativa $\mathbf{n}^{\circ}$ 476, 13 de março de 2012. Altera a Resolução Normativa no 440, de 5 de julho de 2011, que estabelece os critérios para a consideração de pequenas usinas nos modelos computacionais de planejamento da operação e formação de preço. Acesso em 20 de 11 de 2015. Disponível em: http://www.aneel.gov.br.

ANEEL. Agência Nacional de Energia Elétrica. Resolução Normativa $\mathbf{n}^{\circ}$ 482, 17 de abril de 2012. Estabelece as condições gerais para o acesso de microgeração e minigeração distribuída aos sistemas de distribuição de energia elétrica, o sistema de compensação de energia elétrica, e dá outras providências. Acesso em 20 de 11 de 2015. Disponível em: http://www.aneel.gov.br. 
ANEEL. Agência Nacional de Energia Elétrica. Resolução Normativa $\mathbf{n}^{\circ}$ 517, 11 de dezembro de 2012. Altera a Resolução Normativa $n^{\circ}$ 482, de 17 de abril de 2012, e o Módulo 3 dos Procedimentos de Distribuição PRODIST. Acesso em 20 de 11 de 2015. Disponível em: http://www.aneel.gov.br.

ANEEL. Agência Nacional de Energia Elétrica. Resolução Normativa $\mathbf{n}^{\circ}$ 687, 24 de novembro de 2015. Altera a Resolução Normativa no 482, de 17 de abril de 2012, e o Módulo 3 dos Procedimentos de Distribuição PRODIST. Acesso em 02 de 03 de 2017. Disponível em: http://www.aneel.gov.br.

Bassous, G. F. (2015). Análise dos dados solarimétricos brasileiros e elaboração das curvas características de cada submercado do SIN. Projeto Final de Graduação. Engenharia Ambiental e Sanitária, PUC-Rio.

Box, G. E. P e Jenkins, G. M. (1976). Time series analysis forecasting and control. San Francisco: Holden - Day, Edição revisada.

Benders, J. F. (1962). Partitioning Procedures for Solving Mixed-Integer Programming Problems. Numerisch Mathematik.

BRASIL. Lei $n^{\circ}$ 10.438, de 2002. Dispõe sobre a expansão da oferta de energia elétrica emergencial, recomposição tarifária extraordinária, cria o Programa de Incentivo às Fontes Alternativas de Energia Elétrica (Proinfa), a Conta de Desenvolvimento Energético (CDE), dispõe sobre a universalização do serviço público de energia elétrica.

BRASIL. Projeto de Lei $\mathbf{n}^{\circ} \mathbf{3 . 8 3 1}$, de 2004 . Dispõe sobre incentivos à geração de energias alternativas e dá outras providências.

BRASIL. Projeto de Lei $\mathbf{n}^{\circ}$ 7.692, de 2006. Institui o Programa Brasileiro de Geração Descentralizada de Energia Elétrica e dá outras providências.

BRASIL. Projeto de Lei $n^{\circ}$ 523, de 2007. Institui a Política Nacional de Energias Alternativas e dá outras providências. 
BRASIL. Projeto de Lei $\mathbf{n}^{\circ}$ 1.563, de 2007. Dispõe sobre fontes renováveis de energia, com o objetivo de promover a universalização, a geração distribuída e a racionalização energética.

BRASIL. Projeto de Lei $\mathbf{n}^{\circ}$ 2.737, de 2008. Estabelece incentivos à geração de energia a partir de fonte solar.

BRASIL. Lei $\mathbf{n}^{\circ} \mathbf{1 0 . 2 9 5}$, de 2001. Dispõe sobre a Política Nacional de Conservação e Uso Racional de Energia e dá outras providências.

BRASIL. Lei $\mathbf{n}^{\circ} \mathbf{9 . 6 4 8}$, de 1998. Introduziu as seguintes modificações na indústria de energia elétrica brasileira.

Calili, R. F. (2013). Políticas de Eficiência Energética no Brasil: uma Abordagem em um Ambiente Econômico sob Incerteza. Tese de Doutorado, Departamento de Engenharia Elétrica, PUC-Rio.

Cellura, M. et al. (2012). Photovoltaic electricity scenario analysis in urban contests: An Italian case study. Renewable and Sustainable Energy Reviews, Oxford, v. 16, n. 4, p. 2041-2052, 2012.

CEPEL (2012). Manual de Referência do Modelo NEWAVE. Revisão 1.

CNPE. Conselho Nacional de Política Energética. Resolução CNPE $n^{\circ} 5$, de 2003.

Costa, R. C.; Prates, C. P. T. (2005). O papel das fontes renováveis de energia no desenvolvimento do setor energético e barreiras à sua penetração no mercado. BNDES Setorial, Rio de Janeiro, $n^{0} 21$.

CRESESB. Centro de Referência para Energia Solar e Eólica Sérgio de Salvo Brito (2000). Manual de engenharia para sistemas fotovoltaicos. Rio de Janeiro: CEPEL.

Dickey, D. A.; Fuller, W. A. (1979). Distribution of the Estimators for Autoregressive Time Series with a Unit Root. Journal of the American Statistical Association 74, pp. 427-431. 
EPE. Empresa de Pesquisa Energética (2014). Inserção da Geração Fotovoltaica Distribuída no Brasil - Condicionantes e Impactos. Nota técnica DEA 19/14. Acesso em 20 de 08 de 2016, disponível em: http://www.epe.gov.br/.

EPE. Empresa de Pesquisa Energética (2015a). Plano Decenal da Expansão 2024. Acesso em 20 de 08 de 2016, disponível em: http://www.epe.gov.br/.

EPE. Empresa de Pesquisa Energética (2015b). Projeção da demanda de energia elétrica para os próximos 10 anos (2015-2024). Nota técnica DEA 03/15. Acesso em 20 de 08 de 2016, disponível em: http://www.epe.gov.br.

EPE. Empresa de Pesquisa Energética (2016a). Balanço Energético Nacional. Acesso em 15 de 01 de 2017, disponível em: http://www.epe.gov.br.

EPE. Empresa de Pesquisa Energética (2016b). Avaliação e compatibilização das informações de geração, carga e consumo de energia elétrica no SIN. Acesso em 15 de 01 de 2017, disponível em: http://www.epe.gov.br.

Freedman, D. A.; Bickel, P.J. (1981). Some asymptotic theory for the Bootstrap. California: Berkeley.

Galdino, M. A.; Lima, J. H. G. (2002). PRODEEM - O Programa Nacional de Eletrificação Rural Baseado em Energia Solar Fotovoltaica. CEPEL - Centro de Pesquisas de Energia Elétrica. Congresso Brasileiro de Energia 2002.

Ghisi, E.; Montibeller, A.; Schmidt, R. W. (2006). Potential for potable water savings by using rainwater: an analysis over 62 cities in southern Brazil. Building and Environment, Oxford, v. 41, n. 2, p. 204-210, 2006. 
Gomes, R. (2012). A gestão do sistema de transmissão do Brasil. Rio de Janeiro: Editora FGV.

Gonçalves, S. S.; Calili, R. F. (2015). Análise das Séries Sintéticas de Energia Natural Afluente Bruta da Região Nordeste do Brasil. Pesquisa Operacional. Artigo publicado nos Anais do SBPO.

Green, M. A. et al. (2000). Solar cell efficiency tables: version 16. Progress in Photovoltaics: Research and Applications, Sydney, v. 8, p. 377384.

Hamilton, J. D. (1994). Time series analysis. New Jersey: Princeton University Press.

IBGE. Instituto Brasileiro de Geografia e Estatística (2010). Censo demográfico 2010. Acesso em 10 de janeiro de 2017, disponível em: http://www.censo2010.ibge.gov.br/sinopse/index.php?dados=P12\&uf=00.

INMETRO. Instituto Nacional de Metrologia, Qualidade e Tecnologia (2011). Portaria $n^{\circ} 4$. Dispõe sobre a Política Nacional de Conservação e Uso Racional de Energia e dá outras providências.

INMETRO. Instituto Nacional de Metrologia, Qualidade e Tecnologia. (2017). PBE fotovoltaico. Acesso em 15 de 01 de 2017, disponível em: http:// http://www.inmetro.gov.br.

Izquierdo, S.; Rodrigues, M.; Fueyo, N. (2008). A method for estimating the geographical distribution of the available roof surface area for large-scale photovoltaic energy-potential evaluations. Solar Energy, Oxford, v. 82, n. 10, p. 929-939.

Landeira, J. L. F. (2013). Análise sobre a viabilidade de implantação de sistemas de geração fotovoltaica distribuída no Brasil. Dissertação de Mestrado, Programa de Pós-Graduação em Planejamento Energético, COPPE - UFRJ. 
Lange, W. (2012). Metodologia de mapeamento da área potencial de telhados de edificações residenciais no Brasil para fins de aproveitamento energético fotovoltaico. Estudo interno elaborado por meio da terra GIS. Rio de Janeiro: EPE/GIZ.

Maceira, M. E. P.; Terry, L. A.; Costa, F. S.; Damázio, J. M.; Melo, A. C. G. (2002). Chain of Optimization Models for Setting the Energy Dispatch and Spot Price in the Brazilian System. In Anais do XIV Power Systems Computation Conference, session 43, paper 1, Sevilla, Spain.

Maceira, M. E. P.; Penna, D. D. J.; Damázio, J. M. (2006). Geração de cenários sintéticos de energia e vazão para o planejamento da operação energética. Cadernos do IME - série estatística. Universidade do Estado do Rio de Janeiro - UERJ. Rio de Janeiro - RJ - Brasil. ISSN $1413-9022$ / v. 21 p. $11-35$.

Miranda, R. F. C. (2013). Análise da inserção de geração distribuída de energia solar fotovoltaica no setor residencial brasileiro. Dissertação de Mestrado, Programa de Pós-Graduação em Planejamento Energético, COPPE - UFRJ.

Miranda, R.; Szklo, A.; Schaeffer, R. (2015). Technical-economic potential of PV systems on brazilian rooftops. Renewable Energy, Oxford, v. 75, p. 694-713.

MME. Ministério de Minas e Energia (2015). Energia Solar no Brasil e no Mundo. Acesso em 08 de 11 de 2016. Disponível em: http://www.mme.gov.br/.

Moreira, D. A. (1998). Administração da Produção e Operações. $3^{a}$ ed. São Paulo: Pioneira.

Morettin, P. A.; Toloi, C. M. C. (1987). Previsão de séries temporais. 2ªed. São Paulo: Atual Editora. 
Neto, A. C.; Souza, R. C. A. (1996). Bootstrap Simulation Study in ARMA $(p, q)$ Structures. Journal of Forecasting, Vol. 15. n.4, p.343-353.

Oliveira, F. L. C. (2010). Nova abordagem para Geração de Cenários de Afluências no Planejamento da Operação Energética de Médio Prazo. Dissertação de Mestrado, Departamento de Engenharia Elétrica, PUC-Rio.

ONS. Operador Nacional do Sistema Elétrico (2000). Descrição da cadeia de modelos utilizada. Documento interno.

ONS. Operador Nacional do Sistema Elétrico (2005). O SIN e os modelos para planejamento e programação da operação energética. Documento interno.

ONS. Operador Nacional do Sistema Elétrico (2017). Acesso em 11 de novembro de 2016, disponível em: http://www.ons.org.br.

Pereira, B. E.; Martins, F. R.; Abreu, S. L.; Ruther, R. (2006). Atlas brasileiro de energia solar. São José dos Campos: INPE.

Pires, J. C.; Rosa, L. P.; Tolmasquim, M. T. (1998). Reforma do setor elétrico. Rio de Janeiro: Relumé-Dumará.

R Core Team (2015). R: A language and environment for statistical computing. R Foundation for Statistical Computing, Vienna, Austria. URL https://www.R-project.org/.

Souza, R. C.; Camargo, M. E. (2004). Análise e Previsão de Séries Temporais: os modelos ARIMA. $2^{2}$ ed. Rio de Janeiro: Editora Regional.

Souza, R. C.; Marcato, A. L. M.; Dias, B. H.; Oliveira, F. L. C. (2012). Optimal Operation of Hydrothermal Systems with Hydrological Scenario Generation through Bootstrap and Periodic Autoregressive Models. European Journal of Operational Research, v. 222, p. 1/EOR11111-26. 
Tolmasquim, M. T. (2016). Energia Termelétrica: gás natural, biomassa, carvão nuclear. Rio de Janeiro: EPE.

UFPE; CEPEL; CHESF. (2000). Atlas Solarimétrico do Brasil. Pernambuco: Universitária UFPE. Disponível em: http://www.cresesb.cepel.br/publicacoes/download/Atlas_Solarimetrico_do _Brasil_2000.pdf

Vergara, S. C. (2007). Projetos e relatórios de pesquisa em administração (9ª ed.). São Paulo: Atlas.

Zheng, Y.; Weng, Q. (2014). Assessing solar potential of commercial and residential buildings in Indianapolis using LIDAR and GIS modeling. In: International workshop on earth observation and remote sensing applications. China. Changsha: IEEE, 2014. p. 398-402.

Wiginton, L. K.; Nguyen, H. T.; Pearce, J. M. (2010). Quantifying rooftop solar photovoltaic potential for regional renewable energy policy. Computers, Environment and Urban Systems, Oxford, v. 34, n. 4, p. 345357, 2010. 